c. 3

US Army Corps

of Engineers

Waterways Experiment

Station

\title{
Demonstration of the Department of Defense Groundwater Modeling System (GMS) at Columbus Air Force Base, Columbus, MS
}

by Mansour Zakikhani, WES

Kenneth C. Black, Environmental Consulting Engineers

Jeffrey A. Gerald, AScl Corporation

United States Government 
The contents of this report are not to be used for advertising, publication, or promotional purposes. Citation of trade names does not constitute an official endorsement or approval of the use of such commercial products.

The findings of this report are not to be construed as an official Department of the Army position, unless so designated by other authorized documents. 

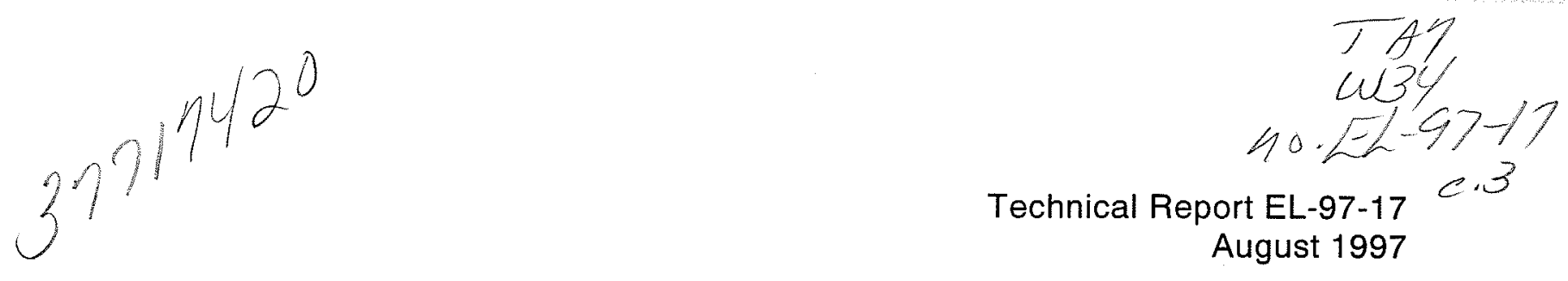

\section{Demonstration of the Department of Defense Groundwater Modeling System (GMS) at Columbus Air Force Base, Columbus, MS}

by Mansour Zakikhani

U.S. Army Corps of Engineers

Waterways Experiment Station

3909 Halls Ferry Road

Vicksburg, MS 39180-6199

Kenneth C. Black

Environmental Consulting Engineers

P.O. Box 22668

Knoxville, TN 37933

Jeffrey A. Gerald

AScl Corporation

1365 Beverly Road

McLeen, VA 22101

Final report

Approved for public release; distribution is unlimited

Prepared for U.S. Army Environmental Center

Aberdeen Proving Ground, MD 21010-5401 


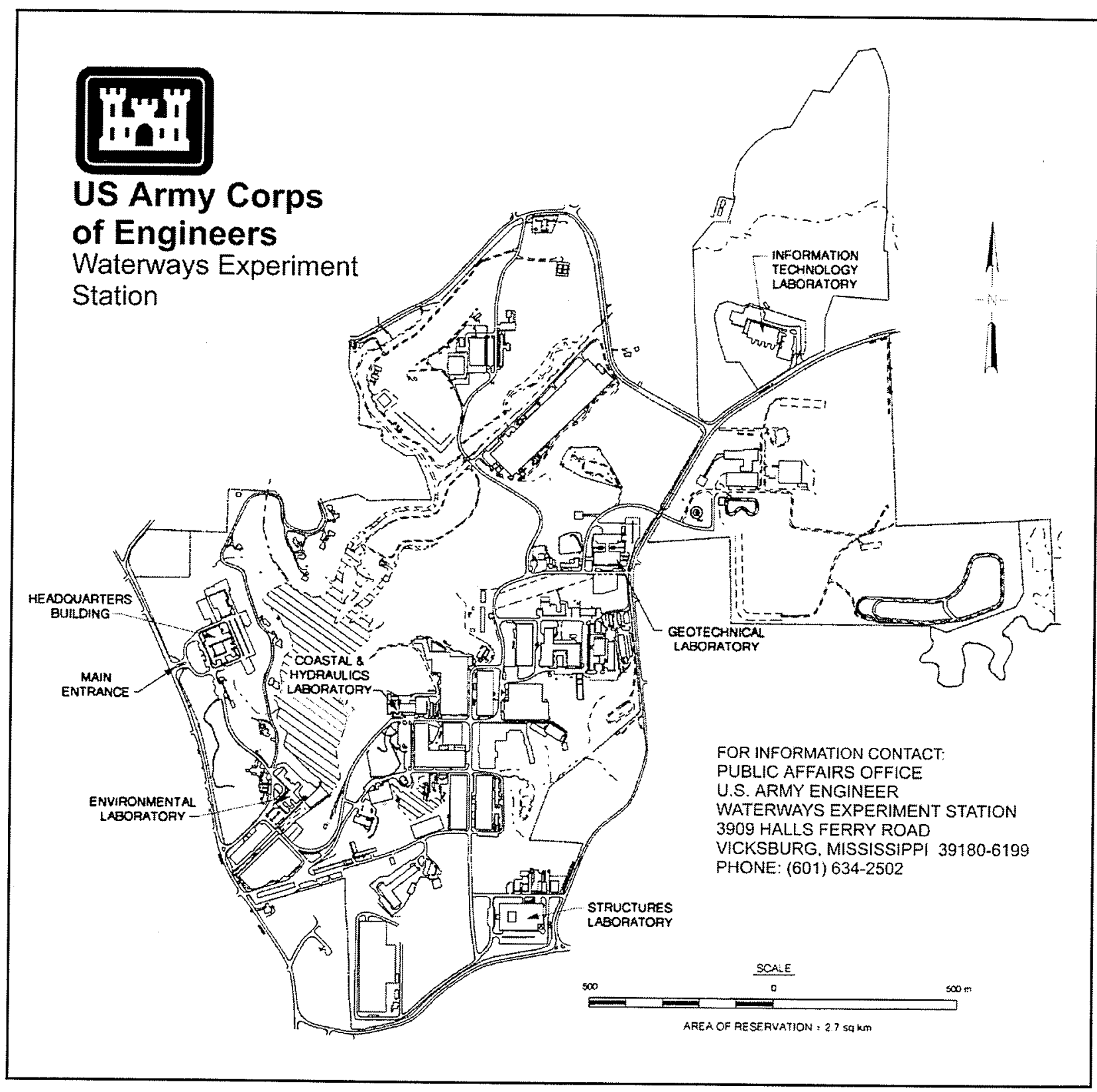

Waterways Experiment Station Cataloging-in-Publication Data

Zakikhani, Mansour, 1954-

Demonstration of the Department of Defense groundwater modeling system (GMS)

at Columbus Air Force Base, Columbus, MS / by Mansour Zakikhani, Kenneth C.

Black, Jeffrey A. Gerald; prepared for U.S. Army Environmental Center.

177 p. : ill. ; $28 \mathrm{~cm}$. - (Technical report ; EL-97-17)

Includes bibliographic references.

1. Groundwater - Research - Mathematical models. 2. Groundwater -

Mathematical models - Mississippi - Columbus Air Force Base. 3. Hydrogeology - Mathematical models. I. Black, Kenneth C. (Kenneth Charles), 1963- II. Gerald, Jeffrey A. III. United States. Army. Corps of Engineers. IV. U.S. Army Engineer Waterways Experiment Station. V. Environmental Laboratory (U.S. Army Engineer Waterways Experiment Station) VI. U.S. Army Environmental Center. VII. Title. VIII. Series: Technical report (U.S. Army Engineer Waterways Experiment Station); EL-97-17.

TA7 W34 no.EL-97-17 


\section{Contents}

Preface .....................

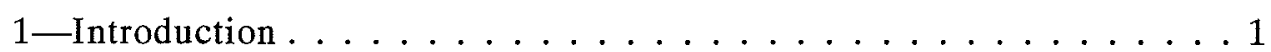

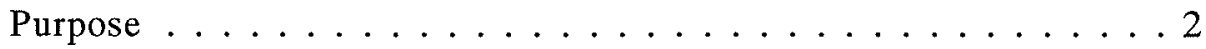

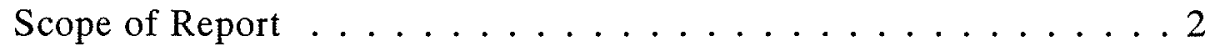

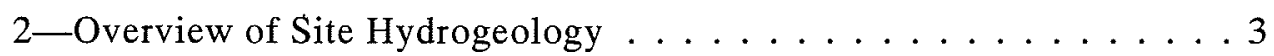

Site Description . . . . . . . . . . . . . . 3

Description of the Experiment . . . . . . . . . . 6

Hydrogeologic and experimental data $\ldots \ldots \ldots \ldots \ldots$

Hydraulic conductivity . . . . . . . . . . 7

Monthly water levels . . . . . . . . . . . . . 7

Continuously recorded groundwater levels $\ldots \ldots \ldots \ldots 7$

Tracer data . . . . . . . . . . . . . . . . . . .99

3-Model Development with FEMWATER . . . . . . . . 10

Summary of FEMWATER Model . . . . . . . . . . . 10

Modifications to the GMS/FEMWATER System . . . . . . 11

Maximum allowable material properties . . . . . . . . 11

Maximum allowable boundary conditions . . . . . . . 12

Conceptual Groundwater Flow and Transport Model

(FEMWATER) . . . . . . . . . . . . . . . . 12

Areal and vertical discretization of the model . . . . . . . . 14

Hydraulic conductivity distributions . . . . . . . . . . 19

Boundary conditions ............... 20

General description of flow boundary conditions . . . . . . 22

General description of transport boundary conditions . . . . 23

4-FEMWATER Application and Results . . . . . . . . . . . . 24

Use of Gauge Plots and Methods of Model Calibration . . . . . 25

Steady-State Flow Calibration . . . . . . . . . . . . 25

Transport Analysis . . . . . . . . . . . . . . 32

Summary of Transport Results . . . . . . . . . . . . . 46

Sensitivity Analysis . . . . . . . . . . . . . 46 
Conclusions on FEMWATER Application . . . . . . . . . . 48

Suggestions for Additional Work ............. . . 50

5 -MODFLOW Modeling Approach . . . . . . . . . . . 51

Summary of MODFLOW Model . . . . . . . . . . . . . 51

Model grid . . . . . . . . . . . . . . . . . . . . 52

Hydraulic conductivity ................ 52

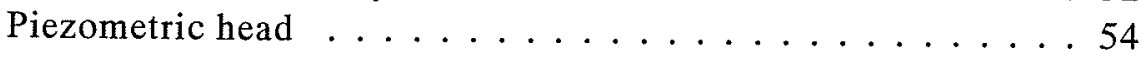

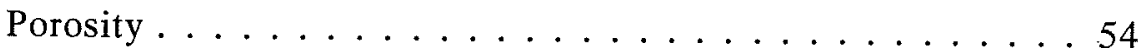

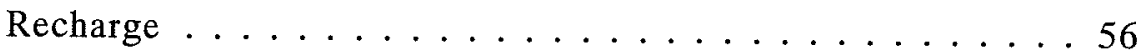

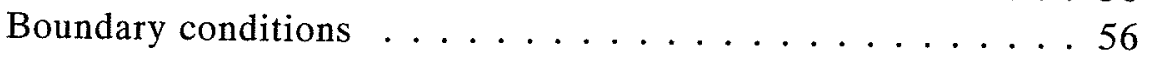

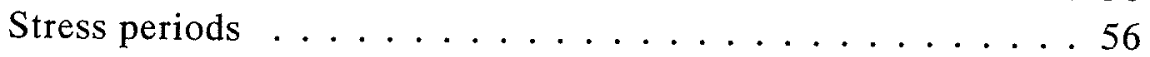

MODFLOW Simulation Results . . . . . . . . . . . . . . 56

MODFLOW Model Calibration . . . . . . . . . . . . . . 57

MODFLOW Model Sensitivity Analysis . . . . . . . . . . . 60

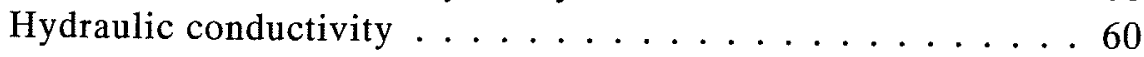

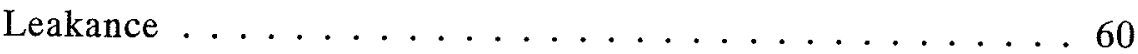

Recharge ........................ 64

Summary of MODFLOW Simulations . . . . . . . . . . 64

6 -MT3D Modeling Approach . . . . . . . . . . . . . . 70

Summary of MT3D Model . . . . . . . . . . . . . . . 70

MT3D Model Input . . . . . . . . . . . . . . . . . . . . . . . . . . . .

Flow data . . . . . . . . . . . . . . . . 71

Chemical injection data $\ldots \ldots \ldots \ldots \ldots 71$

Model grid . . . . . . . . . . . . . . . . 72

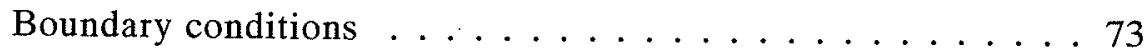

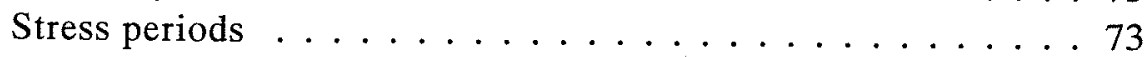

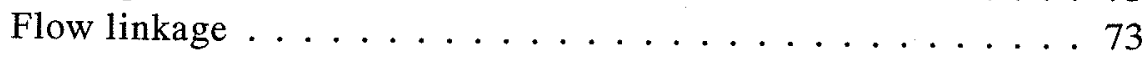

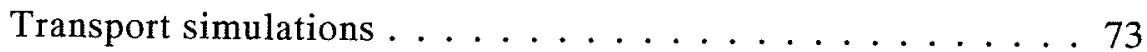

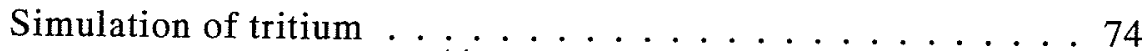

Simulation of carbon $14\left({ }^{14} \mathrm{C}\right) \ldots \ldots \ldots \ldots \ldots$

Simulation of benzene ................. 84

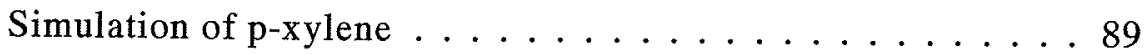

Simulation of o-dichlorobenzene ............ 94

Simulation of naphthalene . . . . . . . . . . . . . 99

MT3D Model Calibration . . . . . . . . . . . . . . . . . 105

Sensitivity Analysis . . . . . . . . . . . . . . . . . 110

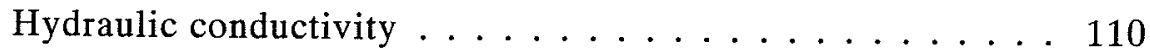

Porosity . . . . . . . . . . . . . . . 110

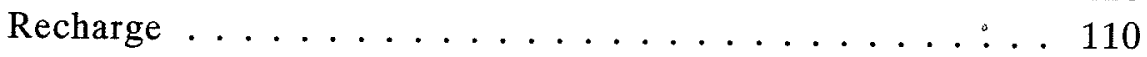

First-order decay rate . . . . . . . . . . . . 110

Summary and Discussion of MT3D Results . . . . . . . . . 115 


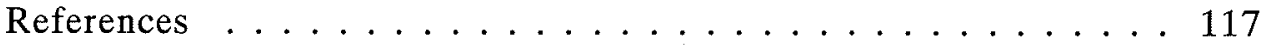

Appendix A: Interpolated Hydraulic Conductivity $\ldots \ldots \ldots$ A1

Appendix B: Piezometric Head Contours . . . . . . . . . . . . B1

Appendix C: Gauge Plots of Transient Flow Simulations . . . . . . . . C1

SF 298

\section{List of Figures}

Figure 1. Site location map with regional features such as rivers and oxbow channels ................ . . 4

Figure 2. Aerial photo showing the MADE-2 injection site and the location of the meander channel, with an orthographic projection showing the fluvial deposits of a typical

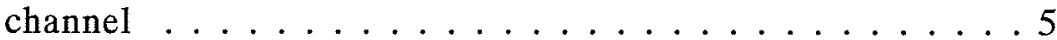

Figure 3. Well locations with nested wells labeled "A/B" ......8

Figure 4. Plan-view distribution of vertical hydraulic gradient with respect to fluvial deposits .............. 13

Figure 5. Continuous well hydrograph of P-53A, which is located at coordinates $(-4.92,-10.33)$ or $11.5 \mathrm{~m}$ southwest of the injection site .................. 15

Figure 6. Well hydrographs of eight continuously recorded "A-series" (shallow) wells . . . . . . . . . . 16

Figure 7. Well hydrographs of eight continuously recorded "B-series" (deep) wells . . . . . . . . . . . . . . 17

Figure 8. Orthographic projection of the three-dimensional finite-element grid . . . . . . . . . . . . 18

Figure 9. Orthographic projection showing boundary conditions used for steady-state flow . . . . . . . . . . . . 21

Figure 10. Example plot comparing model calculated to measured hydraulic heads (data not from MADE-2 model) . . . . . 26

Figure 11. Steady-state total head distribution for the low-watertable condition $(9 / 17 / 90) \ldots \ldots . \ldots 28$

Figure 12. Steady-state total head distribution for the high-watertable condition $(3 / 8 / 91) \ldots \ldots . \ldots 29$

Figure 13. Orthographic projection of steady-state Darcy velocity for the low-water-table condition ......... . 30 
Figure 14. Orthographic projection of steady-state Darcy velocities for the high-water-table condition . . . . . . . . 31

Figure 15. Plan view of $50-\mathrm{pCi} / \mathrm{ml}$ tritium plume at 27 days . . . . 33

Figure 16. Plan view of $50-\mathrm{pCi} / \mathrm{ml}$ tritium plume at 132 days $\ldots 34$

Figure 17. Plan view of $50-\mathrm{pCi} / \mathrm{ml}$ tritium plume at 224 days . . . . 35

Figure 18. Plan view of $50-\mathrm{pCi} / \mathrm{ml}$ tritium plume at 328 days . . . 36

Figure 19. Vertical view of $50-\mathrm{pCi} / \mathrm{ml}$ tritium plume at a) 27 days, b) 132 days, c) 224 days, d) 328 days . . . . . . . . . 37

Figure 20. Plan view of $5-\mathrm{pCi} / \mathrm{ml}$ tritium plume at 27 days . . . . . . 39

Figure 21. Plan view of $5-\mathrm{pCi} / \mathrm{ml}$ tritium plume at 132 days . . . . . 40

Figure 22. Plan view of $5-\mathrm{pCi} / \mathrm{ml}$ tritium plume at 224 days . . . . . 41

Figure 23. Plan view of $5-\mathrm{pCi} / \mathrm{ml}$ tritium plume at 328 days . . . . 42

Figure 24. Location of gauge wells used for concentration curves . . . 43

Figure 25. Concentration curve at location 1018 showing measuredversus-computed tritium $(\mathrm{pCi} / \mathrm{ml}) \ldots \ldots . \ldots 44$

Figure 26. Concentration curve at location 1644 showing measuredversus-computed tritium $(\mathrm{pCi} / \mathrm{ml}) \ldots \ldots \ldots 4$

Figure 27. Maximum total head versus calibrated up-gradient flux multiplier . . . . . . . . . . . . . 4 47

Figure 28. Maximum horizontal Darcy velocity versus calibrated upgradient flux multiplier . . . . . . . . . . . . . . 49

Figure 29. MODFLOW three-dimensional grid system . . . . . . . 53

Figure 30. Location of hydraulic conductivity wells . . . . . . . . . 53

Figure 31. Piezometric well locations relative to grid . . . . . . . 55

Figure 32. MODFLOW simulated total head for layers 3 and 7 at time $=328$ days $\ldots \ldots \ldots \ldots$

Figure 33. Plan and vertical view of piezometric head measurement

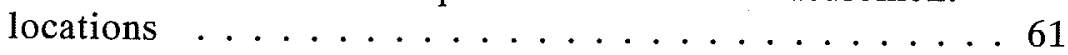

Figure 34. Observed piezometric heads in layers 3 and 7 of the numerical grid ................... 62

Figure 35. Differences in total head in layers 3 and 7 (time $=$ 328 days) caused by a 10 -percent increase in hydraulic conductivity .............. 63

Figure 36. Change in total head in layers 3 and 7 due to leakance change ................... 65 
Figure 37. Change in total head in layer 1 due to increase of recharge rate .................. 66

Figure 38. Changes in total head in layer 3 due to increase of recharge rate ................. 67

Figure 39. Change in total head in layer 7 due to increase of recharge rate ................... 68

Figure 40. View of GMS/MT3D particle screen showing parameters used in simulations . . . . . . . . . . . 73

Figure 41. Plan view of simulated $50-\mathrm{pCi} / \mathrm{ml}$ tritium iso-surface at a) day 27, b) day 132, c) day 234 , and d) day $328 \ldots 75$

Figure 42. Oblique view of simulated $50-\mathrm{pCi} / \mathrm{ml}$ tritium iso-surface at a) day 27, b) day 132, c) day 234 , and d) day $328 \ldots 76$

Figure 43. Oblique view of simulated $5-\mathrm{pCi} / \mathrm{ml}$ tritium iso-surface at a) day 27, b) day 132, c) day 234 , and d) day $328 \ldots 77$

Figure 44. Observed horizontal extent of relative concentration tritium plume at $27,132,224$ and 328 days . . . . . 78

Figure 45. Observed vertical and longitudinal extent of tritium plume at $27,132,224$, and 328 days . . . . . . . . . . 79

Figure 46. Plan view of simulated $3-\mathrm{pCi} / \mathrm{ml}$ carbon-14 iso-surface at a) day 27, b) day 132 , c) day 234 , and d) day $328 \ldots 80$

Figure 47. Oblique view of simulated $3-\mathrm{pCi} / \mathrm{ml}$ carbon- 14 isosurface at a) day 27, b) day 132 , c) day 234 , and d) day $328 \ldots \ldots \ldots$. . . . . . . . . . . . . . . . . . . .

Figure 48. Oblique view of simulated $0.3-\mathrm{pCi} / \mathrm{ml}$ of carbon-14 iso-surface at a) day 27, b) day 132 , c) day 234 , and d) day $328 \ldots \ldots \ldots$. . . . . . . . . . . . . . . . . .

Figure 49. Observed vertical and longitudinal extent of carbon-14 plume at $27,132,224$, and 328 days . . . . . . . 83

Figure 50. Plan view of simulated $50-\mathrm{mg} / \mathrm{m}^{3}$ benzene iso-surface at a) day 27, b) day 132, c) day 234 , and d) day $328 \ldots 85$

Figure 51. Oblique view of simulated $50-\mathrm{mg} / \mathrm{m}^{3}$ benzene isosurface at a) day 27, b) day 132 , c) day 234 , and d) day $328 \ldots \ldots \ldots$. . . . . . . . . . . . . . . . . . . .

Figure 52. Oblique view of simulated $5-\mathrm{mg} / \mathrm{m}^{3}$ benzene iso-surface at a) day 27, b) day 132, c) day 234 , and d) day $328 \ldots 87$

Figure 53. Observed vertical and longitudinal extent of benzene plume at $27,132,224$, and 328 days . . . . . . 88

Figure 54. Plan view of simulated $50-\mathrm{mg} / \mathrm{m}^{3}$ p-xylene iso-surface at a) day 27, b) day 132, c) day 234 , and d) day $328 \ldots 90$ 
Figure 55. Oblique view of simulated $50-\mathrm{mg} / \mathrm{m}^{3} \mathrm{p}$-xylene iso-surface at a) day 27, b) day 132, c) day 234 , and d) day $328 \ldots 91$

Figure 56. Oblique view of simulated $5-\mathrm{mg} / \mathrm{m}^{3} \mathrm{p}$-xylene iso-surface at a) day 27, b) day 132, c) day 234 , and d) day $328 \ldots 92$

Figure 57. Observed vertical and longitudinal extent of p-xylene plume at $27,132,224$, and 328 days . . . . . . . . 9 93

Figure 58. Plan view of simulated $50-\mathrm{mg} / \mathrm{m}^{3}$ o-DCB iso-surface at a) day 27, b) day 132, c) day 234 , and d) day $328 \ldots 95$

Figure 59. Oblique view of simulated $50-\mathrm{mg} / \mathrm{m}^{3}$ o-DCB iso-surface at a) day 27, b) day 132 , c) day 234 , and d) day $328 \ldots 96$

Figure 60. Oblique view of simulated $5-\mathrm{mg} / \mathrm{m}^{3}$ o-DCB iso-surface at a) day 27, b) day 132, c) day 234 , and d) day $328 \ldots 97$

Figure 61. Observed vertical and longitudinal extent of o-DCB plume at $27,132,224$, and 328 days . . . . . . . . 98

Figure 62. Plan view of simulated $7-\mathrm{mg} / \mathrm{m}^{3}$ naphthalene iso-surface at a) day 27, b) day 132 , c) day 234 , and d) day $328 \ldots 100$

Figure 63. Oblique view of simulated $7-\mathrm{mg} / \mathrm{m}^{3}$ naphthalene isosurface at a) day 27, b) day 132 , c) day 234 , and d) day $328 \ldots \ldots \ldots \ldots 1 . \ldots \ldots 1$

Figure 64. Oblique view of simulated $0.7-\mathrm{mg} / \mathrm{m}^{3}$ naphthalene iso-surface at a) day 27, b) day 132 , c) day 234 , and d) day $328 \ldots \ldots \ldots \ldots \ldots$. . . . . . . . . . . . . . . . . .

Figure 65. Observed vertical and longitudinal extent of naphthalene plume at $27,132,224$, and 328 days . . . . . . . 103

Figure 66. View of GMS/MT3D point source entry screen . . . . 104

Figure 67. View of GMS/MT3D chemical reaction package entry screen ..................... 104

Figure 68. Comparison of observed and simulated concentration of tritium at gauge point 19 and layer 6 of the grid . . . 106

Figure 69. Comparison of observed and simulated concentration of tritium at gauge point 32 and layer 6 of the grid . . 107

Figure 70. Comparison of observed and simulated concentration of naphthalene at gauge point 45 and layer 6 of the grid . . 108

Figure 71. Comparison of observed and simulated concentration of naphthalene at gauge point 100 and layer 6 of the grid . . 109

Figure 72. Sensitivity analysis using distributed porosities of 0.31 , $0.2,0.1,0.31$, from top to bottom in plan view . . . 111

Figure 73. Simulated tritium plume distribution at day 328 using porosity distribution of Figure $72 \ldots \ldots 112$ 
Figure 74. Simulated tritium plume distribution at day 328 with increased infiltration rate . . . . . . . . . 113

Figure 75. Naphthalene concentration change due to an increase in the biodegradation rate from 0.007 to 0.010 /day for

a) layer 3, b) layer 4, c) layer 5 , and d) layer $6 \ldots 114$

\section{List of Tables}

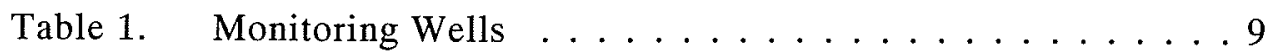

Table 2. Piezometric Head Manual Measurement Dates . . . . . . 54

Table 3. Statistical Summary of Porosity Measurements . . . . . . 54

Table 4. Observed (Obs) and Simulated (Sim) Heads in Model Layer $2 \ldots \ldots \ldots$. . . . . . . . . . . . . . 59

Table 5. Observed (Obs) and Simulated (Sim) Heads in Mode1 Layer $3 \ldots \ldots$. . . . . . . . . . . . . . 59

Table 6. Observed (Obs) and Simulated (Sim) Heads in Model Layer $7 \ldots \ldots \ldots$. . . . . . . . . . . . . 6 60

Table 7. Injected Chemicals . . . . . . . . . . . 71

Table 8. Biodegradation Rates Used in MT3D Simulations . . . . . 72

Table 9. Sorption Data Used in MT3D Simulations . . . . . . . . 72

Table 10. Relative Distance of Gauge Points from Injection Point for Layer 6 . . . . . . . . . . . . . . . 105 


\section{Preface}

This report describes the evaluation and application of the Department of Defense Groundwater Modeling System (GMS, Version 1.2) at Columbus Air Force Base, Columbus, MS. The project was conducted as part of the U. S. Army Engineer Waterways Experiment Station (WES) groundwater model development and application program. The primary objective of this work was to evaluate GMS/FEMWATER and GMS/MODFLOW-MT3D using data from the MADE-2 groundwater flow and transport experiment. The project was performed as a component of the WES Groundwater Modeling Program and was funded by the U.S. Army Environmental Center (AEC). Mr. Ira May is the AEC technical monitor for the project. Field data were provided by Dr. Thomas Stauffer, Armstrong Laboratory Environics, Tyndall Air Force Base, FL.

The study was conducted under the direct supervision of Dr. Mark S. Dortch, Chief, Water Quality and Contaminant Modeling Branch (WQCMB), and under the general supervision of Dr. Richard E. Price, Chief, Environmental Processes and Effects Division, and Dr. John Harrison, Director, Environmental Laboratory. This report was written by Dr. Mansour Zakikhani, WQCMB, Mr. Kenneth C. Black, Environmental Consulting Engineers, and Mr. Jeffrey A. Gerald, AScI Corporation.

Acknowledgment is made to Mr. Chris McGrath, WQCMB, and Dr. Fred Tracy, WES Information Technology Laboratory, for their review and valuable suggestions.

The work was coordinated by Dr. Jeffery P. Holland, Director, Computational Hydraulics Institute, WES Coastal and Hydraulics Laboratory, and WES Groundwater Modeling Program Manager.

At the time of publication of this report, Dr. Robert W. Whalin was Director of WES. 
This report should be cited as follows:

Zakikhani, M., Black, K. C., and Gerald, J. A. (1997). "Demonstration of the Department of Defense Groundwater Modeling System (GMS) at Columbus Air Force Base, Columbus, MS," Technical Report EL-97-17, U.S. Army Engineer Waterways Experiment Station, Vicksburg, MS. 


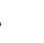




\section{Introduction}

The Department of Defense Groundwater Modeling System (GMS) is a comprehensive computer graphical system. The GMS has been developed as part of an ongoing multi-disciplinary research effort. The purpose of the research initiative was to develop a user environment where existing groundwater models can be used efficiently. The GMS includes modeling tools to facilitate site characterization, model conceptualization, mesh and grid generation, geostatistical computations, and post-processing. Version 1.2 of the GMS provides an interface for subsurface models such as FEMWATER and MODFLOW-MT3D. As part of a project on the GMS evaluation, development, and improvement, the GMS has been applied to selected field problems. This rigorous evaluation of GMS capabilities is intended to identify additional numerical tools needed for advancement of the GMS.

One of the sites which has received significant attention and provides extensive data sets is located on the Columbus Air Force Base (CAFB), Mississippi. CAFB site is the location of two macrodispersion experiments (MADE-1 and MADE-2) and the present ongoing natural attenuation study (NATS). MADE-1 involved the injection and monitoring of bromide and three flourobenzoate tracers between October 1986 and 1988 (Boggs et al. 1988; Boggs et al. 1990). MADE-2 (Boggs et al. 1993) studied physical, chemical, and biological processes affecting transport of two conservative chemicals and four reactive hydrocarbons injected as solutes. The flowmeter-derived hydraulic conductivity profile of the site illustrated the extreme heterogeneity of the aquifer. The hydraulic head field at the site has exhibited complex temporal and spatial variability produced by the large heterogeneity of the aquifer and large seasonal fluctuations of the water table. The MADE-2 study was initiated with a 2-day injection of the dissolved chemicals beginning June 26, 1990. Chemical concentration distributions were monitored using an extensive network of saturated zone multilevel samples at 1 - to 3 -month intervals over a period of 15 months. Detailed information on field monitoring may be found in Boggs et al. (1993). Although extensive data collections and field monitoring have been conducted at the site, few numerical modeling studies have been reported (Gray and Dale 1995). As part of a groundwater model development at the U. S. Army Engineer Waterways Experiment Station selected numerical models in the GMS including FEMWATER and MODFLOW-MT3D have 
been applied to the site using MADE-2 data. In this report, the capability of the GMS Version 1.2 (Brigham Young University 1995) will be discussed and illustrated by applying it to this complex heterogeneous aquifer. The report covers two different numerical modeling approaches: finite element (FEMWATER) and finite difference (MODFLOW-MT3D).

\section{Purpose}

The primary purpose of this demonstration project was to determine the current strengths and weaknesses of the GMS (Version 1.2) and its groundwater models through a field modeling application. Although an attempt was made to calibrate the flow and transport models to measured data, the objective of this project was not to create a highly refined model of the MADE- 2 experiment. The MADE- 2 tracer experiment was selected for the application because the test is well-documented and the hydrogeologic database of the experiment was available. Additionally, accurate numerical simulation of this experiment is generally considered to be a difficult task. ${ }^{1}$ For this reason, this experiment should provide ample opportunity to test many of the features of the GMS/FEMWATER and GMS/MODFLOW-MT3D software system.

\section{Scope of Report}

This report is divided into two main parts. In the first part of the report (Chapters 2, 3, and 4) the reader can find information on general characteristics of the site, and the application, modification, and merits of the GMS/FEMWATER software system. The hydrogeologic setting of the MADE-2 experiment and the hydrogeologic database are described. Results of flow and transport simulations are presented followed by conclusions determined from the modeling exercise. In the second part of the report (Chapters 5 and 6), the application of GMS/MODFLOW-MT3D to MADE- 2 sites is discussed and illustrated. The modeling approaches used to create the flow and transport models are discussed in detail. Interpolated hydraulic conductivity values for each layer of the model grid are presented in Appendix A. Appendix B contains average head contours for both the shallow and deep parts of the aquifer for each day of the available data. Gauge plots of transient flow simulations are presented in Appendix C.

\footnotetext{
1 Personal Communication on the history of work conducted at the MADE site, 1996, Steve Young, Environmental Consulting Engineers, Inc., Knoxville, TN.
} 


\section{Overview of Site Hydrogeology}

\section{Site Description}

The study area is located on the Columbus Air Force Base in Columbus, MS (Figure 1). The site is known as MADE because of a macro dispersion experiment conducted at the site. The air base is situated above a shallow unconfined aquifer, which consists of fluvial deposits underlain by a Eutaw Formation marine sediment aquitard composed of clays, silts, and fine-grained sands. The average thickness of the aquifer is approximately $11 \mathrm{~m}$ and it is composed of poorly sorted to well-sorted sandy gravel and gravelly sand with some silt and clay. The aquifer contains several clay lenses and there is apparent evidence of a prior meandering channel crossing the deposit (Figure 2). The surface of the site is gently sloping northward from an elevation in the southeastern corner of $66.5 \mathrm{~m}$ above mean sea level (A.MSL) to $64.6 \mathrm{~m}$ (A.MSL) in the northern corner. Soil facies, determined from a limited terrace exposure, indicate irregular lenses and layers with horizontal dimensions of $8 \mathrm{~m}$ and vertical dimensions of less than $1 \mathrm{~m}$. The piezometric head and hydraulic gradients at the site exhibit complex spatial and temporal variability. The saturated thickness of the aquifer varies 20 to 30 percent between the low and high water table seasons. The area near the injection wells has steep horizontal gradients while the area furthest north contains less of a horizontal gradient but more of a vertical gradient.

The mean horizontal hydraulic conductivity near the injection site (southernmost end) and at the end (northernmost) of the test area is approximately $0.86 \mathrm{~m} /$ day with significant variation between these two areas (e.g. local areas in excess of $735 \mathrm{~m}$ /day are indicated). The central region with relatively high mean hydraulic conductivities generally corresponds to the former river meander channel that trends southwest to northeast and lies at an approximate 45-deg angle from the direction of groundwater flow. Vertical variability of hydraulic conductivity within a measurement well typically varies by two to four orders of magnitude. 


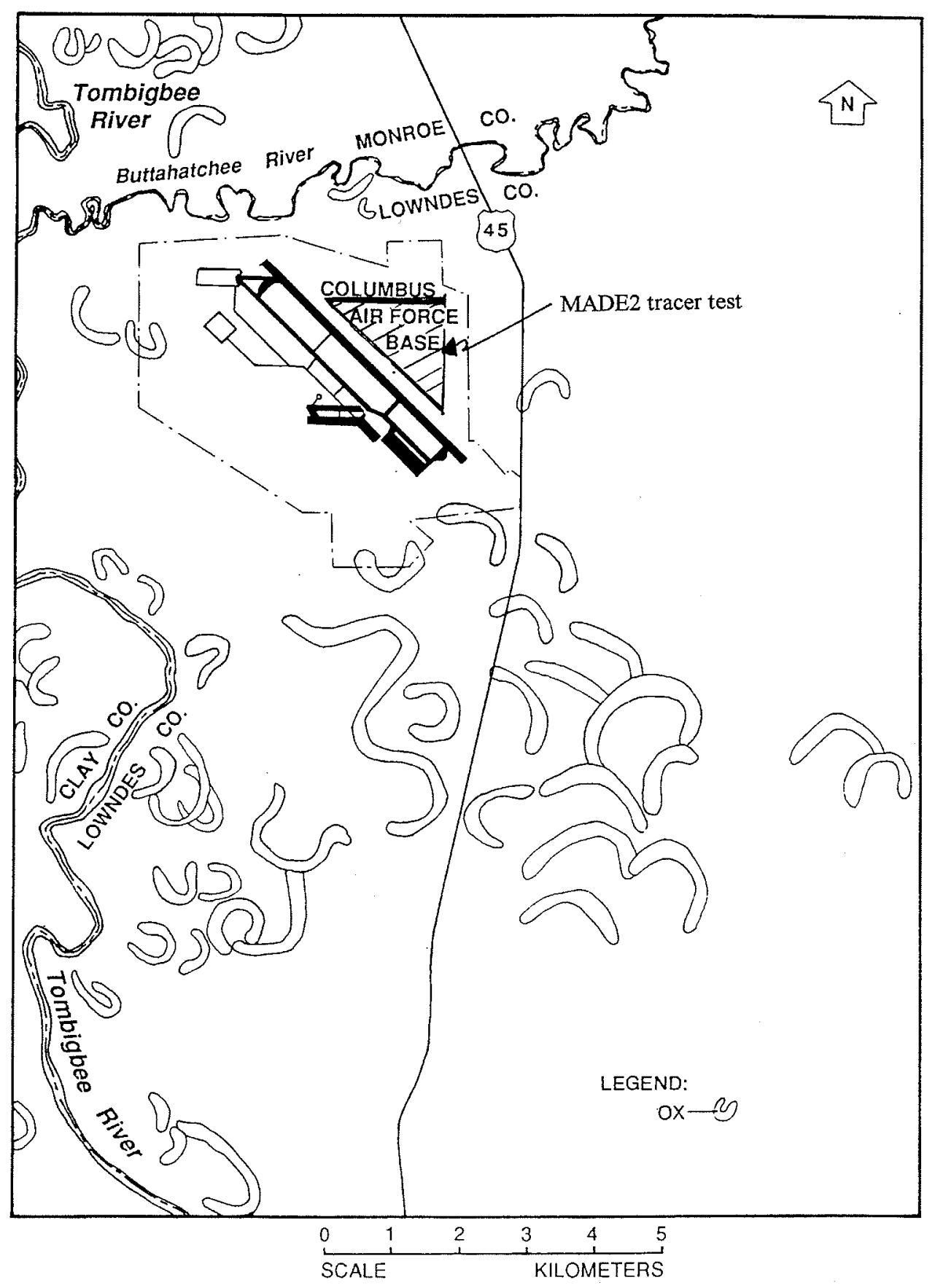

Figure 1. Site location map with regional features such as rivers and oxbow channels 


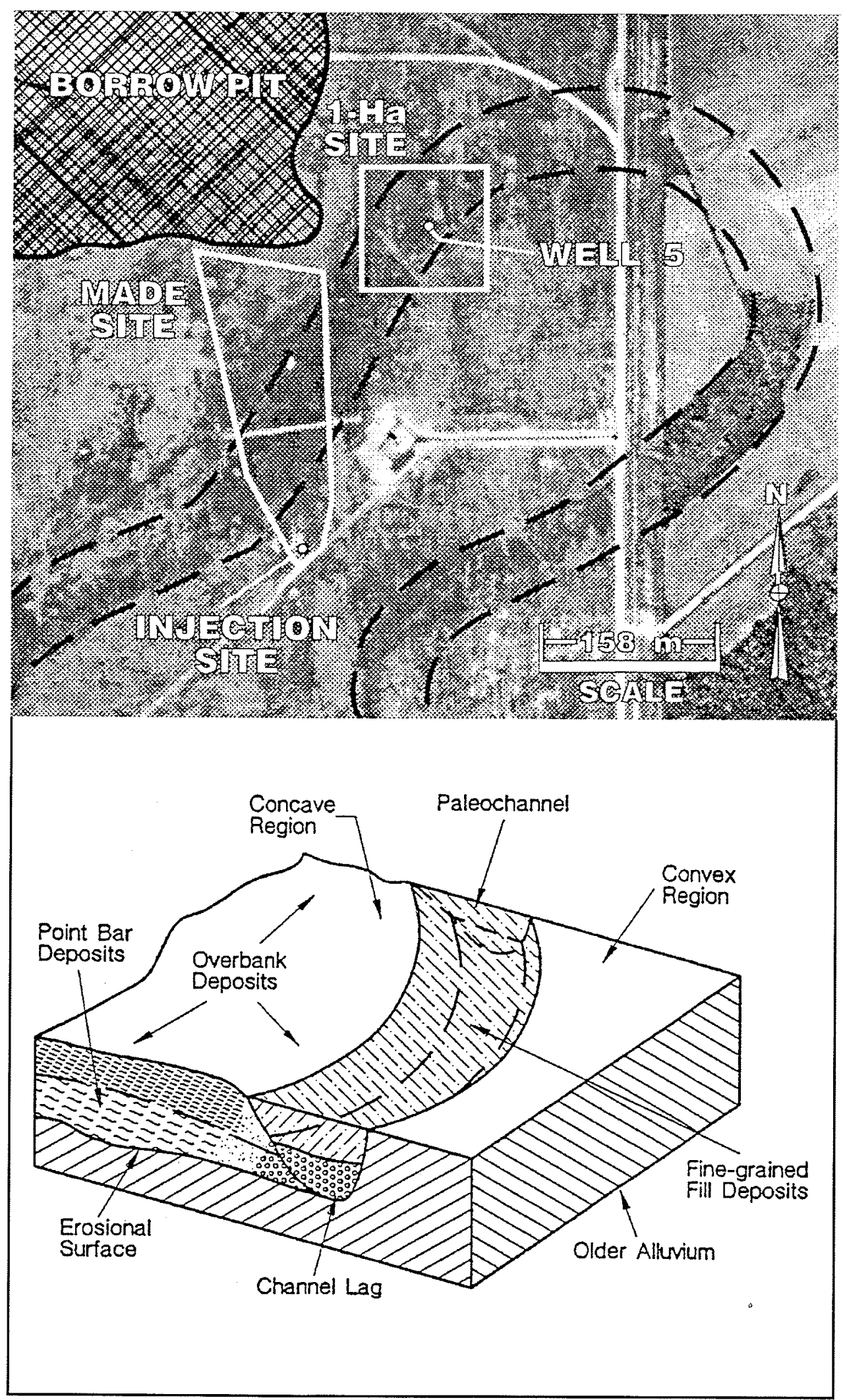

Figure 2. Aerial photo showing the MADE-2 injection site and the location of the meander channel, with an orthographic projection showing the fluvial deposits of a typical channel 
Analysis of the soil mineralogy for the fine-grained deposits of the site indicate quartz, muscovite, potassium feldspar, and clay minerals (predominantly kaolinites and illites, with minor amounts of vermiculite and montmorillonite). The sand and gravel are predominantly composed of feldspar, mica, and quartz.

The climate at the MADE site is temperate with a mean annual air temperature of $63^{\circ} \mathrm{F}$. Most precipitation at the site occurs during the early spring and winter, with the least amount during the early fall and summer. A more detailed description of the site can be found in several references from previous studies (e.g. Rehfelt et al. 1992, Boggs et al. 1990).

\section{Description of the Experiment}

There are numerous publications that describe the site conditions that were measured either during the MADE-1 tracer experiment ( Boggs et al. 1988, Boggs and Young 1988) or the MADE-2 tracer experiment (Electric Power Research Institute (EPRI) 1993a). The MADE-1 experiment, conducted between October 1986 and June 1988, examined the scale-dependence of the macrodispersion coefficients for nonreactive tracers (EPRI 1991). Bromide was the primary tracer used during this experiment. The MADE-2 experiment, conducted between June 1990 and September 1991, included nonreactive, reactive, and degrading chemicals. Four organic chemicals, including ${ }^{14} \mathrm{C}$-labeled p-xylene, o-dichlorobenzene, naphthalene, and benzene were used along with the conservative tracer tritium. FEMWATER was used to simulate the transport of the tritium tracer. MODFLOW/MT3D was used to simulate the transport of all the chemicals mentioned above.

During June $27-28,1990,9.7 \mathrm{~m}^{3}$ of the solution was injected through five wells spaced $1 \mathrm{~m}$ apart having $0.6-\mathrm{m}$ screen sections. The vertical injection interval ranged from an elevation of $57.5 \mathrm{~m}$ to $58.1 \mathrm{~m}$ above mean sea level. The initial mean aqueous concentrations are $55,610 \mathrm{pCi} / \mathrm{mL}$ for tritium, $2,770 \mathrm{pCi} / \mathrm{ml}$ for ${ }^{14} \mathrm{C}$-xylene, $68.1 \mathrm{mg} / \mathrm{L}$ for benzene, $51.5 \mathrm{mg} / \mathrm{L}$ for $\mathrm{p}$-xylene, $7.23 \mathrm{mg} / \mathrm{L}$ for naphthalene, and $32.8 \mathrm{mg} / \mathrm{L}$ for o-dichlorobenzene (EPRI 1993b). Monthly water levels were recorded during the experiment at numerous wells, and water levels at twelve wells were continuously monitored throughout the experiment. Tracer concentrations were sampled throughout the experiment. The available complete concentration data correspond to $27,132,224$, and 328 days after injection.

Some data from the MADE-1 experiment were used in this work (e.g., borehole flowmeter results, well coordinates). One difference between the experiments is that a coordinate transformation is required to convert the MADE-1 coordinates to MADE-2 coordinates (EPRI 1993b, page 3-1). The MADE-2 coordinate system was used for the FEMWATER applications. 


\section{Hydrogeologic and experimental data}

The hydrogeologic and chemical data presented in this report have been acquired from numerous published reports and the MADE-2 database (EPRI 1993b). Descriptions of site conditions were obtained from several reports (EPRI 1989, 1990, 1993a,b). Details of the MADE-2 tracer test were obtained from several sources (EPRI 1993). ${ }^{1}$ The digital data, such as the borehole flowmeter hydraulic conductivities, have been used within GMS to create the data needed for FEMWATER. Digital data utilized for this model include but are not limited to:

a. Borehole flowmeter hydraulic conductivities.

b. Water level data collected on a monthly basis.

c. Continuously recorded groundwater data.

$d$. Tracer data collected at all locations at the selected times.

\section{Hydraulic conductivity}

A total of 2,018 individual hydraulic conductivities were available in the data set (Rehfeldt et al. 1989a, 1989b). These data were analyzed and converted to the form that could be used for GMS/FEMWATER simulations. How these data were incorporated into the model is discussed in Chapter 3.

\section{Monthly water levels}

Monthly water levels were imported to a Microsoft Excel spreadsheet and used to analyze trends in the data. Horizontal and vertical hydraulic gradients, transient water level responses, and snap-shot water level rounds were studied using this data set.

\section{Continuously recorded groundwater levels}

Water levels from 16 wells were continuously recorded for 449 days during the experiment. This information was analyzed to determine the impact of transient water level changes on tracer migration. The water levels collected came from eight vertically nested well pairs including: P-27, P-44, P-53, P-54, P-55, P-60, P-61, and P-8 (Figure 3 and Table 1). The " $A$ " series wells are the shallow wells and the " $B$ " series wells are the deep wells.

1 Personal communication on the history of work conducted at the MADE site, 1996, Steve Young, Environmental Consulting Engineers, Inc., Knoxville, TN. 


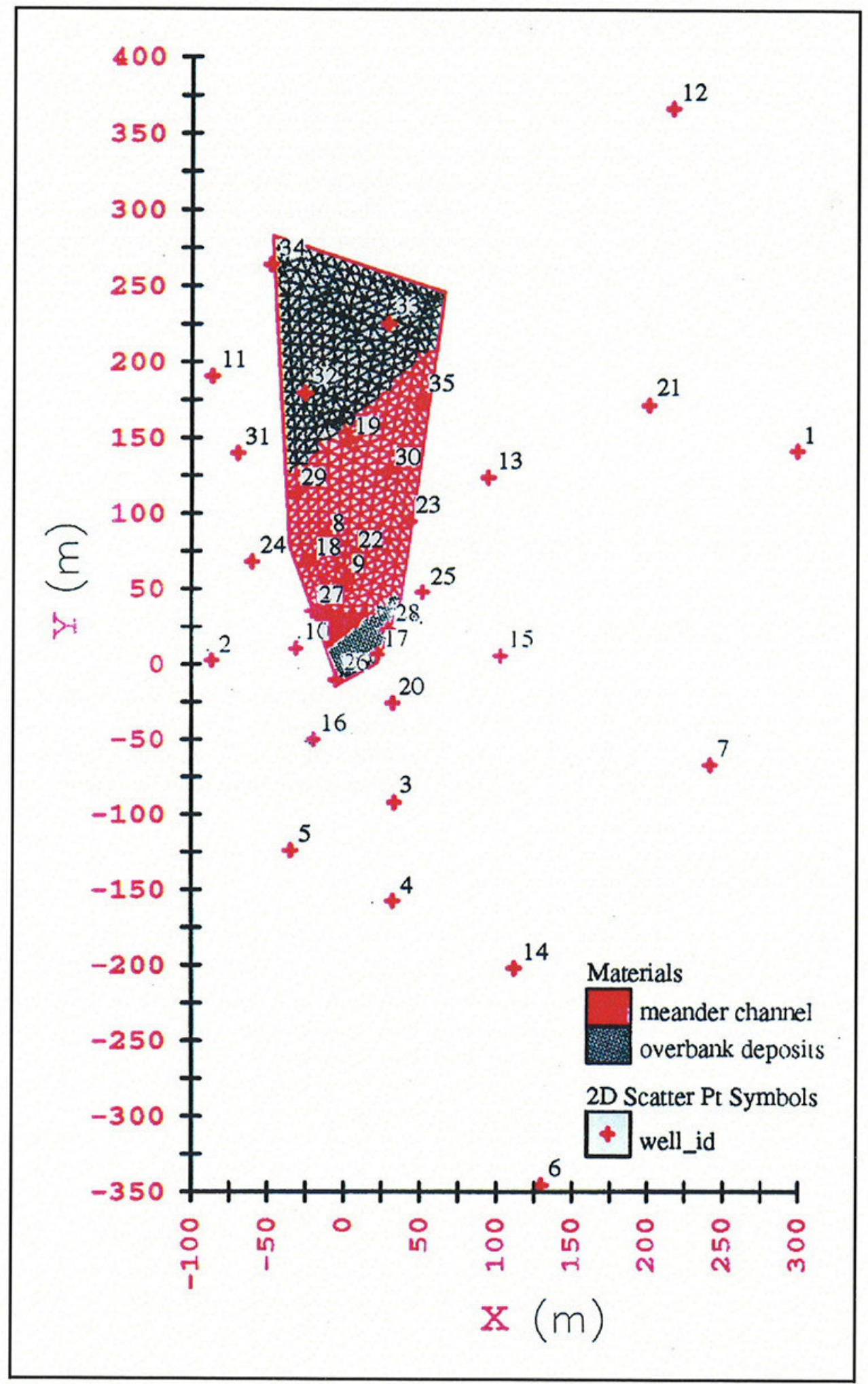

Figure 3. Well locations with nested wells labeled "A/B" 


\begin{tabular}{|c|c|c|c|c|c|c|c|}
\hline ID & $X(m)$ & $Y(m)$ & Well ID & ID & $X(m)$ & $Y(m)$ & Well ID \\
\hline 1 & 299.91 & 141.05 & $P-2$ & 19 & 3.16 & 147.63 & P-27A/B \\
\hline 2 & -86.10 & 2.56 & $P-3$ & 20 & 32.44 & -25.81 & P-34A/B \\
\hline 3 & 33.56 & -92.08 & $P-16$ & 21 & 201.85 & 171.53 & P-36A/B/C/D \\
\hline 4 & 32.61 & -157.50 & P-20 & 22 & 5.55 & 71.69 & P-42A/B \\
\hline 5 & -34.54 & -124.09 & $P-23$ & 23 & 43.33 & 94.53 & $P-43 A / B$ \\
\hline 6 & 130.21 & -345.63 & P-28 & 24 & -59.80 & 67.92 & $\mathrm{P}-44 \mathrm{~A} / \mathrm{B}$ \\
\hline 7 & 242.34 & -66.98 & P-29 & 25 & 52.20 & 47.77 & $\mathrm{P}-46 \mathrm{~A} / \mathrm{B}$ \\
\hline 8 & -11.41 & 83.28 & $P-40$ & 26 & -4.92 & -10.33 & P-53A/B \\
\hline 9 & 1.62 & 56.17 & $P-41$ & 27 & -20.13 & 35.08 & P-54A/B \\
\hline 10 & -30.84 & 10.38 & $P-45$ & 28 & 29.26 & 22.95 & P-55A/B \\
\hline 11 & -85.85 & 190.51 & $P-52$ & 29 & -32.26 & 113.18 & P-56A/B \\
\hline 12 & 217.69 & 366.34 & P-5R & 30 & 29.24 & 127.12 & P-57A/B \\
\hline 13 & 95.13 & 123.75 & $\mathrm{P}-8 \mathrm{~A} / \mathrm{B}$ & 31 & -69.15 & 139.66 & P-58AVB \\
\hline 14 & 112.22 & -201.80 & $P-1$ & 32 & -25.70 & 179.32 & P.59A/B \\
\hline 15 & 103.20 & 5.73 & $P-10 A / B$ & 33 & 29.34 & 225.10 & P-60A/B \\
\hline 16 & -19.40 & -50.16 & $P-22 A / B$ & 34 & -47.80 & 263.96 & P-61A/B \\
\hline 17 & 22.61 & 6.42 & P-24A/B & 35 & 51.93 & 173.77 & P-62A/B \\
\hline 18 & -23.30 & 66.57 & $\mathrm{P}-25 \mathrm{~A} / \mathrm{B} / \mathrm{C}$ & & & & \\
\hline
\end{tabular}

\section{Tracer data}

All tracer concentration data were imported into a Microsoft Excel spreadsheet. The spreadsheet contains all the data for the six tracers, including tritium, carbon-14, benzene, p-xylene, naphthalene, and o-dichlorobenzene. These data were used to compare measured data versus computed data at various locations at various times. 


\section{Model Development with FEMWATER}

During the course of this project, the MADE-2 modeling system was continuously refined. Two numerical grids were developed and several hydraulic conductivity fields were created. Initially, one steady-state flow field was used to represent the entire test. This flow field represented the average water table condition, which is roughly approximated by the water level sampling round of 8 February 1991. This approximation was improved with the development of two steady-state flow fields. The first flow field represents the low water table conditions during the first half of the experiment. The second flow field represents the high water table conditions present during the latter half of the experiment. This chapter discusses FEMWATER model development for the site, beginning with a discussion of how certain features of the software system were modified during this work to make the GMS/FEMWATER (Version 1.2) software system readily applicable to sites as complex as the CAFB test site.

\section{Summary of FEMWATER Model}

FEMWATER is a combination of two public domain models, 3DFEMWATER (flow) and 3DLEWASTE (transport). FEMWATER may be used to solve flow and transport of chemicals in a subsurface using the finite element numerical technique. Some features of the model are as follows:

$a$. It treats heterogeneous and anisotropic media.

$b$. It considers both distributed and point source/sinks that are spatially and temporally dependent.

c. It accepts a prescribed initial condition and time-dependent boundary conditions. 
$d$. It automatically determines variable boundary conditions of evaporation, infiltration, or seepage on the soil-air interface.

e. It provides three solution options for estimating the nonlinear matrix.

$f$. It automatically resets time-step size when boundary conditions or source/sinks change abruptly.

g. It checks the mass balance computation over the entire region for every time-step.

The major transport processes in FEMWATER are advection, dispersion/diffusion, adsorption, first order decay, and source/sink. For detailed information on FEMWATER, the reader is referred to Lin et al. (1996).

\section{Modifications to the GMS/FEMWATER System}

There are a number of features in the GMS/FEMWATER (Version 1.2) modeling system that had to be modified during this work. Some changes were made to the FEMWATER code to allow this model application, while other features will require further modification. A discussion of how the applied modeling approach was affected or altered from the preferred course follows.

\section{Maximum allowable material properties}

The MADE-1 and MADE-2 experiments were designed to assess the effect of heterogeneous media on macrodispersion. Much work has been done on the characterization of this heterogeneous media. By its very nature, the porous medium at the site is highly heterogeneous and this variability causes dispersion of any tracer moving through it. Heterogeneity must be accounted for in any model of the MADE experiments.

Since Version 1.2 of GMS/FEMWATER allows the use of only 20 material properties, this means only 20 hydraulic conductivities and 20 soil moisture characteristic curves (which define porosity) can be used. With this constraint, achieving a highly heterogeneous model was not possible without some modification of GMS/FEMWATER. For the MADE experiment, this condition had to be removed. All necessary arrays in FEMWATER (Version 1.2) were changed so that the number of hydraulic conductivities that could be specified was set equal to the number of elements used in the model. However, Version 1.2 of GMS could not load a large number of material types without an extreme degradation in performance. Once GMS (1.2) reads in more than a few hundred material properties, GMS begins slowing down and eventually stops reading the materials due to an insufficient memory error. To avoid the performance 
degradation, for graphic demonstration only, a geometry file having only one material property is used with GMS on all postprocessing of the highly heterogeneous model simulations. For the flow and transport simulations with FEMWATER which were done outside of GMS, all defined materials and hydraulic conductivities were used.

\section{Maximum allowable boundary conditions}

GMS/FEMWATER (Version 1.2) has an additional hard-wired limitation on the boundary condition specifications. There were a maximum of 1,000 allowable boundary conditions for rainfall-seepage, Neuman fluxes, and Cauchy fluxes. The model developed for this project required boundary condition array sizes greater than 1,000. The FEMWATER code was changed so that up to 3,000 boundary conditions could be specified.

\section{Conceptual Groundwater Flow and Transport Model (FEMWATER)}

Hydrogeologic conceptualizations generally must consider regional geology well beyond the extent of a particular study site (in this case, the CAFB test site) (Figure 2). Regional flow trends and model boundary conditions must be defined. Since the geological setting of the CAFB site is characterized by complex fluvial deposits, it is important to understand how these deposits are distributed and how they affect both regional and local groundwater flow directions and rates.

The fluvial deposits consist of point bar deposits, main channel deposits, channel bottom gravel deposits, and overbank deposits. In meandering systems such as those underlying CAFB (Figure 2), complexities arise from channel migration and avulsion commonly forming meander (oxbow) channels, which subsequently fit any fine-grained sediments. The MADE-2 tracers were injected into finer-grained (low hydraulic conductivity) overbank deposits, traveled across a meander channel fill, and then reentered overbank deposits that are mixed with sand and have higher hydraulic conductivity (Figure 2).

The regional groundwater flow direction is from the south to the north, towards the Buttahatchee River (Figure 1). The northward horizontal hydraulic gradient remains unidirectional throughout the tracer test area. The vertical hydraulic gradients vary depending upon position (Figure 4). Upward gradients exist as horizontal water movement approaches oxbow channels because of the increased hydraulic conductivity $(K)$ of these channels. In the channels themselves, groundwater flow is essentially horizontal, with few to no vertical gradients existing. Downward vertical gradients occur down-gradient of the channels as the water moves into overbank deposits having lower hydraulic conductivity. During transient 


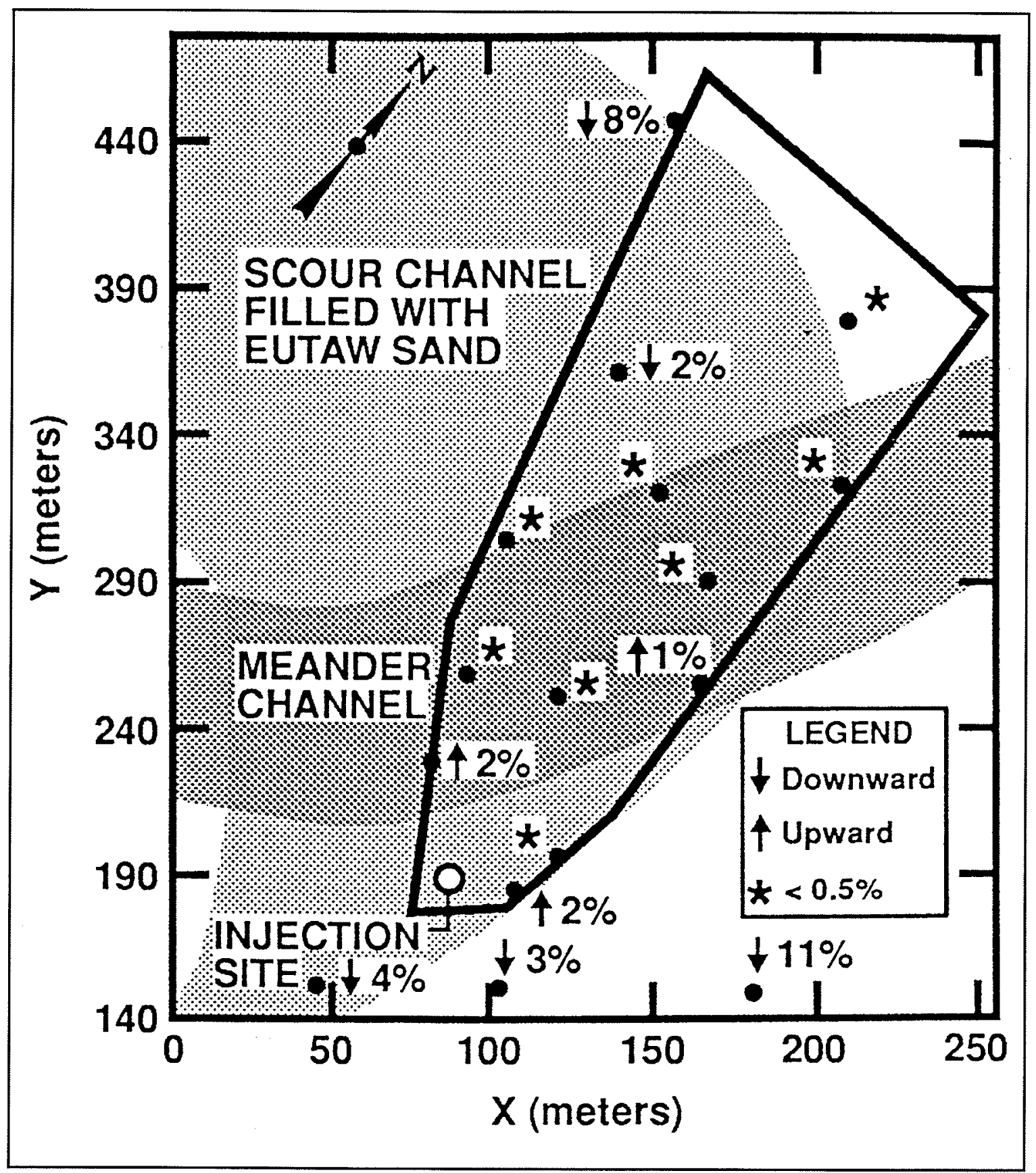

Figure 4. Plan-view distribution of vertical hydraulic gradients with respect to fluvial deposits 
flow events, vertical gradients are larger than during low water table conditions.

Flow conditions during the experiment can be approximated with two steady-state conditions. During the first 170 to 180 days of the experiment, no recharge affected the water level elevations, as shown by the continuous records in Figure 5. Subsequently, numerous water level responses occur. Water levels in the shallow fluvial deposits are quite variable and show rapid response to the rainfall. The continuous records indicate that water level variations of up to $4.7 \mathrm{~m}$ have occurred during the 440 -day experiment (Figure 5). The average variation during this period from all 16 wells was $3.9 \mathrm{~m}$, with a range from $4.7 \mathrm{~m}$ to $3.2 \mathrm{~m}$. When the eight shallow and eight deep wells are plotted simultaneously, it is clear that the shallow wells (Figure 6) respond with the same timing and similar water level responses as the deep wells (Figure 7). This indicates that direct recharge causes the water table to rise in the aquifer. Horizontal hydraulic gradient reversals do not occur, although the gradients are variable because spatial variations in porosity and hydraulic conductivities can cause different water level responses. For example, the horizontal hydraulic gradient between wells P53A and P61A (Figure 3) varies from 0.0019 during a low water table condition on 7 November 1990 to 0.0036 during a high water table condition on 20 May 1991. In other wells, localized horizontal gradients can increase from their low-water table values by a factor of three to four during the period of high recharge that occurs in the latter half of the experiment.

During the first 180 days of the experiment, the groundwater system did not receive much recharge and the water levels showed a continuous decline. This period of slow draining of the aquifer is considered a near steady-state condition. Another flow condition developed thereafter and continued roughly for another 180 -day period, followed by another period of declining water levels. It is apparent that during the late fall, winter, and into early spring, the groundwater system received recharge. During the late spring, through summer, and into early fall, the groundwater system generally drained. The tracer test was affected by water level variations during the transient conditions for two reasons. First, the increasing horizontal hydraulic gradients during the transient period caused faster tracer movement. Secondly, the additional recharge supplied to the aquifer caused significant dilution and dispersion of the leading edge of the tracers. This aspect of the conceptual model is a very important factor to consider when the tracer test concentration data are analyzed.

\section{Areal and vertical discretization of the model}

The plan view area covered by this model is $21.0 \times 10^{3} \mathrm{~m}^{3}$ (5.2 acres) (Figure 4). The topographic elevation in the test area is about $65 \mathrm{~m}$ above mean sea level. The finite-element nodes were stacked 13 high with each node vertically separated by $1 \mathrm{~m}$ (Figure 8 ). The nodal layers spanned the elevations from $65 \mathrm{~m}$ down to $53 \mathrm{~m}$. The grid is variably discretized in plan 


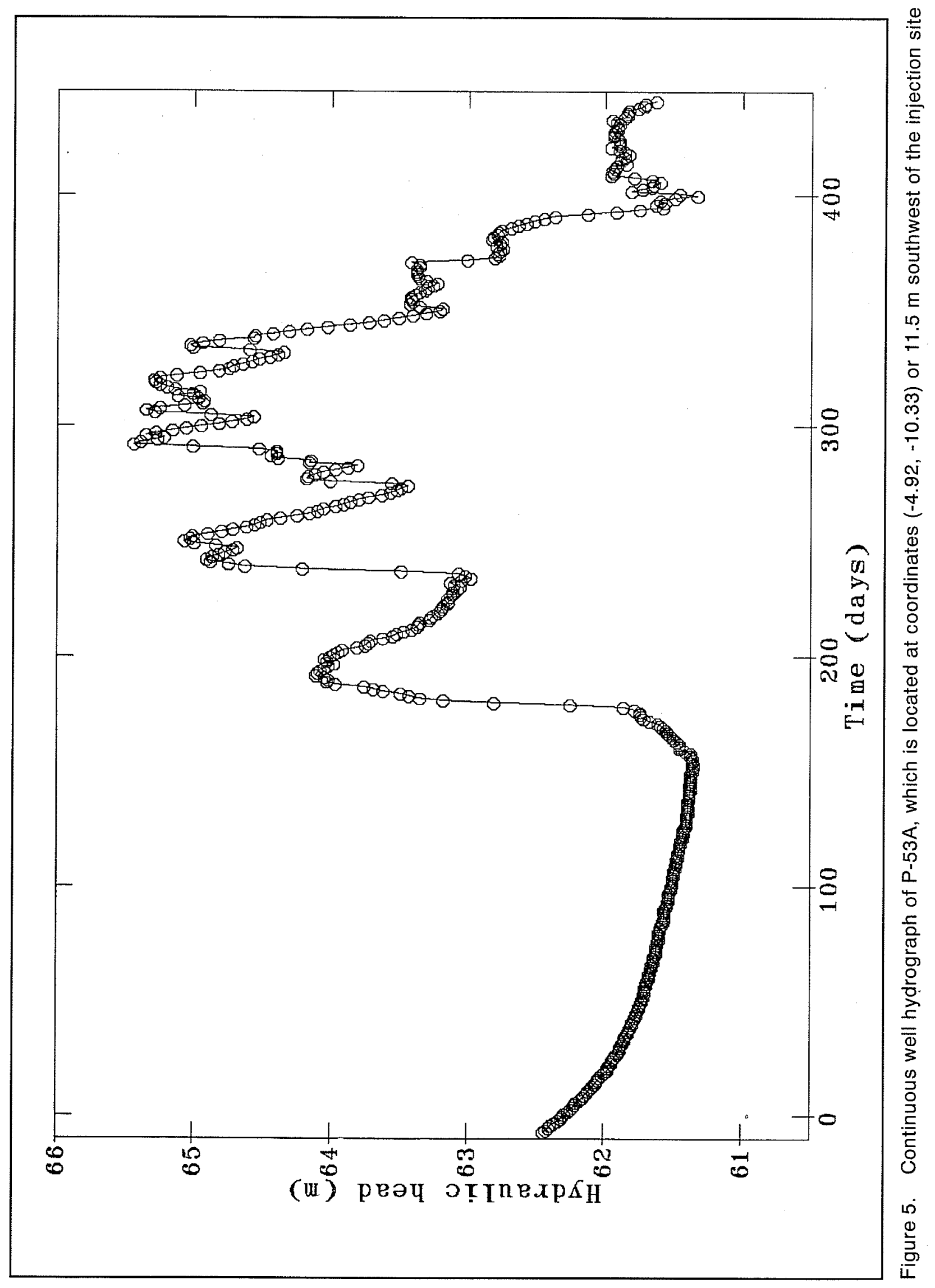

Chapter 3 Model Development with FEMWATER 


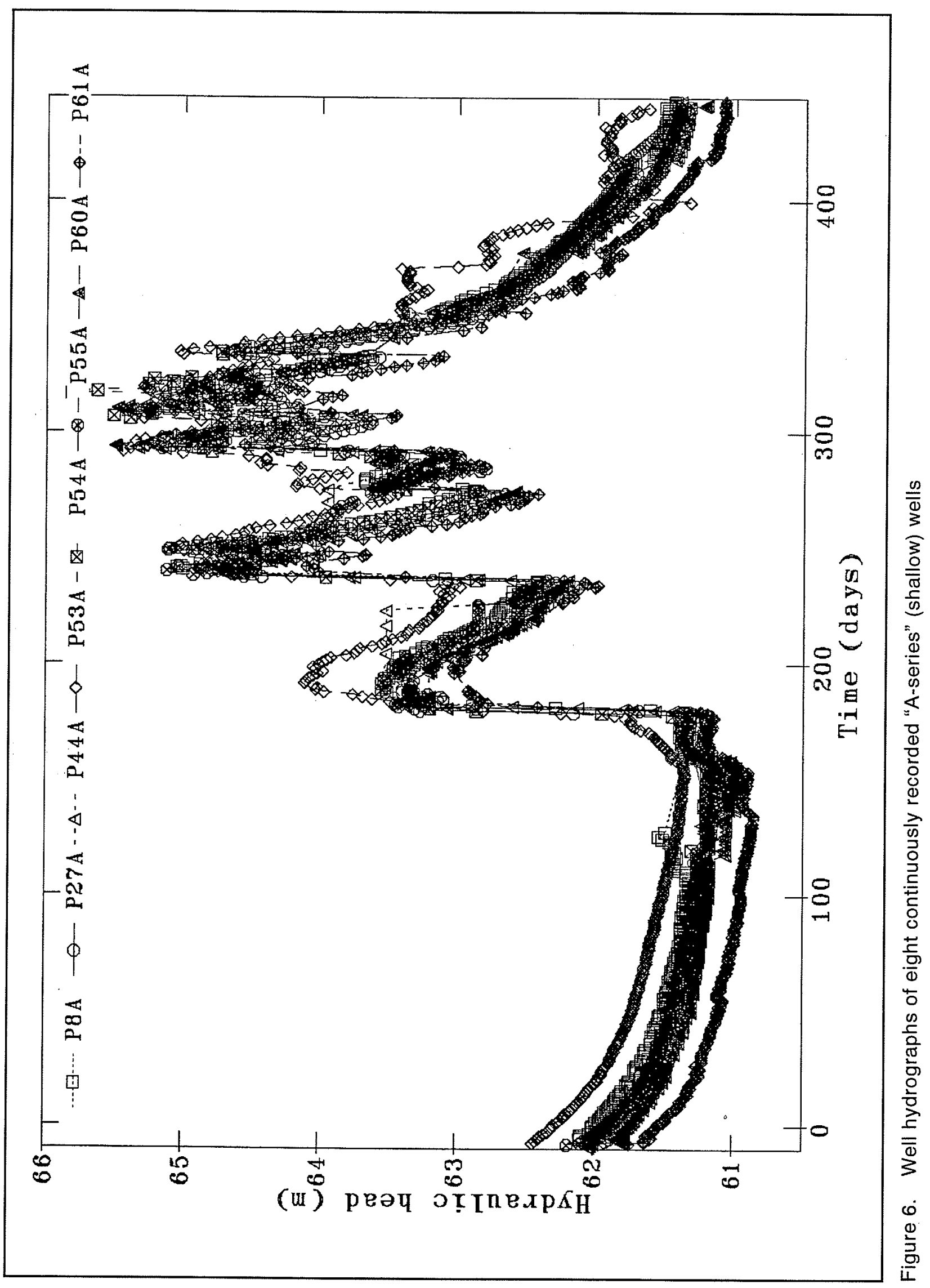




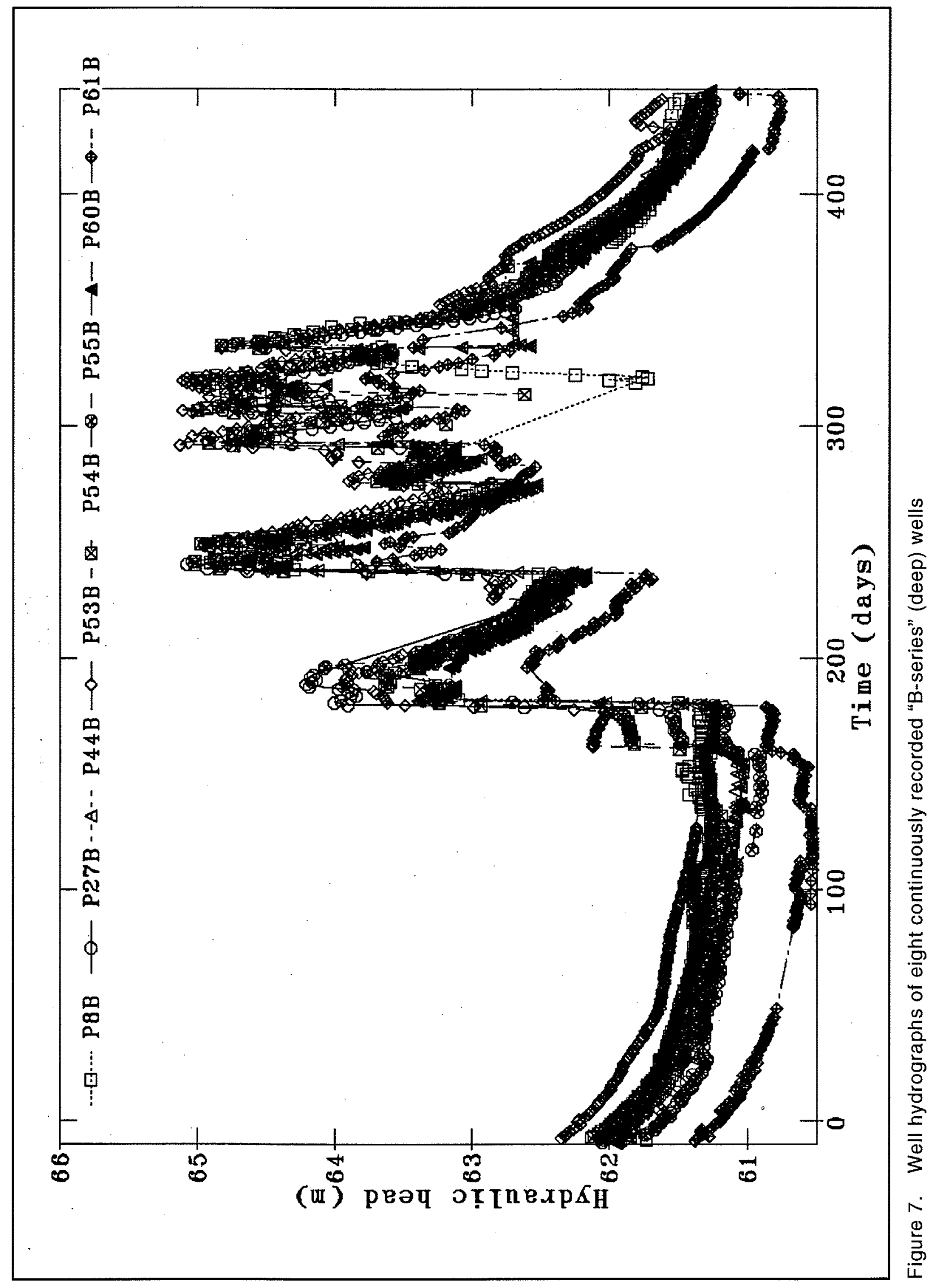

Chapter 3 Model Development with FEMWATER 


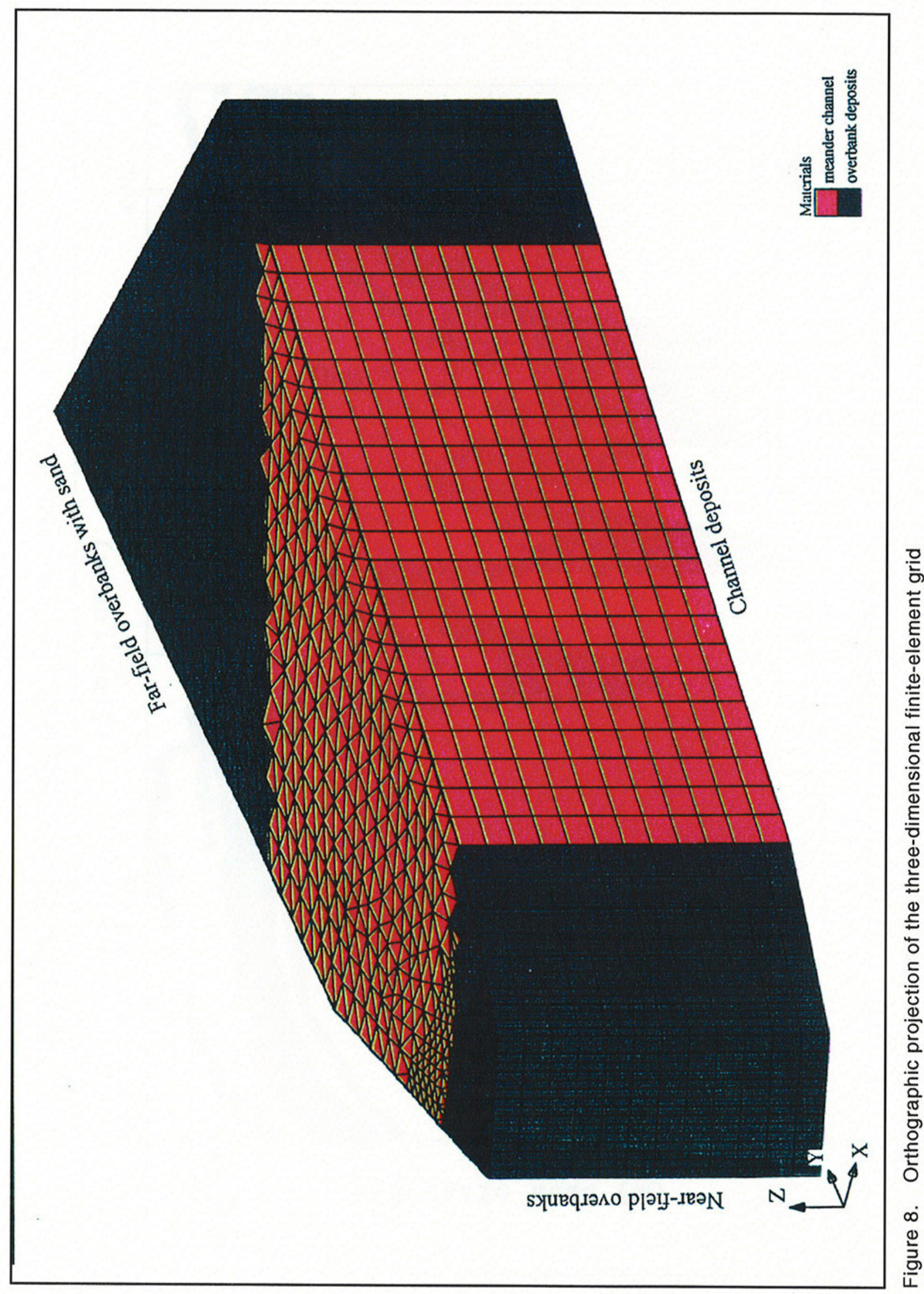


view, with a minimum nodal spacing of about $1 \mathrm{~m}$ in the injection area, enlarging gradually to a maximum average spacing of $8 \mathrm{~m}$. The total number of nodes used to cover this area is 10,621 and the total number of triangular prismatic (pentahedral) elements is 18,144 . The total volume of the model is $275,275 \mathrm{~m}^{3}$. Since transport through the saturated zone was of primary concern in this study, vertical refinement of nodes located in the vadose zone (from the surface downward to the water table) was not studied. If transient flow modeling were to be conducted, finer vertical discretization would be required.

\section{Hydraulic conductivity distributions}

As described earlier, the GMS/FEMWATER (Version 1.2) program, under review here, has a limit of 20 material properties. For an application such as this, 20 hydraulic conductivities is not enough considering the degree of hydraulic conductivity variation measured with the borehole flowmeter. Therefore, for this application; the limit of 20 material properties was removed in FEMWATER (Version 1.2) so that each element could have its own hydraulic conductivity. This precluded the use of GMS for displaying the material properties because there are 18,144 hydraulic conductivities, which could not be loaded and displayed by GMS (1.2).

The hydraulic conductivity field generated for this model used the borehole flowmeter hydraulic conductivities available in the MADE-2 database. A total of 2,018 individual hydraulic conductivities (K) were available in the data set. For each borehole location, the $\mathrm{K}$ data was vertically averaged over $1-\mathrm{m}$ intervals, thereby reducing the 2,018 points to 405 points. Vertical averaging was done because the vertical element spacing used in the model is $1 \mathrm{~m}$. The range of measured K's is from 0.08 to $1,249 \mathrm{~m} /$ day, with an arithmetic average of $32.8 \mathrm{~m} /$ day.

Using the vertically averaged hydraulic conductivity data, three main hydrogeologic zones consistent with the fluvial facies model may be delineated (Figure 3). For each of these zones, an average vertical profile of hydraulic conductivity was determined by using all available wells in the zone. The first zone, termed the near-field overbank deposits, has an overall average $\mathrm{K}$ of $4.2 \mathrm{~m} /$ day and an effective porosity of 0.31 . The second zone, termed the channel deposits, has an overall average $\mathrm{K}$ of $61 \mathrm{~m} /$ day and an effective porosity of 0.11 . The lower effective porosity seems contradictory considering that these are the channel deposits. Analysis of pumping tests indicates that three-dimensional connections of hydraulic conductivity exist, with relatively narrow high conductivity channels being interconnected in three-dimensional space. These channels allow much of the flow through the aquifer, with an estimate that over 80 percent of the aquifer material allows less than 10 percent of the total 
flow through the aquifer. ${ }^{1}$ This information, combined with the observation of the extreme acceleration of the leading edge of the plume through the channel deposits, indicates that these deposits have an overall lower effective porosity. The third zone, termed the far-field overbank deposits (intermixed with channel sands), has an overall $\mathrm{K}$ of $17 \mathrm{~m} /$ day with a 0.31 effective porosity. Within each zone, the $\mathrm{K}$ profile changes with depth (Figure 8). If GMS 3-D interpolation is completed using only the measured borehole flowmeter data, the interpolation routines have to extrapolate out to the boundaries of the model because flowmeter data do not exist outside the model boundaries. This extrapolation generally created hydraulic conductivities which are heavily weighted towards the highest or lowest measured data. When this occurs, the hydraulic conductivity field does not fit the geologic model because low $\mathrm{K}$ or high $\mathrm{K}$ zones are erroneously (numerically) created.

To avoid this problem, randomly located, randomly generated $\mathrm{K}$ boreholes were placed throughout the three $\mathrm{K}$ zones so that the GMS interpolation routine would have enough information throughout the model domain to avoid extrapolation. Thirty-five additional boreholes were placed in zones 2 and 3 , while seventeen boreholes were placed in zone 1 . The vertical $K$ profile was randomly generated using the average $K$ vertical profile for each of the three zones. The randomness within each borehole at each elevation was proportional to the standard deviation in measured K's. This technique creates vertical $\mathrm{K}$ variations in the boreholes that mimics the measured data. With the additional 87 randomly located boreholes added to the measured data, GMS successfully interpolated the 3-D K field to the nodal points of the finite-element domain. Since FEMWATER (Version 1.2) requires that $K$ be assigned for elements, an averaging program was written that took the six nodal K's for each element and arithmetically averaged them. When viewed with a $3-\mathrm{D}$ graphics program, the resulting $\mathrm{K}$ field fits the site geologic model and does not have artificially high or low $\mathrm{K}$ zones.

During calibration, no changes were made to the individual hydraulic conductivities. It is possible that the model calibration could be improved by manually changing the $\mathrm{K}$ field. This level of detail was not attempted in this effort.

\section{Boundary conditions}

There are essentially five sides to this model, including a top and bottom side, and three lateral sides. Both constant head and flux conditions were used in the steady-state flow models (Figure 9), whereas interior sources were used in the injection area to introduce the concentration for the transport models.

\footnotetext{
1 Personal communication on the history of work conducted at the MADE site, 1996, Steve Young, Environmental Consulting Engineers, Inc., Knoxville, TN.
} 


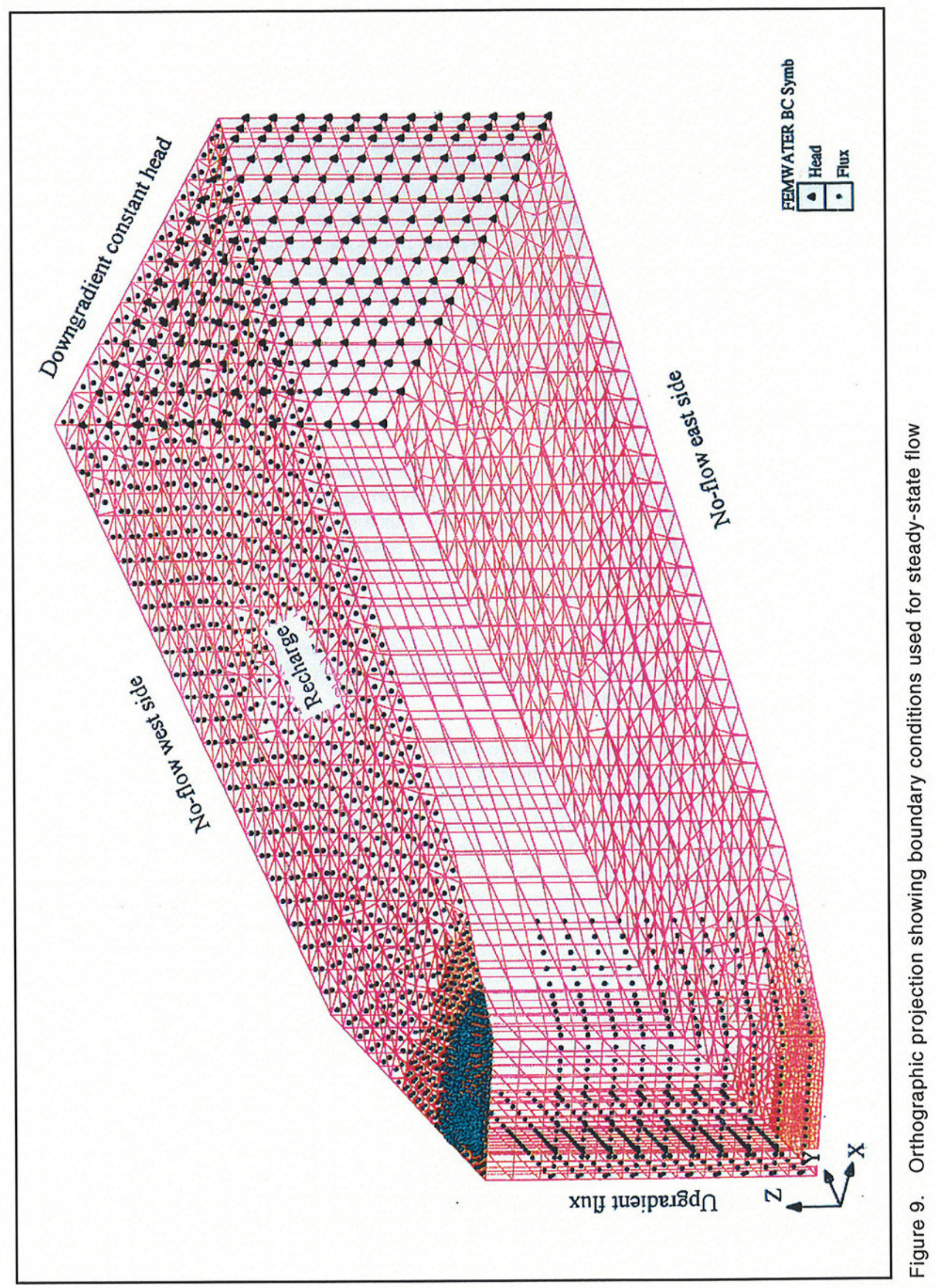




\section{General description of flow boundary conditions}

Since two steady-state flow situations were simulated, the boundary conditions used represent low and high average water level conditions during the experiment. The actual water level data sets used to set boundary conditions were measured on 17 September 1990 (low conditions) and 8 March 1991 (high conditions). Sensitivity analysis was used to determine the up-gradient flux boundary conditions needed to obtain the proper hydraulic head conditions within the aquifer for each time simulated. The down-gradient boundary conditions were set to constant head conditions, with individual boundary conditions set for each time simulated. The constant heads set along the down-gradient boundaries are variable, with the highest heads on the east side of the model and the lowest on the west. Portions of the lateral boundaries were considered no-flow boundaries and portions were considered up-gradient flux conditions (Figure 9). A uniform recharge was specified through the top of the model. A no-flow condition was specified along the bottom.

The top boundary consisted of a constant flux condition to represent recharge to the aquifer. The constant flux was set equal to an average recharge rate of $18.3 \mathrm{~cm} /$ year $(7.2 \mathrm{in} . /$ year). Since no rainfall data were available in the MADE-2 database, it was not possible to determine what percentage of rainfall this represents. A sensitivity analysis was conducted to investigate the importance of this boundary condition.

A uniform no-flux bottom boundary condition was used at $53 \mathrm{~m}$. The transport of all tracers occurs above this lower boundary throughout the duration of the experiment.

The lateral boundaries used in this model nearly form a triangular area (Figure 9). The apex of the triangle is located on the up-gradient side of the model, near the injection area. In this area, horizontal groundwater flux is allowed to enter the model, to simulate the regional flow of water into the model domain. The lateral flux used along this boundary is either constant from top to bottom (low water table) or is vertically variable (high water table). This boundary condition is variable because during transient groundwater flow, larger vertical gradients exist along this boundary and a vertically variable flux is needed to generate these gradients. For the high water table conditions, the up-gradient fluxes are greatest near the water table and decrease downward. The average of these fluxes is equal to the measured hydraulic gradient across the boundary multiplied by the average hydraulic conductivity of the up-gradient area. In other words, the fluxes are physically realistic.

The down-gradient boundary is set to a constant head. Since this boundary is at an angle with respect to the regional flow system, variable constant heads are used along its length (Figure 9). Hydrostatic heads are set for each vertical column of nodes and these head conditions are based on the measured down-gradient water levels each time period simulated. 


\section{General description of transport boundary conditions}

The transport boundary conditions were set to represent injection of the tracers. The maximum measured concentration from each sampling period was determined and plotted with respect to time. These data indicated that the concentrations generally decreased over time, as would be expected. From these data, transient concentrations were set at the injection well. Numerous simulations were performed using various boundary conditions for the injection wells, and this decreasing concentration condition was found to be the best representation of the experiment. The use of constant concentrations at the injection well was shown to be inappropriate through numerous simulations. No other transport boundary conditions were required because the plume stayed within the model boundaries during the entire simulation.

Interior sources were used to represent the injection of tracer into the model. Four vertically stacked nodes at coordinates $(0.5,0.3 \mathrm{~m})$ were used to represent the injection interval. These nodes span the elevation of $61 \mathrm{~m}$ to $57 \mathrm{~m}$. The actual screened-section openings in the injection wells span the range of 58.1 to $57.5 \mathrm{~m}$. Due to increased fluid pressure in the injection well area, the injected concentrations were initialized slightly above and below the screened-section interval. 


\section{FEMWATER Application and Results}

The modeling approach adopted here simulates the experiment with a combination of two steady-state flow fields and transient transport. The first flow field represents early-time, low-water-table conditions from day 0 (starting day) to day 180 . The second flow field represents high-water-table conditions during the latter portion of the test (day 180 to 450 ). During this GMS/FEMWATER application, it was determined that transient flow and transient transport would require too much time to successfully complete. The computational demands of that approach would substantially limit the number of modeling runs that could be completed.

During the course of this study, several iterations on the model grid discretization and on representation of the three-dimensional hydraulic conductivity field were made. Once these were defined, numerous model runs were made to determine the model sensitivity to the applied boundary conditions. The best boundary conditions were selected for both the low and high water table conditions, and steady-state solutions were achieved. These solutions are termed calibrated conditions, but these really represent a reasonable comparison between the calculated and measured water levels and hydraulic gradients across the entire site.

To ensure that FEMWATER source code changes made during this project were valid, code accuracy had to be verified after the code changes were completed. A simple two-dimensional flow and transport example was created so that the FEMWATER flow and transport results could be compared to the analytical solution for this problem. This example is a simple tracer experiment in which a constant concentration is injected along a boundary into a uniform flow field. The growth of the example plume is dependent upon the ratio between the velocity and dispersion terms used. Although a detailed numerical analysis was not conducted to compare the results of the example, graphical comparisons of results appeared to be reasonable. 


\section{Use of Gauge Plots and Methods of Model Calibration}

One of the goals of site-specific modeling is to compare measured parameters to simulated parameters. To accomplish this, GMS allows comparison of measured values at one well (gauge) to the model-calculated values at the same location. Up to five comparisons can be made at any one location so that water level, concentration, velocity, etc. can be compared. It is also expected in GMS that measurements will have been made at more than one time (i.e., data are transient). This presents two difficulties that have to be overcome. First, the comparisons can be made at only one location at a time. This type of comparison works best for a tracer breakthrough curve, for example, but it is not efficient for comparing a complete water level round to the calculated values. Secondly, it is not possible to compare single readings at any location, such as one might generate during a water table elevation sampling round. Therefore, the use of gauge plots makes it very difficult to determine how well a flow model is calibrated at a particular time. A common calibration practice is to compare a set of water levels measured at numerous wells to model-calculated water levels (Figure 10), for any given time. This type of information is valuable in calibrating a model because well-by-well comparisons can be made and inaccuracies in the model can be revealed quickly. Having a software for calibration purposes in numerical groundwater flow models is very useful and allows a rapid analysis of the well- by-well water level comparisons. Normally a file consisting of well coordinates and measured water levels at various times is created from the measured data. This file is used by the model after convergence is reached so that interpolations of the modelcalculated water levels can be compared to the measured data. Statistical summaries of the comparison can be created and used to assess or document how well a model is calibrated.

GMS/FEMWATER (Version 1.2) did not allow this type of comparison to be made. Therefore, it is difficult to assess how well a model is calibrated. The gauge plot methodology in GMS (Version 1.2) requires that each well be compared individually to determine how well model-computed water levels compare to measured values. In applied modeling this is inefficient and a change needs to be made so that a simultaneous well-by-well comparison can be made. For this reason, in this application, computed versus measured water levels are compared graphically.

\section{Steady-State Flow Calibration}

As with any model, the solutions obtained for the hydraulic head field can be achieved with different sets of input parameters because the solutions are not unique. The intent of this modeling was not to make the most highly calibrated model possible, but rather to create a model that used as much of the available site data. In light of this philosophy, the 


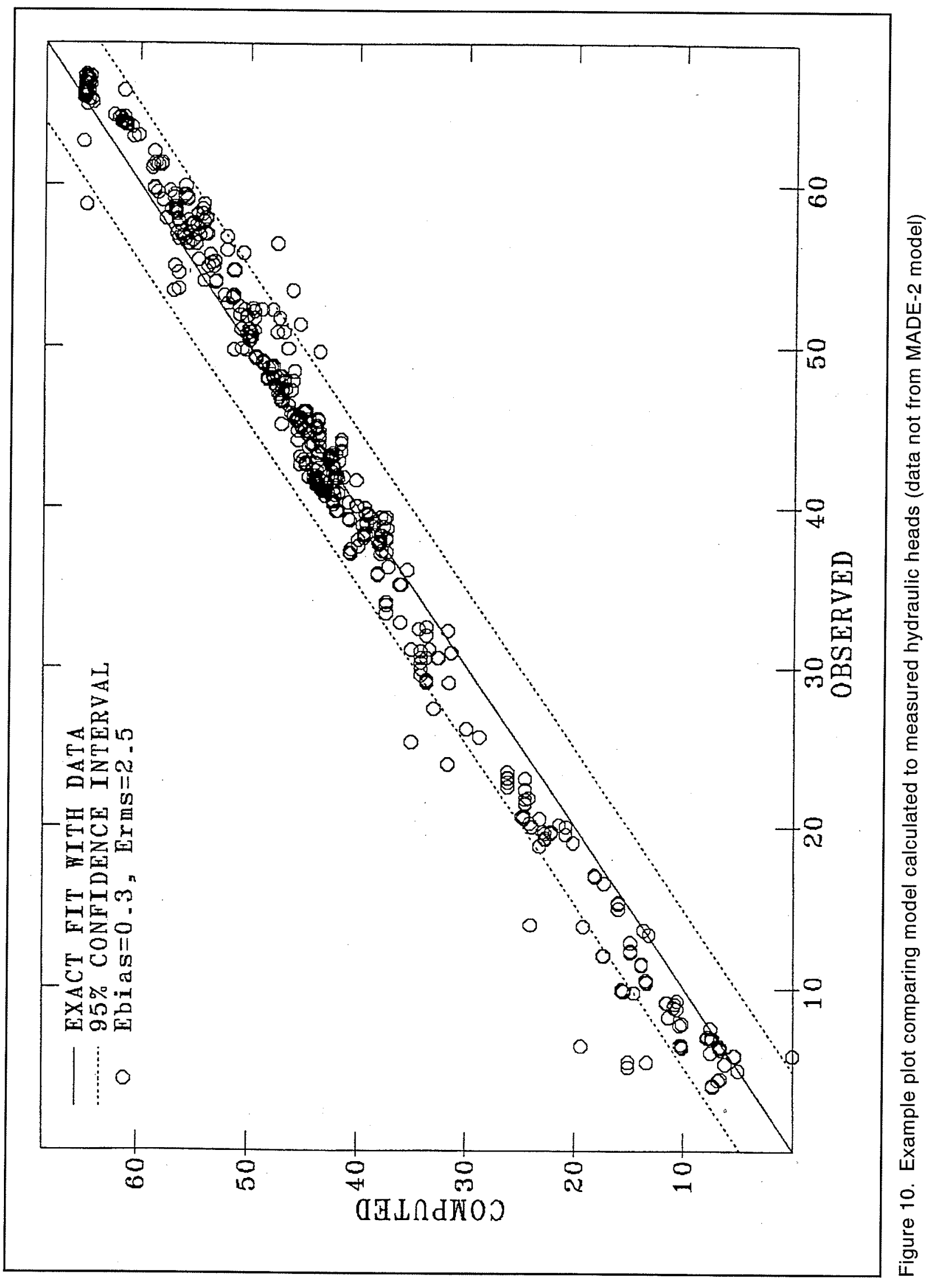


conductivities were not altered on an element-by-element basis to improve the calibration, nor was variable recharge applied in any areas. The final hydraulic conductivity field used is based only on measured data.

The primary goal in developing the low- and high-water-table models was to create two hydraulic gradient fields that could be used to advect the tracers. These gradient fields have different properties, with the average gradient being higher during the high-water-table condition. During low-water-table conditions, vertical gradients are minimal and the horizontal hydraulic gradient through the injection area is less than during high-water-table conditions. The increased hydraulic gradients that exist during the latter half of the experiment cause the tracers to move through the channel faster. In addition, the recharge that occurs during the second half of the experiment dilutes and disperses the tracers that exist in the channel deposits.

The average hydraulic head difference across the site during the low-water-table condition is $0.72 \mathrm{~m}$ and is $0.95 \mathrm{~m}$ during high-water-table conditions. The total head steady-state solutions for the low-water-table condition (Figure 11) and the high-water-table condition (Figure 12) are shown along with the measured water levels. The water levels plotted at the well locations represent either a single water level reading taken at a well or vertically averaged values, if a nested well exists at that location. As can be seen in these plots, differences exist between calculated and measured water levels (total heads) throughout the model domain. Once again, no attempt was made to reduce the difference between computed and simulated water levels. The primary goal was to obtain a reasonable approximation to the water table in general and to make sure the hydraulic gradients were correct in magnitude and direction.

The velocity fields corresponding to these solutions (Figures 13 and 14) generally show unidirectional flow, from the south to the north. The velocity profiles vary more for the high-water-table condition because the up-gradient flux boundary condition was vertically variable, whereas it is uniform during low-water-table conditions. The average along-gradient velocity in the high-water-table condition is 2.2 times greater than during the low-water-table condition. The vertical variation in velocity is also greater.

These flow solutions were used as input to the tritium transport model. The low-water-table solution was used for the first 180 days of the experiment. The concentration field solution for day 180 was used as an initial condition for transport during the high-water-table condition. 


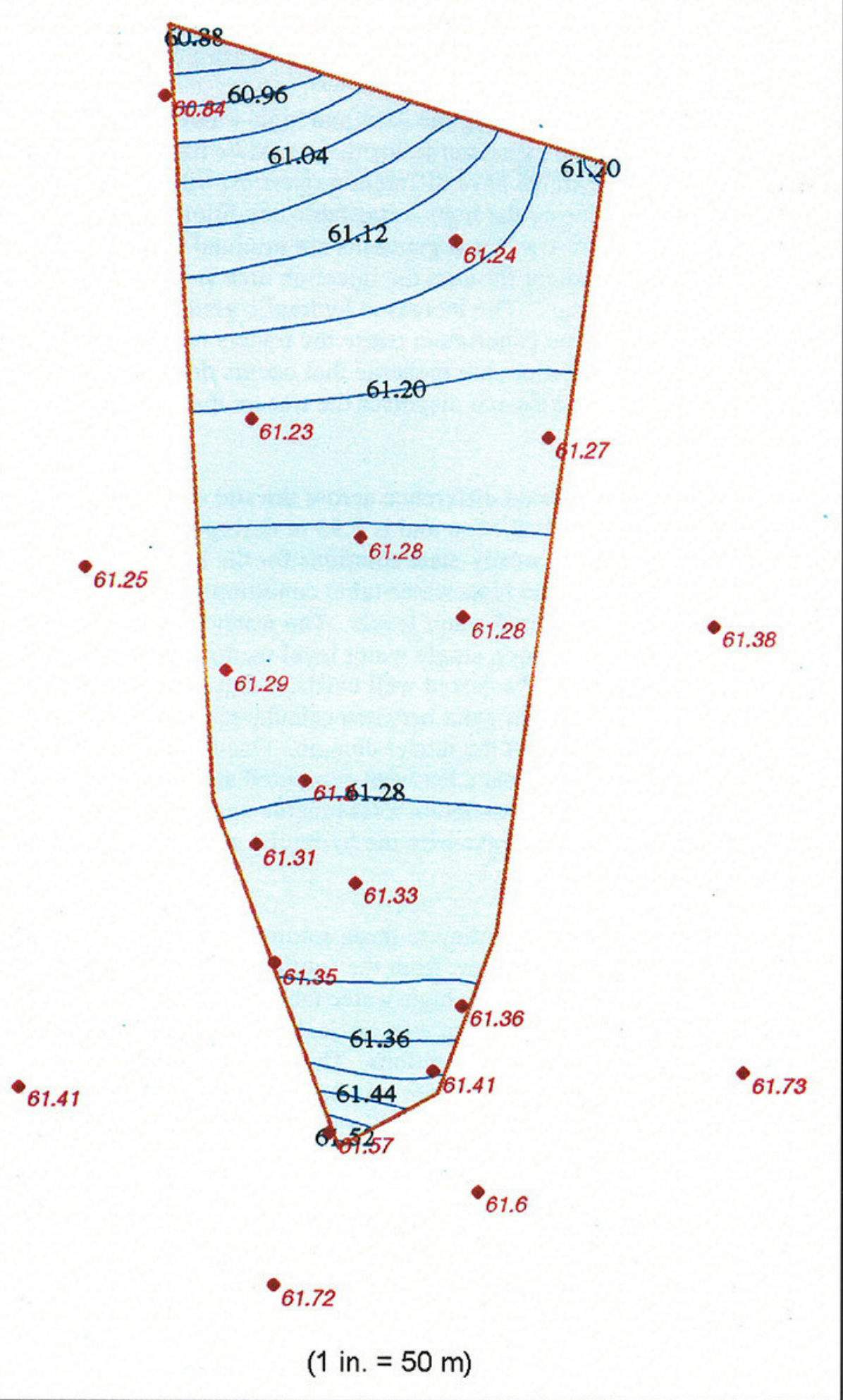

Figure 11. Steady-state total head distribution for the low-water-table condition $(9 / 17 / 90)$ 


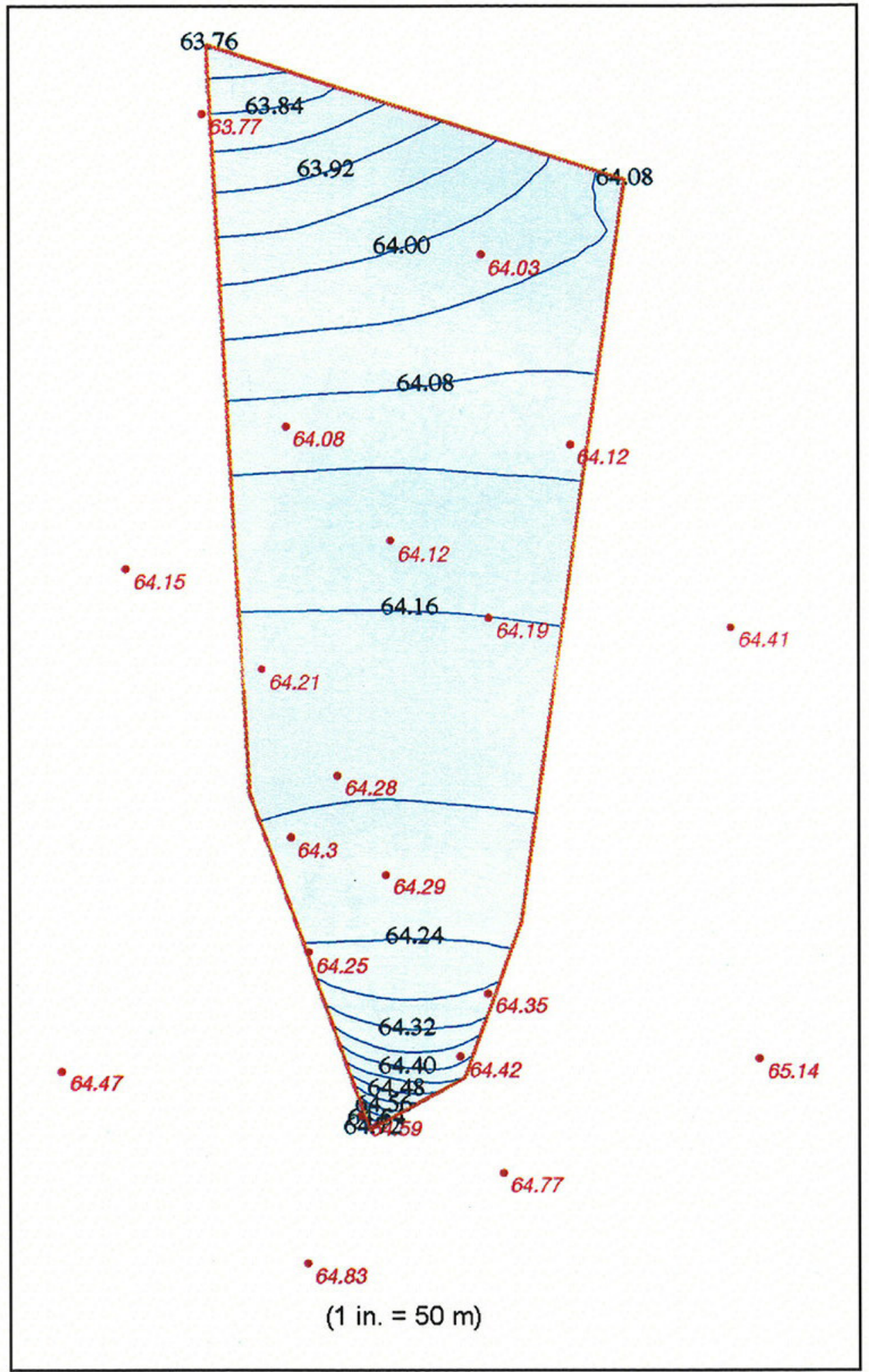

Figure 12. Steady-state total head distribution for the high-water-table condition $(3 / 8 / 91)$ 


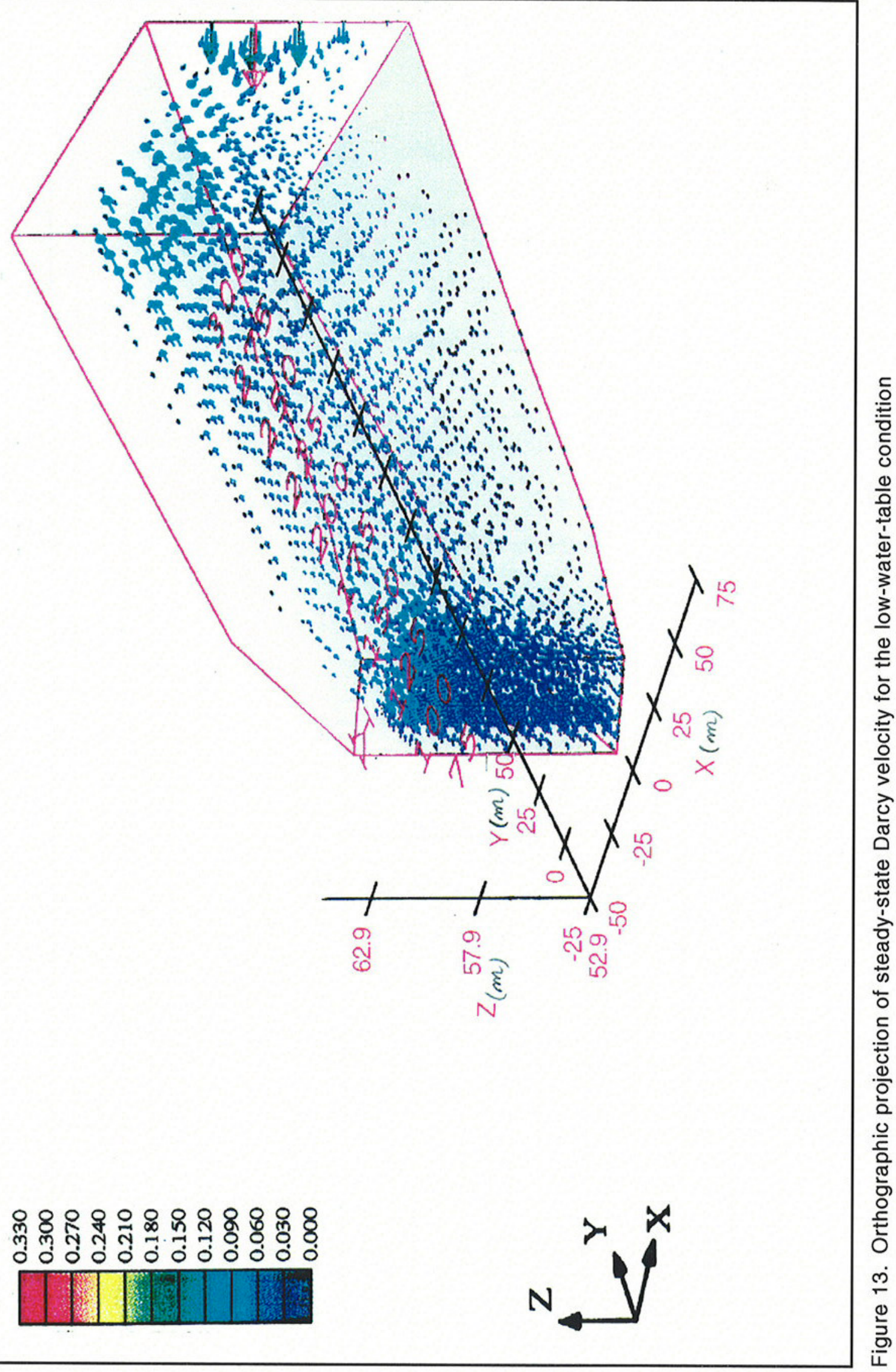




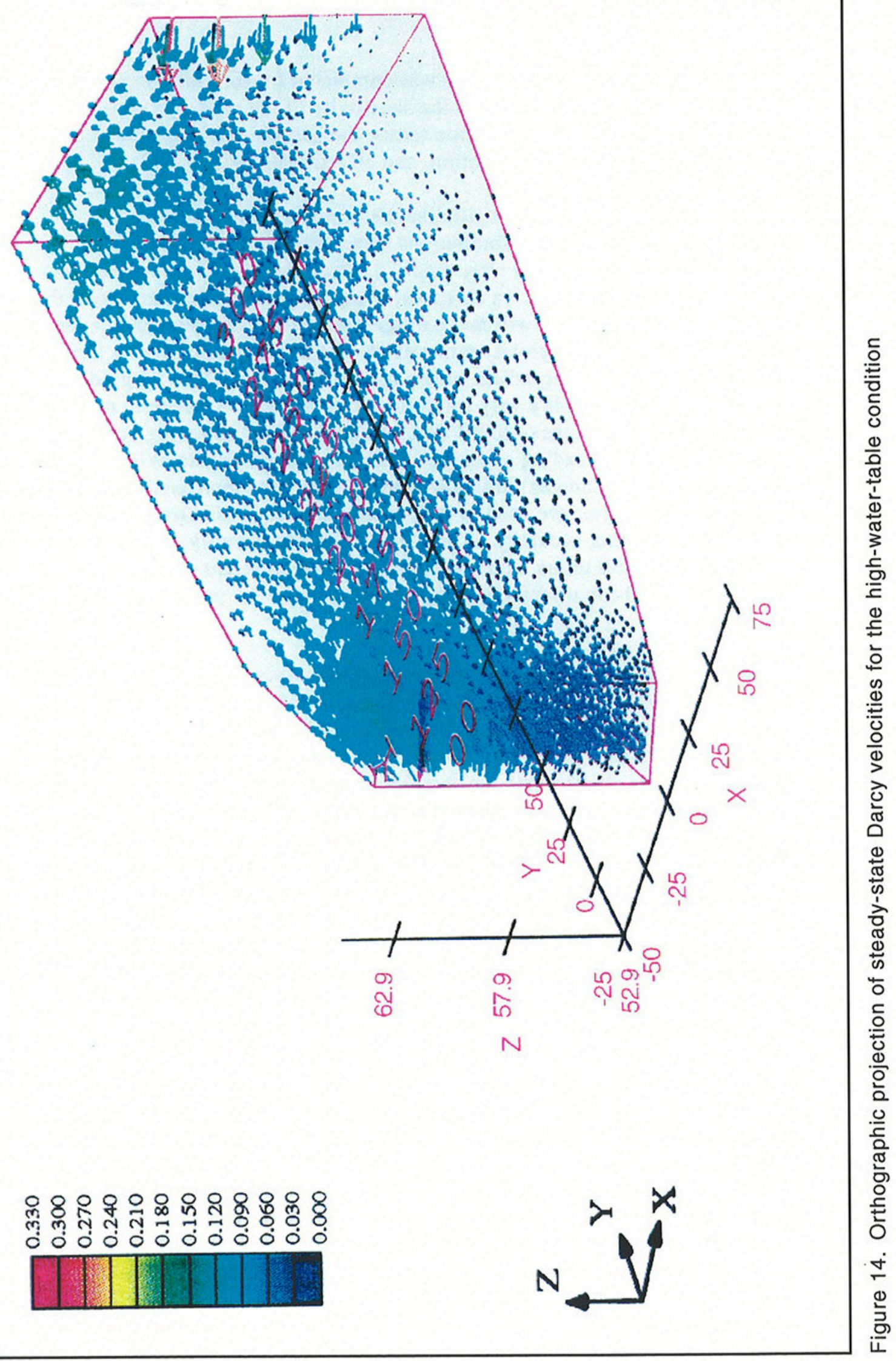




\section{Transport Analysis}

Simulation of the tritium plume was completed for the entire experiment. Numerous runs were made to test the sensitivity of the model to various parameters including the dispersion terms, the particle tracking parameters of FEMWATER, time-step selection, and effective porosity.

Two terms representing longitudinal and transverse dispersivity are available in FEMWATER. Simulations using longitudinal dispersivity ranging from $10 \mathrm{~m}$ to $0.5 \mathrm{~m}$ were made. Lateral dispersivities ranging from $5 \mathrm{~m}$ to $0.01 \mathrm{~m}$ were tested. In all cases, if any dispersion terms are used, the computed concentrations will move up-gradient of the injection area, even though no up-gradient velocity terms exist. The larger the dispersion term used, the more that up-gradient plume spreading occurs. This up-gradient spreading occurs even if a very small time-step is used. Short-term models were run with time-steps of 0.001 day, and up-gradient spreading occurred. This up-gradient spreading occurred even when the particle tracking parameters $(n x, n y$, and $n z)$ in GMS/FEMWATER were increased from 2,2,2 to $4,4,4$. These terms are used to split elements in each direction to improve the particle tracking accuracy. Although difficult to quantify, it seemed that by increasing these terms, less up-gradient spreading might occur.

However, model run time increased because the time for particle tracking increased.

With a highly heterogeneous hydraulic conductivity field in this model, inherent numerical dispersion occurs in these simulations. Tortuous flow paths can occur because different hydraulic conductivities are found from element to element. Computed versus measured concentrations are shown in series of four representing the sampling rounds of $27,132,224$, and 328 days. These rounds were conducted about 100 days apart. With an injection concentration of $55,610 \mathrm{pCi} / \mathrm{ml}$, the tritium results are shown for $50 \mathrm{pCi} / \mathrm{ml}\left(10^{-3} \mathrm{C} / \mathrm{Co}\right)$ and $5 \mathrm{pCi} / \mathrm{ml}\left(10^{-4} \mathrm{C} / \mathrm{Co}\right)$. The computed plumes are shown as blue isosurfaces, whereas the measured data are shown as a solid circle, square, or triangle. These point measurements represent every location where a measurement was taken and the value was greater than the contoured value. For example, for a $50-\mathrm{pCi} / \mathrm{ml}$ plot, every solid point represents a reading of at least $50 \mathrm{pCi} / \mathrm{ml}$. The sampling points that measured less than $50 \mathrm{pCi} / \mathrm{ml}$ are not shown. The $50-\mathrm{pCi} / \mathrm{ml}$ plumes for days $27,132,224$, and 328 are shown in plan view (Figures 15-18) and vertical view (Figures 19a-19d). From an examination of these plots, several features of the transport simulation can be determined. First, the areal extent of the 27th day plume is underpredicted because the effect of the two-day injection is not included in the simulation. The early time plume is larger than would be expected, given the flow field because the injection forced the tracers to move in directions other than just down-gradient. Secondly, the $50-\mathrm{pCi} / \mathrm{ml}$ plume is simulated quite well through the 224-day period (Figures 15-17, 19a,b,c). This sampling round is about 40 days into the transient flow portion of the test. This implies that the first portion of the test, the low-water-table condition, is simulated quite 


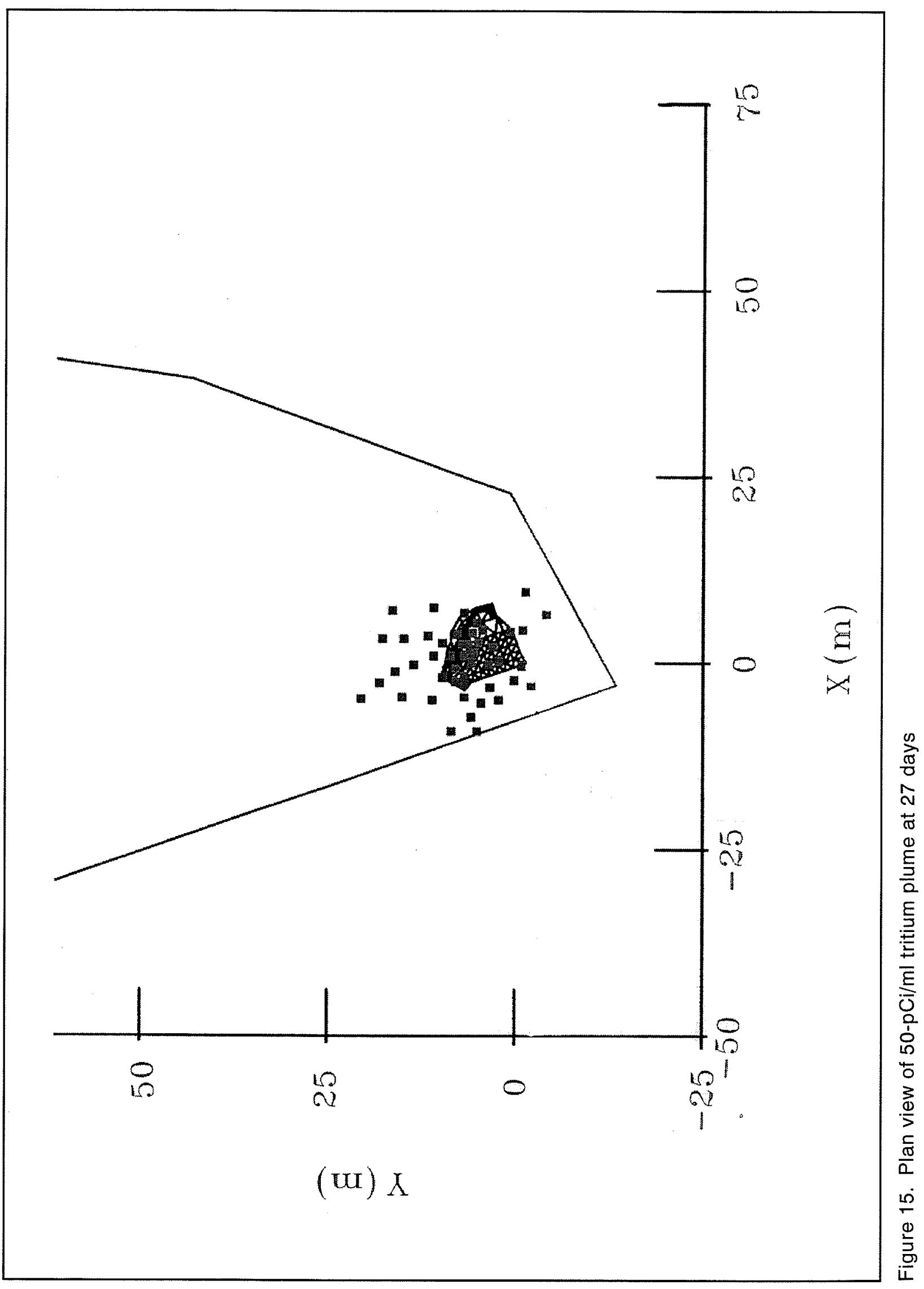




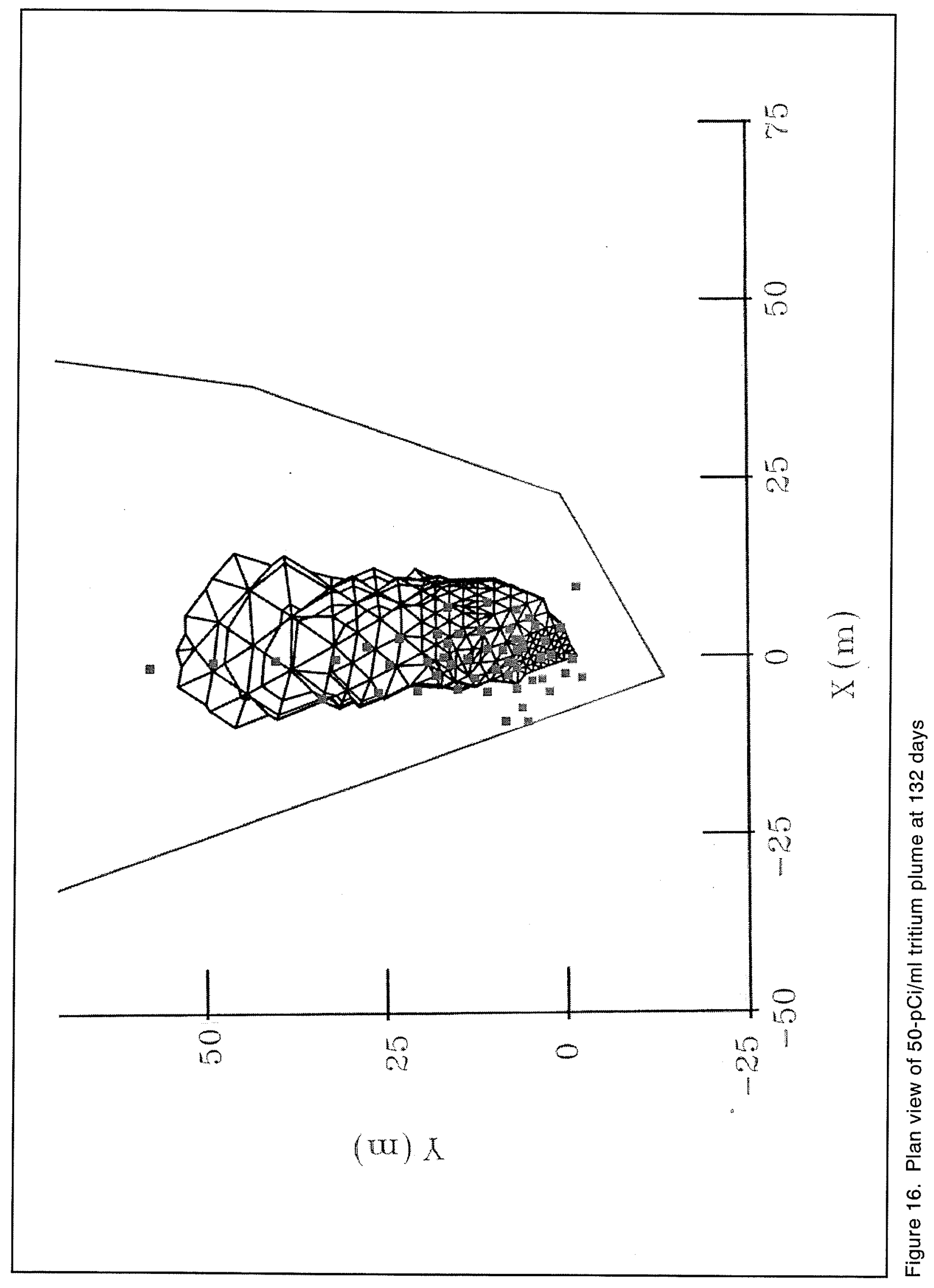




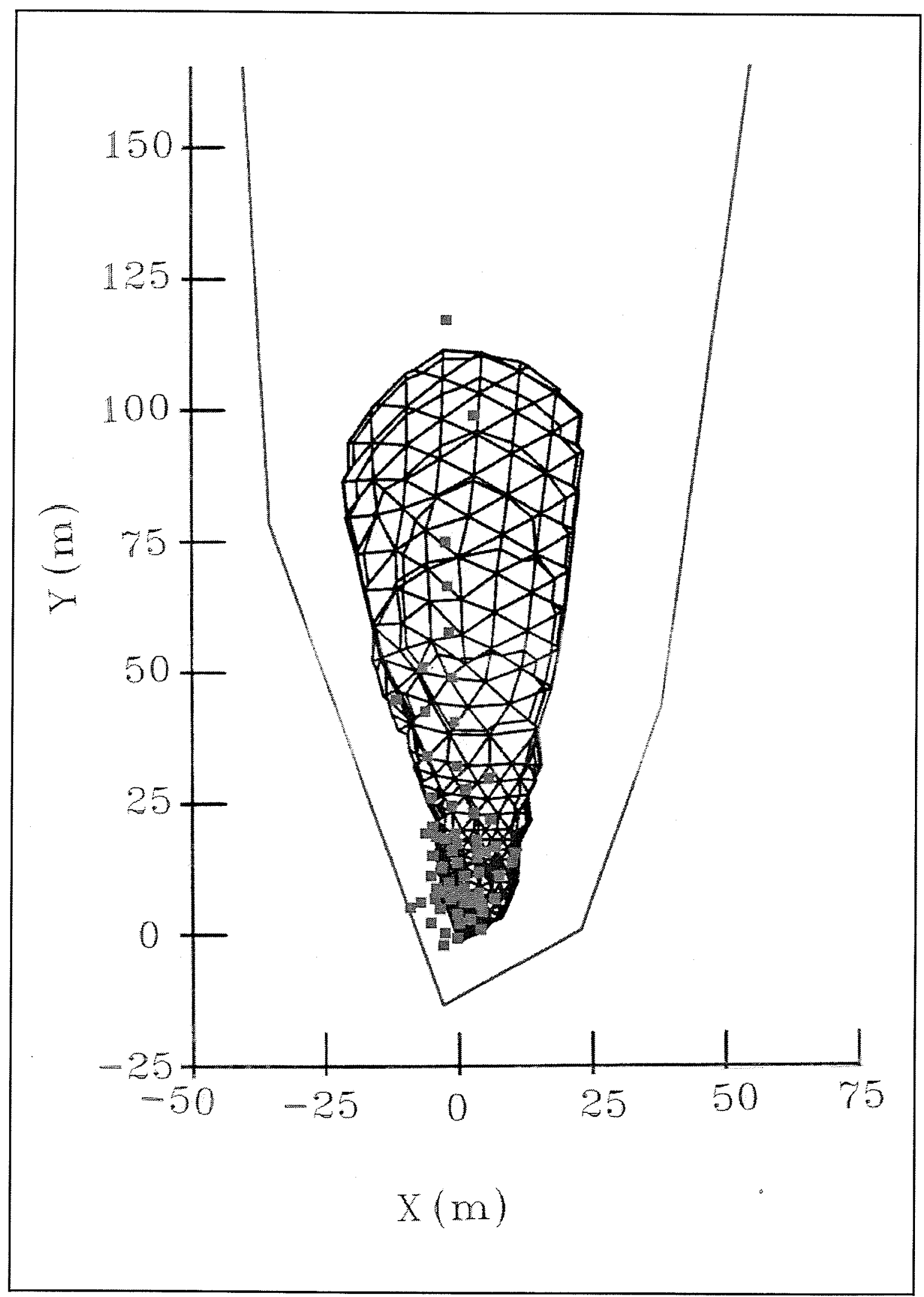

Figure 17. Plan view of $50-\mathrm{pCi} / \mathrm{ml}$ tritium plume at 224 days 


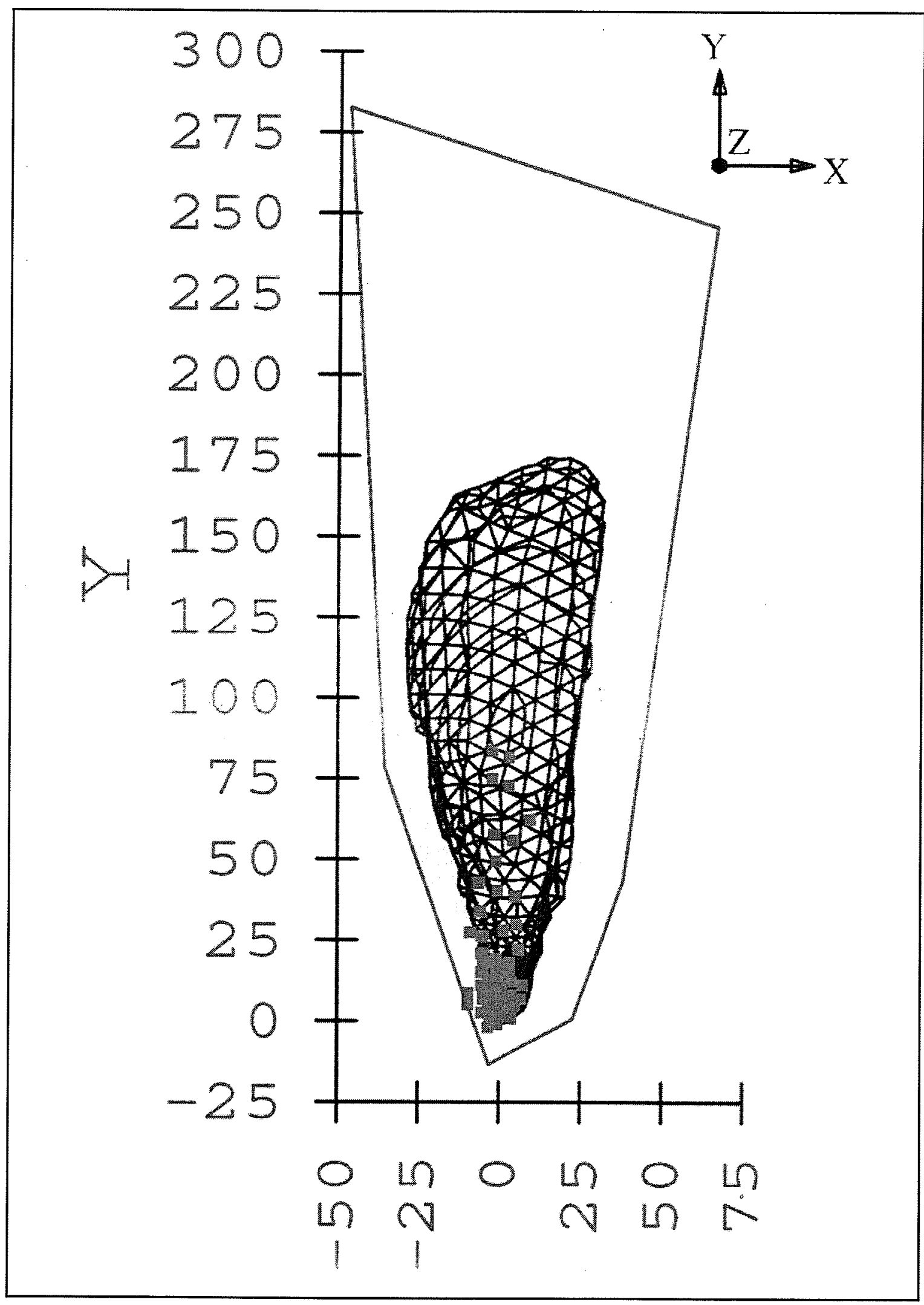

Figure 18. Plan view of $50-\mathrm{pCi} / \mathrm{ml}$ tritium plume at 328 days 


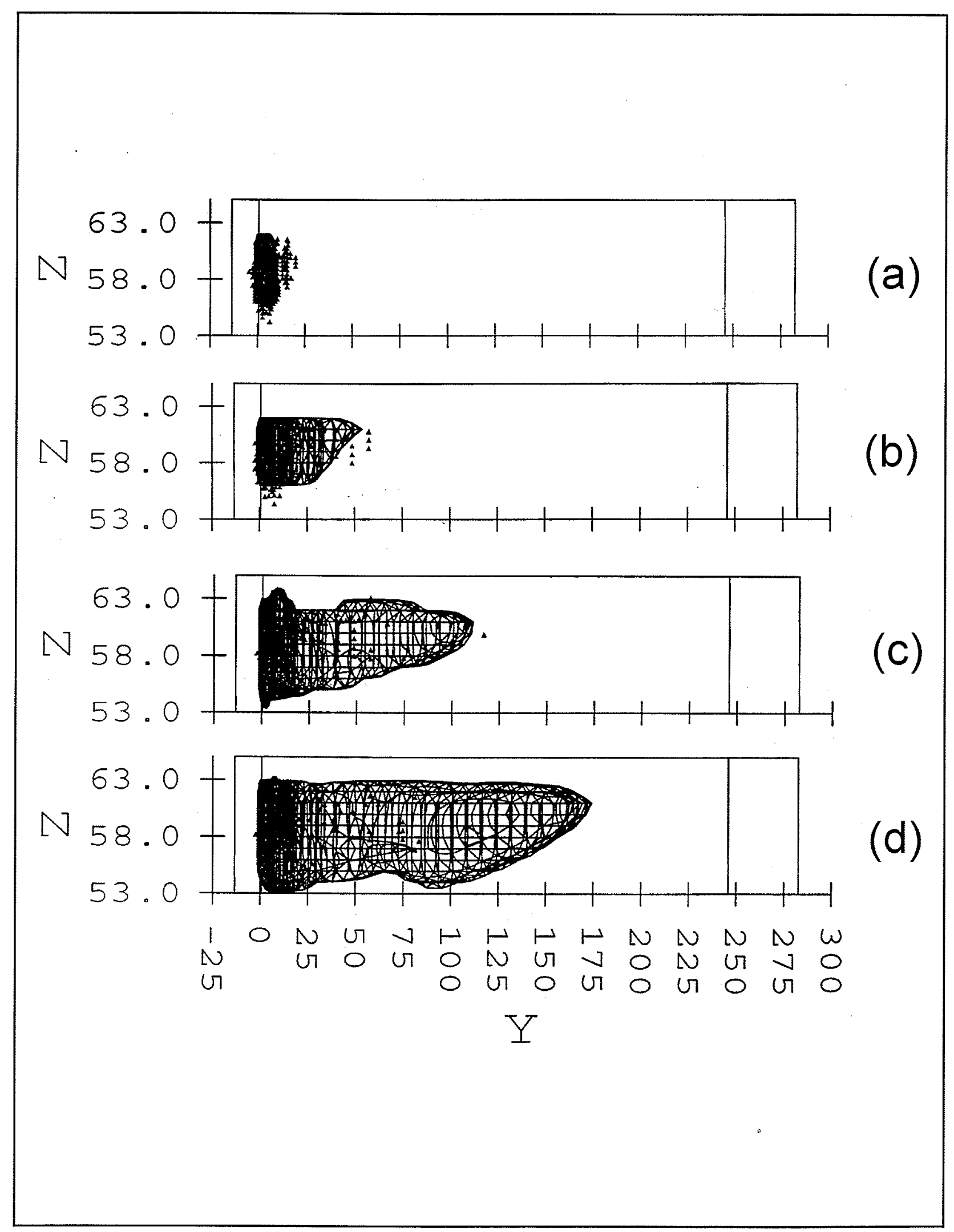

Figure 19. Vertical view of 50-pCi/ml tritium plume at: a) 27 days, b) 132 days, c) 224 days, d) 328 days 
well. By the time the 328-day sampling round was conducted, the $50-\mathrm{pCi} / \mathrm{ml}$ plume was predicted to be about $100 \mathrm{~m}$ further down-gradient than it was measured (Figure 18). This implies that enhanced dilution from the recharge during the transient portion of the test diluted the leading edge of the plume such that no readings over $50 \mathrm{pCi} / \mathrm{ml}$ were measured. This is supported by the fact that the $50-\mathrm{pCi} / \mathrm{ml}$ plume was measured further down-gradient at day 224 than it was at day 328. Dilution was an important process operating during the last half of this experiment.

The 5-pCi/ml plumes for days $27,132,224$, and 328 are shown in plan view (Figures 20 - 23). The down-gradient plan view extent of this plume is always underpredicted. The early time data show that one effect of injection was to move the $5-\mathrm{pCi} / \mathrm{ml}$ plume about $25 \mathrm{~m}$ further down-gradient than would be expected due to advection. If $25 \mathrm{~m}$ were added to each calculated plume extent, the simulations for days 27 and 132 would be very accurate. The plume longitudinal extents for days 224 and 328 are also underpredicted, but this time by more than $25 \mathrm{~m}$. The lateral extents of these plumes, however, are very accurate. Lateral dispersion of this plume is simulated quite well. Without additional recharge during the transient phases of this test, however, it is not possible to get the $5-\mathrm{pCi} / \mathrm{ml}$ plume to accelerate all the way to the down-gradient edge of the model while keeping the $50-\mathrm{pCi} / \mathrm{ml}$ plume limited to a down-gradient extent of $125 \mathrm{~m}$.

To add another piece of evidence to the analysis that indicates the pronounced effect of dilution after day 180, GMS gauge plots can be used. Gauge plots are used to show measured versus computed values at any location in the model domain. Eight locations were randomly selected from the concentration database (Figure 24). From two of these near-field locations, tritium break-through curves are displayed (Figures $25-26$ ). At location 1018 , which is located at coordinates $-0.1,13.5,58.85$, the model predicts the timing and magnitude of the tritium peak concentration quite well (Figure 25). Between the sampling round of days 132 and 224, the observed tritium declined from 1,987 to $1,940 \mathrm{pCi} / \mathrm{ml}$. During this time, this sampling point was located between 2.87 and $5.78 \mathrm{~m}$ beneath the top of the water table. For the remainder of the sampling events, this location showed a typical tailing-edge of the concentration breakthrough curve. In other words, the additional recharge did not cause dilution at this point, which was at least $2.87 \mathrm{~m}$ below the top of the water table.

At location 1644 , which is located at coordinates $-4.8,25.9,60.23$, the measured tritium breakthrough curve was quite different. Between the sampling rounds of days 132 and 224, the concentration dropped from 73 to $2 \mathrm{pCi} / \mathrm{ml}$. The modeled tritium concentration also shows the same effect. The modeled effect occurred because at day 180 , the water table instantaneously rose from the low- to the high-water-table condition. This instantaneously caused dilution, as can be seen in the breakthrough curve. With this sampling point being only $1.13 \mathrm{~m}$ below the low water table position, it is more likely that the effect of dilution can be observed. 


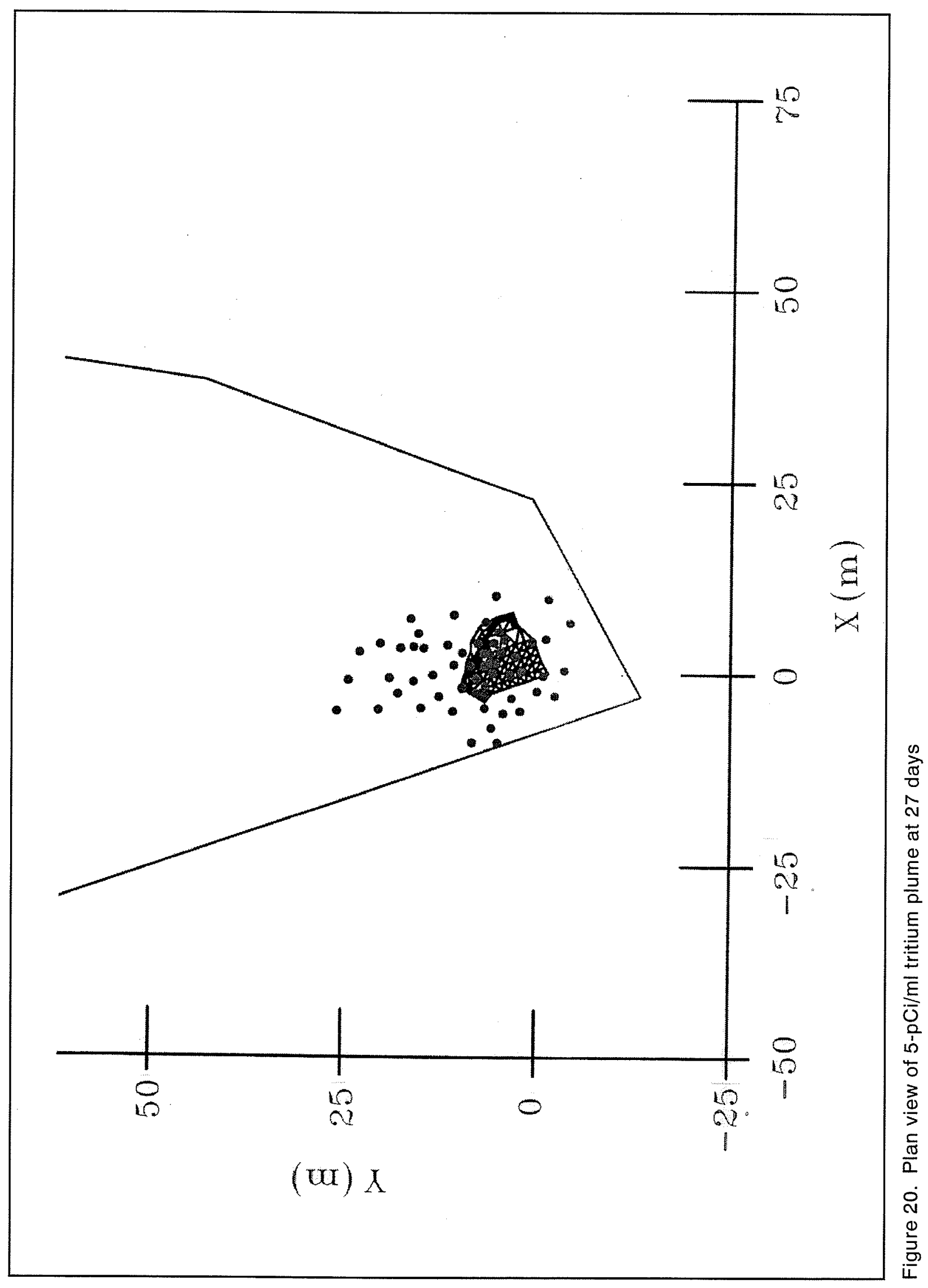




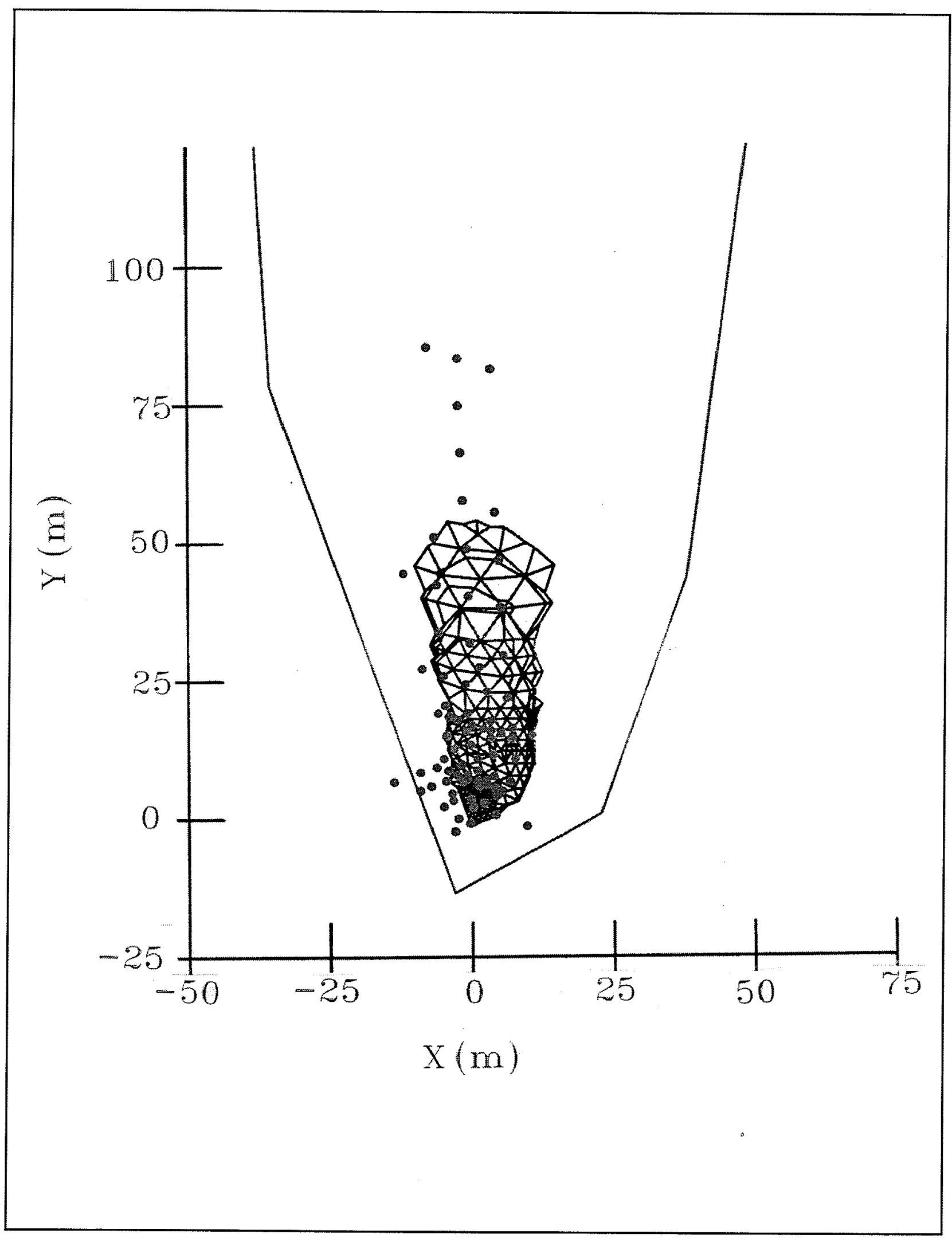

Figure 21. Plan view of $5-\mathrm{pCi} / \mathrm{ml}$ tritium plume at 132 days 


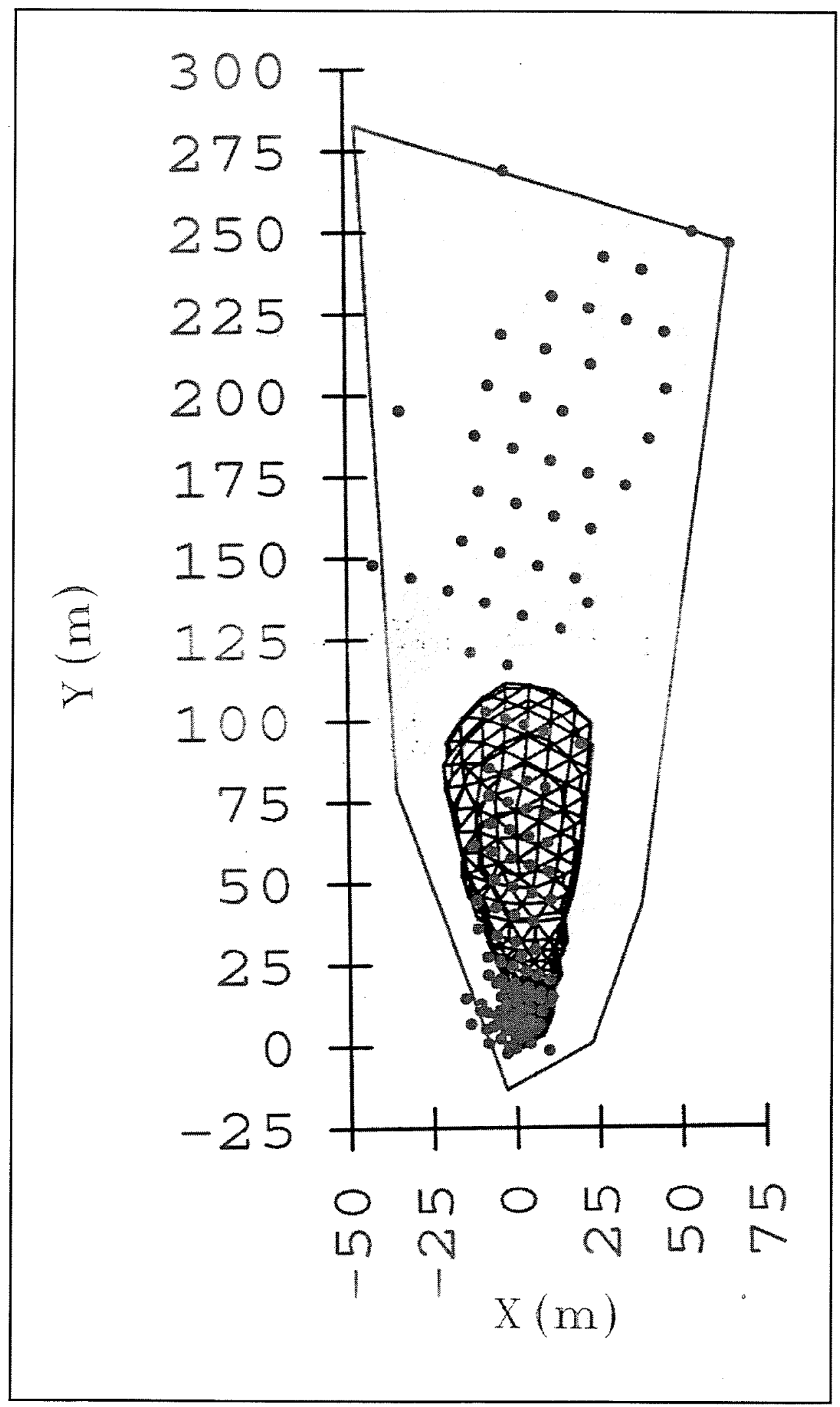

Figure 22. Plan view of $5-\mathrm{pCi} / \mathrm{ml}$ tritium plume at 224 days 


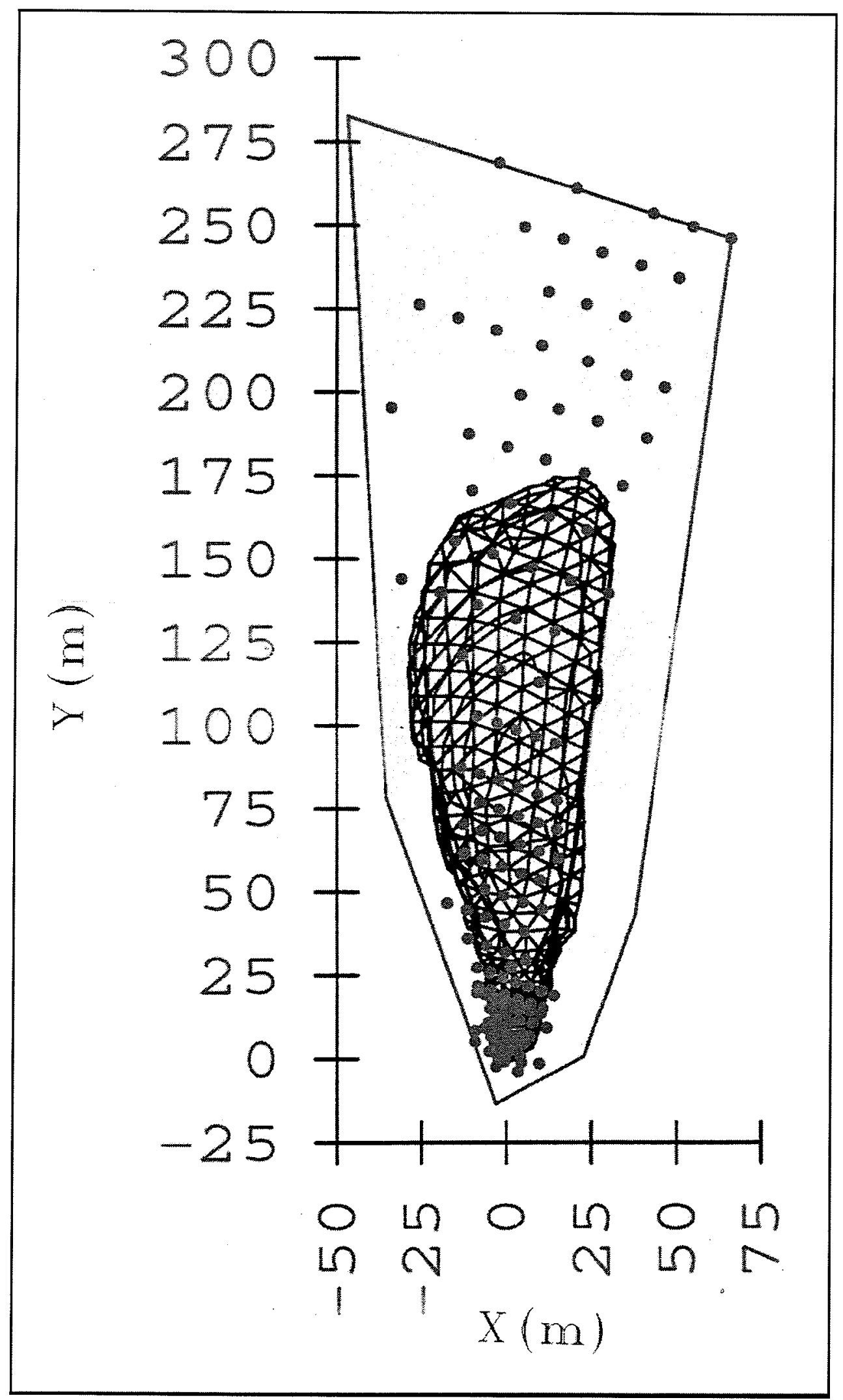

Figure 23. Plan view of $5-\mathrm{pCi} / \mathrm{ml}$ tritium plume at 328 days 


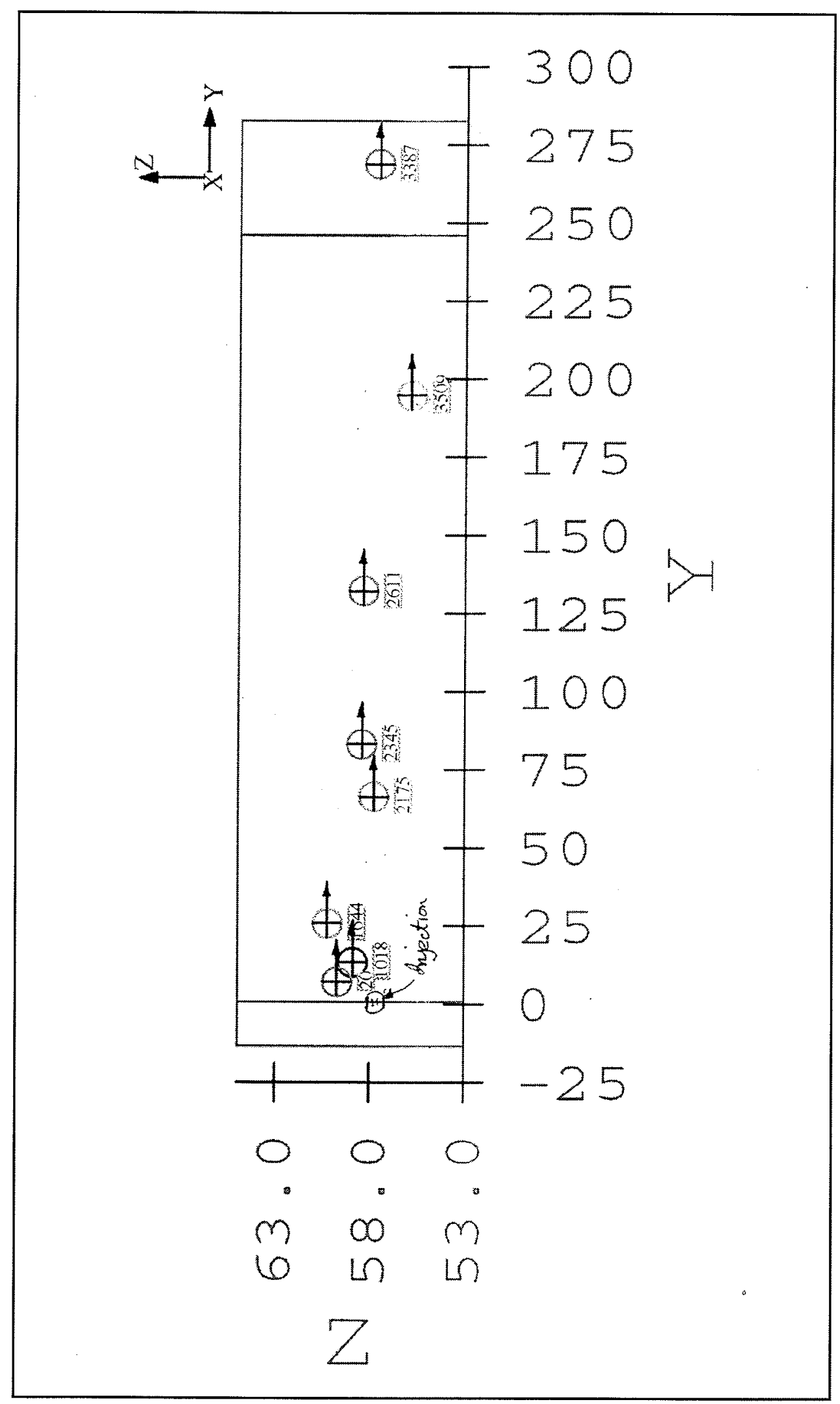

Figure 24. Location of gauge wells used for concentration curves 


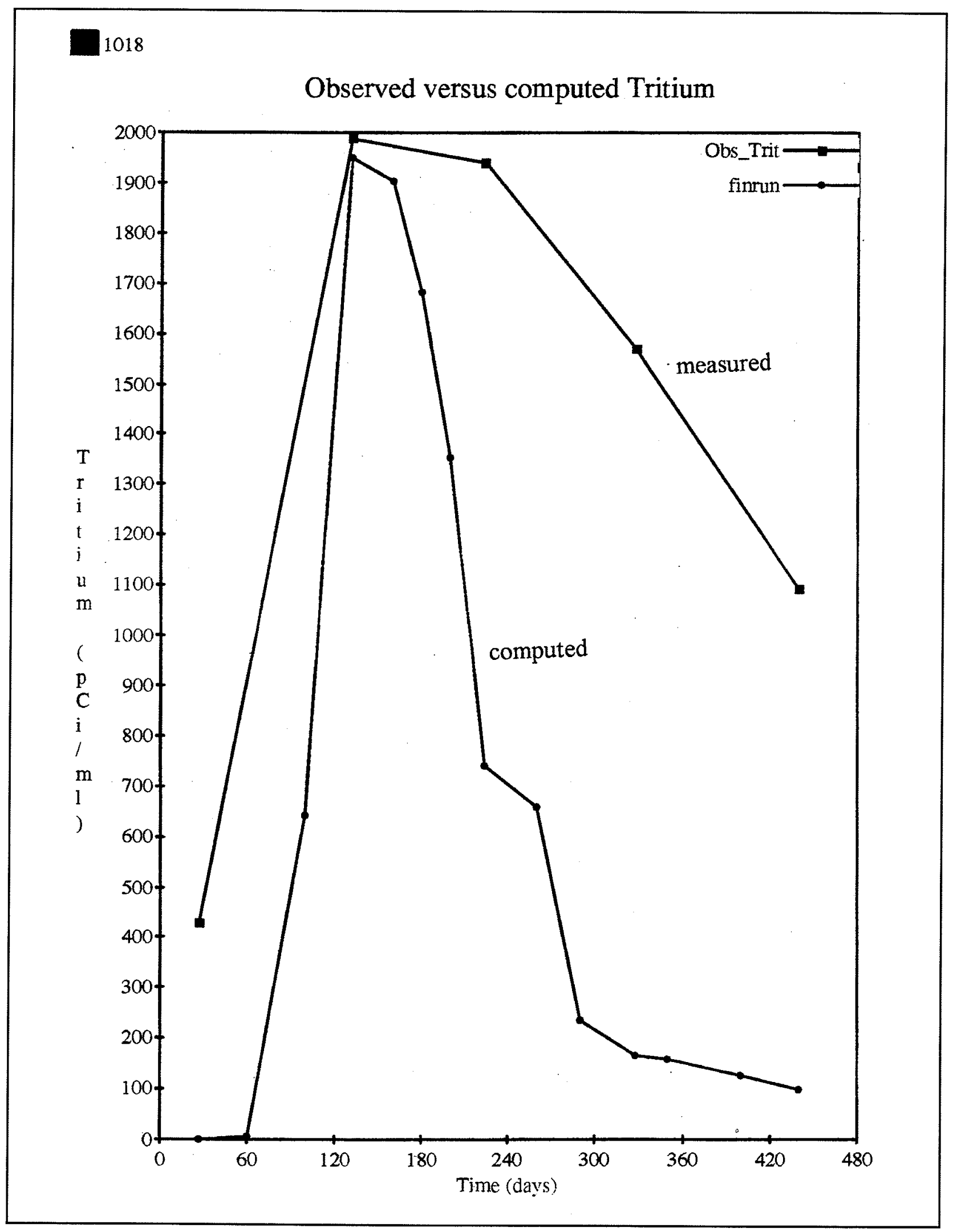

Figure 25. Concentration curve at location 1018 showing measured-versus-computed tritium (pCi/ml) 
1644

\section{Observed versus computed Tritium}

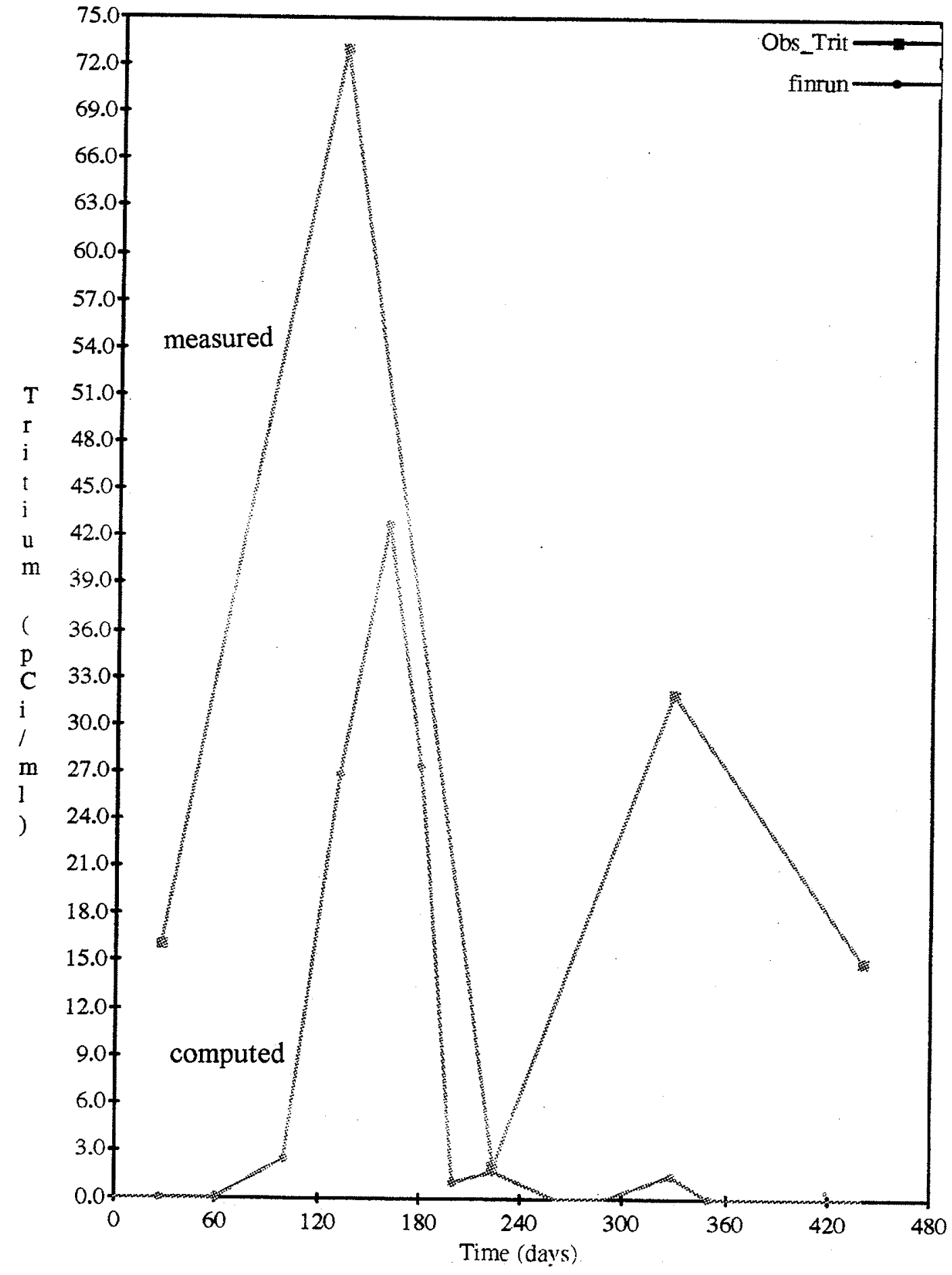

Figure 26. Concentration curve at location 1644 showing measured-versus-computed tritium ( $\mathrm{pCi} / \mathrm{ml}$ ) 


\section{Summary of Transport Results}

Although two steady-state flow fields were used to generate the tritium plume, it does not appear possible to accurately simulate this experiment with steady-state flow fields. After extensive model testing and analysis of the concentration data, the dilution effects caused by transient recharge during the last half of the experiment make it virtually impossible to match the low-concentration, leading edge of the tracer plumes. For example, the tritium plume has a peculiar characteristic in that much of the high concentration portions of the plume stay in the injection area during most of the experiment. During the entire duration of the experiment, the $50-\mathrm{pCi} / \mathrm{ml}$ isopleth $\left(10^{-3} \mathrm{C} / \mathrm{C}_{\mathrm{o}}\right)$ moved a maximum distance of roughly $125 \mathrm{~m}$ down-gradient of the injection area. The total transport distance is over $300 \mathrm{~m}$ for far-field concentrations of $5 \mathrm{pCi} / \mathrm{ml}\left(10^{-4} \mathrm{C} / \mathrm{C}_{\mathrm{o}}\right)$. This disparity between the 50 - and $5-\mathrm{pCi} / \mathrm{ml}$ isopleths makes this experiment very difficult to simulate. Transient recharge fluxes and hydraulic gradients are necessary to cause dilution and dispersion at the leading edge of the tritium plume. The effects of these two features cannot be captured within steady-state flow models.

\section{Sensitivity Analysis}

The flow model was tested for sensitivity to the up-gradient horizontal flux boundary condition and the recharge rate. The transport model was tested for sensitivity to the dispersion terms, effective porosity, and time-step selection. The results of the transport sensitivity have already been discussed in the previous section.

Generally, sensitivity analysis is performed on a model after it is calibrated. Changes are made to input parameters and model response is evaluated. In this case, because it is difficult to quantify calibration with Version 1.2 of the GMS/FEMWATER software system, only general model behavior can be reported. The new version of GMS (Version 2.0) may have improved numerical tools for model calibration. Sensitivity analysis was completed on the important input parameters.

The up-gradient horizontal flux boundary condition, along with direct recharge through the top of the model, controls water levels throughout the model. The maximum water levels recorded during the experiment always occur along the up-gradient boundary. A series of model runs were conducted to show the relationship between the up-gradient flux boundary condition and the maximum water levels in the model (Figure 27). For these runs, recharge was held constant at $18.3 \mathrm{~cm}(7.2 \mathrm{in}$.) per year. It can be seen that a nearly linear relationship exists between the up-gradient boundary flux and the calculated heads in the domain. For every 1-m rise in the water table, the up-gradient flux has to be increased by a factor of 4 . This relationship is linear throughout the entire range of up-gradient fluxes 


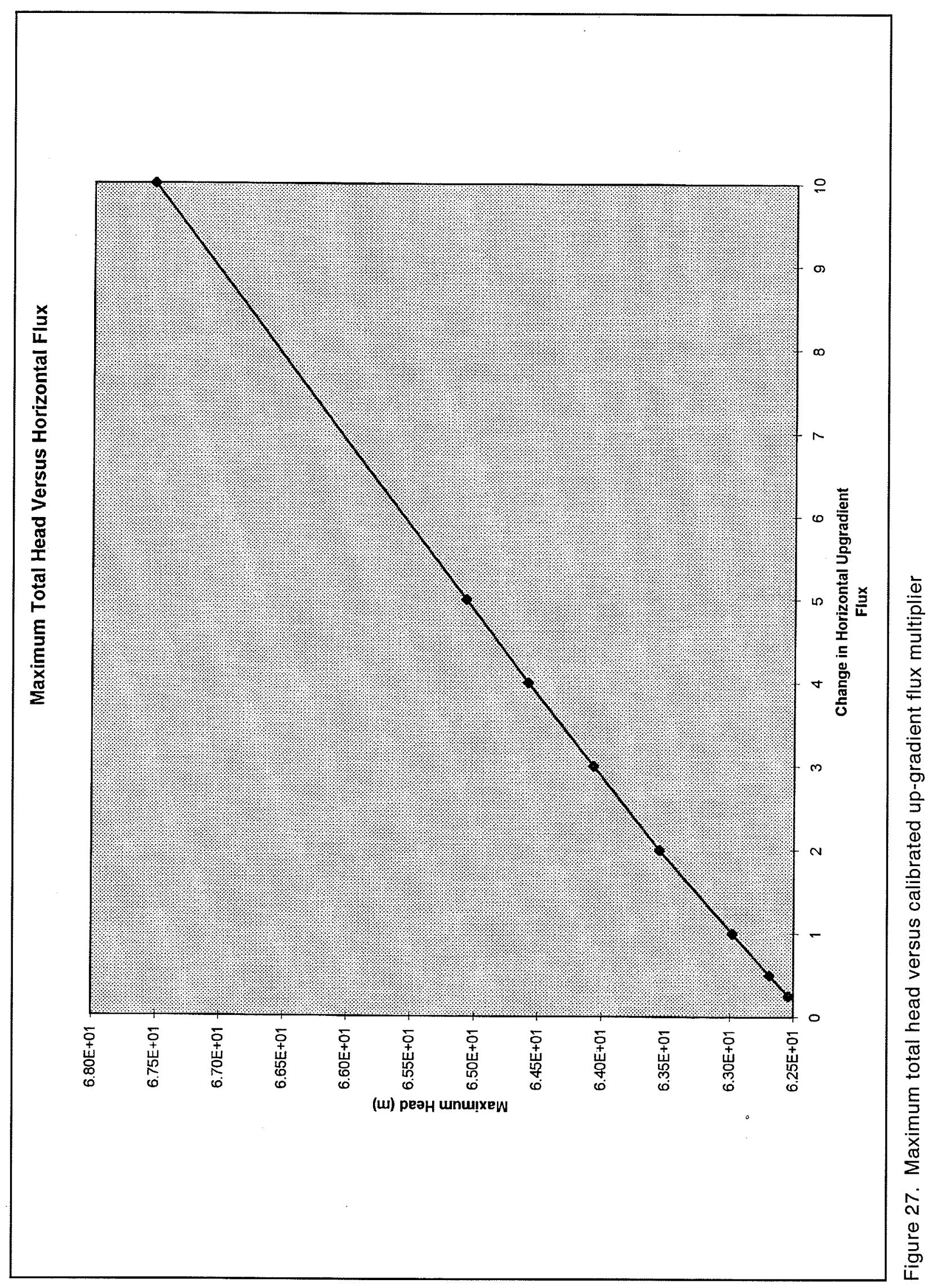

Chapter 4 FEMWATER Application and Results 
measured. The maximum horizontal velocity corresponding to these cases is not quite linear, however (Figure 28). If the up-gradient flux is multiplied by a factor greater than 1 , the maximum velocity also increases by that factor. If the multiplicative factor is less than 1 , the velocity diminishes less rapidly. In this case, the up-gradient boundary condition heads are nearing the down-gradient heads, and the relationship begins breaking down because up-gradient flow begins occurring.

Similarly, a series of model runs were conducted for various recharge rates, holding the up-gradient horizontal flux constant. Results from these tests indicate that the overall mass balance of this model is satisfied by the natural balance between the up-gradient flux entering the model and the down-gradient boundary flux leaving the model. No matter what recharge flux was used, the recharge contribution was only a small fraction of the total water movement through the model. If the up-gradient flux was not used, the entire recharge rate was correctly calculated by FEMWATER. If up-gradient flux was used, the calculated recharge rate did not equal what was used in the boundary conditions - it was always less than expected. Tests were even conducted in which linear soil moisture characteristic curves were used. In this case, slightly more recharge entered the model but it still did not equal the rate specified on the boundary conditions.

There are three possible explanations for this behavior. The up-gradient boundary condition is being specified along a triangular-shaped model boundary that happens to be located in a zone of converging flow. Even with analyzing the available water level data from this area, it is difficult to tell how much of the up-gradient boundary should be set as a flux condition. The areal coverage currently specified by the up-gradient boundary flux conditions might be larger than required. This implies that more water might be horizontally moving into the model than is actually occurring in this area. The net effect is that this additional water overrides the effect of recharge. Secondly, because recharge is entering through the unsaturated zone, the total flux is being computed with a relative hydraulic conductivity term that is less than one, because the top of the model is always unsaturated in the steady-state solutions. It is possible that a transient flow model would produce a more accurate model containing recharge.

\section{Conclusions on FEMWATER Application}

A careful examination of the MADE-2 hydrogeologic databases is necessary to fully realize the difficulty in numerically simulating this experiment, especially during the last half of the experiment. Movement of the tracers was strongly influenced by the heterogeneous porous media in which the experiment took place and by the transient flow system during the latter half of the experiment. Simulated results of the first 180 days of

the experiment show that tracer concentrations can be reproduced quite well with FEMWATER. The concentration distributions of the latter half of the experiment are difficult to reproduce. The transient rainfall recharge that 


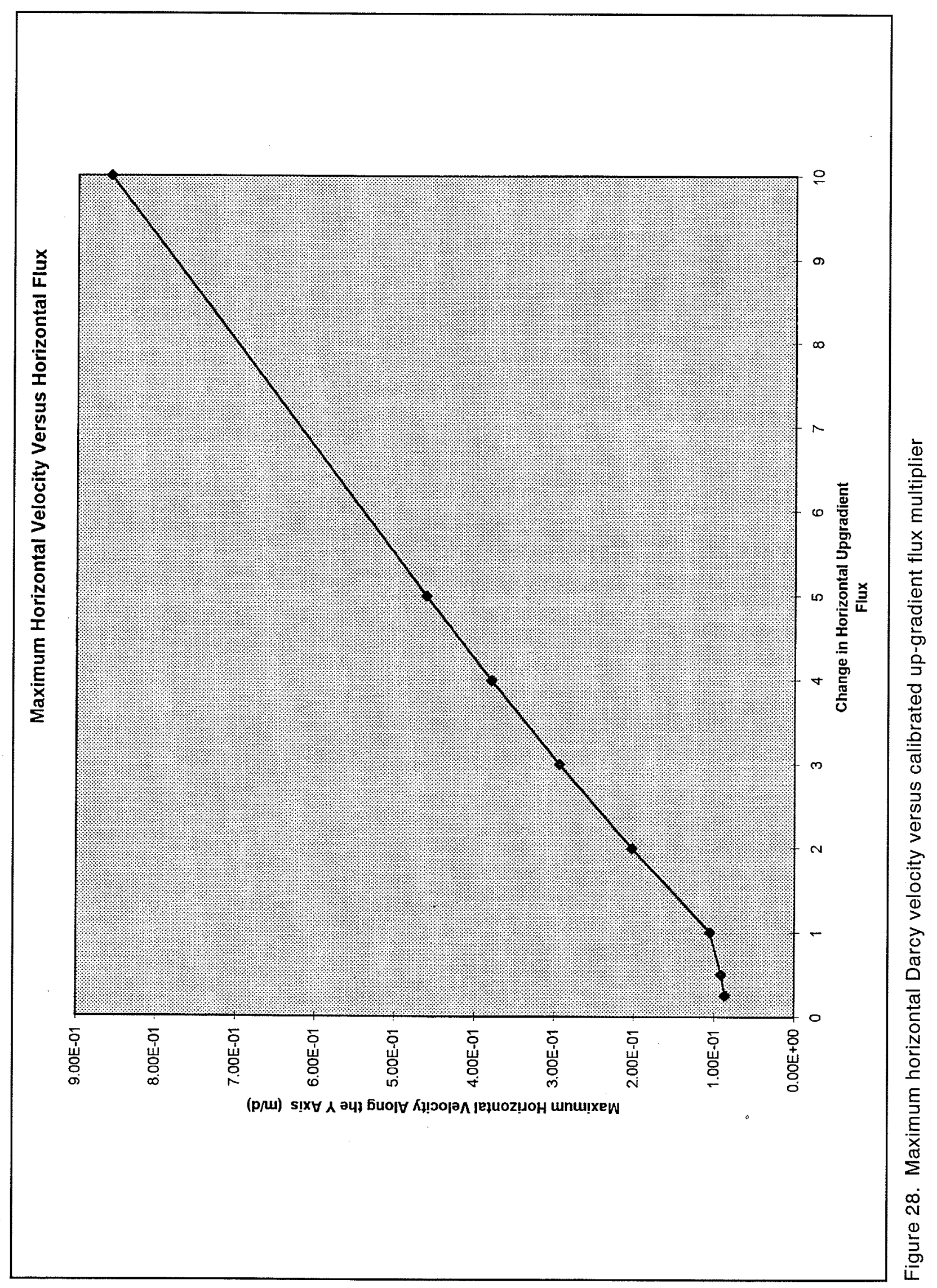


occurred during this time had two net effects which must be accounted for to obtain accurate numerical results. First, the hydraulic gradients increased, at times by as much as a factor of 4 . Secondly, the additional infiltrated water diluted the plume, causing reduced and dispersed concentrations at the leading edge of the plume. With a steady-state flow field approach, these effects could not be accurately reproduced.

\section{Suggestions for Additional Work}

Additional modeling could attempt to perform transient flow and transport modeling of the latter half of the experiment. The conditions that will be required for success in this endeavor include obtaining a successful dynamic balance between three transient data sets. Transient up-gradient fluxes, down-gradient head profiles, and recharge fluxes must be balanced. The transient recharge fluxes will have to be derived from the continuous water level records measured during the experiment. If a rainfall record is available for the experiment (it is not in the database), the rainfall-seepage boundary condition could be used in FEMWATER. In any case, it is expected that transient flow and transport analysis of this portion of the experiment will be computationally very demanding. The numerical grid will require additional vertical refinement between elevations 65 and $62 \mathrm{~m}$, with cells placed every $0.2 \mathrm{~m}$. The new grid necessary for transient flow would then have at least 25 vertical layers, with greater than 20,000 nodes and nearly 40,000 elements. 


\section{MODFLOW Modeling Approach}

The remainder of this report describes the application of GMS/

MODFLOW-MT3D to the CAFB test site. In MODFLOW/MT3D, the modeling domain was discretized to a structured (rectangular) grid system. The distribution of hydrogeologic data input for the grid system is different than the mesh system used by FEMWATER. For a detailed description of FEMWATER and MODFLOW/MT3D data requirements, the reader is referred to the GMS user's manual (Brigham Young University 1995). The MADE site hydrogeologic data were interpolated again to fit data requirements for MODFLOW/MT3D. This section describes the development of a conceptual model for application of MODFLOW/MT3D using MADE-2 data sets. Descriptions of flow and transport simulations have been separated into two chapters, Chapter 5 for flow and Chapter 6 for transport.

\section{Summary of MODFLOW Model}

MODFLOW is a widely used three-dimensional, finite-difference groundwater (saturated zone) flow model. It has a modular structure that allows it to be modified for a particular application. Many new capabilities have been added to the original model. The GMS/MODFLOW version used in this demonstration was the latest one available from the U.S. Geological Survey.

The model simulates steady and unsteady flow in aquifer layers which can be confined, unconfined, or a combination of both. Flow from external stresses, such as flow to wells, areal recharge, evapotranspiration, flow to drains, and flow through riverbeds, can be simulated. Hydraulic conductivities or transmissivities for any layer may differ spatially (heterogeneous) and be anisotropic. The storage coefficient may also change spatially. Specified head and specified flux boundary conditions can be imposed. Head-dependent flux across the model's outer boundary can be specified. This option allows water to be supplied to a boundary block in the 
modeled area at a rate proportional to the current head difference between a "source" of water outside the modeled area and the boundary block.

The groundwater flow equation is solved using approximated block-centered finite differences. Several solutions are provided to solve the associated matrix problem; the user can choose the best solution for the particular problem. Mass balances are computed for each time-step and as a cumulative volume from each source and type of discharge.

In order to use MODFLOW, initial conditions, hydraulic properties, and stresses must be specified for every model cell in the finite-difference grid.

Primary output is head, which can be written to the listing file or into a separate file. Other output includes the complete listing of all input data, drawdown, and budget data. Budget data are printed as a summary in the listing file, and detailed budget data for all model cells can be written into a separate file. The hydraulic head distribution can be visualized by GMS. For detailed information on MODFLOW, the reader is referred to McDonald and Harbaugh (1988).

\section{Model grid}

The final grid developed and used with GMS for the site study consisted of 25,025 blocks comprised from 11 layers, 65 rows, and 35 columns as shown in Figure 29. A uniform grid with block dimensions of $5 \times 5 \times 1 \mathrm{~m}$ was used. The grid spacing used is relatively coarse for the degree of heterogeneity at the MADE site, but was chosen because of computational speed and data storage requirements. The elevation of the top of the first layer was set to $62.5 \mathrm{~m}$ with the thickness of each underlying layer being $1 \mathrm{~m}$ and a bottom elevation of the lowermost layer of $51.5 \mathrm{~m}$.

\section{Hydraulic conductivity}

The available hydraulic conductivity data from the MADE experiments include 2,187 measurements (borehole flowmeter data) for 67 wells (Figure 30). Hydraulic conductivity varies from $10^{-4} \mathrm{~cm} / \mathrm{s}$ to $10^{-2} \mathrm{~cm} / \mathrm{s}$. The variance of the natural logarithm of hydraulic conductivity for the aquifer is 4.5 (Rehfelt, Boggs, and Gelhar 1992; Boggs et al. 1990). This high variance indicates that the site is one of the most heterogeneous sites extensively investigated and is an order of magnitude larger than that for the Borden and Cape Cod test sites, both of which have measurement scales comparable to the MADE site.

The hydraulic conductivity data were interpolated to estimate values at each cell of the grid. GMS has several data interpolation options including inverse distance weighting, nearest neighbor, and kriging. These options were applied to the hydraulic conductivity data and the results were compared. To apply field hydrogeologic conditions into the numerical grid, 


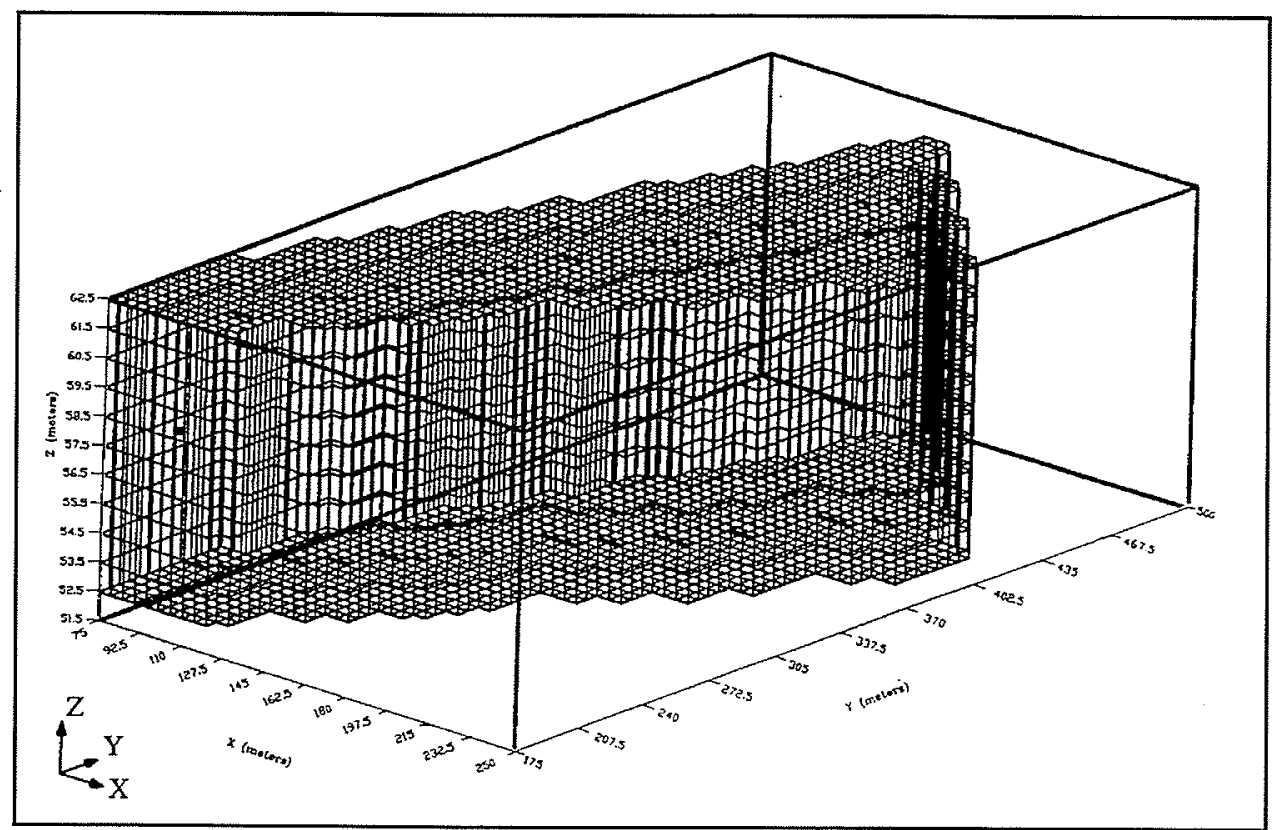

Figure 29. MODFLOW three-dimensional grid system

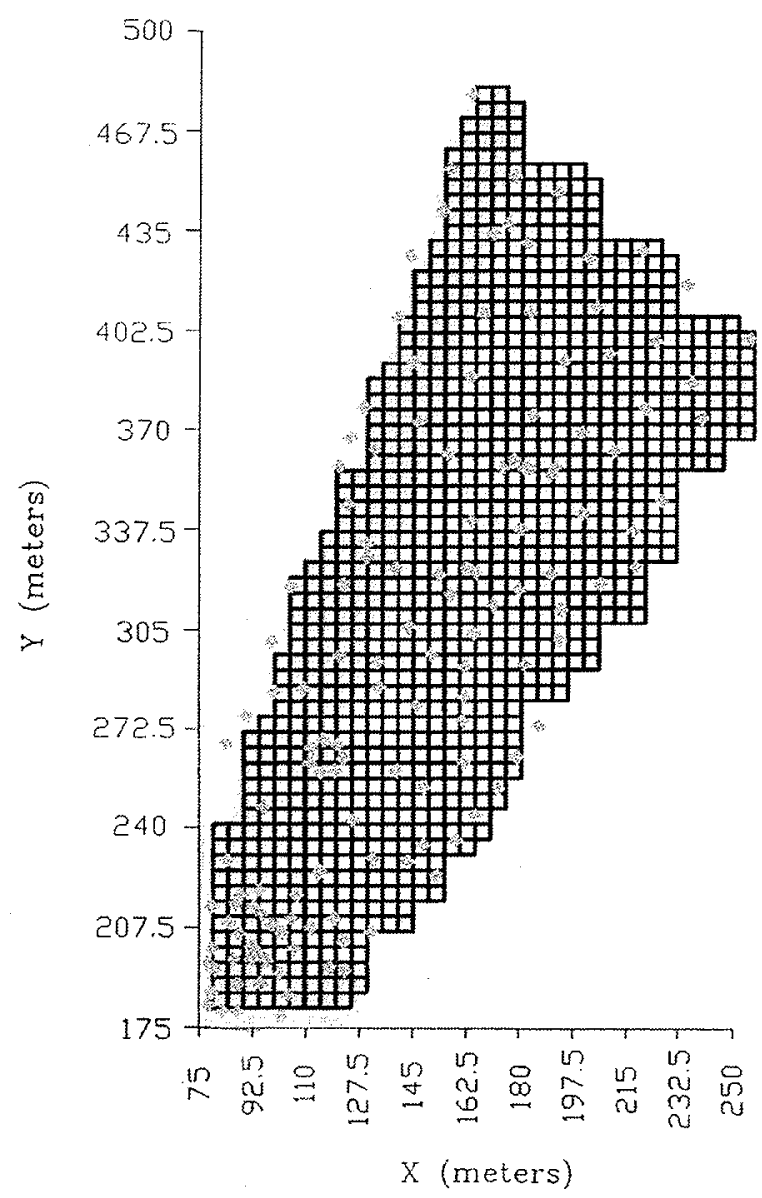

Figure 30. Location of hydraulic conductivity wells 
the 2-D and 3-D data interpolation routines available under GMS 1.2 and a commercial interpolation package were used. The interpolated hydraulic conductivity numbers were incorporated into the numerical grid using the GMS scalar data file format.

\section{Piezometric head}

Piezometric head data were measured at approximately 2 -week intervals during MADE-2. The accuracy of the measurements is approximately \pm 0.6 $\mathrm{cm}$. Data were available for manual measurements and some continuous monitoring wells. This study only used the manually measured data because more wells were measured manually than continuously. Table 2 below indicates the dates for which manual piezometric measurements were taken and Figure 31 shows the location of the piezometric measurement wells in relation to the simulation grid.

\section{Table 2 \\ Piezometric Head Manual Measurement Dates}

\begin{tabular}{|l|l|l|l|}
\hline \hline June 19, 1990 & November 7,1990 & April 4, 1991 & August 19, 1991 \\
\hline July 23, 1990 & December 5, 1990 & May 10, 1991 & September 11, 1991 \\
\hline August 13, 1990 & January 8, 1991 & May 20, 1991 & \\
\hline September 17, 1990 & February 8, 1991 & June 13, 1991 & \\
\hline October 15, 1990 & March 8, 1991 & July 9, 1991 & \\
\hline
\end{tabular}

\section{Porosity}

The average porosity from 84 core samples collected from 4 coreholes at the MADE site was 0.32 (Boggs et al. 1990, Table 3 below). These samples were taken from areas relatively close to the injection point. Three of the core sample locations were within approximately $25 \mathrm{~m}$ of the injection area while the other core sample location was less than $80 \mathrm{~m}$ from the injection area.

\section{Table 3}

Statistical Summary of Porosity Measurements

\begin{tabular}{|l|l|l|}
\hline \hline Corehole & Mean Porosity & Standard Deviation \\
\hline \hline CD18 & 0.30 & 0.07 \\
\hline CD21 & 0.32 & 0.09 \\
\hline CM66 & 0.32 & 0.09 \\
\hline CM151 & 0.32 & 0.07 \\
\hline
\end{tabular}




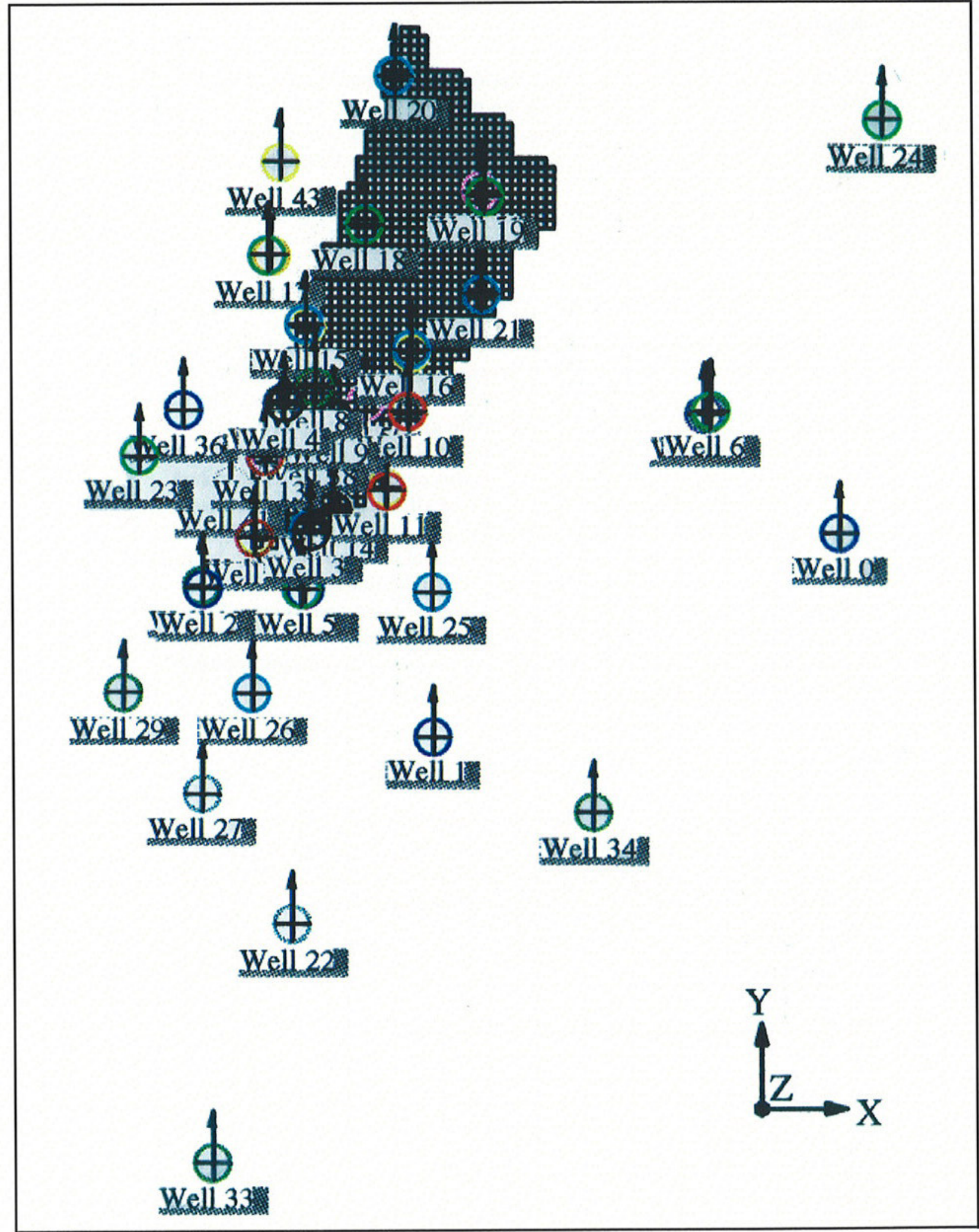

Figure 31. Piezometric well locations relative to grid 


\section{Recharge}

The recharge rate for this study was set to a constant value of $7.0 \mathrm{E}-04 \mathrm{~m} /$ day using a flow calibration procedure. Available meteorological data from Memphis, TN, Birmingham, AL, and Meridian, MS used with the Environmental Protection Agency's Pesticide and Root Zone Model (PRZM-2, Mullins et al. 1993) calculated an average daily recharge rate of $9.6 \mathrm{E}-03 \mathrm{~m} /$ day for those areas surrounding the site area.

\section{Boundary conditions}

The lowermost layer of the grid was set to a no-flow boundary to assume the site conditions of a relatively impervious layer. Boundary conditions used for the 328-day simulation were specified-head boundaries. The head contours were overlain with the MADE site grid and the head for selected boundary cells was obtained for the February 8, 1991 data set. The February 1991 piezometric head data set was chosen because it matched closely with the average head distribution of all the data sets. The specified head was then placed into a file representing the heads for a selection of outer boundary cells located on the four vertical sides of the grid. A series of simulations were conducted and the specified boundary heads were adjusted until a satisfactory match between simulated and observed head at each measurement well location within the simulated domain was obtained. In addition, a series of simulations were run using time-variant boundary conditions. The results are given in Appendix B.

\section{Stress periods}

Two stress periods were defined in the GMS/MODFLOW model. This corresponds to one stress period for the injection period and one stress period for the recovery period. The first stress period covered 2 days of injection, while the second was 326 days long, up to the end of measurements.

\section{MODFLOW Simulation Results}

A series of modeling scenarios were run using the defined conceptual model with proper initial and boundary conditions. The strongly implicit numerical solution option (SIP) of MODFLOW was selected for all applications. The simulation was performed using the transient option of MODFLOW. Two transient simulations were done. In the first one, time-variable boundary conditions were applied and in the second one, time-invariant average head boundary conditions were used. Results of the first approach were not used in the MT3D simulations (Chapter 6); however, they are given in Appendix B. The maximum number of iterations was set to 600 with an acceleration parameter of one. The head change criterion for 
convergence was set to $1.0 \mathrm{E}-05 \mathrm{~m}$. The leakance required by the model was calculated using vertical hydraulic conductivities of $1 / 10$ th the value of the horizontal hydraulic conductivities. Storage coefficients used in the simulation were assumed to be 1.0E-01 for the unconfined model layer and $1.0 \mathrm{E}-04$ for each of the remaining layers.

The injection of chemicals in the field occurred through five wells spaced $1 \mathrm{~m}$ apart and screened over a $0.6-\mathrm{m}$ interval between elevations of 57.5 and $58.1 \mathrm{~m}$. For MODFLOW simulation, the five wells were combined into one well, since the cell size of the grid system covers the area of the five wells used at the site. The total fluid injection was $9.7 \mathrm{~m}^{3}$ over a period of $48.5 \mathrm{hr}$. This was simulated as $4.85 \mathrm{~m}^{3} /$ day over a period of 2 days. Injection was induced into layer 5 of the model, with a top elevation of $58.5 \mathrm{~m}$ and a bottom elevation of $57.5 \mathrm{~m}$.

The MODFLOW available in GMS Version 1.2 could not be used to simulate time-variant specified-head boundary conditions. The specified-head boundary condition capability in MODFLOW was achieved by adding a suitable algorithm (Leake and Prudic 1988) to the MODFLOW code. This addition to the model allowed simulation of the region of interest with very good results. A preprocessor had to be created to generate the file structure required by this algorithm and is transparent to GMS.

The output from a MODFLOW simulation illustrating the simulated head for layers 3 and 7 at a time of 328 days is shown in Figure 32. The figure shows very steep gradients in the vicinity of the injection area and the leveling off of the gradients in the mid-field and far-field areas, as was indicated from the observed data.

\section{MODFLOW Model Calibration}

As described earlier, hydraulic conductivity plays a major role in the numerical simulation of this heterogeneous site. Discrete measurements of hydraulic conductivity were interpolated to generate values at each of the grid blocks. As part of a calibration process, the interpolated hydraulic conductivity and boundary conditions were changed manually within reasonable limits. Manual changes of these parameters continued until differences between observed and measured hydraulic heads were not significant.

Table 4 compares simulated and observed heads for layer 2 of the model grid. Likewise, Tables 5 and 6 compare heads for model layers 3 and 7 , respectively. The maximum difference between simulated and observed heads was $0.25 \mathrm{~m}$, or 0.4 percent, as shown in Tables $4-6$. The 0.4 -percent maximum difference occurred at a well located in layer 7 . These layers were selected for comparison because the piezometric measurement locations predominantly fell within these three layers (Figures $33 \mathrm{a}$ and $33 \mathrm{~b}$ ). It 


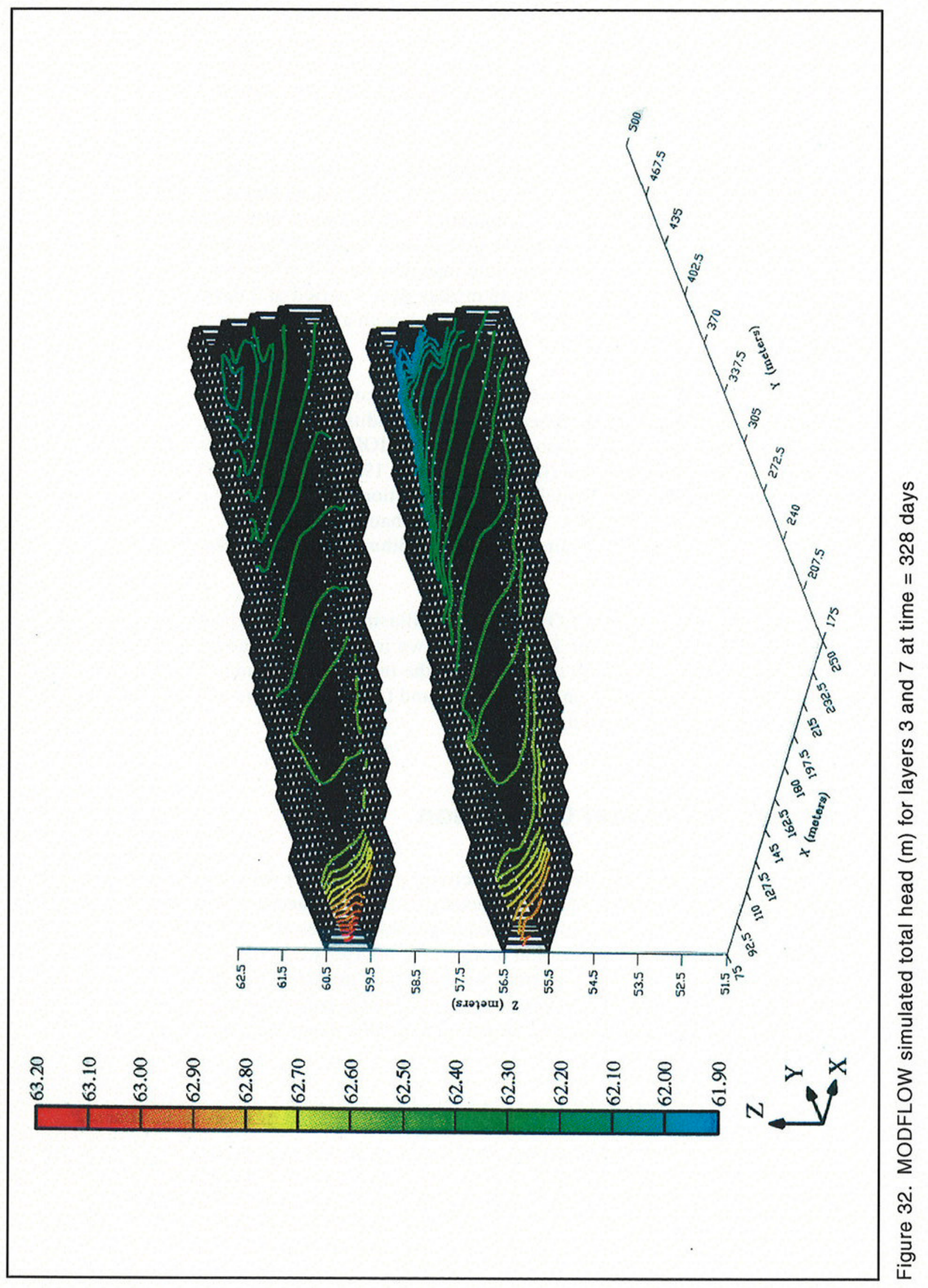


$33 b)$. It should be noted that in this study, the relatively good calibrated flow model was not the best one for the transport model. The final hydraulic conductivity profile used was chosen because it demonstrated the best overall agreement between observed and simulated heads and observed and simulated contaminant concentrations. Figure 34 shows the February 8 , 1991 observed piezometric heads in layers 3 and 7 of the numerical grid (shallow and deep part of aquifer, respectively). Although the simulated results are not shown in the figure, there is a reasonable agreement between the simulated and observed data. The cumulative MODFLOW volume balance discrepancy for the simulation was almost 0 percent.

\begin{tabular}{|c|c|c|c|}
\hline \multicolumn{4}{|c|}{$\begin{array}{l}\text { Table } 4 \\
\text { Observed (Obs) and Simulated (Sim) Heads in Model Layer } 2\end{array}$} \\
\hline Well No. & Obs (m) & Sim (m) & Difference $(\mathrm{m})$ \\
\hline 2 & 62.65 & 62.78 & +0.13 \\
\hline 3 & 62.53 & 62.53 & \pm 0.0 \\
\hline 8 & 62.62 & 62.60 & -0.01 \\
\hline 10 & 62.47 & 62.54 & +0.07 \\
\hline 17 & 62.25 & 62.20 & -0.05 \\
\hline
\end{tabular}

\begin{tabular}{|l|l|l|l|}
\hline \multicolumn{4}{|l|}{$\begin{array}{l}\text { Table 5 } \\
\text { Observed (Obs) and Simulated (Sim) Heads in Model Layer 3 }\end{array}$} \\
\hline Well No. & Obs (m) & Sim (m) & Difference (m) \\
\hline 9 & 63.11 & 63.03 & -0.08 \\
\hline 11 & 62.58 & 62.59 & \pm 0.01 \\
\hline 7 & 62.52 & 62.54 & +0.02 \\
\hline 6 & 62.50 & 62.53 & +0.03 \\
\hline 13 & 62.46 & 62.49 & +0.03 \\
\hline 12 & 62.49 & 62.49 & \pm 0.0 \\
\hline 18 & 62.41 & 62.44 & +0.03 \\
\hline 15 & 62.42 & 62.39 & -0.03 \\
\hline 16 & 62.37 & 62.35 & -0.02 \\
\hline
\end{tabular}




\begin{tabular}{|c|c|c|c|}
\hline \multicolumn{4}{|c|}{$\begin{array}{l}\text { Table } 6 \\
\text { Observed (Obs) and Simulated (Sim) Heads in Model Layer } 7\end{array}$} \\
\hline Well No. & Obs (m) & $\operatorname{Sim}(m)$ & Difference (m) \\
\hline 22 & 62.80 & 62.77 & -0.03 \\
\hline 34 & 62.61 & 62.64 & +0.03 \\
\hline 26 & 62.55 & 62.54 & -0.01 \\
\hline 27 & 62.50 & 62.54 & +0.04 \\
\hline 38 & 62.37 & 62.53 & +0.16 \\
\hline 36 & 62.46 & 62.49 & +0.03 \\
\hline 35 & 62.49 & 62.48 & -0.01 \\
\hline 41 & 62.46 & 62.44 & -0.02 \\
\hline 39 & 62.37 & 62.35 & -0.02 \\
\hline 40 & 61.87 & 62.12 & +0.25 \\
\hline
\end{tabular}

\section{MODFLOW Model Sensitivity Analysis}

The accuracy of the MODFLOW results (as for any numerical model) depends on the accuracy of measured or estimated input parameters. For some applications, it is useful to develop a criterion to estimate the sensitivity of the model results to the changes of input parameters. This will provide a tool for the user to quantify the range of uncertainties associated with the input parameters. In what follows, some of the important input parameters have been changed arbitrarily and effects on the simulations are assessed.

\section{Hydraulic conductivity}

As described earlier, hydraulic conductivity has a major effect on the outcome of simulations. All values of hydraulic conductivity were increased by 10 percent and compared to simulated results. Figure 35 shows the difference in simulated head when the hydraulic conductivity values were increased by 10 percent. The hydraulic head was affected more in the area of converging flow and steep gradients.

\section{Leakance}

Leakance in MODFLOW is a function of the vertical hydraulic conductivity and the confining layer thickness and is needed for every layer except the bottom layer of the grid system. A decrease of the leakance by 

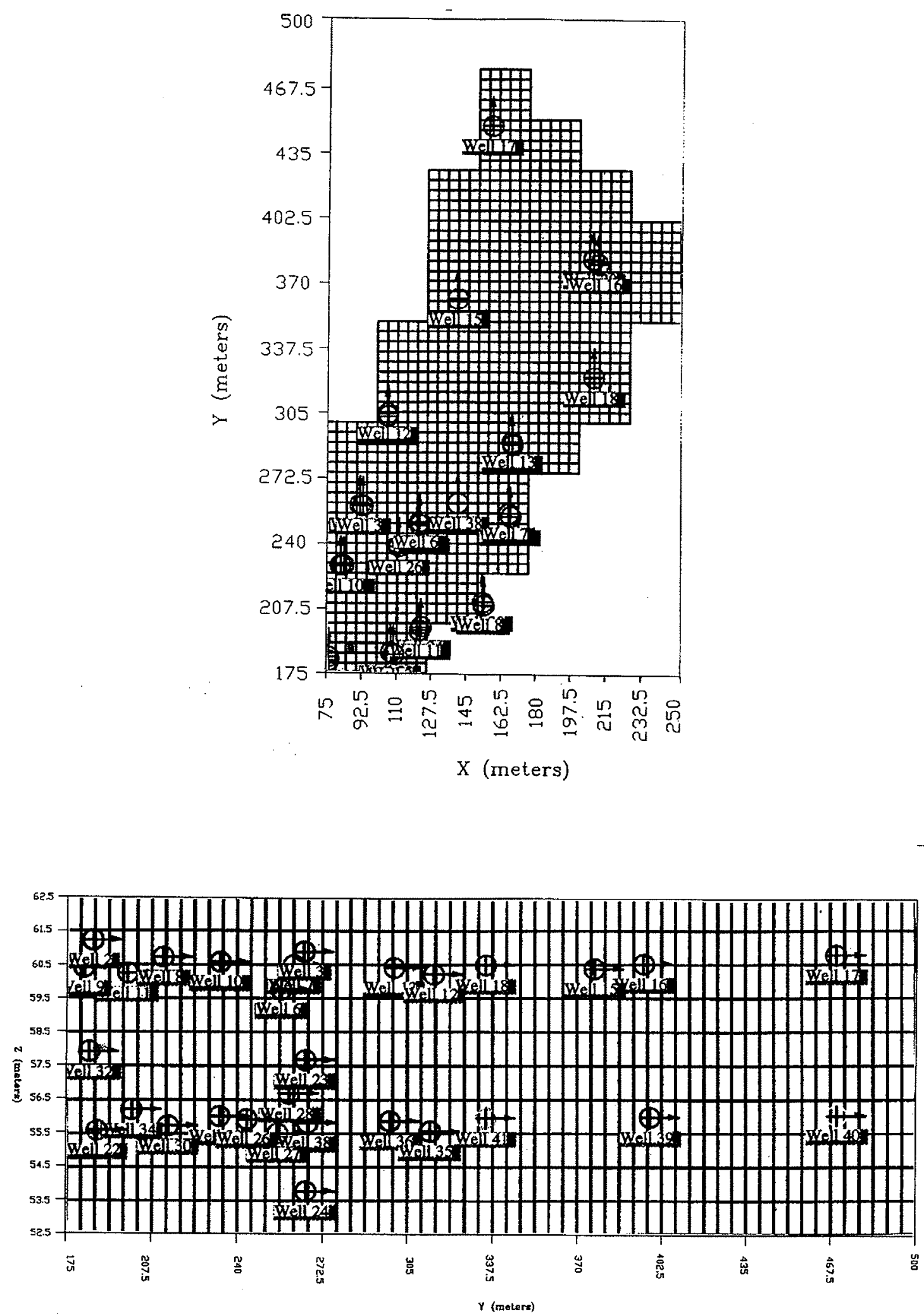

Figure 33. Plan $(X-Y)$ and vertical view $(Z-Y)$ of piezometric head measurement locations 


$$
\text { II }
$$




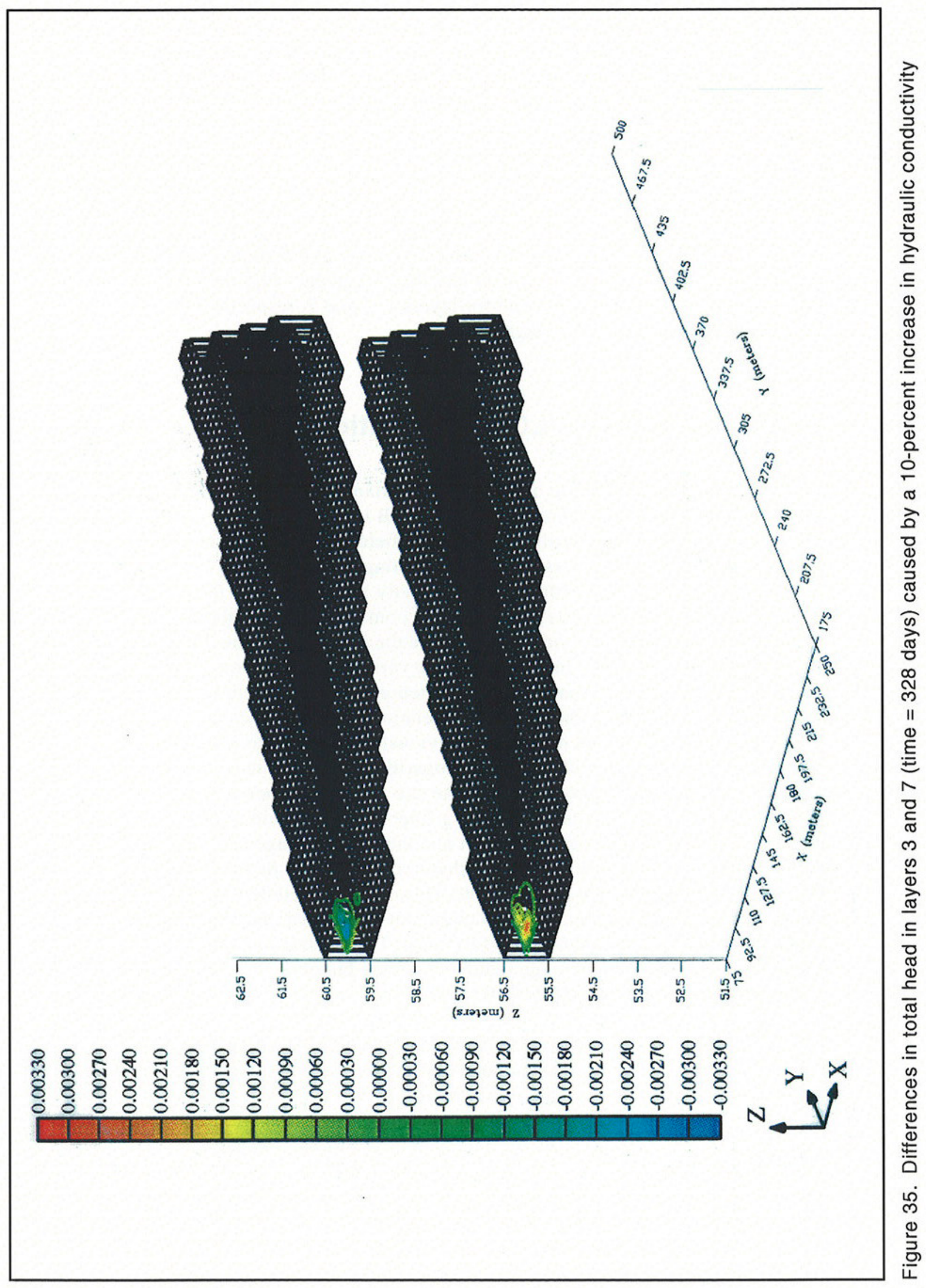


10 percent caused a change of 5 percent in the hydraulic head. The changes were noticeable in the area with steep gradients. This change of leakance had little effect on the mid-field and far-field regions of the model grid (Figure 36 for layers 3 and 7) because of horizontal hydraulic conductivity distribution in those areas.

\section{Recharge}

Increasing the recharge rate by an arbitrary factor of 6.5 changed the head by a maximum absolute value of less than 1 percent. Figures 37, 38, and 39 illustrate the change in head for layers 1, 3 and 7, respectively, caused by this increase in recharge.

\section{Summary of MODFLOW Simulations}

The study showed that one of the most important controlling factors for modeling a heterogeneous system such as CAFB is the numerical characterization of the hydraulic conductivity field. A large portion of the time devoted to this study was spent in attempting to determine as accurately as possible the hydraulic conductivity for each cell of the model grid. This task was enormous in that several commercial interpolation applications were used in trying to determine the hydraulic conductivity to be used in the model grid. In addition to the various interpolation packages used, several interpolation methods were attempted. Another controlling factor in the simulation is the grid size in relation to the variance of the hydraulic conductivity. As mentioned previously, the grid size was $5 \mathrm{~m} \mathrm{x}$ $5 \mathrm{~m} \mathrm{x} 1 \mathrm{~m}$ and the variance of the natural logarithm of hydraulic conductivity was 4.5. The extreme heterogeneity of the site requires a finer resolution grid to achieve better results. However, a finer resolution grid in turn requires additional computational effort and increased storage capacity for the simulations. A nonuniform grid perhaps could provide better results with less computer storage requirements. However, if a detailed correct distribution of hydraulic conductivity could not be defined, the nonuniform grid would not be better than the uniform grid. The accuracy desired, computational effort, and storage requirements are factors to consider in any particular application of GMS/MODFLOW.

The flow simulation appeared to match the observed data relatively well. The simulated piezometric heads in most cases were within $0.2 \mathrm{~m}$ of the observed data. The largest difference obtained between observed and simulated values was $0.25 \mathrm{~m}$ (less than 1 percent). The simulation assumed steady-state conditions taken as the average of the piezometric head monitoring data from June 1990 through September 1991. The average piezometric head for this time period was very close to the February 1991 monitoring data and thus these data were used to drive the flow model. The water table at the site had about 20 to 30 percent variation between low- and high-water-table seasons. However, the simulations conducted assumed an 


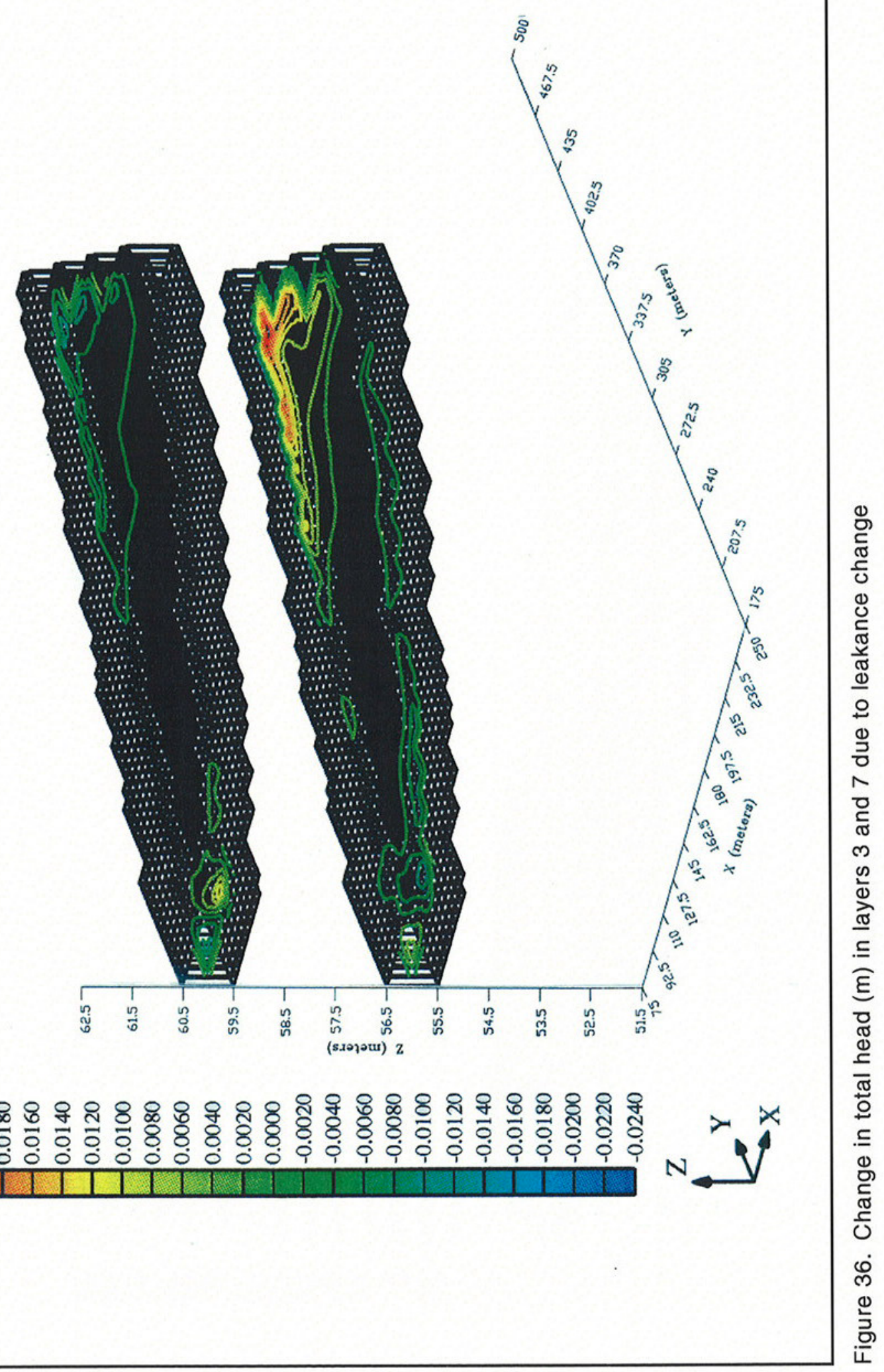

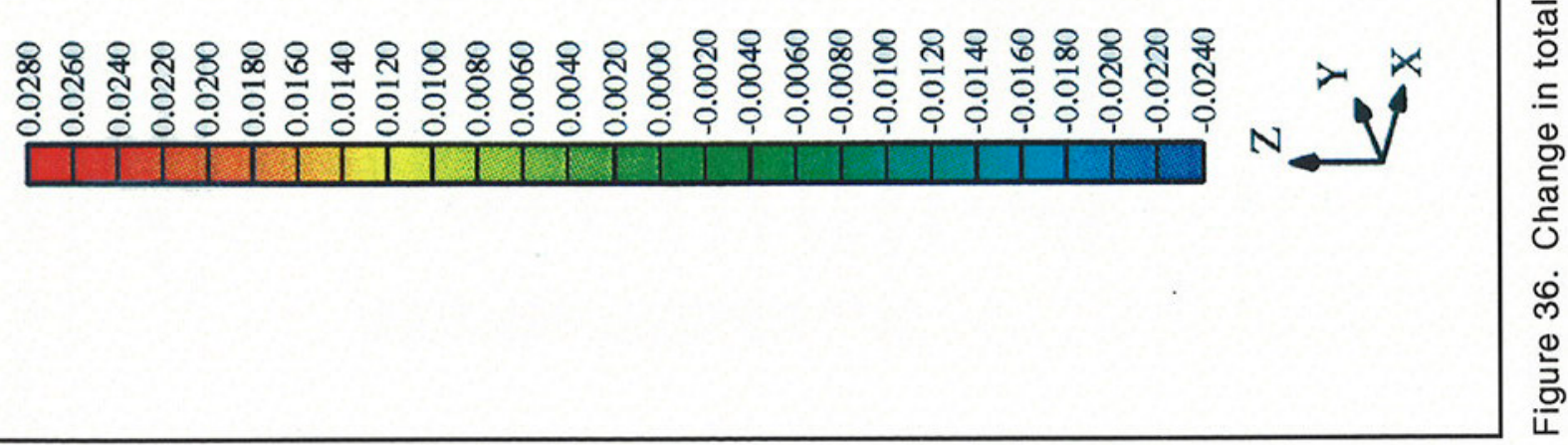




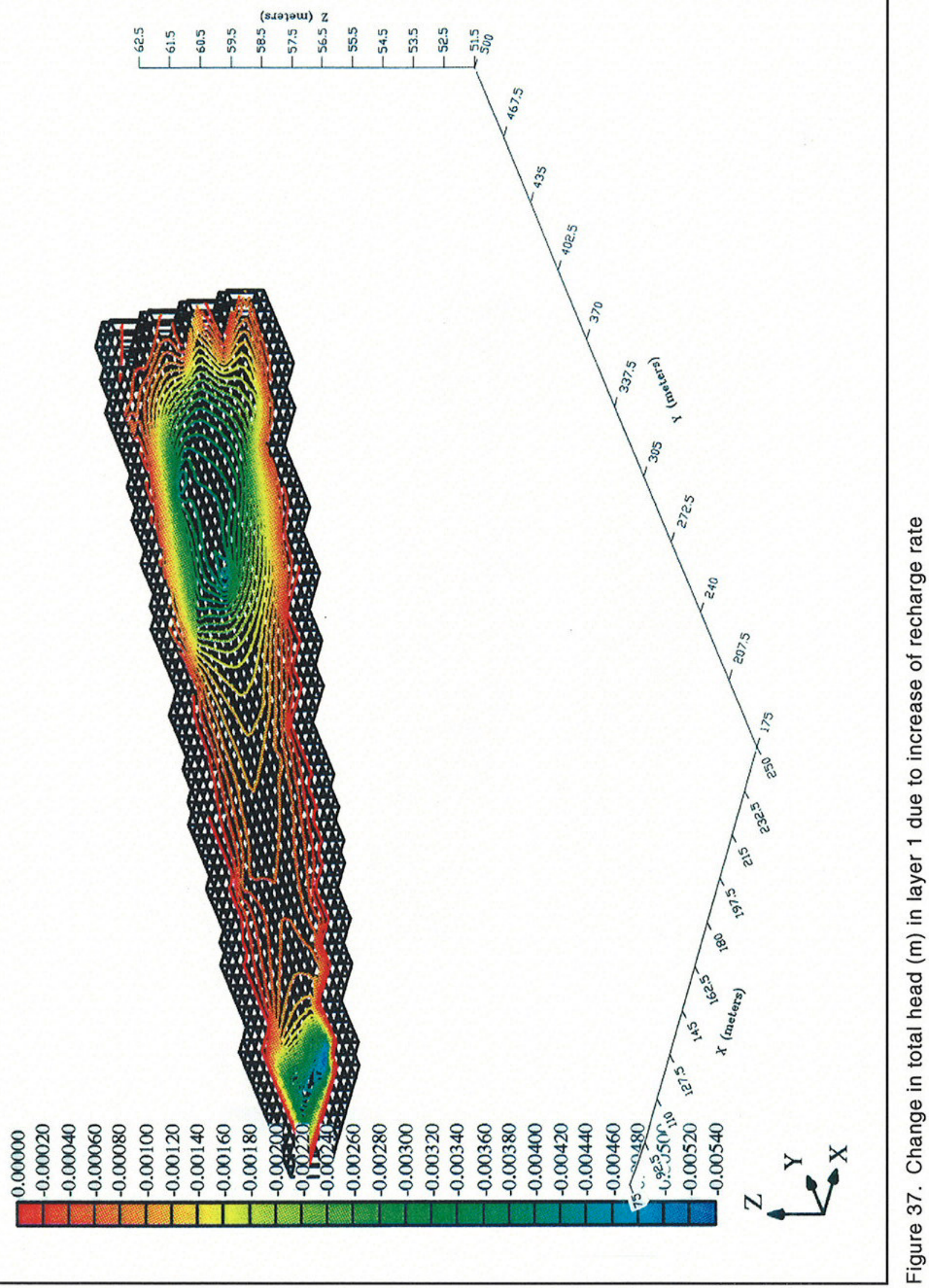




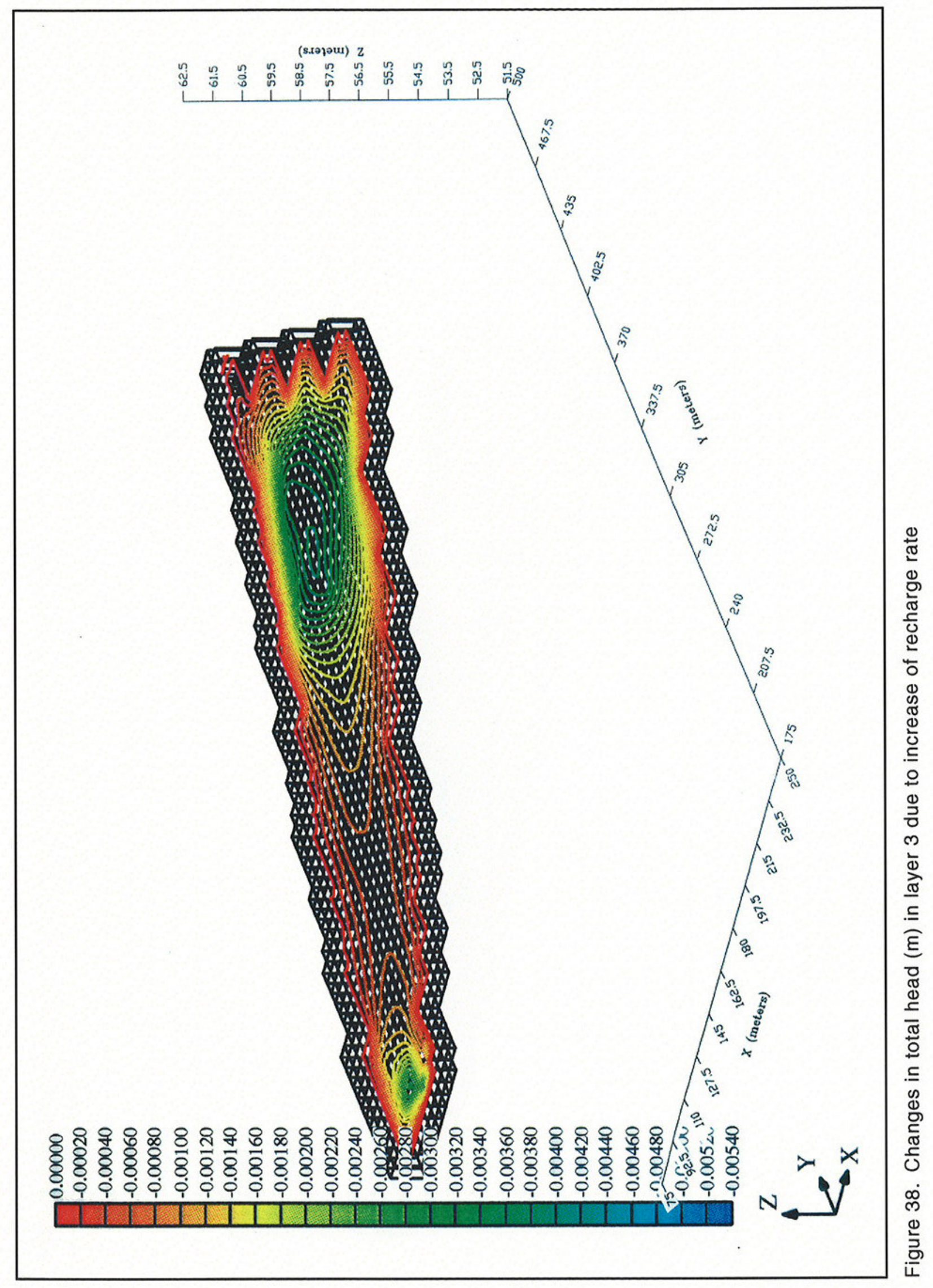




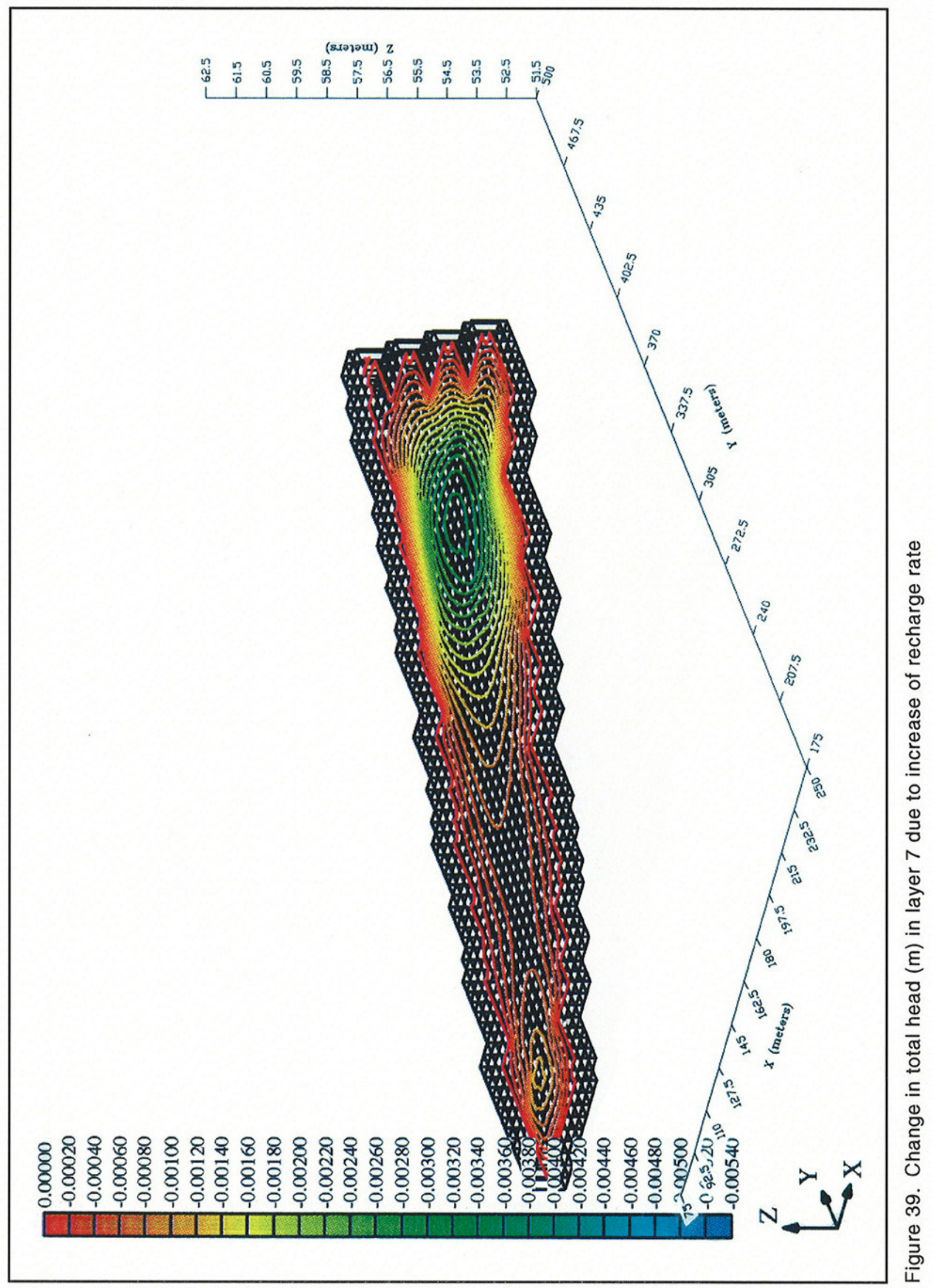


an average constant head for the duration of the simulation. It is very likely that the simulation could have been improved overall by simulating a low and high water table for the simulation period of 328 days as described in the FEMWATER application chapters. The simulation without the high-water-table event showed that the travel extent of simulated contaminant plumes is limited compared to observed plumes.

The simulation did not appear to be very sensitive to the recharge rate from the scenarios evaluated. Increasing the rate of recharge by 6.5 times caused a maximum absolute change in head of less than 1 percent.

The model was sensitive to the changes in hydraulic conductivity and indicates the importance of a good hydraulic conductivity representation for the model. Increasing the hydraulic conductivity for all cells by 10 percent caused a notable difference in the simulated head in the area near the injection point. The effects were almost totally limited to the near-field region of the simulation domain. There was little effect of the hydraulic conductivity change in the middle- and far-field regions.

The model was also sensitive to changes of leakance. Decreasing the leakance by 10 percent caused a maximum absolute change of 5 percent in the pressure head. The effect of this change was most notable in the lower layers and also in the far-field region of the simulated domain. The far-field region coincides with steep vertical gradients.

Calibration was done manually by changing the hydraulic conductivity and boundary condition pressure heads. This could be better accomplished by the use of a parameter estimation program. The program should be capable of running the simulation, comparing the simulated values to observed values, and then revising the specified-head boundary condition file and repeating this process until a satisfactory match can be obtained. In regard to the MODFLOW model, MODFLOWP (Hill 1990) provides these capabilities.

Recommendations for future simulations include better numerical characterization of the hydraulic conductivity for the site and a model grid with finer resolution and/or an adaptive grid. Models capable of simulating both the saturated and unsaturated zones with transient boundary conditions perhaps provide better simulation of the site flow conditions. 


\section{MT3D Modeling Approach}

This chapter describes the application of a modular three-dimensional transport model, MT3D/GMS (Zheng 1990), to the CAFB site. The selected chemicals used in the simulations are tritium, ${ }^{14} \mathrm{C}$, benzene, p-xylene, naphthalene, and o-dichlorobenzene. The chemical characteristics of the groundwater at the site are described in Boggs et al. (1990). The flow information required by MT3D was calculated previously using MODFLOW as described in Chapter 5.

\section{Summary of MT3D Model}

MT3D is a 3-D solute transport model which calculates advection, dispersion, and chemical reactions (1st order decay) of contaminants in groundwater systems. The numerical technique used in MT3D is a block-centered finite difference. The MT3D computer program adopts a modular structure to permit simulation of transport components independently or jointly. MT3D is designed for linkage to the MODFLOW model (Chapter 5). However, other flow models also may be adopted for use by MT3D. MT3D has three basic solution options: the method of characteristics (MOC), modified method of characteristics (MMOC), and a hybrid of these two methods (HMOC). This approach combines the strength of MOC for reducing numerical dispersion and the computational efficiency of MMOC, making MT3D flexible for a wide range of field problems. In addition, MT3D can also be used in a standard finite-difference mode. The general types of boundary conditions can be assigned in MT3D. The boundary conditions can be either a known concentration around the boundary (Dirichlet), a concentration gradient across the boundary (Neumann), or a combination of these two. 


\section{MT3D Model Input}

\section{Flow data}

MT3D/GMS requires inter-cell flow/flux data calculated by MODFLOW. The required flow data are stored in a linkage file that is assigned by the user during the MODFLOW application. The flow parameters used to drive the transport model are described in Chapter 5.

\section{Chemical injection data}

A total of $9.7 \mathrm{~m}^{3}$ of the selected chemical solution was injected into the aquifer over a 2 -day period. The injection concentrations and total mass injected are summarized in Table 7 . The tracer solution was prepared from ambient groundwater taken $75 \mathrm{~m}$ up-gradient from the injection point. The tritium and pure-phase organic compounds were mixed and stored in two $2.7-\mathrm{m}^{3}$ thermally insulated tanks equipped with a propeller mixer and floating lids. Samples of the tracer solution were collected at 1 - and $2-\mathrm{hr}$ intervals from tubes leading to the injection wells. The mass injected for each tracer was estimated by volume-weighting of these tracer concentration samples.

\section{Table 7 Injected Chemicals}

\begin{tabular}{|l|l|l||}
\hline Tracer & Mean Concentration & Mass Injected \\
\hline \hline tritium & $55,610 \mathrm{pCi} / \mathrm{ml}$ & $0.5387 \mathrm{Ci}$ \\
\hline${ }^{14} \mathrm{C}(\mathrm{p}$-xylene) & $2,770 \mathrm{pCi} / \mathrm{ml}$ & $0.0268 \mathrm{Ci}$ \\
\hline benzene & $68.1 \mathrm{mg} / \mathrm{L}$ & $659.7 \mathrm{~g}$ \\
\hline p-xylene & $51.5 \mathrm{mg} / \mathrm{L}$ & $402.0 \mathrm{~g}$ \\
\hline O-dichlorobenzene & $32.8 \mathrm{mg} / \mathrm{L}$ & $317.7 \mathrm{~g}$ \\
\hline naphthalene & $7.23 \mathrm{mg} / \mathrm{L}$ & $70.0 \mathrm{~g}$ \\
\hline \hline
\end{tabular}

The downstream transport of these contaminants was tracked by sampling from multiple ports in wells for a given time period using an array of 328 multi-level samplers. Details of the sampling procedure are given in a report by EPRI (1993b). The samplings were done 27, 132, 224, and 328 days after injection. A special sampling strategy was developed for the organic tracer since volatile losses from the former sampling method could reduce organic tracer concentrations. This alternative sampling method used 56 positive-displacement samplers oriented along two parallel rows or "fencelines" normal to the flow direction in the area near the injection site. The rows were placed $10 \mathrm{~m}$ apart and were located at distances of approximately 6 and $16 \mathrm{~m}$ from the tracer injection point. The sampling 
devices were installed in $15-\mathrm{cm}$-diam auger holes with no more than two sampling points per hole. The sampling points were isolated by bentonite seals located approximately $0.6 \mathrm{~m}$ above and below the samplers in the annular space. The sampling frequency for the fencelines varied from 2 -week intervals to 3 -month intervals.

Boggs et al. (1993) estimated the biodegradation rates from mass balance analysis of MADE-2 data (Table 8). These data were used as the first-order decay coefficient in the MT3D model.

\section{Table 8}

Biodegradation Rates Used in MT3D Simulations

\begin{tabular}{|l|l|l|l||}
\hline Tracer & Estimated rate $\left(\mathbf{d}^{-1}\right)$ & $\begin{array}{l}\text { Lower 95\% } \\
\text { confidence interval }\end{array}$ & $\begin{array}{l}\text { Upper 95\% } \\
\text { confidence interval }\end{array}$ \\
\hline \hline benzene & 0.008 & 0.004 & 0.011 \\
\hline$p$-xylene & 0.011 & 0.006 & 0.016 \\
\hline o-dichlorobenzene & 0.006 & 0.001 & 0.010 \\
\hline naphthalene & 0.007 & 0.004 & 0.010 \\
\hline
\end{tabular}

The sorption data used in this study were obtained from laboratory data obtained from prior studies on the MADE site (Boggs et al. 1993). Table 9 indicates the sorption data used in this study for benzene, naphthalene, p-xylene, and o-dichlorobenzene.

\section{Table 9}

Sorption Data Used in MT3D Simulations

\begin{tabular}{|l|l|}
\hline Tracer & Kd $(\mathrm{mL} / \mathrm{g})$ \\
\hline \hline benzene & 0.059 \\
\hline p-xylene & 0.048 \\
\hline o-dichlorobenzene & 0.065 \\
\hline naphthalene & 0.085 \\
\hline
\end{tabular}

\section{Model grid}

The uniform grid developed with GMS for the MADE site contaminant transport study consisted of 25,025 block elements in 11 layers, 65 rows, and 35 columns, as shown in Figure 29. The elevation of the top of the first layer was set to $62.5 \mathrm{~m}$ with the thickness of each underlying layer being 1 $\mathrm{m}$ and a bottom elevation of the lowermost layer of $51.5 \mathrm{~m}$. 


\section{Boundary conditions}

The lowermost layer of the grid coincided with the no-flow boundary of the flow grid and reflects the site conditions of an impervious layer approximately at this location. The boundary conditions used for the 328-day simulation were no-mass flux boundaries.

\section{Stress periods}

The simulation used two stress periods. This corresponds to one stress period for the injection and one stress period for the recovery. The total simulation time for the model was 328 days.

\section{Flow linkage}

The MODFLOW results were required as input to the MT3D transport model. The actual injection in the field occurred through five wells spaced $1 \mathrm{~m}$ apart and screened over a $0.6-\mathrm{m}$ interval between elevations of 57.5 and $58.1 \mathrm{~m}$. The actual field injection rate for the five wells was $3.3 \mathrm{~L} / \mathrm{min}$ over a period of $48.5 \mathrm{hr}$ with a total volume injected of $9.7 \mathrm{~m}^{3}$. For the simulations, the flow rates of five wells in the field were combined into a single well with a flow rate of $4.8 \mathrm{~m}^{3} /$ day. Injection occurred in layer 5 of the model, which had a top elevation of $58.5 \mathrm{~m}$ and a bottom elevation of $57.5 \mathrm{~m}$.

\section{Transport simulations}

Transport simulations incorporated (a) advection and dispersion, and (b) advection-only options of MT3D into the calculations. Advection was attempted with several solution scheme options including MOC, MMOC, HMOC, and upstream finite difference. It appeared that the hybrid method of characteristics advective solution scheme and no dispersion may provide better results for this site. The particle tracking algorithm used for the study was Runge-Kutta at or near sources and Euler elsewhere with a concentration weighting factor of 0.5 . The number of particles and the maximum number of cells a particle was allowed to move during the simulations are shown in Figure 40.

Porosity for the simulation grid was set to 0.10 in the meander channel and 0.31 elsewhere. The simulation of each of the five modeled contaminants is described below.

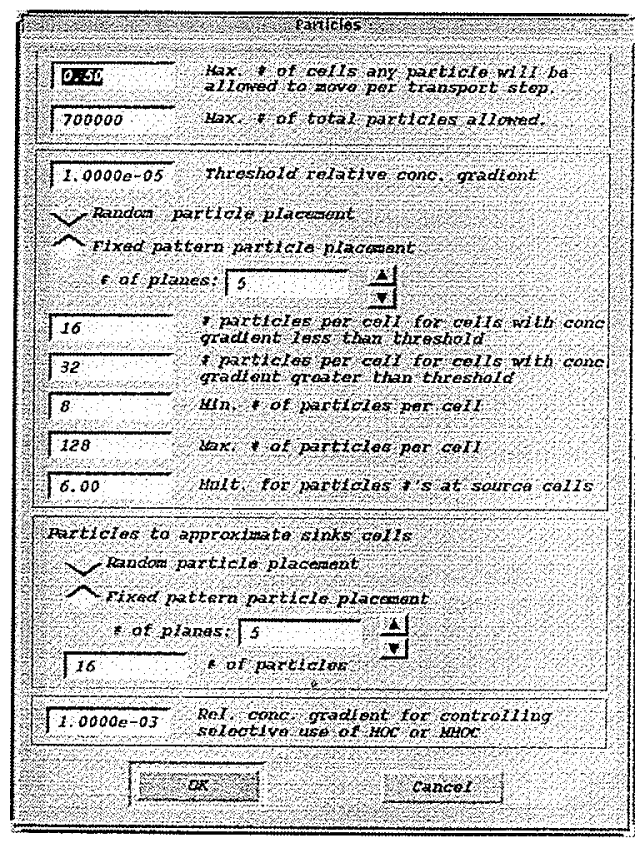

Figure 40. View of GMS/MT3D particle screen showing parameters used in simulations 


\section{Simulation of tritium}

MT3D was used to simulate 328 days of tritium transport at the CAFB site. Tritium is treated as a conservative tracer, i.e., negligible adsorption and decay.

Output from MT3D simulation expressed in plan view and in oblique view (vertical view) for a $50-\mathrm{pCi} / \mathrm{mL}$ iso-surface is shown in Figures 41 and 42 , respectively. Figure 43 shows an oblique view of a $5-\mathrm{pCi} / \mathrm{ml}$ tritium iso-surface at days $27,132,224$, and 328 . The observed concentrations of tritium are shown in Figures 44 and 45 (Boggs et al. 1993). Note that Figures 44 and 45 show the relative concentration, and the scale of these graphs is different from the one used in Figures 41, 42, and 43.

When the simulated and observed plumes are compared graphically, several observations as to the relative agreement between the plumes can be made. At day 27 , the simulated and observed plumes agree well with each other, and velocity and low hydraulic conductivity in the region are mimicked well. The simulated and observed plumes of $50-\mathrm{pCi} / \mathrm{mL}$ iso-surface at day 132 agree well with each other. However, the observed and simulated plumes at a lower concentration of $5 \mathrm{pCi} / \mathrm{mL}$ showed a larger discrepancy in terms of the areal extent of the plume (the simulated lagging approximately $56 \mathrm{~m}$ behind the observed). At day 224 , the observed $5-\mathrm{pCi} / \mathrm{mL}$ plume had reached a downgradient extent in excess of $270 \mathrm{~m}$ while the simulated plume had only traveled approximately $80 \mathrm{~m}$ from the initial point of injection. The $50-\mathrm{pCi} / \mathrm{mL}$ observed and simulated plumes have traveled nearly the same extent. The observed $5-\mathrm{pCi} / \mathrm{mL}$ and the $50-\mathrm{pCi} / \mathrm{mL}$ iso-surfaces at this time period are noticeably different in travel extent. The observed plume differences suggest the possibility of preferential flow pathways that the monitoring equipment could not discern due to monitoring location. At day 328 , the simulated plume of $5-\mathrm{pCi} / \mathrm{mL}$ iso-surfaces lagged the observed plume by approximately $78 \mathrm{~m}$. The $50-\mathrm{pCi} / \mathrm{mL}$ simulated and observed iso-surfaces show the simulated plume having traveled approximately $177 \mathrm{~m}$ further than the observed plume.

\section{Simulation of carbon $14\left({ }^{14} \mathrm{C}\right)$}

The simulation of ${ }^{14} \mathrm{C}$ transport through the MADE system was performed for a period of 328 days. The decay rate used for carbon-14 was based on a half-life of 5,700 years and no adsorption was simulated for this tracer. Output from the MT3D simulation expressed in plan view for a $3-\mathrm{pCi} / \mathrm{mL}$ iso-surface is shown in Figure 46 for days 27, 132, 242, and 328. The simulated 3-pCi/mL iso-surface is shown in oblique view in Figure 47 for days $27,132,234$, and 328 . Figure 48 shows the simulated plume with a concentration of $0.3 \mathrm{pCi} / \mathrm{mL}$. Figure 49 (Boggs et al. 1993) shows the vertical and longitudinal extent of the relative concentration ${ }^{14} \mathrm{C}$ plume at $27,132,224$, and 328 days. The ${ }^{14} \mathrm{C}$ plume and tritium plumes show very similar behavior, which was expected and is evident in the observed plume figures. The ${ }^{14} \mathrm{C}$ plume does not travel the downgradient extent of the 


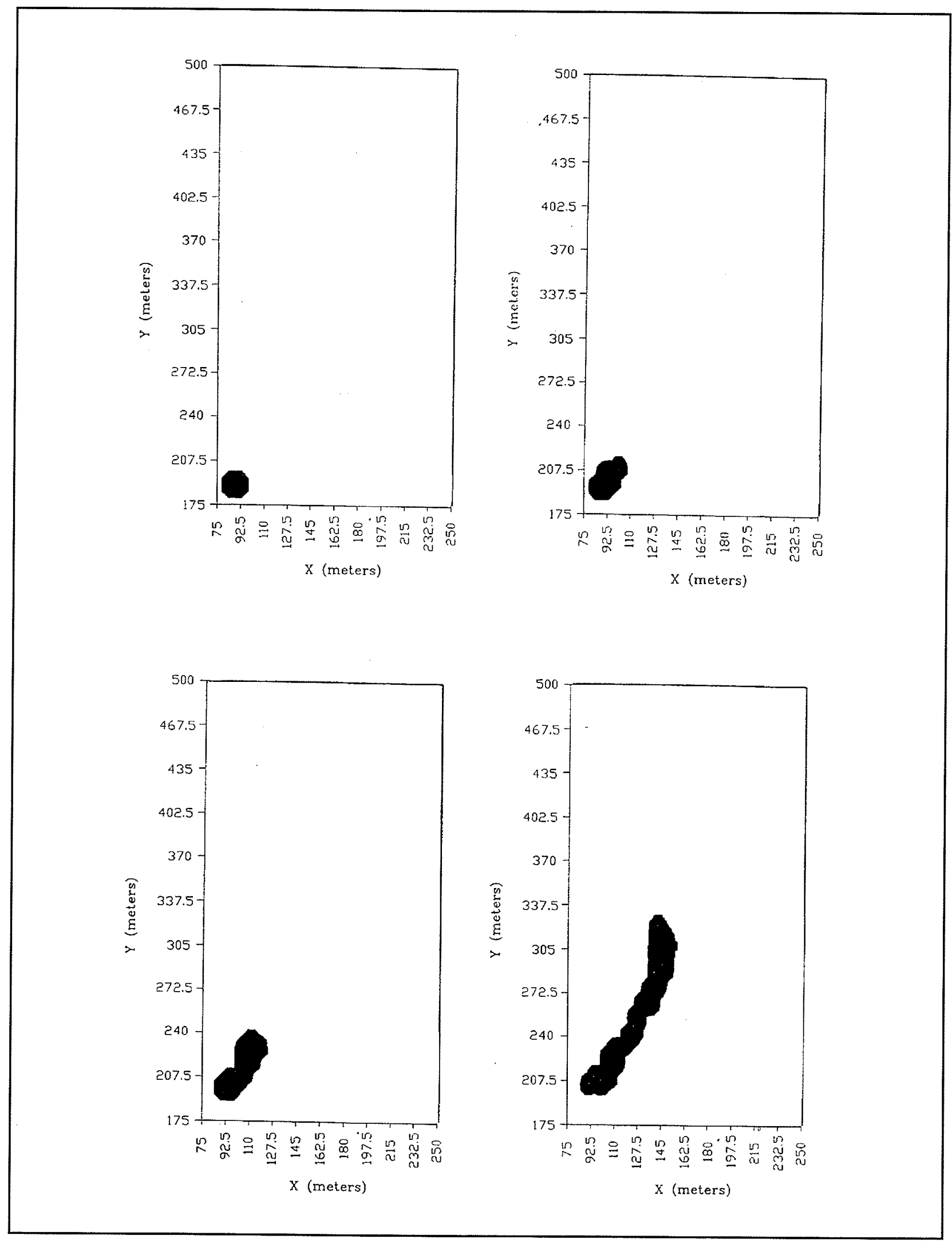

Figure 41. Plan view of simulated $50-\mathrm{pCi} / \mathrm{ml}$ tritium iso-surface at a) day 27 , b) day $132, \mathrm{c}$ ) day 234 , and d) day 328 


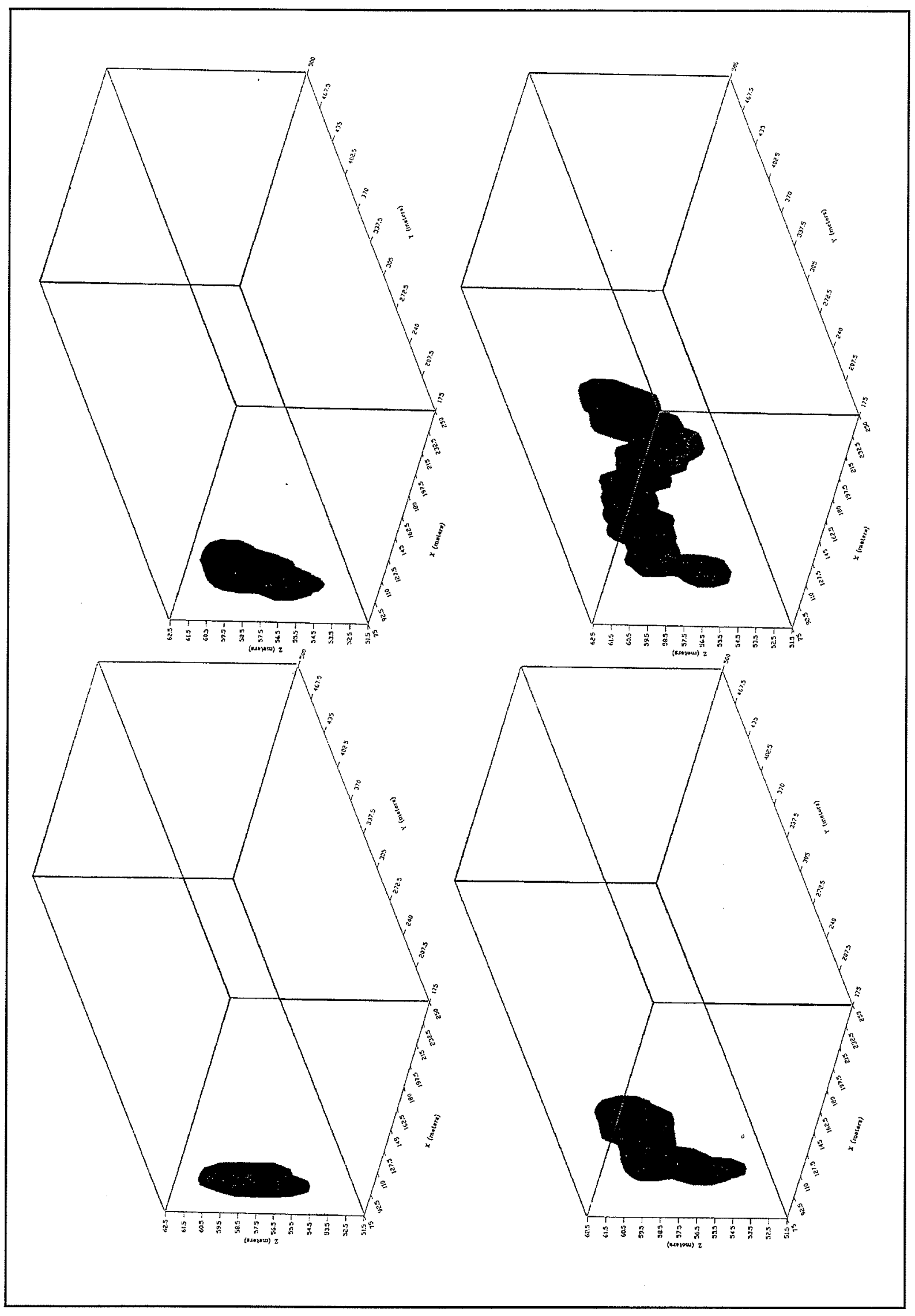

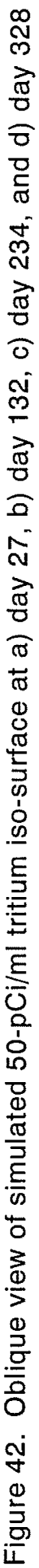




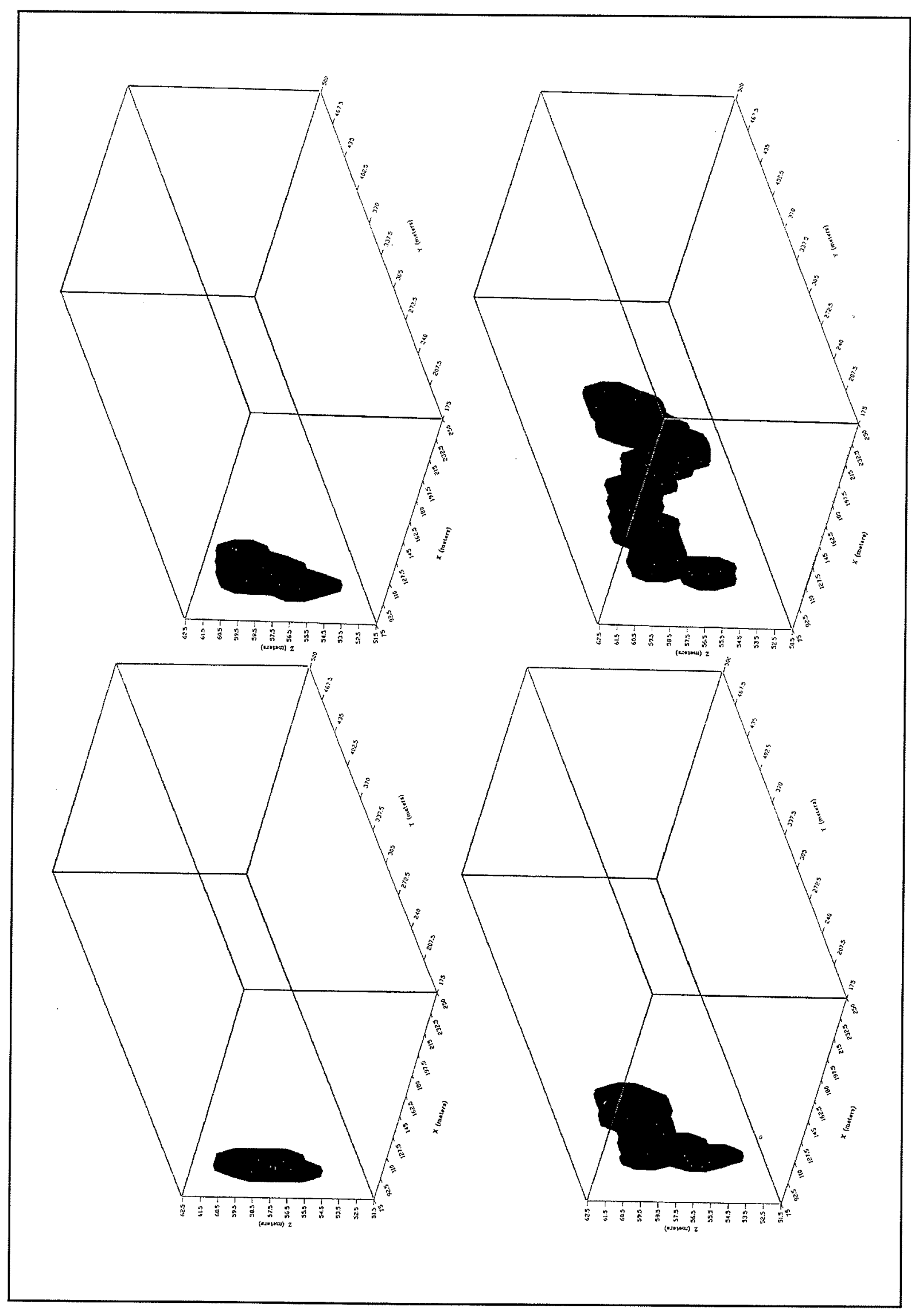

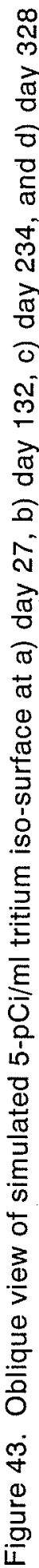




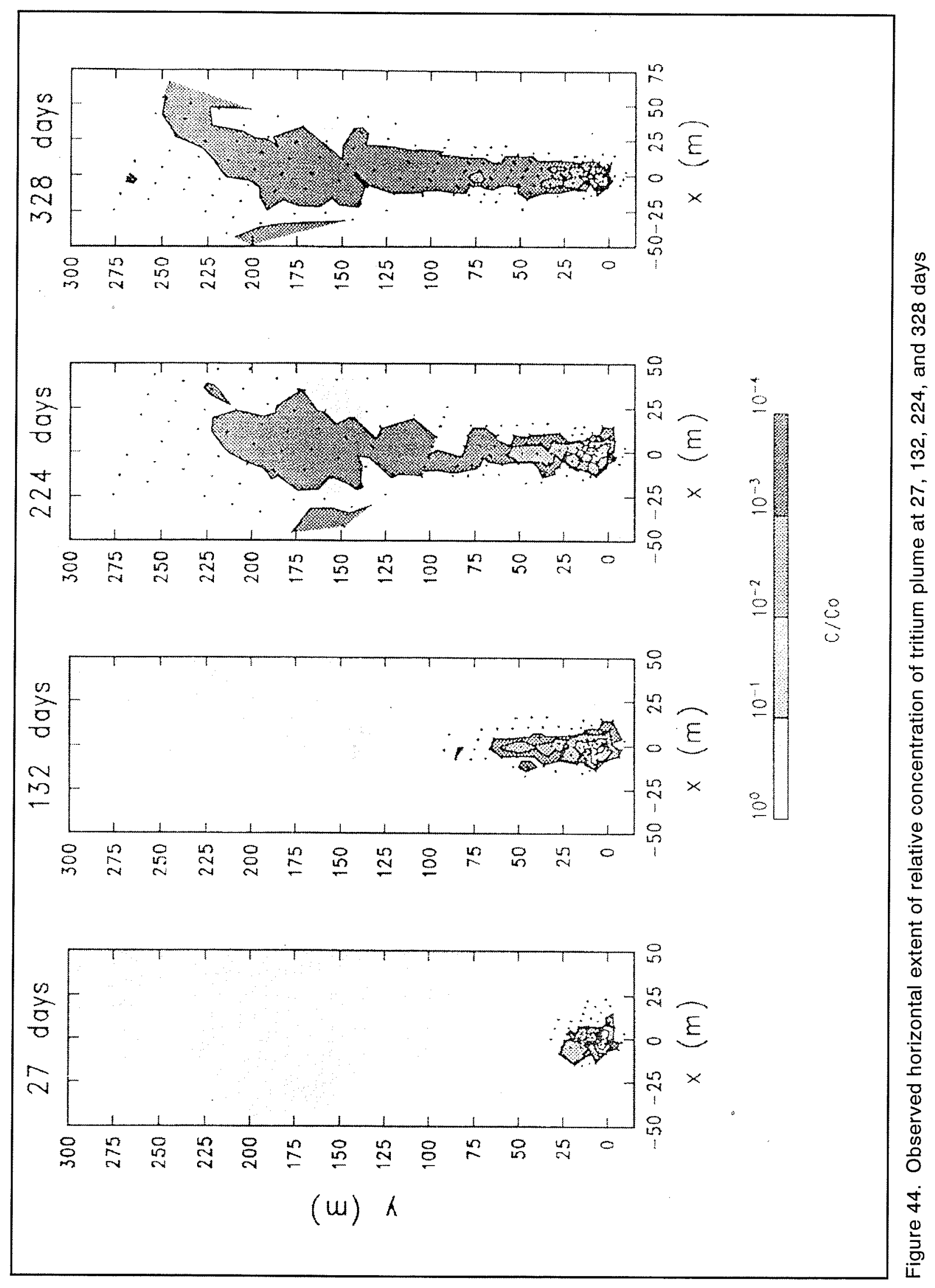


27 days

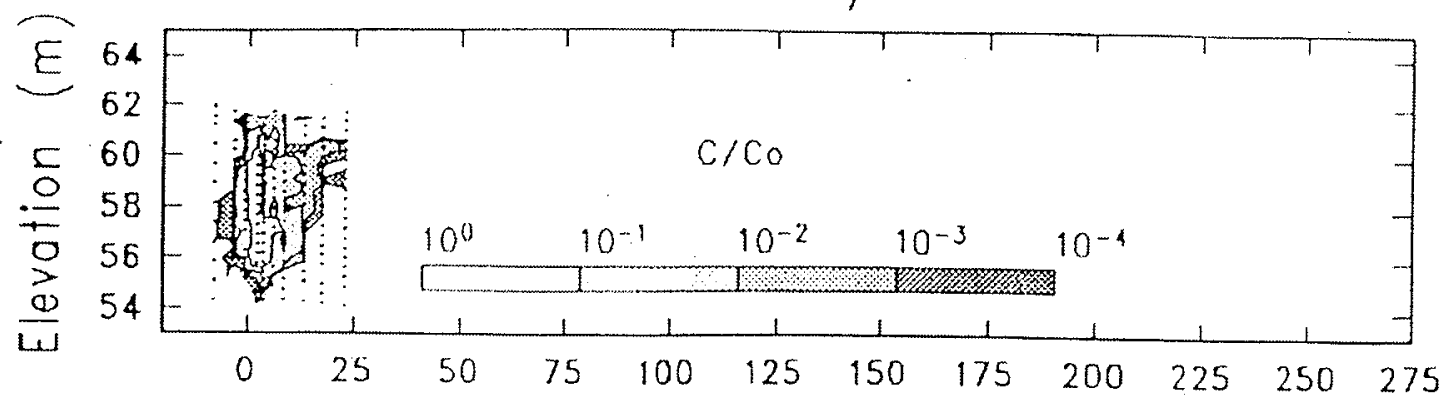

132 days

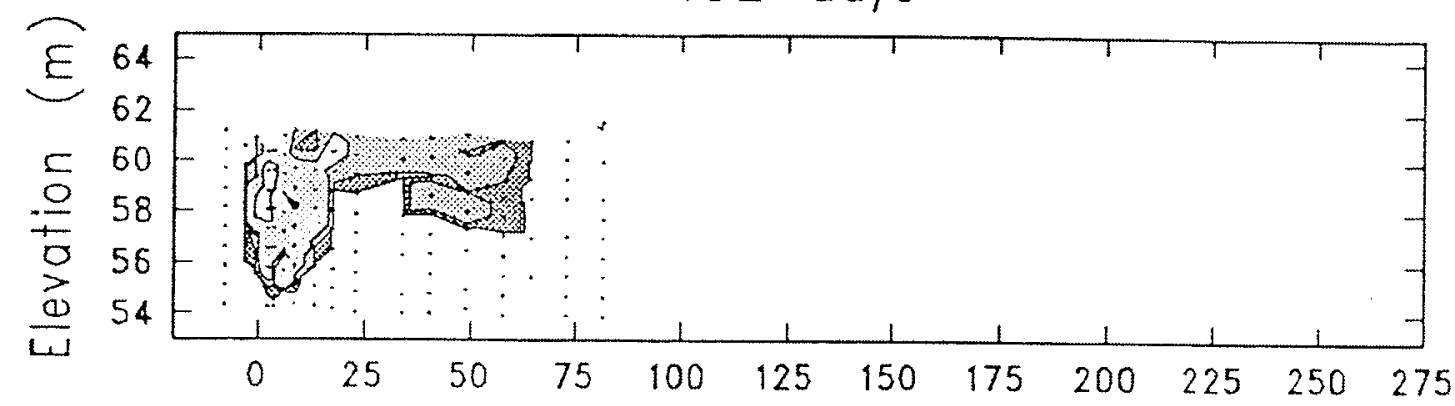

224 days

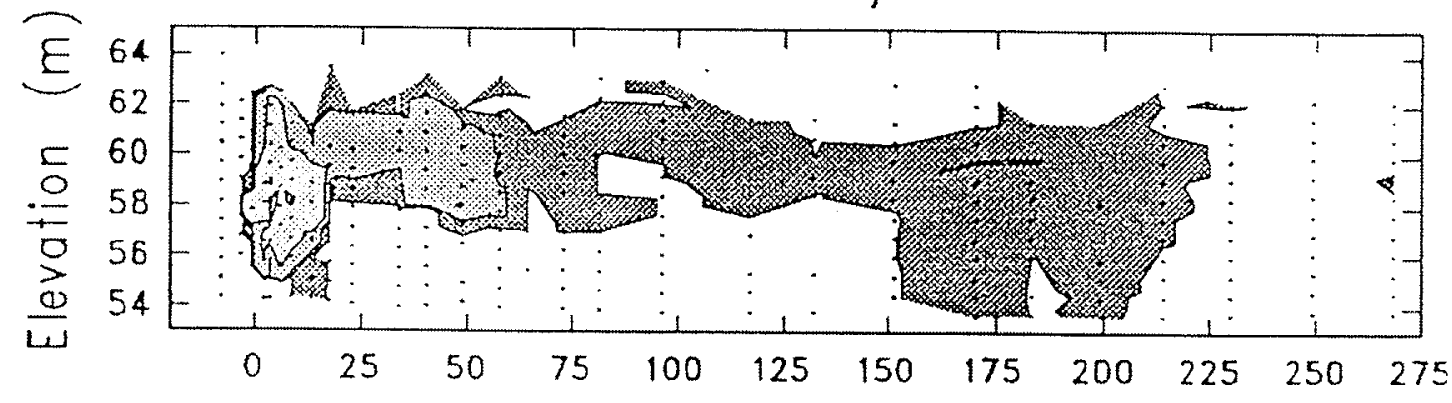

328 days

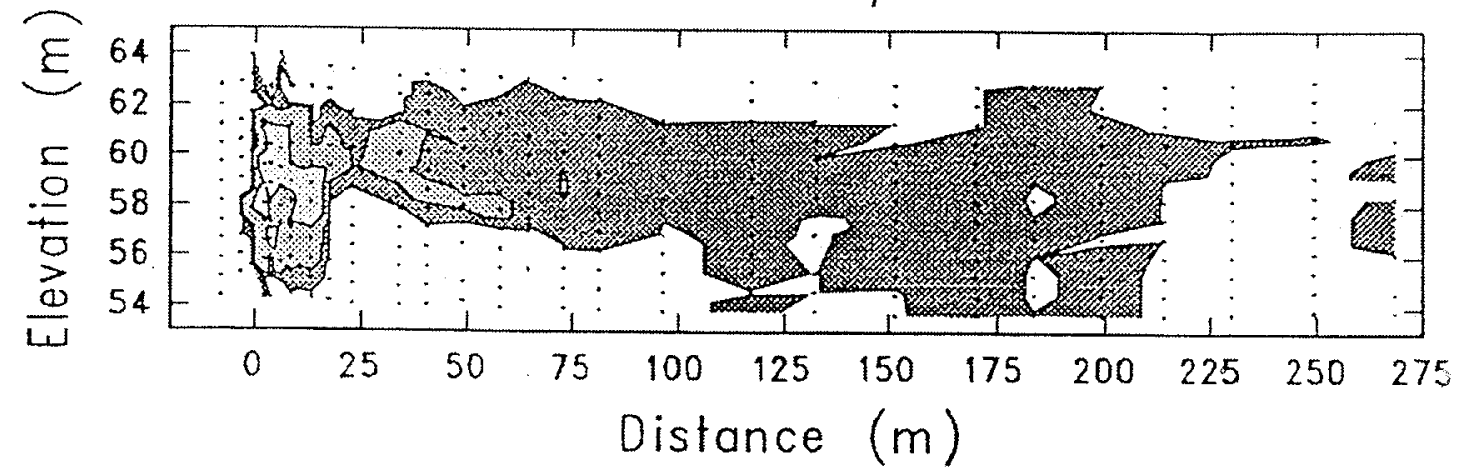

Figure 45. Observed vertical and longitudinal extent of tritium plume at $27,132,224$, and 328 days 


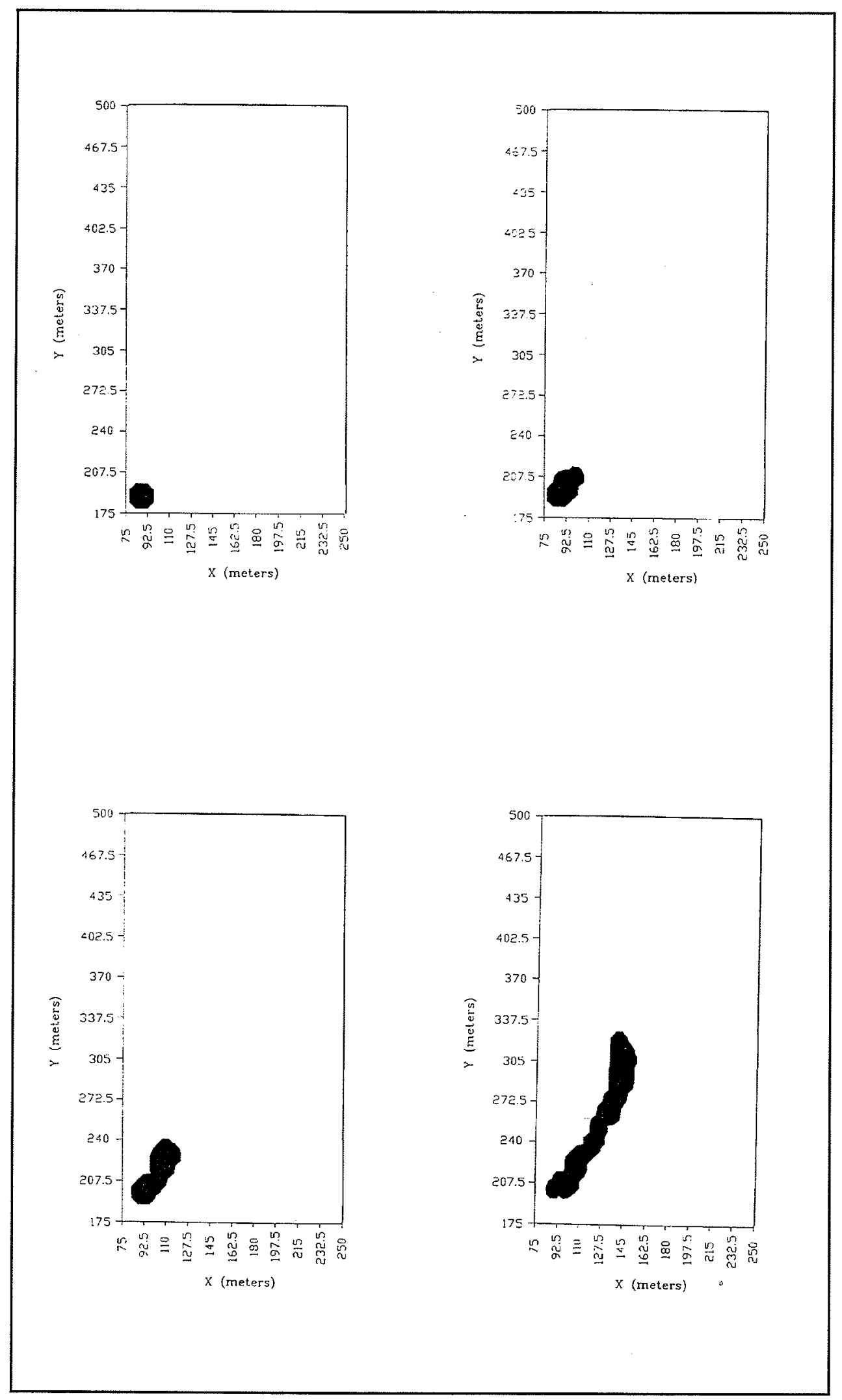

Figure 46. Plan view of simulated $3-\mathrm{pCi} / \mathrm{ml}$ carbon-14 iso-surface at a) day 27 , b) day 132 , c) day 234 , and d) day 328 


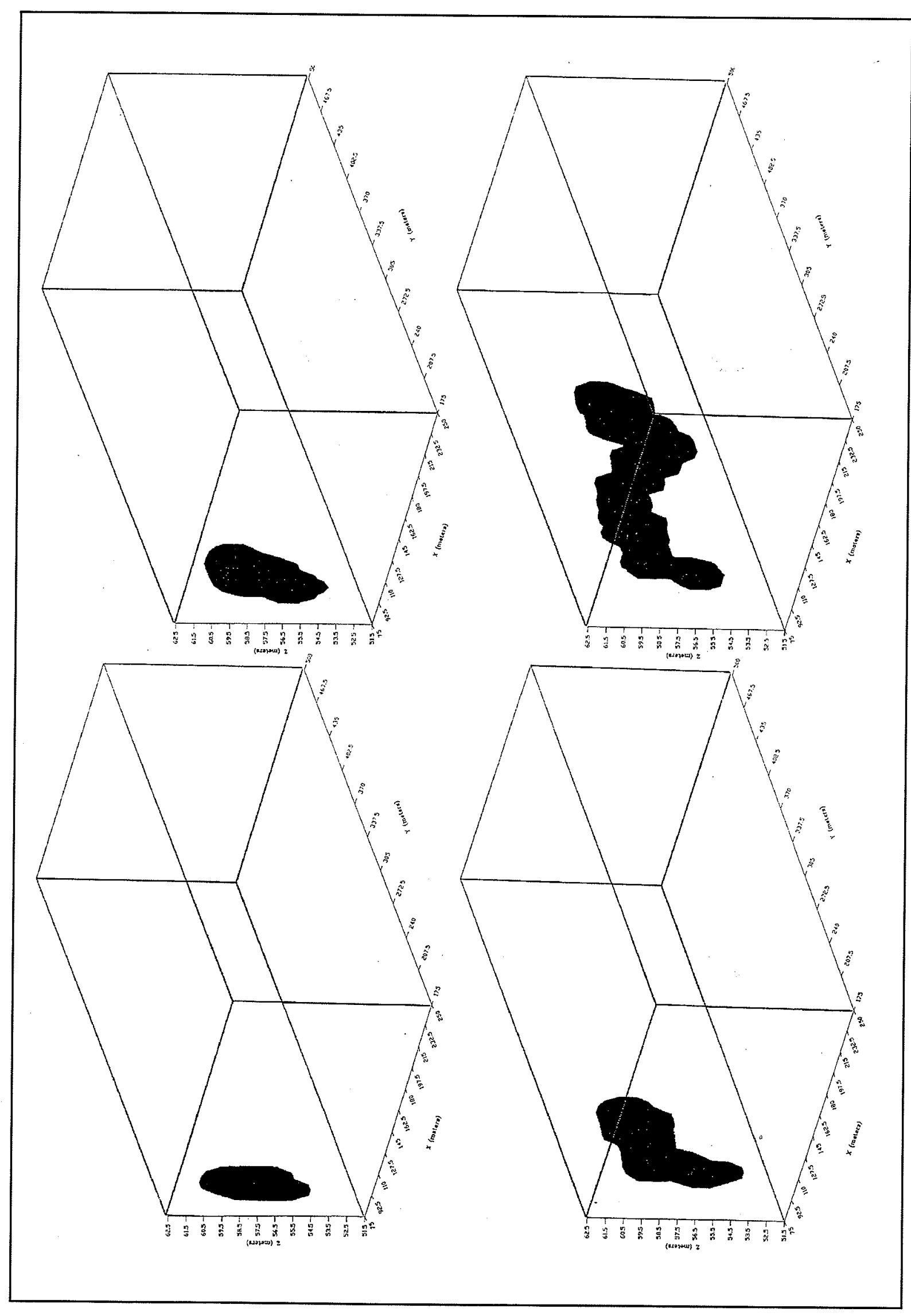

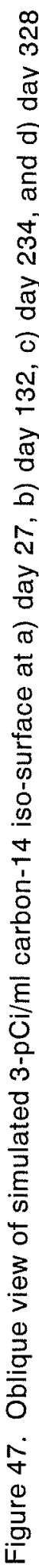




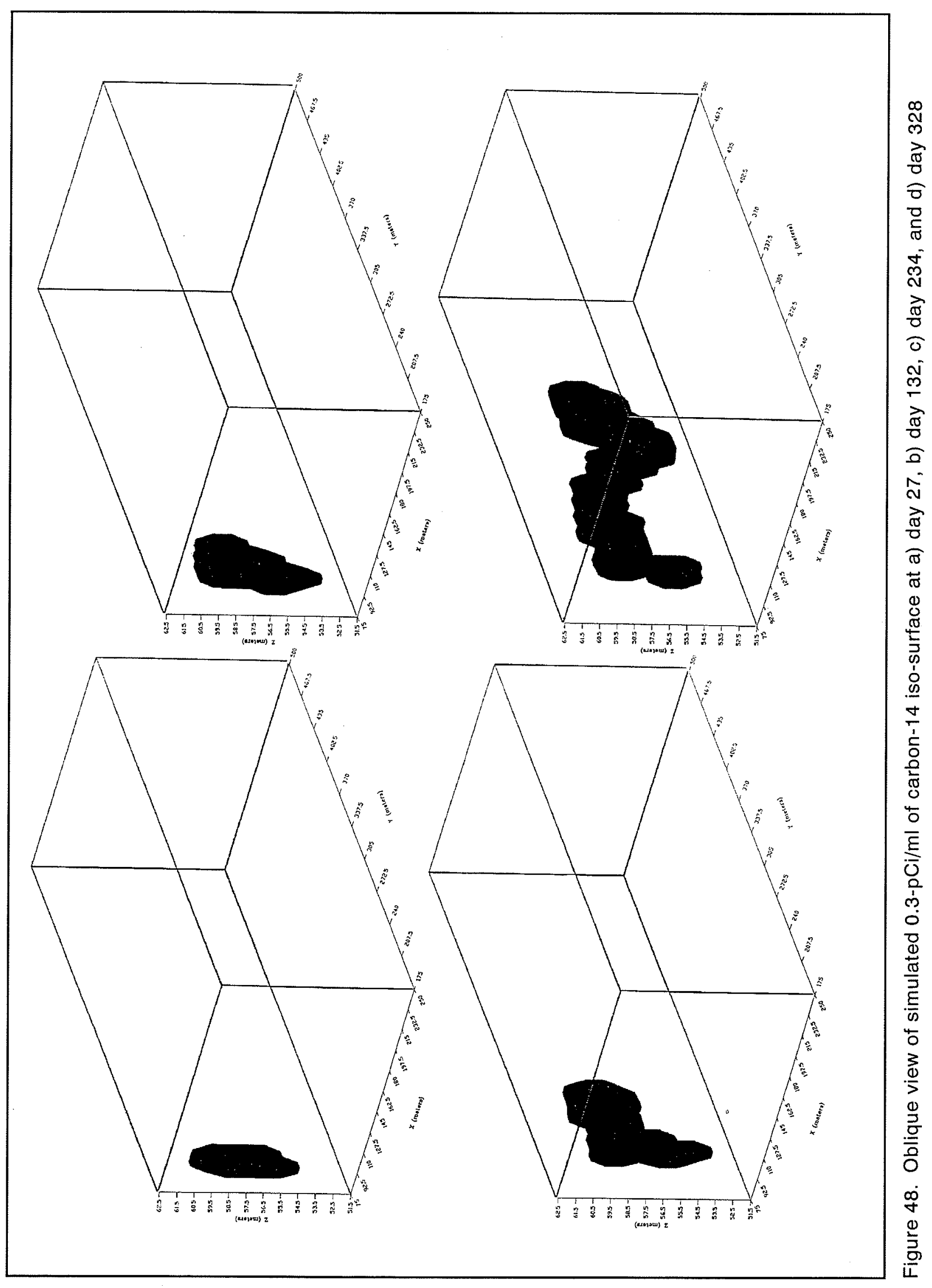




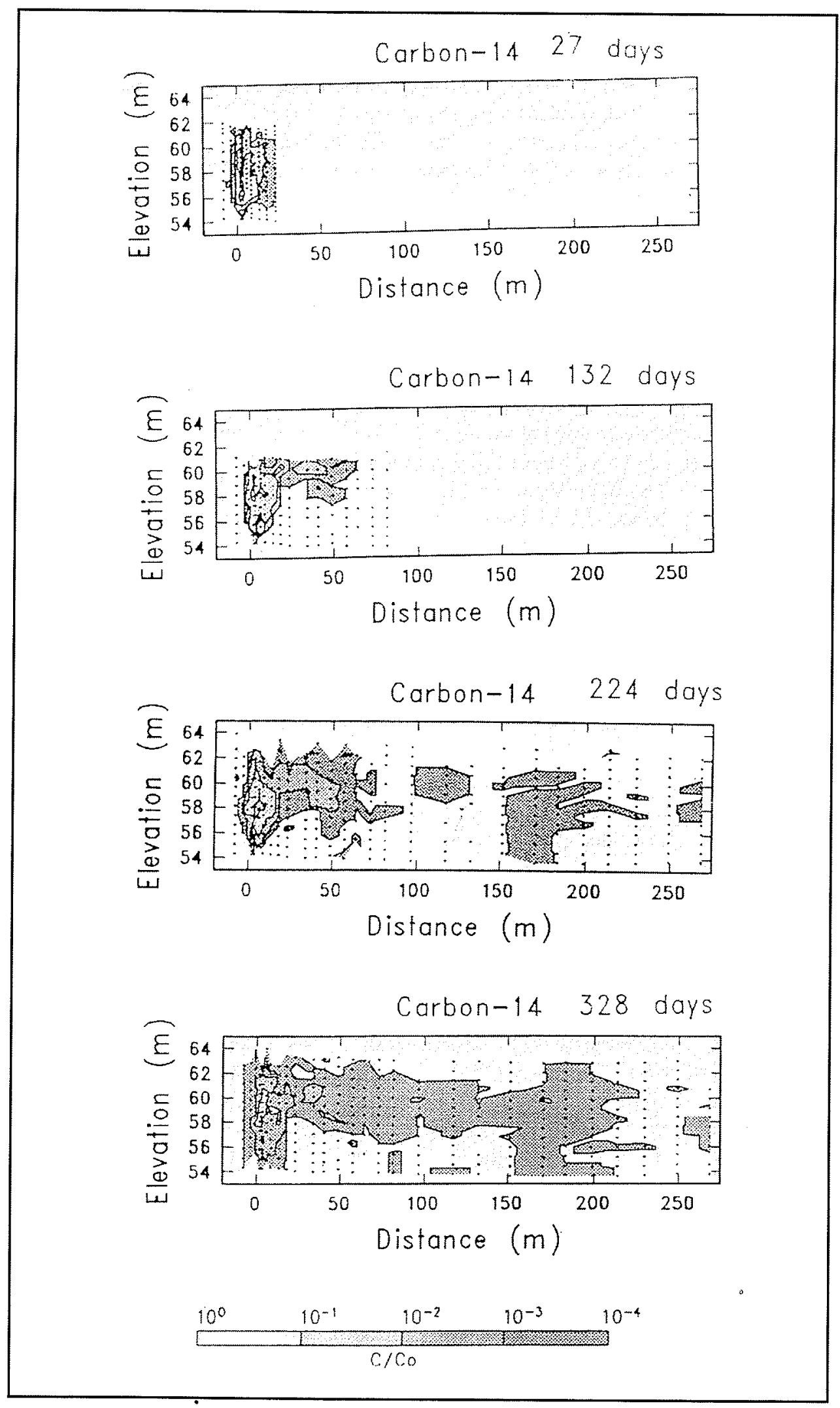

Figure 49. Observed vertical and longitudinal extent of carbon-14 at 27, 132, 224 , and 328 days 
observed plume nor does it show the spreading of the advancing front. As shown in the figures of the simulated and observed ${ }^{14} \mathrm{C}$ plumes at 27,132 , 224 , and 328 days, the simulation was able to match reasonably well until day 224 , when the simulation lagged the observed plume. At day 328 the simulation of the $0.3-\mathrm{pCi} / \mathrm{ml}$ iso-surface still lagged the observed plume, but showed a tendency to move further downgradient, probably due to increased velocity in this area of the aquifer. Also at day 328 , the simulated and observed 3-pCi/ml plumes showed that the simulated plume had traveled further downgradient than the observed plume. The reason for the lag between the simulated plume and the observed plume could be due to the hydrologic conditions occurring at about this time. Piezometric data show that at approximately day 203 of the simulation, the piezometric head is at its highest point since the beginning of the monitoring. Only steady-state flow was conducted here and thus the flow model lacks the seasonal fluctuation in the water table. The lower concentration $0.3-\mathrm{pCi} / \mathrm{mL}$ observed and simulated plumes show a larger discrepancy (approximately $56 \mathrm{~m}$ ) between them. At day 224 , the simulated and observed $0.3-\mathrm{pCi} / \mathrm{mL}$ iso-surfaces have significant differences. The observed $0.3-\mathrm{pCi} / \mathrm{mL}$ plume has reached a downgradient extent in excess of $270 \mathrm{~m}$ from the injection point, while the simulated plume has traveled only approximately $80 \mathrm{~m}$ from the initial point of injection. The $3-\mathrm{pCi} / \mathrm{mL}$ observed and simulated plumes have traveled nearly the same extent. The difference between the observed $0.3-\mathrm{pCi} / \mathrm{mL}$ and the $3-\mathrm{pCi} / \mathrm{mL}$ iso-surfaces at this time period is noticeably different in travel extent. The observed plume differences suggest the possibility of preferential flow pathways that the monitoring equipment could not discern due to monitoring location. At day 328 , the observed and simulated $0.3-\mathrm{pCi} / \mathrm{mL}$ iso-surfaces show the simulated plume lagging the observed plume by approximately $78 \mathrm{~m}$. The 3 -pCi/mL simulated and observed iso-surfaces show the simulated plume having traveled approximately $177 \mathrm{~m}$ further than the observed plume.

\section{Simulation of benzene}

Benzene transport through the MADE system was simulated for a period of 328 days. Input parameters included adsorption and first-order biodecay coefficients (Tables 7, 8, and 9). Output from the MT3D simulation expressed in plan view for a $50-\mathrm{mg} / \mathrm{m}^{3}$ iso-surface is shown in Figure 50 for days $27,132,242$, and 328 . The simulated $50-\mathrm{mg} / \mathrm{m}^{3}$ iso-surface is shown in oblique view in Figure 51 for days 27, 132, 234, and 328. Figure 52 shows an oblique view of a $5-\mathrm{mg} / \mathrm{m}^{3}$ benzene iso-surface at days $27,132,224$, and 328. Figure 53 shows the observed vertical and longitudinal extent of the relative concentration benzene plume at $27,132,224$, and 328 days (Boggs et al. 1993). The simulated benzene plume advanced downgradient more than the observed plume, but overall was a fairly good match. As can be seen from the figures of the simulated and observed benzene plumes at 27 , 132,224 , and 328 days, the simulation was able to match reasonably well until day 224 , after which the simulated plume propagated further than the observed plume. At day 328 , the simulated $5-\mathrm{mg} / \mathrm{m}^{3}$ and $50-\mathrm{mg} / \mathrm{m}^{3}$ iso-surfaces had still traveled further than the observed corresponding 


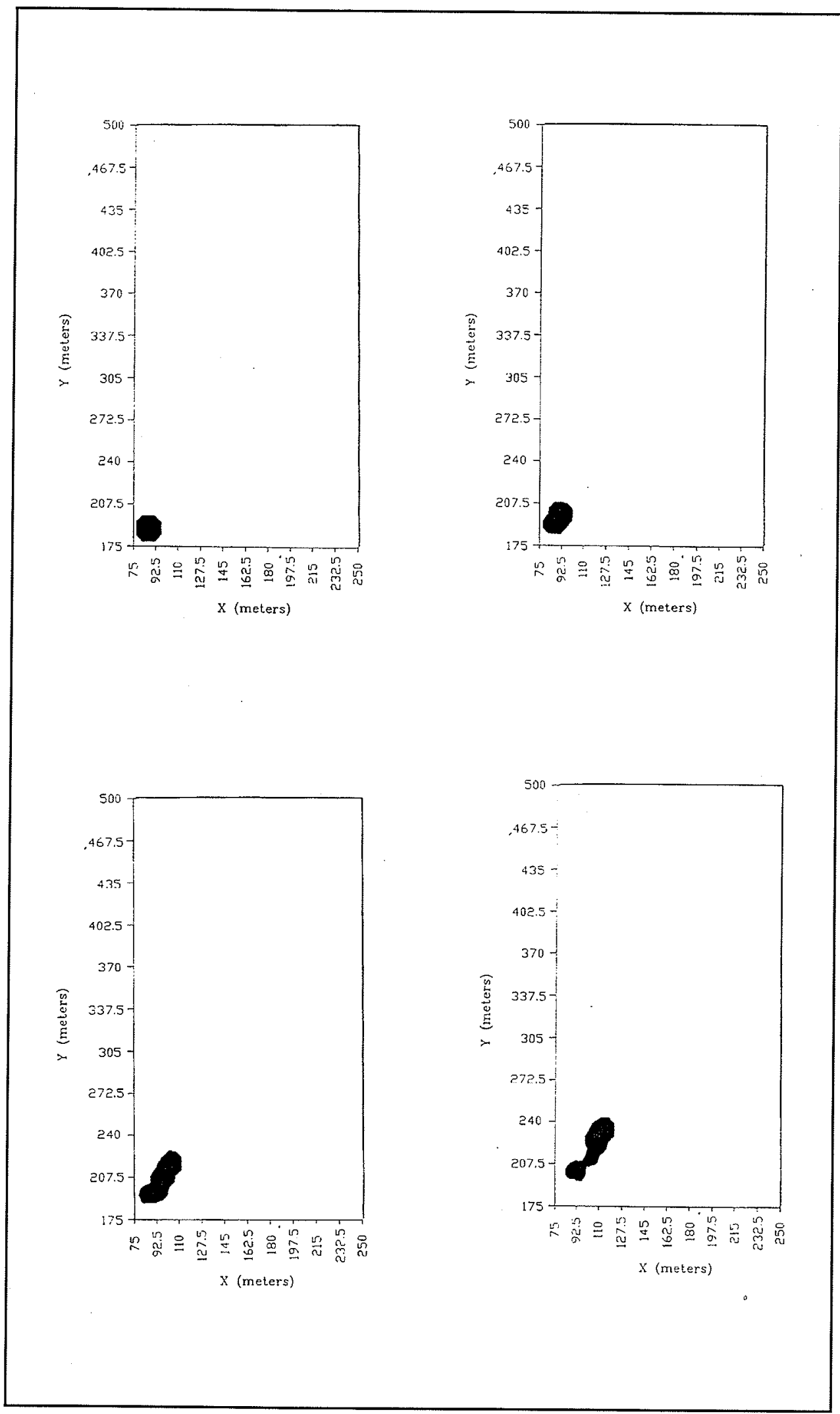

Figure 50. Plan view of simulated $50-\mathrm{mg} / \mathrm{m}^{3}$ benzene iso-surface at a) day 27 , b) day 132, c) day 234 , and d) day 328 


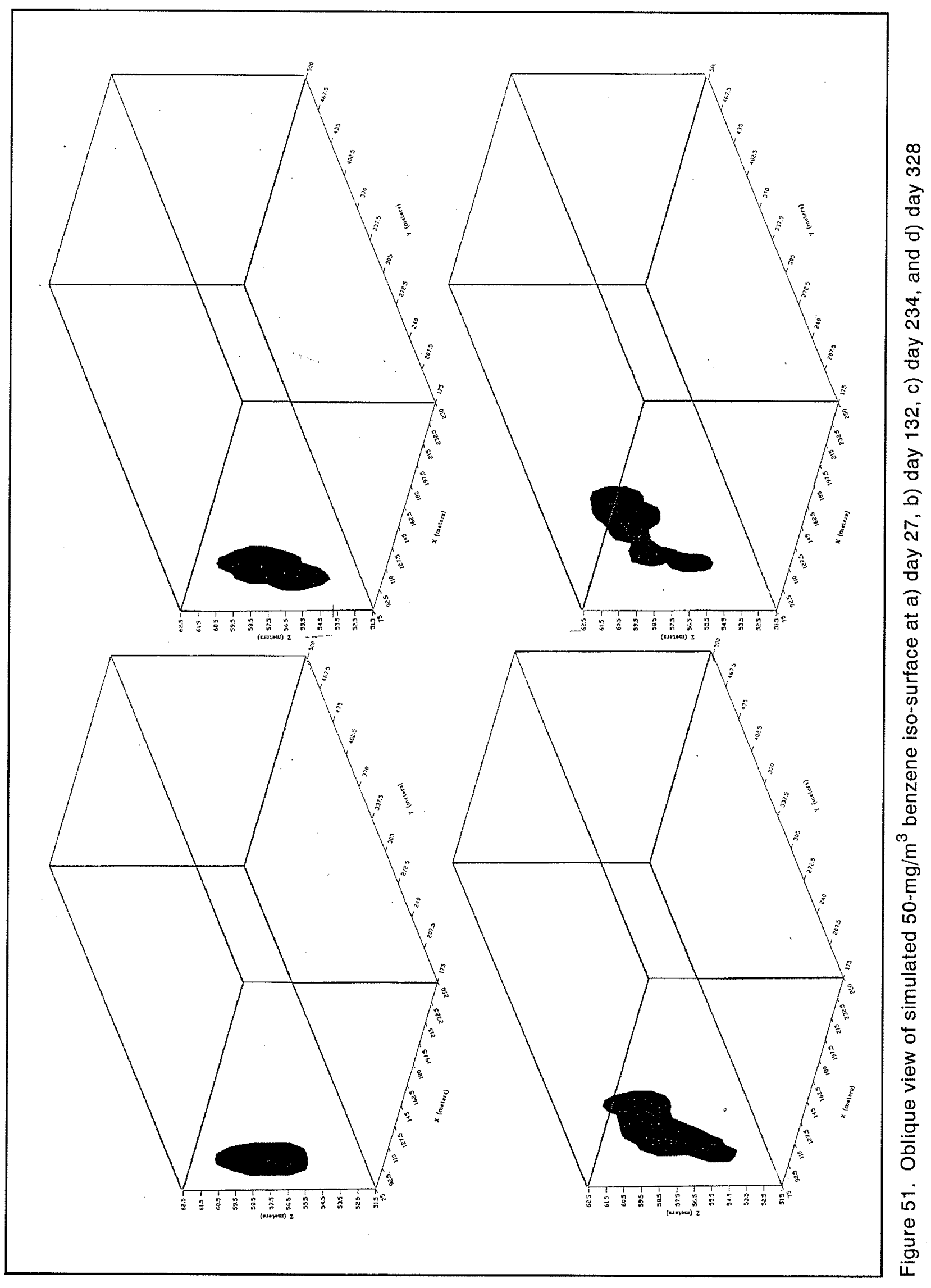




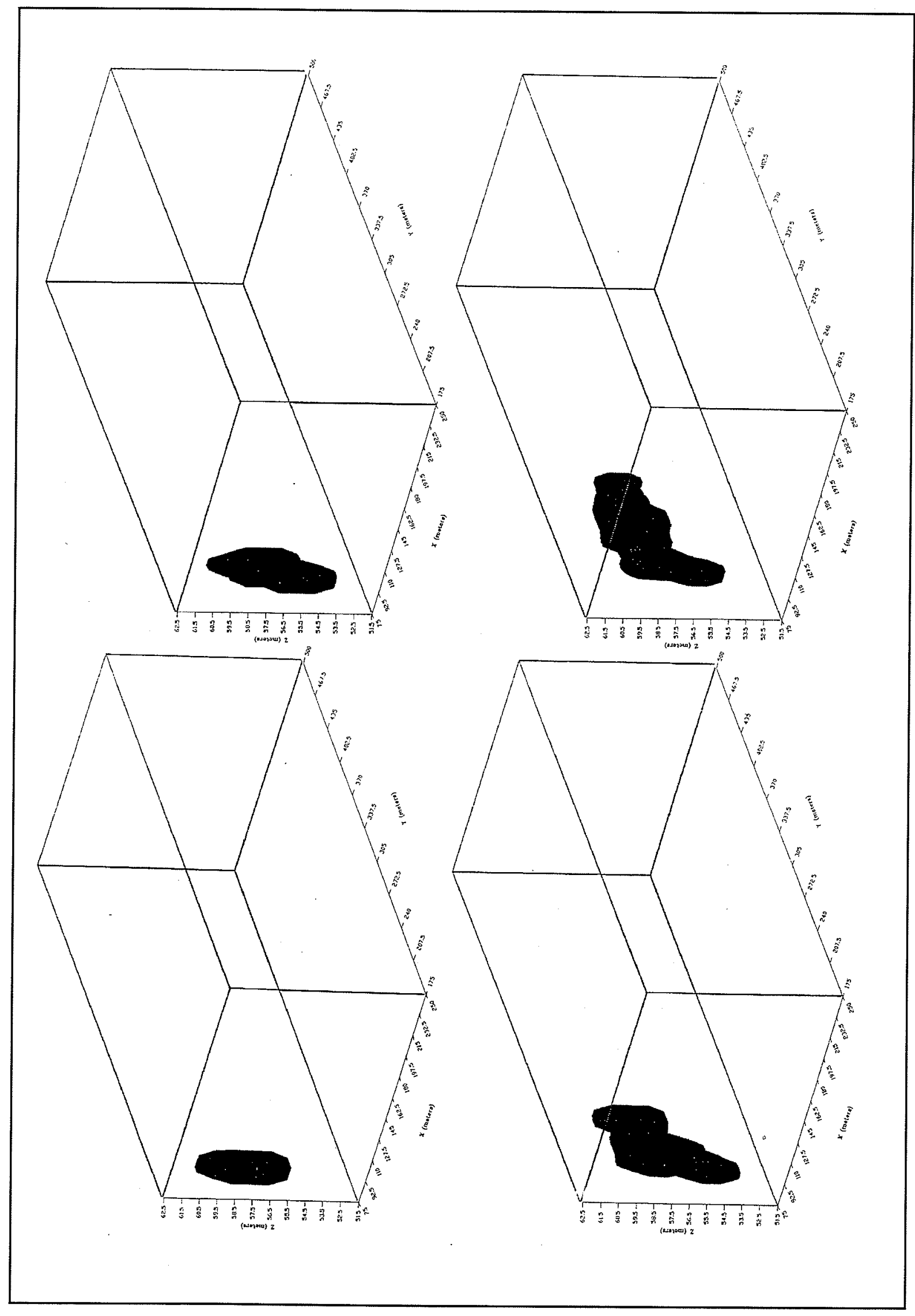

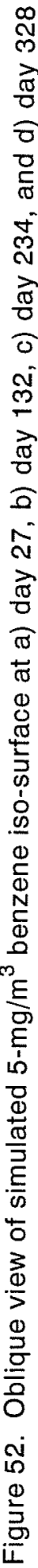




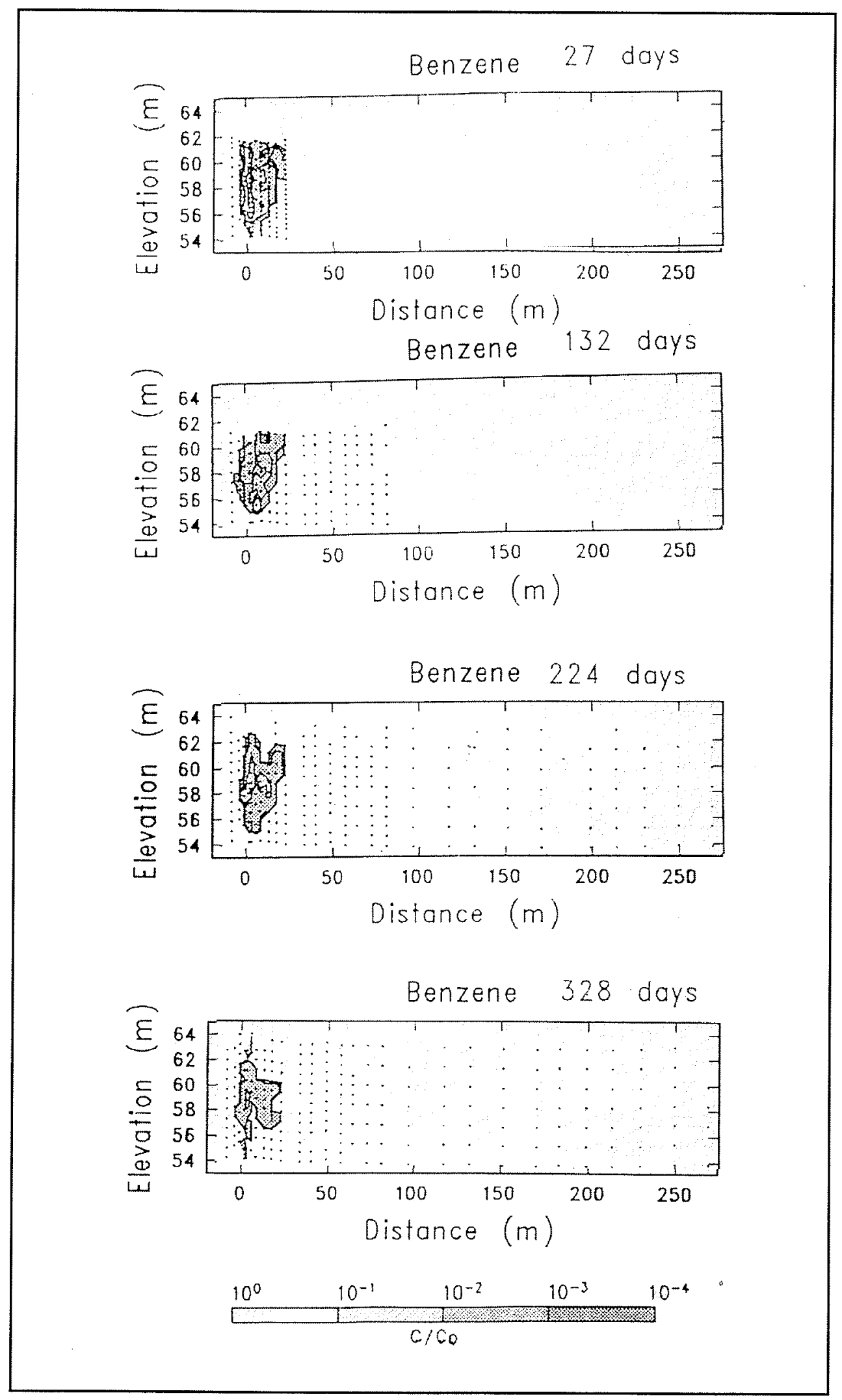

Figure 53. Observed vertical and longitudinal extent of benzene plume at 27, 132,224 , and 328 days 
plumes, but had shown a tendency to remain in place since it had only moved approximately $10 \mathrm{~m}$ further downgradient over a 104-day period. At day 27 , the simulated and observed plumes agree well with each other. The simulated and observed $50-\mathrm{mg} / \mathrm{m}^{3}$ plumes both traveled downgradient approximately $25 \mathrm{~m}$ while the $5-\mathrm{mg} / \mathrm{m}^{3}$ iso-surfaces had both traveled approximately $25 \mathrm{~m}$ also. At day 132, the simulated and observed plumes of the $50-\mathrm{mg} / \mathrm{m}^{3}$ and $5-\mathrm{mg} / \mathrm{m}^{3}$ iso-surfaces agree well with each other. At day 224 , the simulated and observed $50-\mathrm{mg} / \mathrm{m}^{3}$ and $5-\mathrm{mg} / \mathrm{m}^{3}$ iso-surfaces depart from the behavior of the tritium and ${ }^{14} \mathrm{C}$ contaminants in that the simulated plumes travel further downgradient than the observed plumes. The observed $50-\mathrm{mg} / \mathrm{m}^{3}$ plume has reached a downgradient extent of approximately $15 \mathrm{~m}$ while the simulated plume traveled approximately $40 \mathrm{~m}$ from the initial point of injection. At day 328 , the observed $50-\mathrm{mg} / \mathrm{m}^{3}$ iso-surface shows the observed plume has still remained at approximately $15 \mathrm{~m}$ from the injection point, while the simulated plume has extended to approximately $75 \mathrm{~m}$ from the source. The $5-\mathrm{mg} / \mathrm{m}^{3}$ simulated and observed iso-surfaces show the simulated plume having traveled approximately $70 \mathrm{~m}$ further than the observed plume.

\section{Simulation of p-xylene}

P-xylene transport in the CAFB site was simulated for a period of 328 days. The input parameters include adsorption and biodecay coefficients (Tables 7, 8, and 9). Output from the MT3D simulation expressed in plan view for a $50-\mathrm{mg} / \mathrm{m}^{3}$ iso-surface is shown in Figure 54 for days 27, 132, 242 , and 328 . The simulated $50-\mathrm{mg} / \mathrm{m}^{3}$ iso-surface is shown in oblique view in Figure 55 for days 27, 132, 234, and 328. Figure 56 shows an oblique view of a $5-\mathrm{mg} / \mathrm{m}^{3} \mathrm{p}$-xylene iso-surface at days $27,132,224$, and 328 . Figure 57 (Boggs et al. 1993) shows the vertical and longitudinal extent of the relative concentration p-xylene plume at $27,132,224$, and 328 days.

The simulated results match reasonably well with observed data until day 224 , after which the observation lagged the simulated plume. At day 328 , both the simulated $5-\mathrm{mg} / \mathrm{m}^{3}$ and $50-\mathrm{mg} / \mathrm{m}^{3}$ iso-surfaces had still traveled further than the observed corresponding plumes. Piezometric data show that at approximately day 203 of the simulation, the piezometric head is at its highest since the beginning of the monitoring and because only steady-state flow was conducted, the flow model lacks the seasonal fluctuation in the water table. At day 27 , the simulated and observed plumes agree well with each other. The simulated and observed $50-\mathrm{mg} / \mathrm{m}^{3}$ plumes have a longitudinal extent of approximately 20 and $25 \mathrm{~m}$ from the injection point, respectively. The observed $5-\mathrm{mg} / \mathrm{m}^{3}$ plume has traveled approximately $25 \mathrm{~m}$ from the source, while the simulated plume has also traveled approximately $25 \mathrm{~m}$. At day 132, the simulated and observed plumes agree well with each other when comparing the $50-\mathrm{mg} / \mathrm{m}^{3}$ and $5-\mathrm{mg} / \mathrm{m}^{3}$ iso-surfaces. At day 224 , the simulated and observed $50-\mathrm{mg} / \mathrm{m}^{3}$ and $5-\mathrm{mg} / \mathrm{m}^{3}$ iso-surfaces depart from the behavior of the tritium and ${ }^{14} \mathrm{C}$ plumes; the simulated plumes traveled further downgradient than the observed plumes. The limited displacement of the observed plumes is 

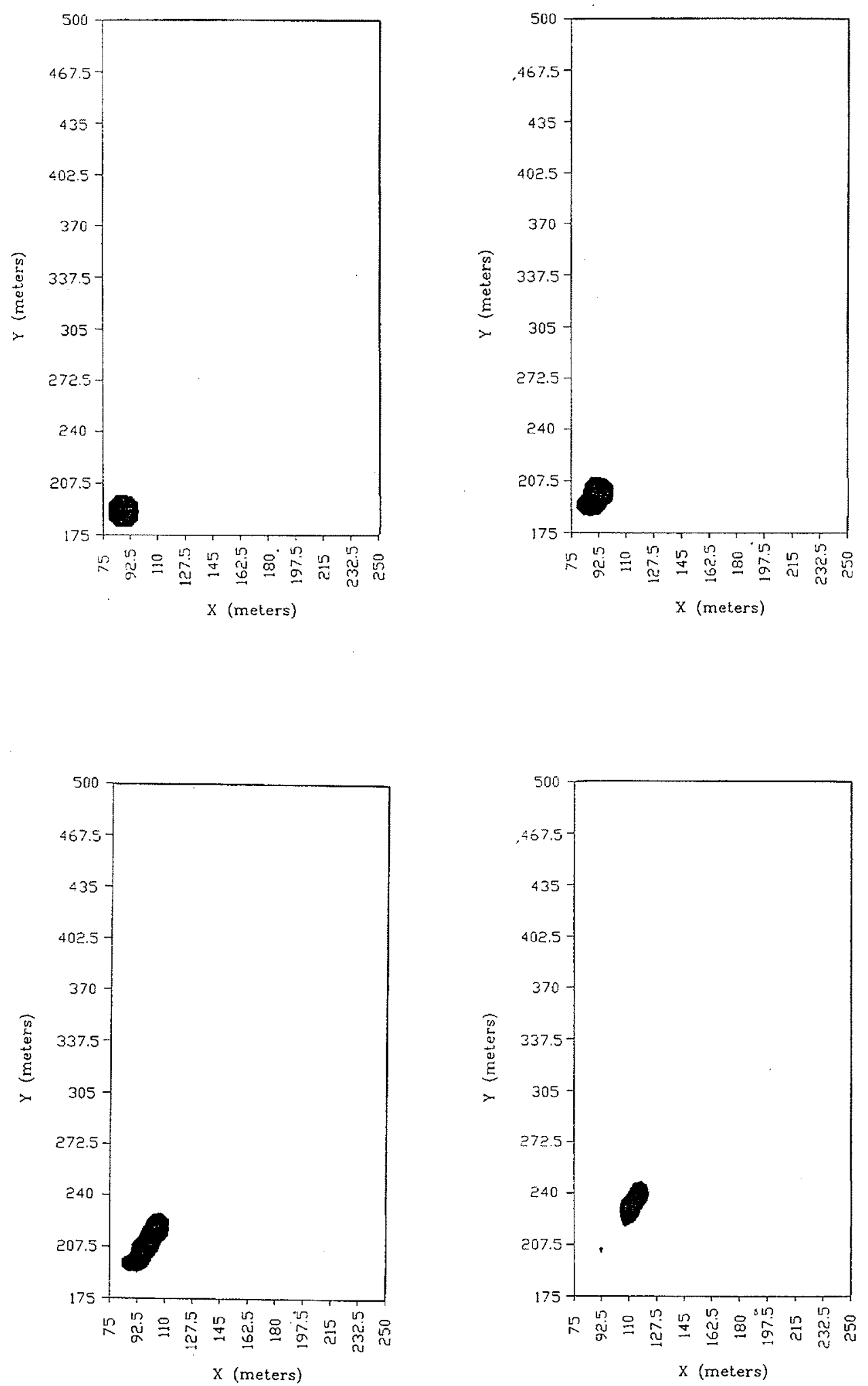

Figure 54. Plan view of simulated $50-\mathrm{mg} / \mathrm{m}^{3}$ p-xylene iso-surface at a) day $27, \mathrm{~b}$ ) day $132, \mathrm{c}$ ) day 234 , and d) day 328 


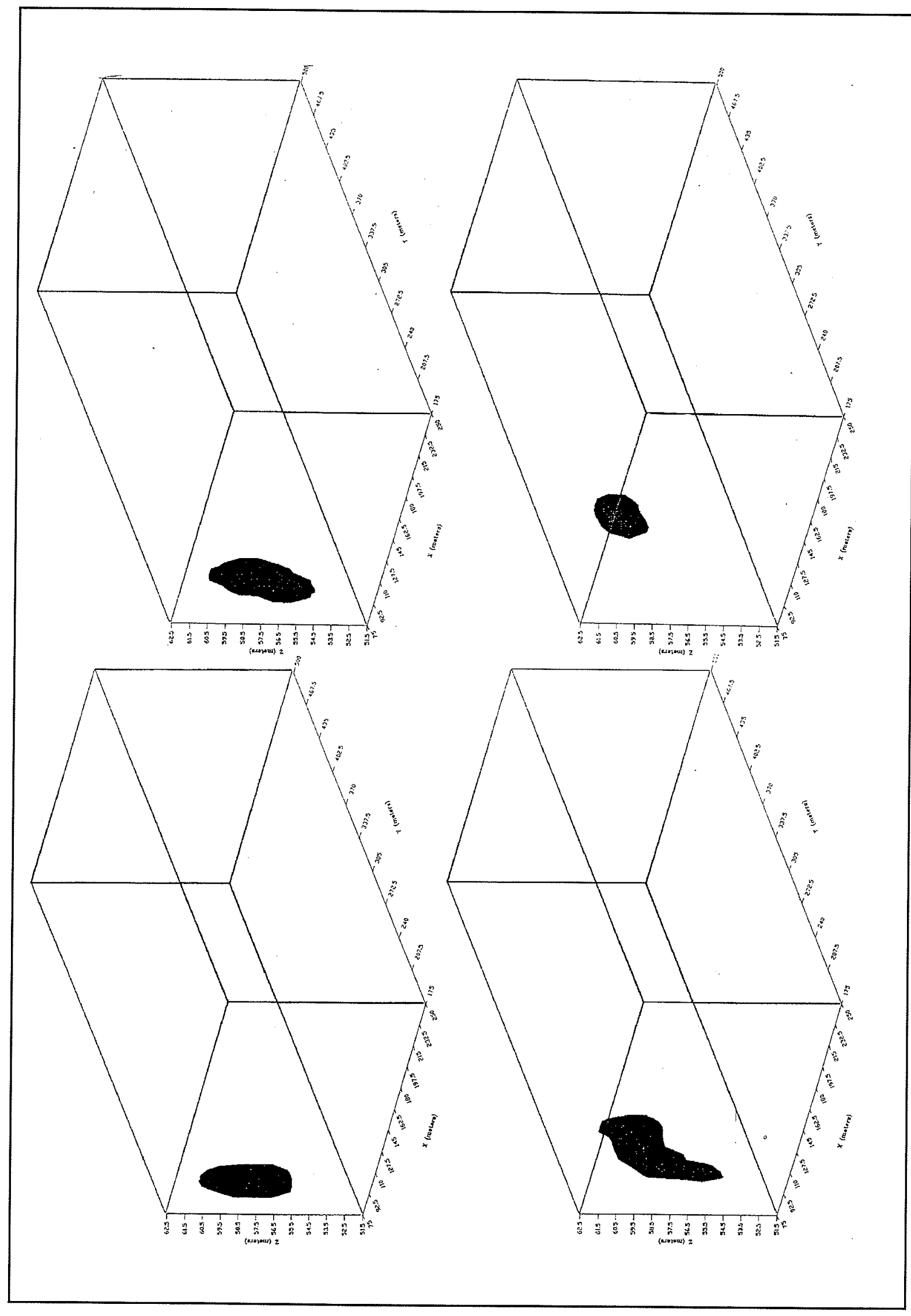

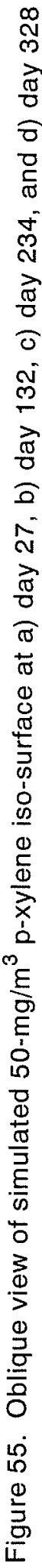




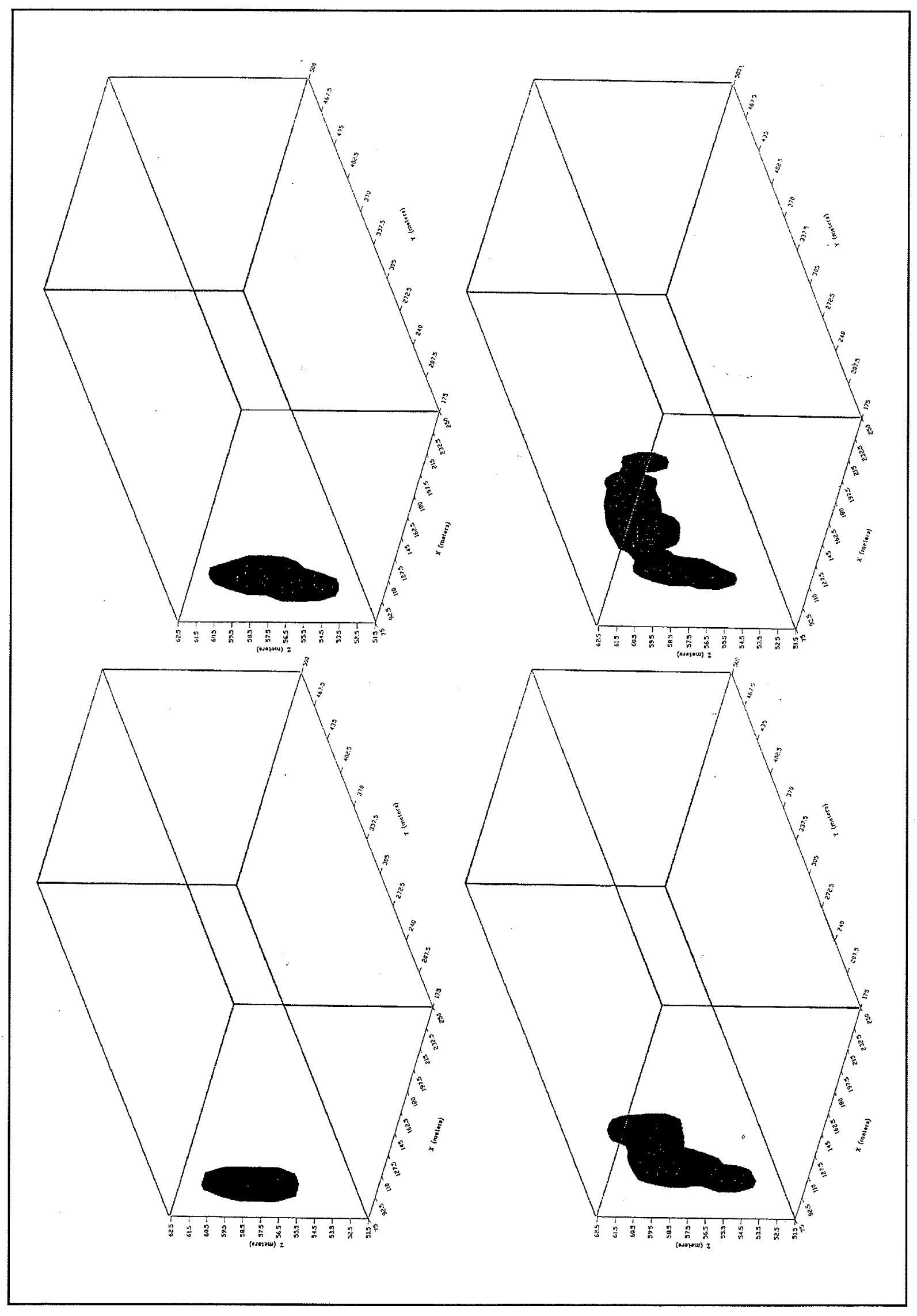

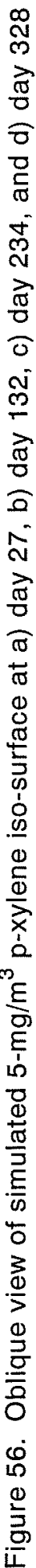




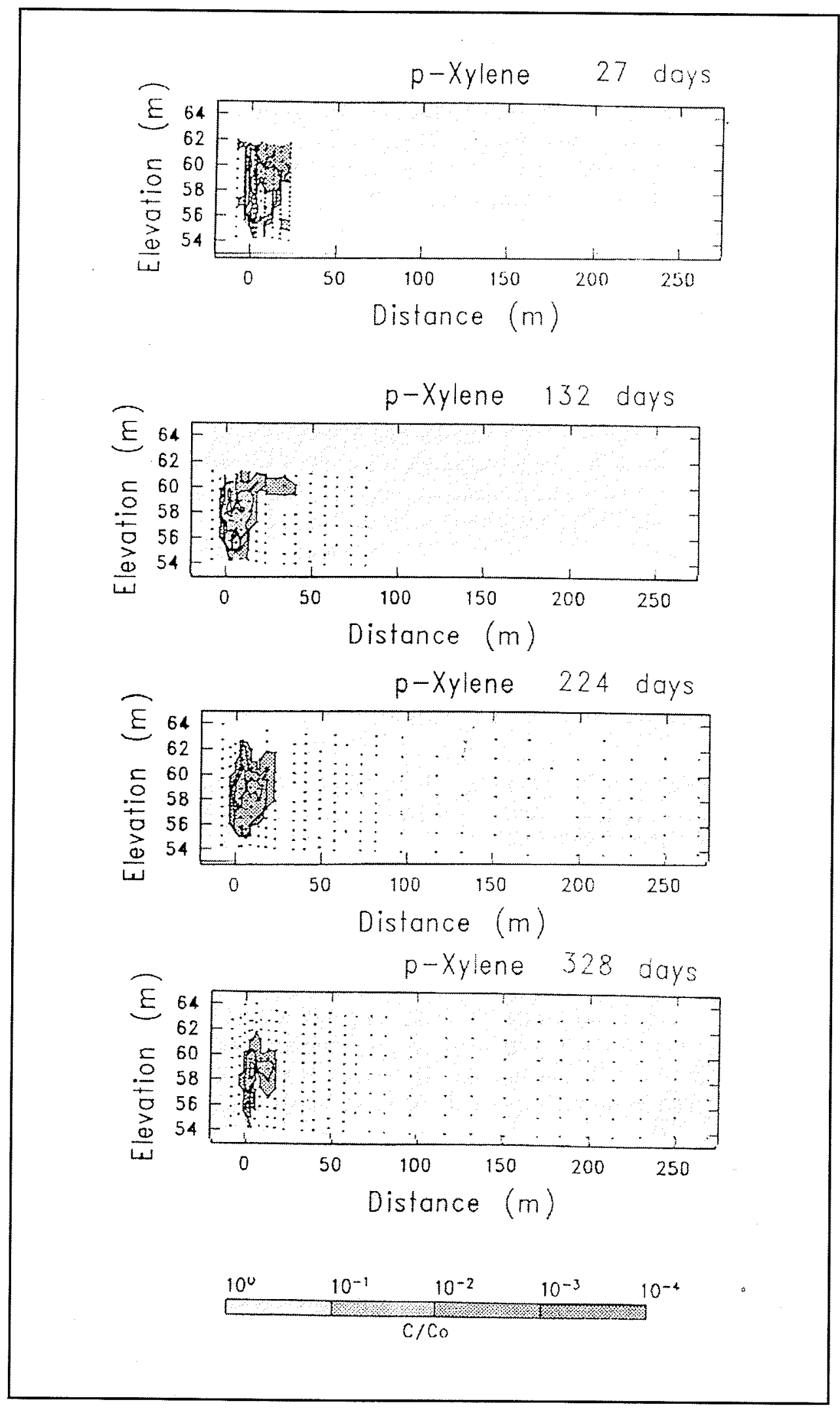

Figure 57. Observed vertical and longitudinal extent of $p$-xylene plume at 27,132 , 224 , and 328 days 
consistent with the effects of bio-transformation, which prior studies at the MADE site indicate are quite significant. The observed $50-\mathrm{mg} / \mathrm{m}^{3}$ plume has reached a downgradient extent of approximately $15 \mathrm{~m}$ while the simulated plume traveled approximately $40 \mathrm{~m}$ from the initial point of injection. At day 328 , the observed $50-\mathrm{mg} / \mathrm{m}^{3}$ iso-surface showed the observed plume has still remained at approximately $15 \mathrm{~m}$ from the injection point, while the simulated plume extended to approximately $75 \mathrm{~m}$ from the source. The $5-\mathrm{mg} / \mathrm{m}^{3}$ simulated and observed iso-surfaces show the simulated plume traveled approximately $70 \mathrm{~m}$ further than the observed plume.

\section{Simulation of o-dichlorobenzene}

O-dichlorobenzene transport through the MADE system was simulated for a period of 328 days. Input parameters included adsorption and biodegradation coefficients (Tables 7, 8, and 9). Output from the MT3D simulation expressed in plan view for a $50-\mathrm{mg} / \mathrm{m}^{3}$ iso-surface is shown in Figure 58 for days $27,132,242$, and 328 . The simulated $50-\mathrm{mg} / \mathrm{m}^{3}$

iso-surface is shown in oblique view in Figure 59 for days 27, 132, 234, and 328. Figure 60 shows an oblique view of the $5-\mathrm{mg} / \mathrm{m}^{3}$ o-DCB iso-surface at days $27,132,224$, and 328 . Figure 61 shows the vertical and longitudinal extent of the observed plumes of o-dichlorobenzene at 27, 132, 224, and 328 days (Boggs et al. 1993). Note that the observed plumes are given as nondimensional relative concentration $\left(\mathrm{C} / \mathrm{C}_{0}\right)$.

The simulated o-dichlorobenzene plume showed behavior similar to that of benzene. This behavior contradicts the observed data (Figure 61), which shows that the o-DCB plume is similar to the tritium plume for the first 132 days. After the first 132 days, the observed plume deviates from the tritium behavior and shows spatial discontinuity. As can be seen from the figures of the simulated and observed o-dichlorobenzene plumes at 27, 132, 224, and 328 days (Figures 59 and 61), the simulation was not able to match the observed data for any period beyond the first 27 days. Piezometric data show that at approximately day 203 of the simulation, the piezometric head is at its highest since the beginning of the monitoring. Because only steady-state flow was conducted, the flow input to the model lacks the seasonal fluctuation in the water table required to get a better simulation. When the simulated and observed plumes are compared, several observations as to the relative agreement between the plumes can be made. At day 27, the simulated and observed plumes agree well with each other. The observed $50-\mathrm{mg} / \mathrm{m}^{3}$ plume has progressed downgradient approximately $25 \mathrm{~m}$ from the injection point. The simulated $50-\mathrm{mg} / \mathrm{m}^{3}$ plume has also moved approximately $25 \mathrm{~m}$ from the injection point. At day 132, the observed plumes progressed further downgradient than the simulated plumes when comparing the $50-\mathrm{mg} / \mathrm{m}^{3}$ and $5-\mathrm{mg} / \mathrm{m}^{3}$ iso-surfaces. The simulated $5-\mathrm{mg} / \mathrm{m}^{3}$ plume has moved approximately $28 \mathrm{~m}$ from the injection point, while the observed plume has moved approximately $65 \mathrm{~m}$. At day 224 , the simulated and observed $50-\mathrm{mg} / \mathrm{m}^{3}$ and $5-\mathrm{mg} / \mathrm{m}^{3}$ iso-surfaces are considerably different. The $50-\mathrm{mg} / \mathrm{m}^{3}$ observed and simulated plumes have 

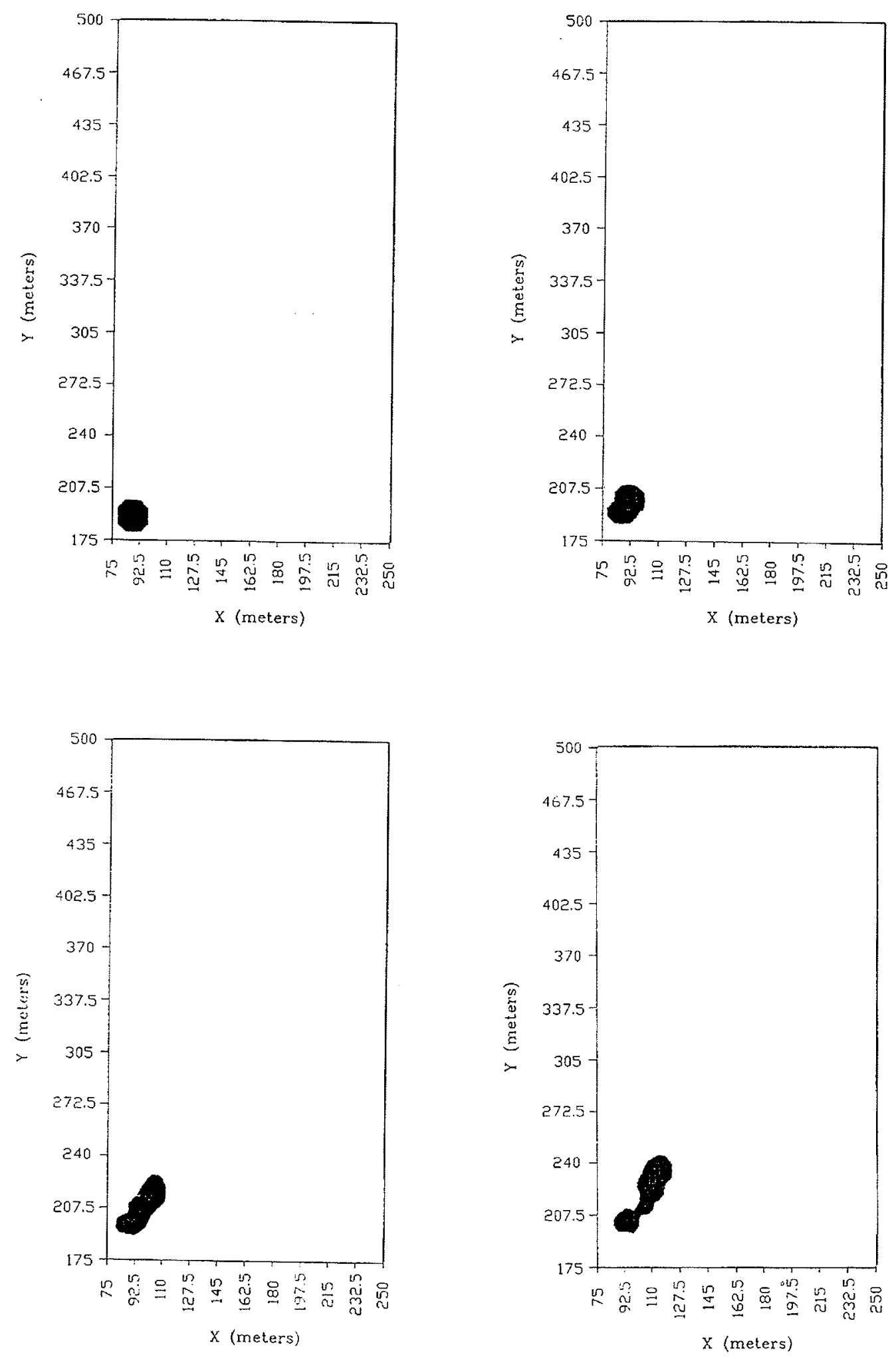

Figure 58. Plan view of simulated $50-\mathrm{mg} / \mathrm{m}^{3}$ o-DCB iso-surface at a) day 27 , b) day $132, \mathrm{c}$ ) day 234 , and d) day 328 


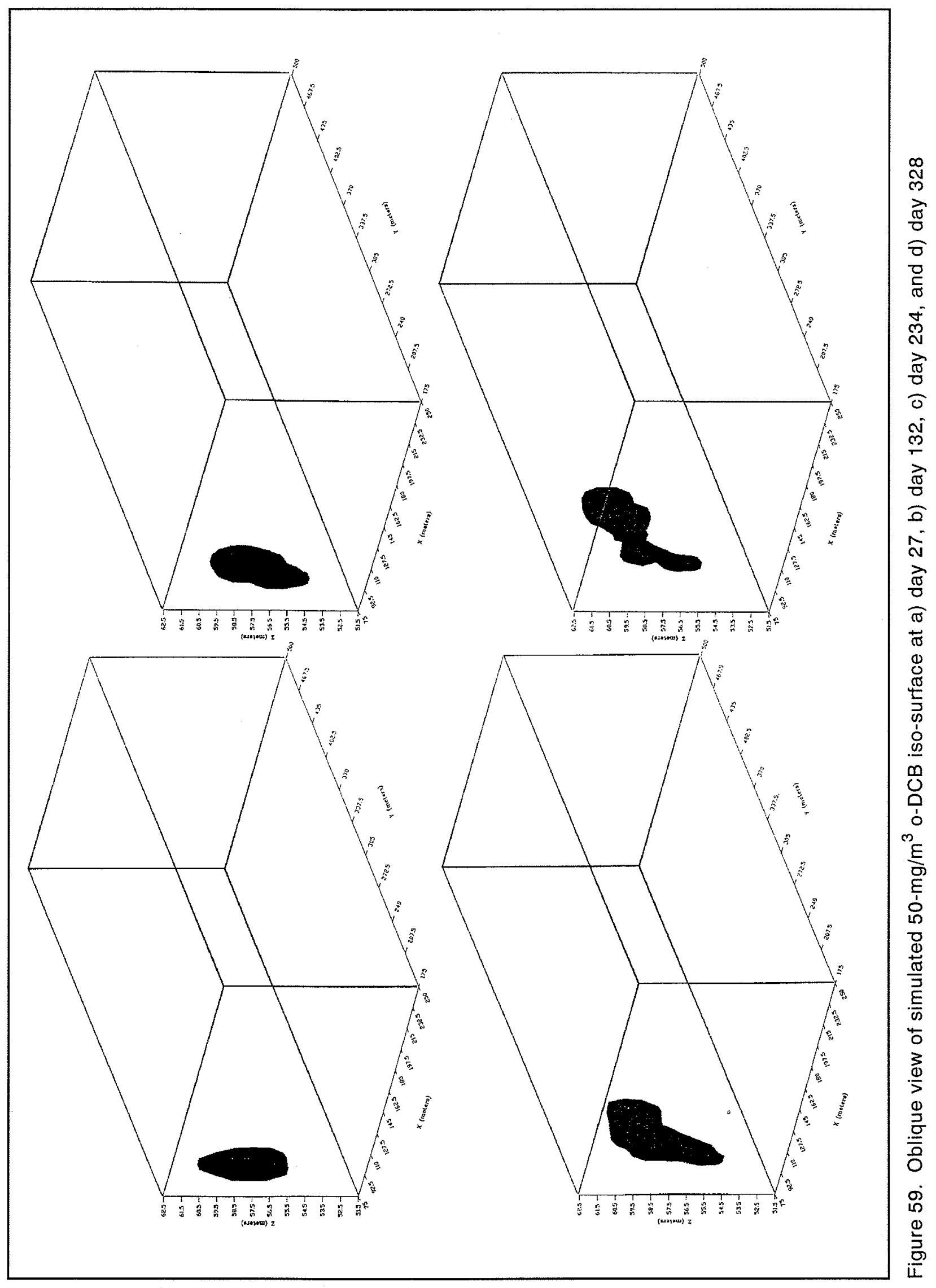




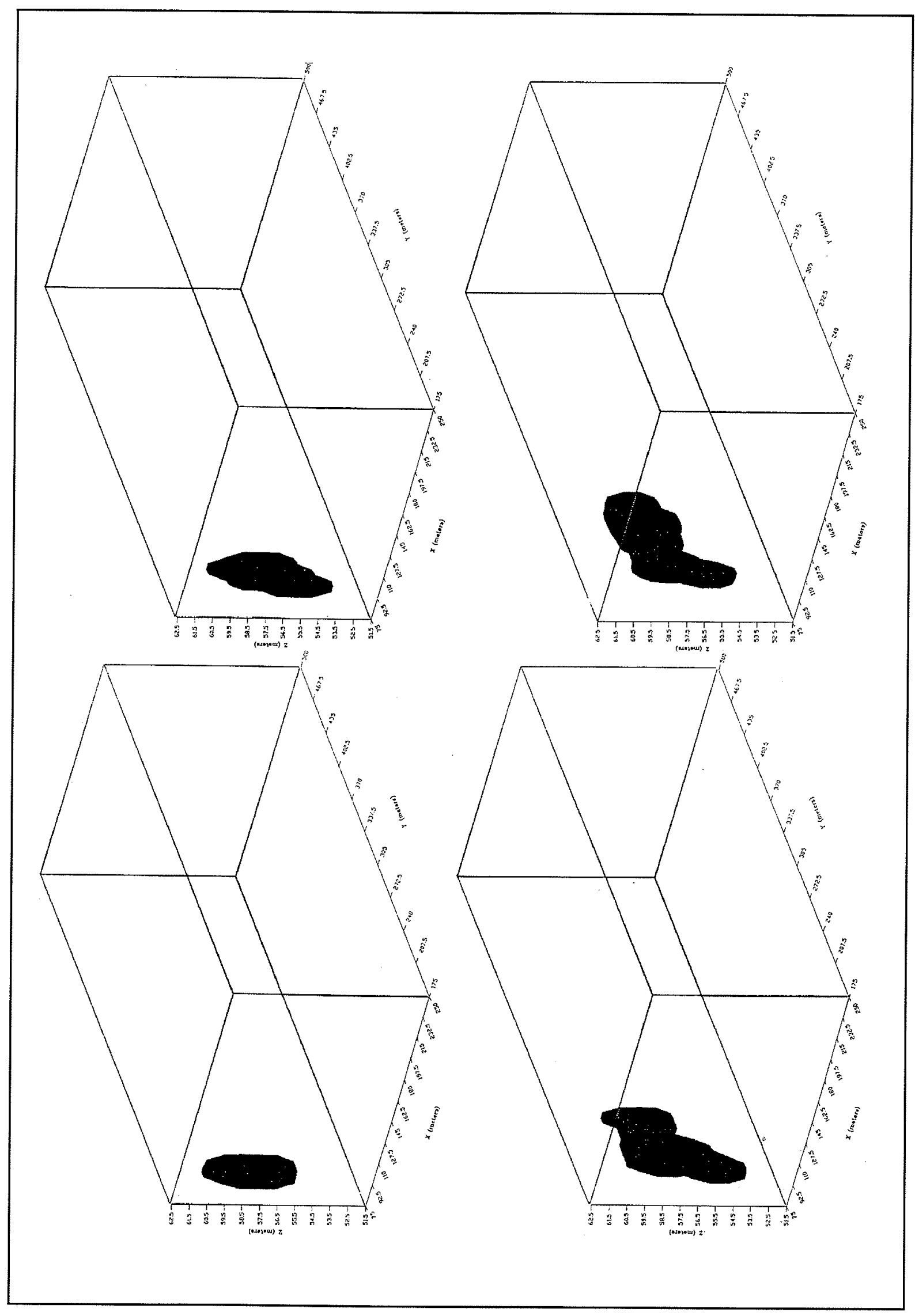

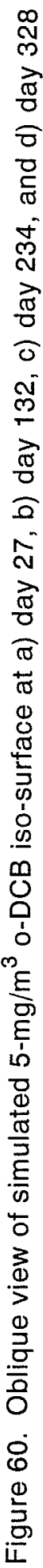




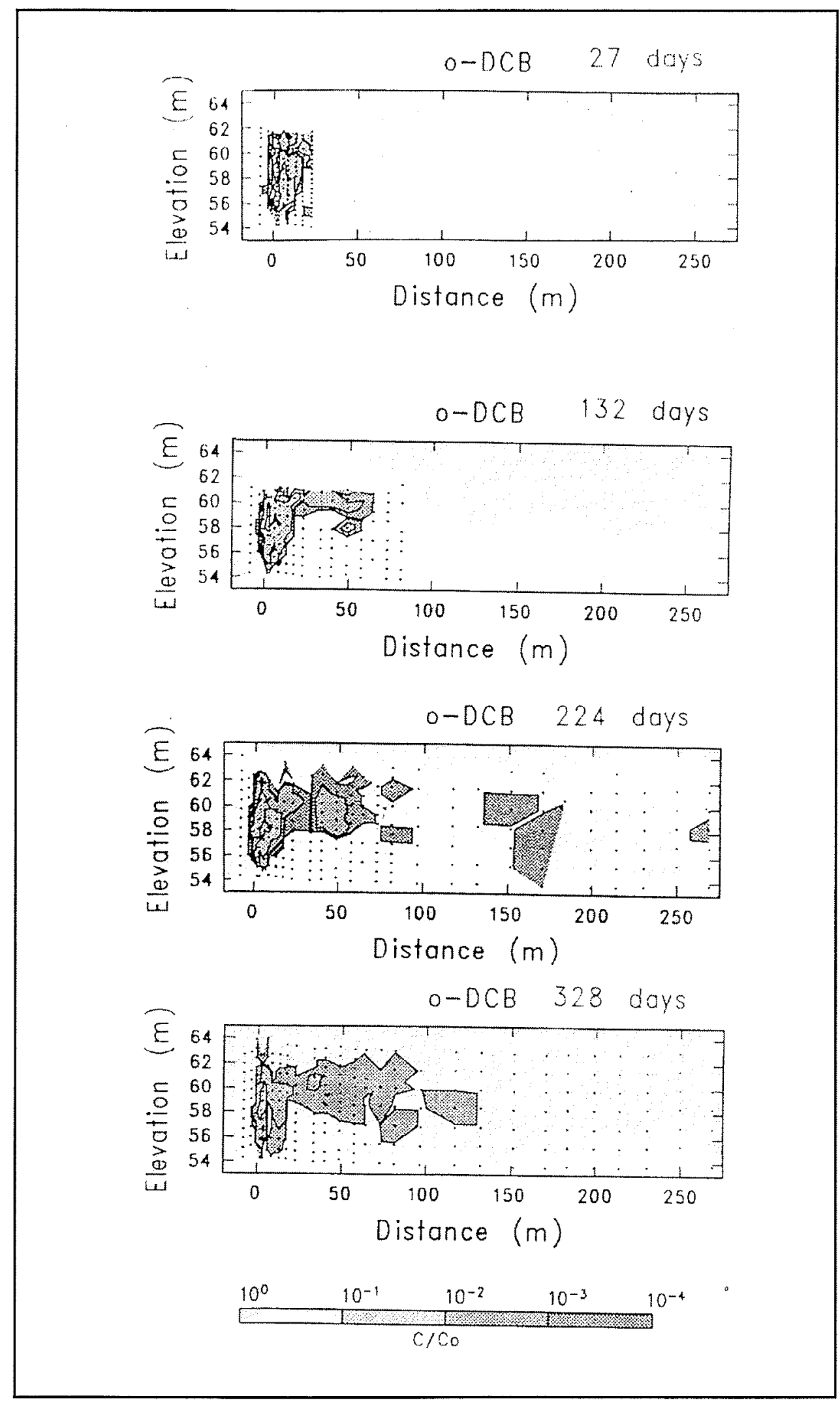

Figure 61. Observed vertical and longitudinal extent of o-DCB plume at 27,132 , 224 , and 328 days 
reached a downgradient extent of approximately $60 \mathrm{~m}$ from the initial point of injection.

The simulated $5-\mathrm{mg} / \mathrm{m}^{3}$ iso-surface has moved approximately $70 \mathrm{~m}$ from the injection point, while the observed plume has moved downgradient in excess of $260 \mathrm{~m}$ from the injection point. At day 328, the observed $50-\mathrm{mg} / \mathrm{m}^{3}$ iso-surface shows the observed plume at approximately $40 \mathrm{~m}$ from the injection point, while the simulated plume has extended to approximately $75 \mathrm{~m}$ from the source. The $5-\mathrm{mg} / \mathrm{m}^{3}$ simulated and observed iso-surfaces show the simulated plume having traveled approximately $85 \mathrm{~m}$ from the injection point, while the observed plume has traveled approximately $130 \mathrm{~m}$ from the injection point.

\section{Simulation of naphthalene}

Naphthalene transport through the MADE system was simulated for a period of 328 days. Input parameters included adsorption and biodecay coefficients. Output from the MT3D simulation was expressed in graphs of concentration. A plan view for a $7-\mathrm{mg} / \mathrm{m}^{3}$ iso-surface is shown in Figure 62 for days $27,132,242$, and 328 . The simulated $50-\mathrm{mg} / \mathrm{m}^{3}$ iso-surface is shown in an oblique view in Figure 63 for days 27, 132, 234, and 328. Figure 64 shows the oblique view of the $0.7-\mathrm{mg} / \mathrm{m}^{3}$ naphthalene iso-surface at days $27,132,224$, and 328 , respectively. The measured normalized concentration of naphthalene (Boggs et al. 1993) in the vertical and longitudinal extent at 27,132, 224, and 328 days is shown in Figure 65. The simulated naphthalene plume showed behavior similar to that of the observed plume, but again fails to reproduce the downgradient spreading in the observed data.

The simulated naphthalene plumes matched the observed concentration plume reasonably well until day 224 , after which the observation lagged the simulation. At day 328 , the simulated $7-\mathrm{mg} / \mathrm{m}^{3}$ and $0.7-\mathrm{mg} / \mathrm{m}^{3}$ iso-surfaces had still traveled further than the observed corresponding plumes, but had shown a tendency to remain in place since that time by moving approximately $10 \mathrm{~m}$ further downgradient over a period of 104 days. At day 27 , the simulated and observed plumes agree well with each other. The observed $7-\mathrm{mg} / \mathrm{m}^{3}$ plume has progressed downgradient approximately $25 \mathrm{~m}$ from the injection point.

The simulated $7-\mathrm{mg} / \mathrm{m}^{3}$ plume has moved approximately $20 \mathrm{~m}$ from the injection point. The simulated $0.7-\mathrm{mg} / \mathrm{m}^{3}$ plume has moved approximately $25 \mathrm{~m}$ from the injection point, while the observed $0.7-\mathrm{mg} / \mathrm{m}^{3}$ plume has moved approximately $25 \mathrm{~m}$. At day 132, the simulated plumes have 。 progressed further downgradient than the observed plumes when comparing the $7-\mathrm{mg} / \mathrm{m}^{3}$ and $0.7-\mathrm{mg} / \mathrm{m}^{3}$ iso-surfaces. The simulated $7-\mathrm{mg} / \mathrm{m}^{3}$ plume has moved approximately $28 \mathrm{~m}$ from the injection point while the observed plume has moved approximately $15 \mathrm{~m}$. At day 224 , the simulated and observed $7-\mathrm{mg} / \mathrm{m}^{3}$ and $0.7-\mathrm{mg} / \mathrm{m}^{3}$ iso-surfaces are slightly different. The simulated $7-\mathrm{mg} / \mathrm{m}^{3}$ plume has reached a downgradient extent of 


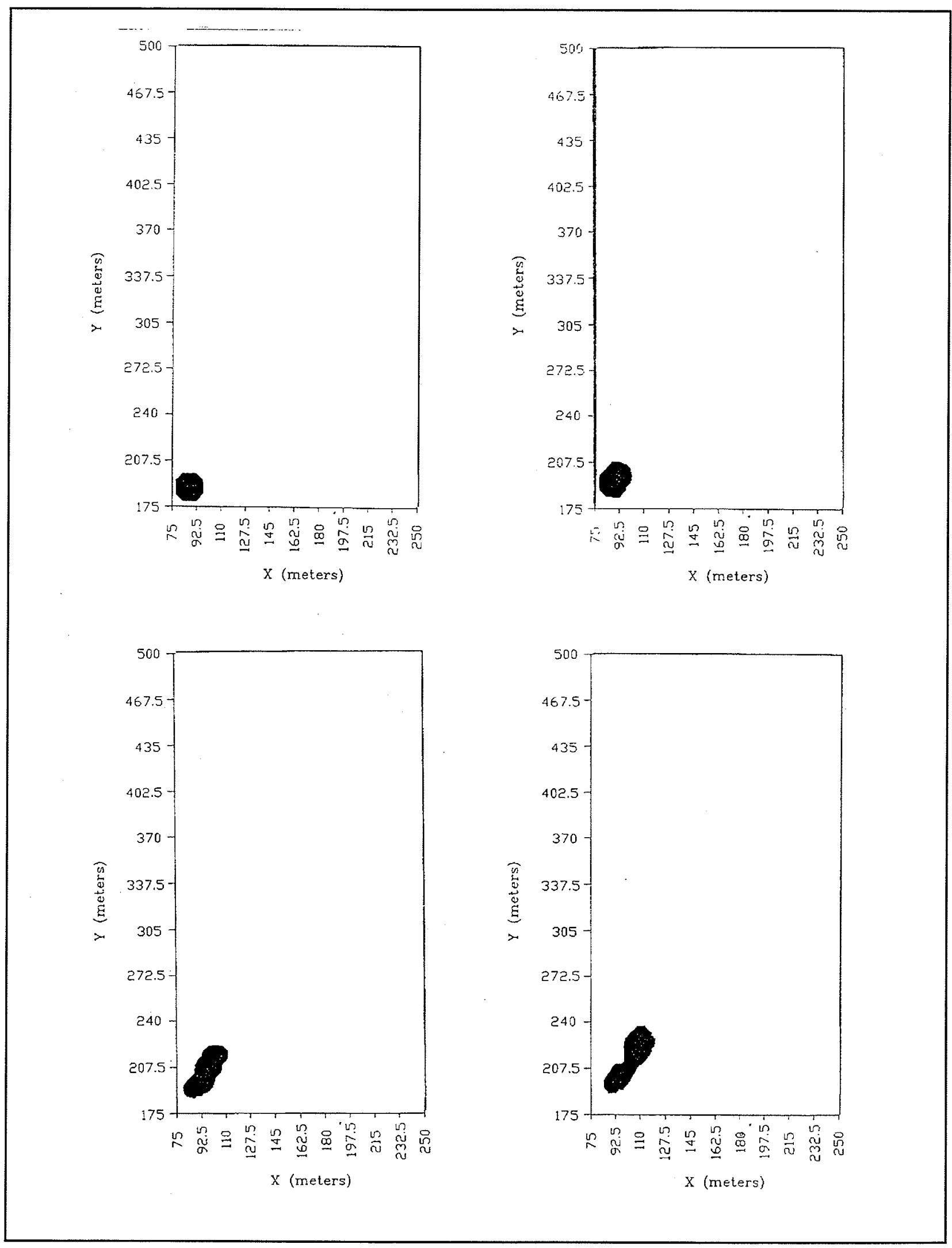

Figure 62. Plan view of simulated $7-\mathrm{mg} / \mathrm{m}^{3}$ naphthalene iso-surface at a) day 27 , b) day 132 , c) day 234 , and d) day 328 


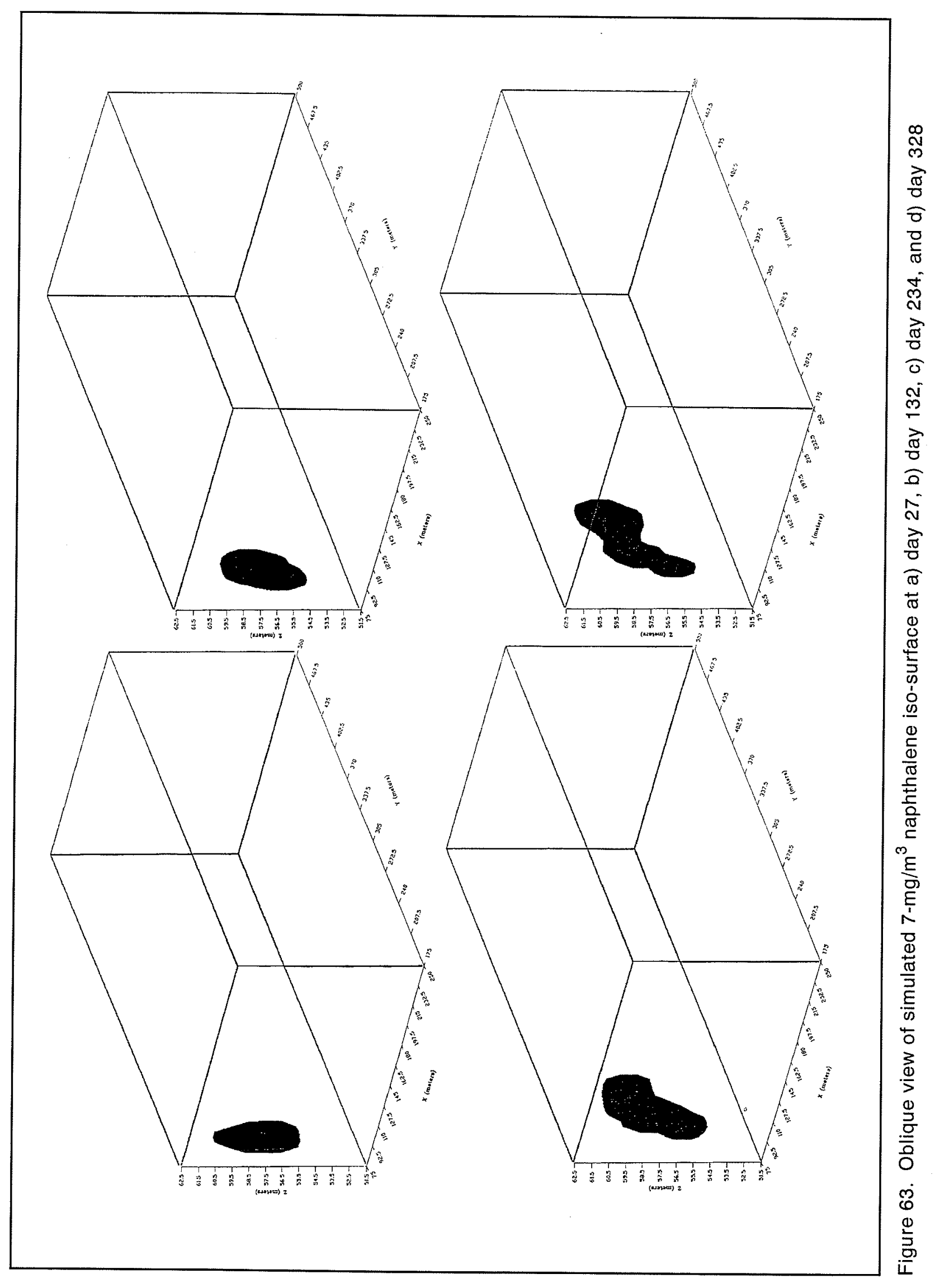




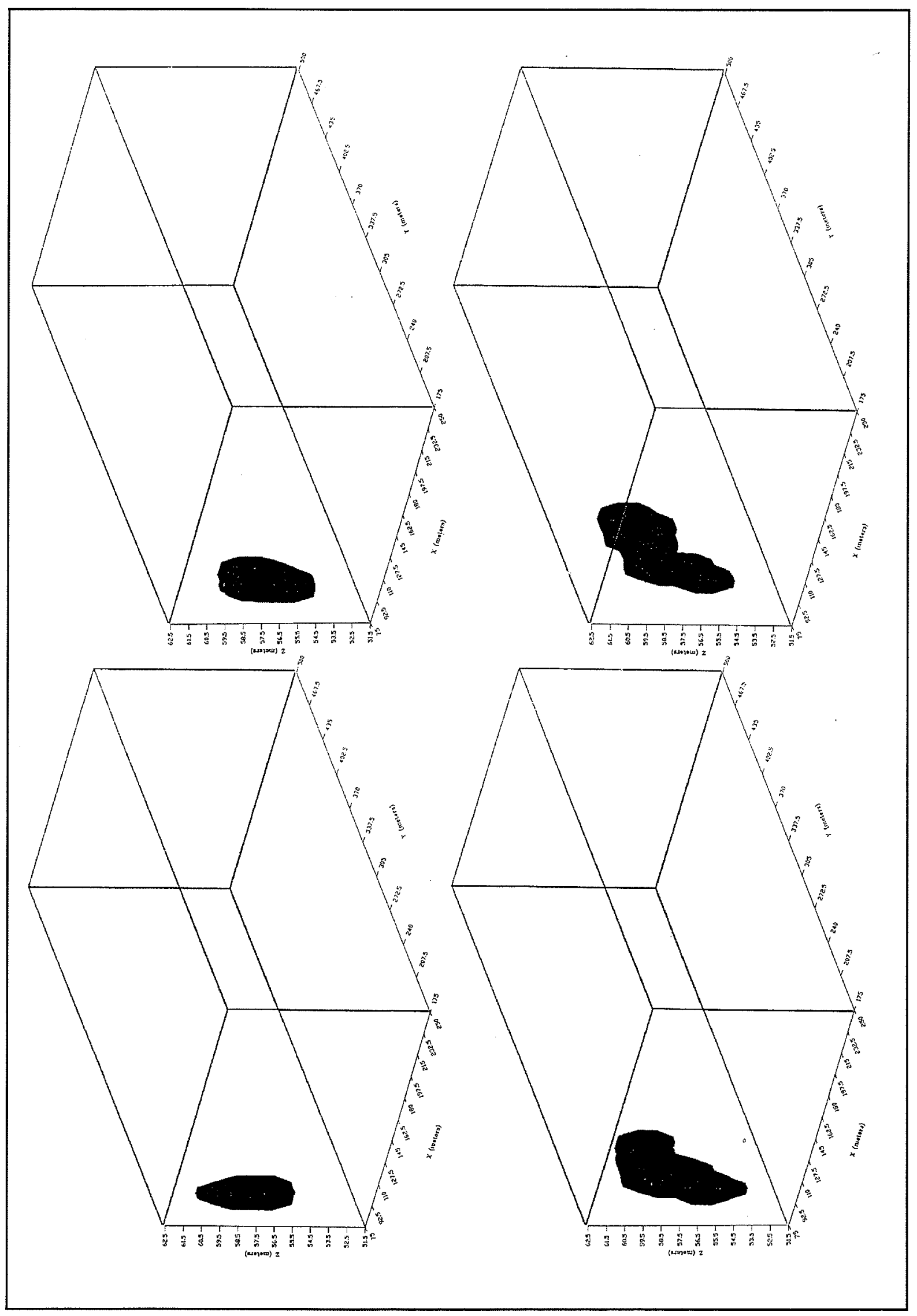

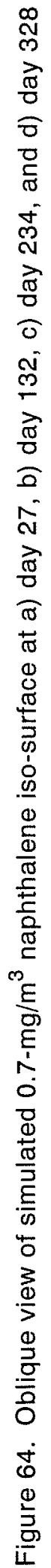




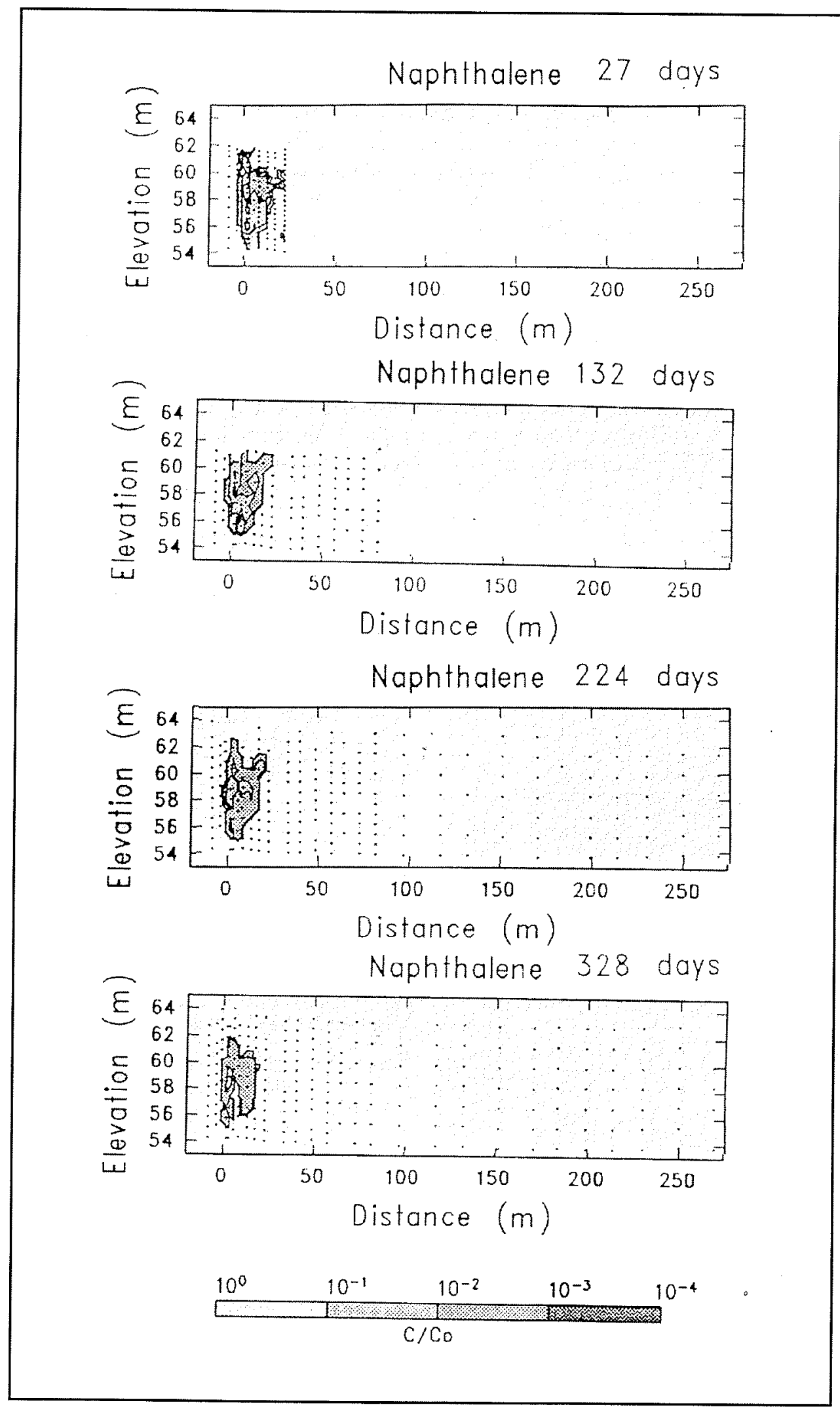

Figure 65. Observed vertical and longitudinal extent of naphthalene plume at 27 , 132,224 , and 328 days 
approximately $50 \mathrm{~m}$ from the initial point of injection, while the observed $7-\mathrm{mg} / \mathrm{m}^{3}$ plume has remained at approximately $15 \mathrm{~m}$ from the source. The simulated $0.7-\mathrm{mg} / \mathrm{m}^{3}$ iso-surface has moved approximately $60 \mathrm{~m}$ from the injection point, while the observed plume has moved downgradient approximately $25 \mathrm{~m}$ from the injection point. At day 328 , the observed $7-\mathrm{mg} / \mathrm{m}^{3}$ iso-surface shows the observed plume has moved approximately $20 \mathrm{~m}$ from the injection point, while the simulated plume has extended to approximately $65 \mathrm{~m}$ from the source. The $0.7-\mathrm{mg} / \mathrm{m}^{3}$ simulated and observed iso-surfaces show the simulated plume having traveled approximately $75 \mathrm{~m}$ from the injection point, while the observed plume has traveled approximately $20 \mathrm{~m}$ from the injection point.

Figure 66 shows the GMS input screen for point sources and shows the injection concentration $\left(7,230 \mathrm{mg} / \mathrm{m}^{3}\right)$ applied for the simulation of naphthalene. A linear adsorption was assumed for naphthalene. A view of the GMS/MT3D chemical reaction package is shown in Figure 67.

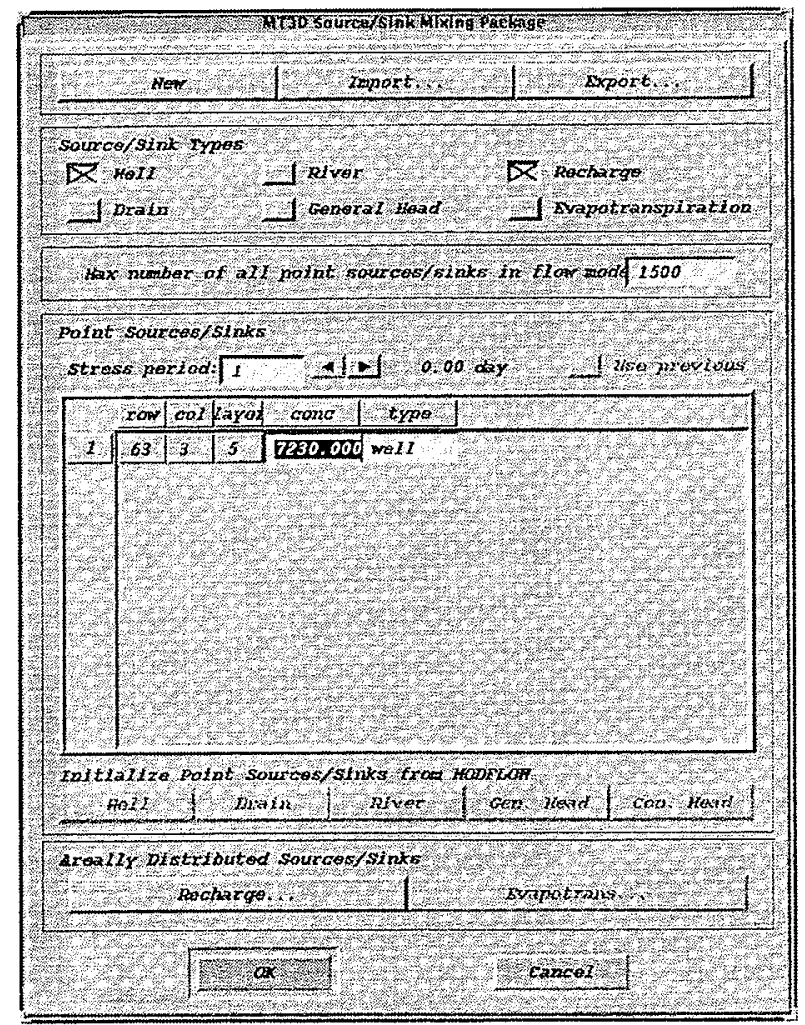

Figure 66. View of GMS/MT3D point source entry screen

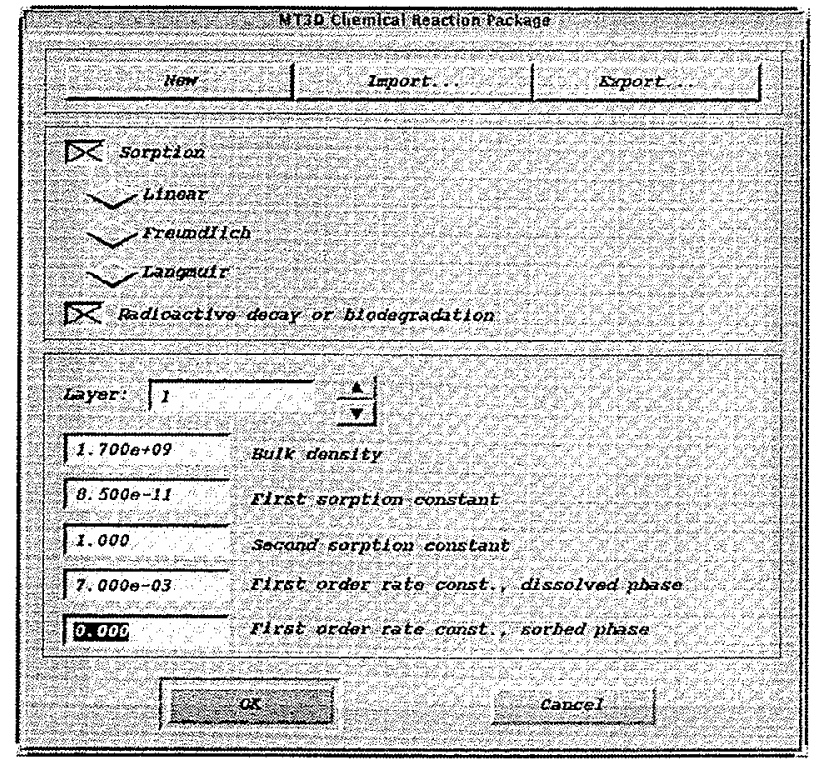

Figure 67. View of GMS/MT3D chemical reaction package entry screen 


\section{MT3D Model Calibration}

Generally, the calibration of the flow model has been sufficient and provided reasonable input for the transport model. In the flow model (Chapter 5), the model was calibrated for total head distribution. In the transport model, some of the input parameters were changed in order to reproduce observed plume behavior.

Advection and dispersion were two main causes of the plume spreading at the site. The initial phase of the simulation process used advection and dispersion. When dispersion was simulated, the contaminant plumes dispersed too quickly. Another observation was that the plume moved backward from the natural gradient in such a manner that it would leave the domain of the simulation grid. Thus, modeling was conducted using advection alone because it was believed that the spatial variability of the hydraulic conductivity of the study site would compensate. When dispersion was eliminated, the problem with the spreading of the plume against the natural gradient and outside the domain of the simulation grid was avoided. Advection alone was able to reproduce reasonably well the general shape of the tritium contaminant plume up until approximately day 224. This day roughly coincides with the increased seasonal fluctuation of the water table (see Appendix B).

Table 10 shows the relative distance between the injection location and selected gauge locations in layer 6 of the simulation grid.

\begin{tabular}{|c|c|}
\hline \multicolumn{2}{|c|}{$\begin{array}{l}\text { Table } 10 \\
\text { Relative Distance of Gauge Points from Injection Point for Layer } 6\end{array}$} \\
\hline Gauge Number & Distance, $\mathrm{m}$ \\
\hline 19 & 16 \\
\hline 32 & 8 \\
\hline 45 & 13 \\
\hline 100 & 29 \\
\hline
\end{tabular}

The observed and simulated time-series of tritium concentration at gauge (well) points 19 and 32 are shown in Figures 68 and 69, respectively. Figures 70 and 71 compare observed and simulated concentrations of naphthalene at gauge points 45 and 100 , respectively. 


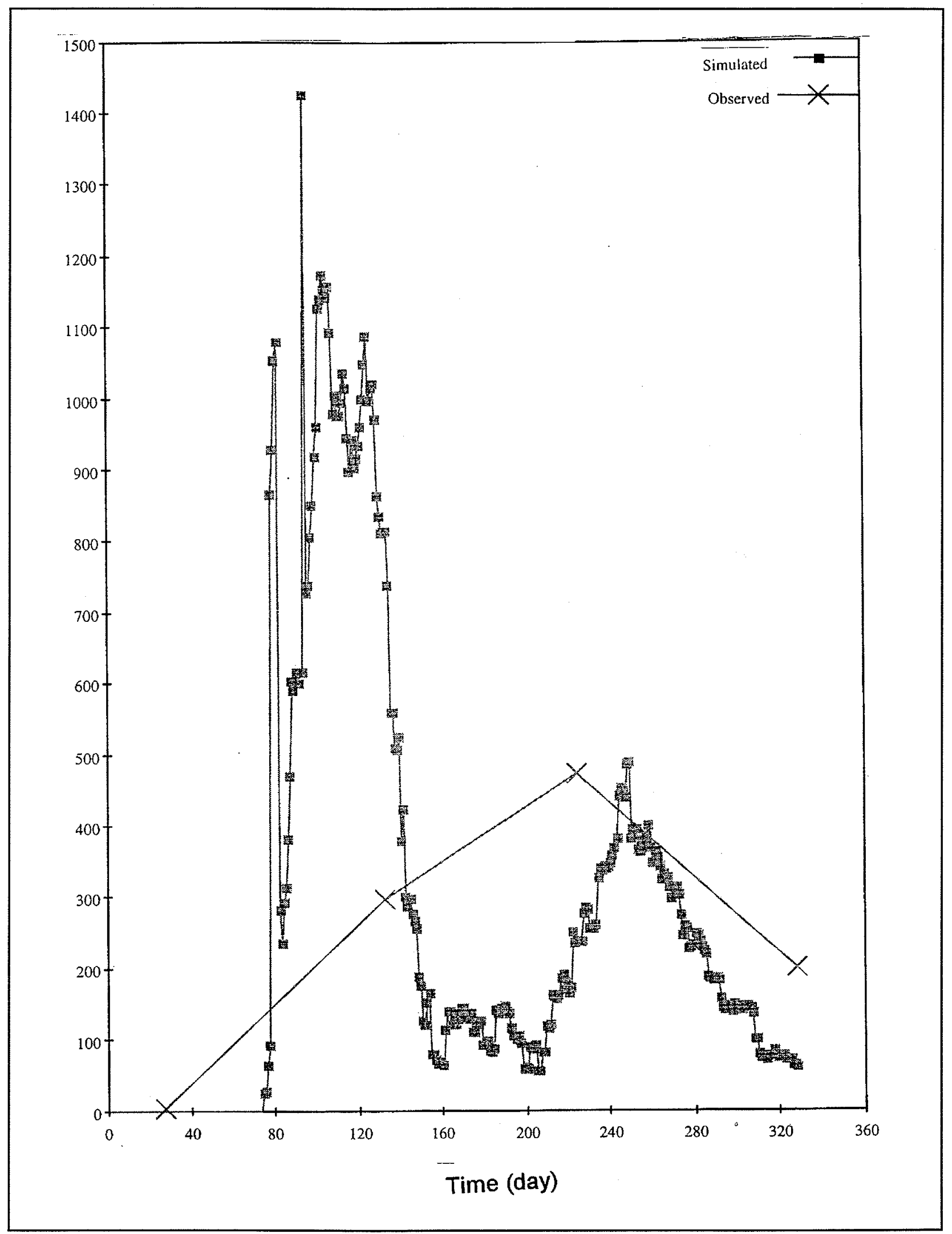

Figure 68. Comparison of observed and simulated concentration of tritium at gauge point 19 and layer 6 of the grid 


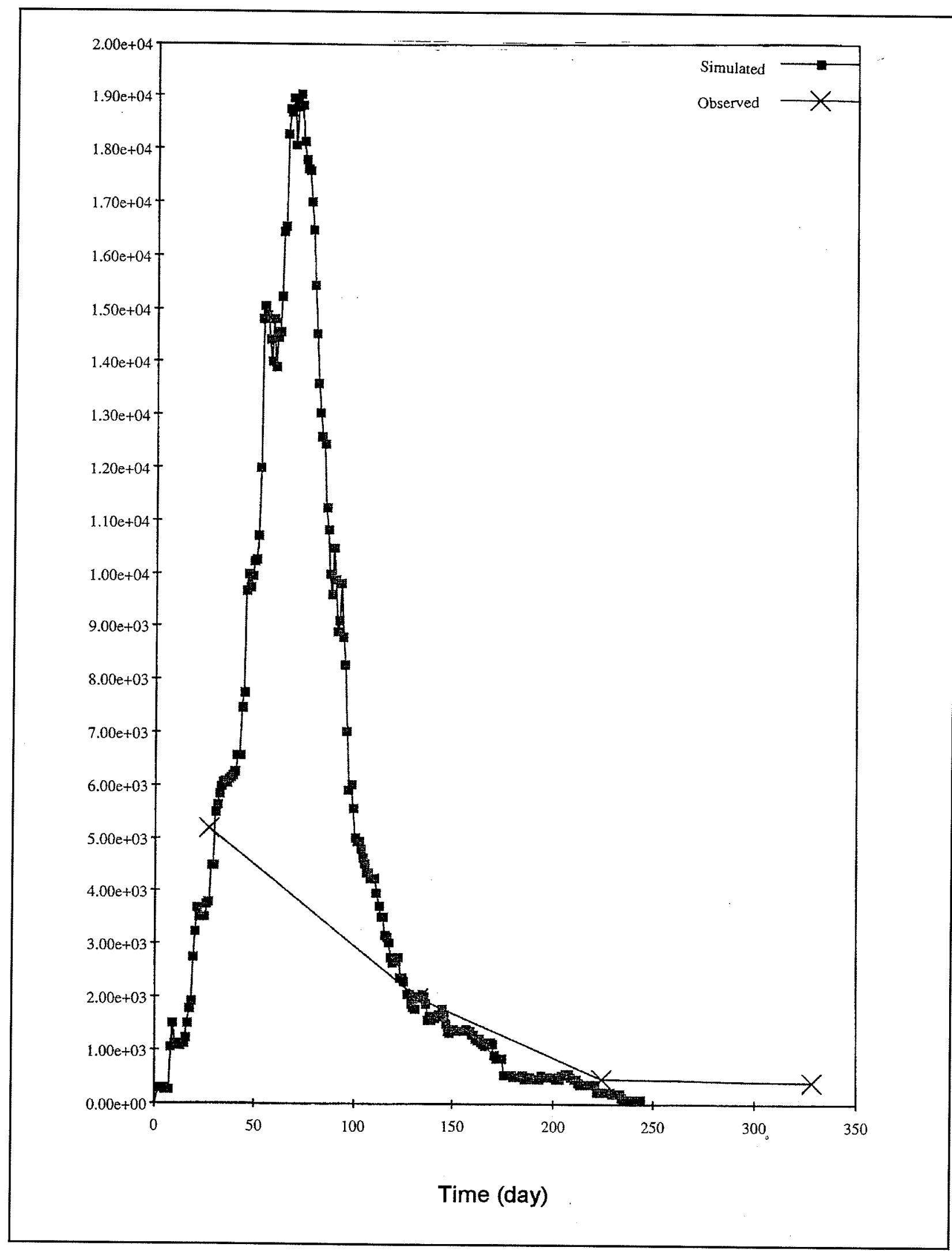

Figure 69. Comparison of observed and simulated concentration of tritium at gauge point 32 and layer 6 of the grid 


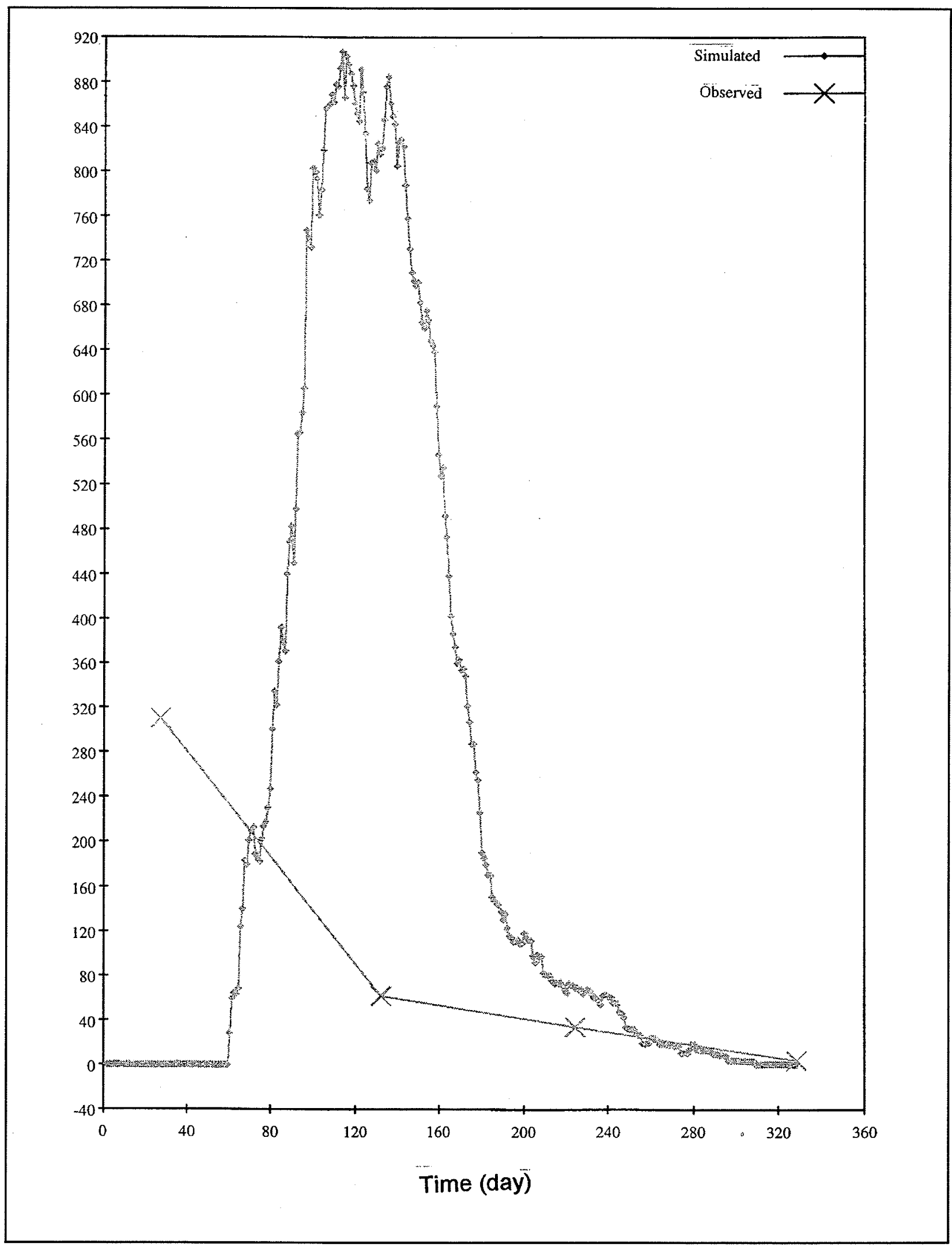

Figure 70. Comparison of observed and simulated concentration of naphthalene at gauge point 45 and layer 6 of the grid 


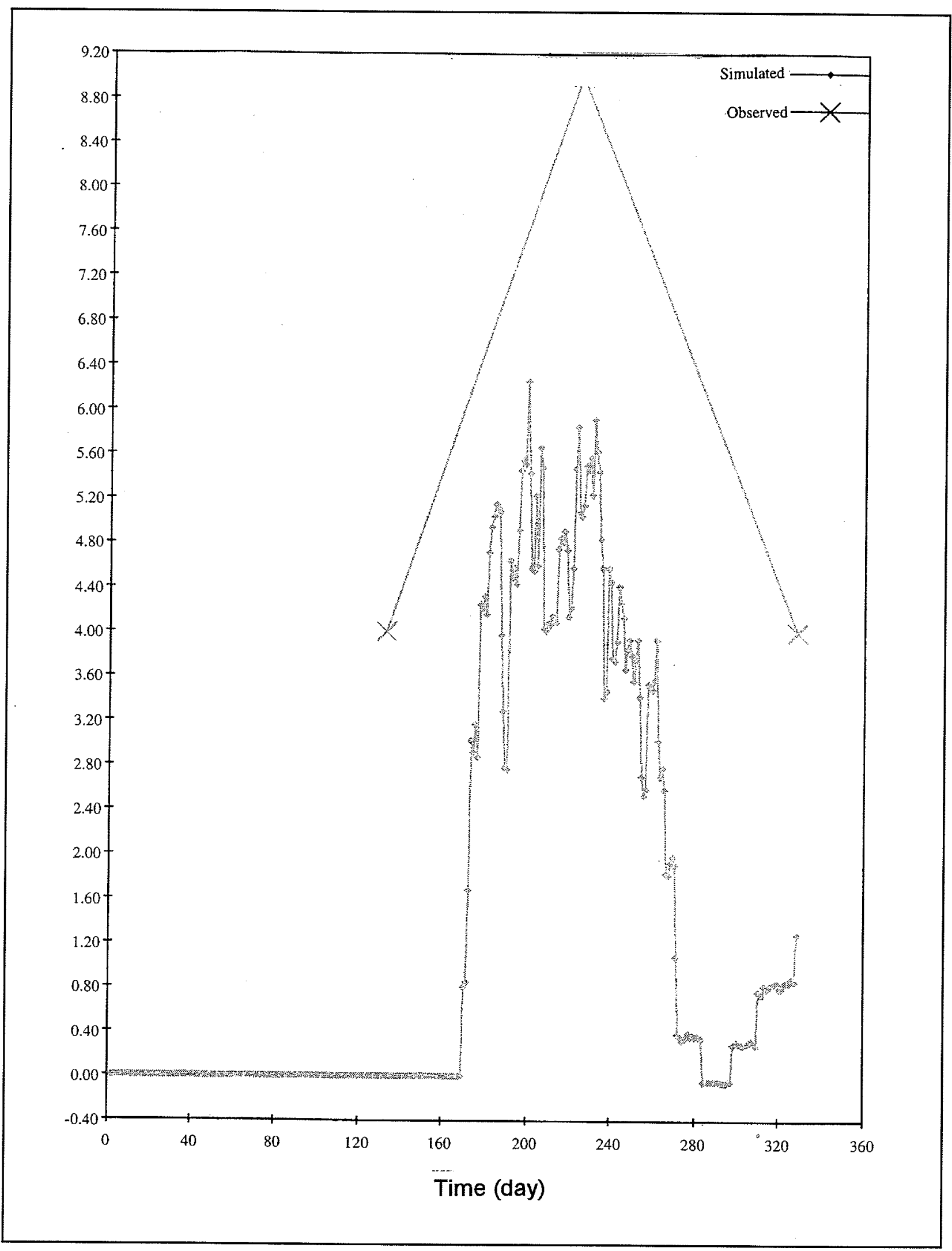

Figure 71. Comparison of observed and simulated concentration of naphthalene at gauge point 100 and layer 6 of the grid 


\section{Sensitivity Analysis}

\section{Hydraulic conductivity}

The distribution of hydraulic conductivity values has major effects on the flow and transport. The effect of decreasing the hydraulic conductivity by a factor of 10 in the immediate cells surrounding the injection point was investigated. With this change to the hydraulic conductivities and the corresponding leakance, the contaminant plumes demonstrated a tendency for the maximum concentration to remain within a few meters of the injection site. Likewise, the fringes of the plumes failed to move as far downstream as before due to extended retention time in the low-conductivity zone.

\section{Porosity}

The effect of changing the porosity in several sections of the aquifer was evaluated. The MT3D simulation grid was divided into four sections for layers 1 through 6 , as shown in Figure 72. A tritium simulation was conducted with a three-tiered porosity change to see the effect of changing the porosity. The porosity in the area immediately above the center line was set to 0.2 and that immediately below the middle line to 0.10 (remaining areas in the near-field and far-field were set to 0.31 ). The effect of this was to move the front of the plume further downgradient than in the simulations, with only a two-tiered or single value for porosity. The simulation conducted with this three-tiered approach moved the tritium plume approximately $30 \mathrm{~m}$ further downgradient than in the two-tiered approach. Figure 73 shows the extent of the tritium plume with this three-tiered approach to porosity at day 328 .

\section{Recharge}

The effect of recharge rates was examined in the MODFLOW discussion (Chapter 5). The recharge rate was increased from $0.07 \mathrm{~m} /$ year to 0.26 $\mathrm{m} /$ year. The effect of the recharge rate on the transport results was minor. Figure 74 shows that the plume's shape changed slightly with little effect on downgradient extent.

\section{First-order decay rate}

The first-order decay rate (biodegradation) was increased from $0.007 /$ day to 0.010 /day and MT3D/GMS was used to compute and illustrate differences between the results. The 43-percent increase in the biodegradation rate caused the maximum concentration during the 328-day simulation to decrease by 2.5 percent. Figure 75 shows the difference 


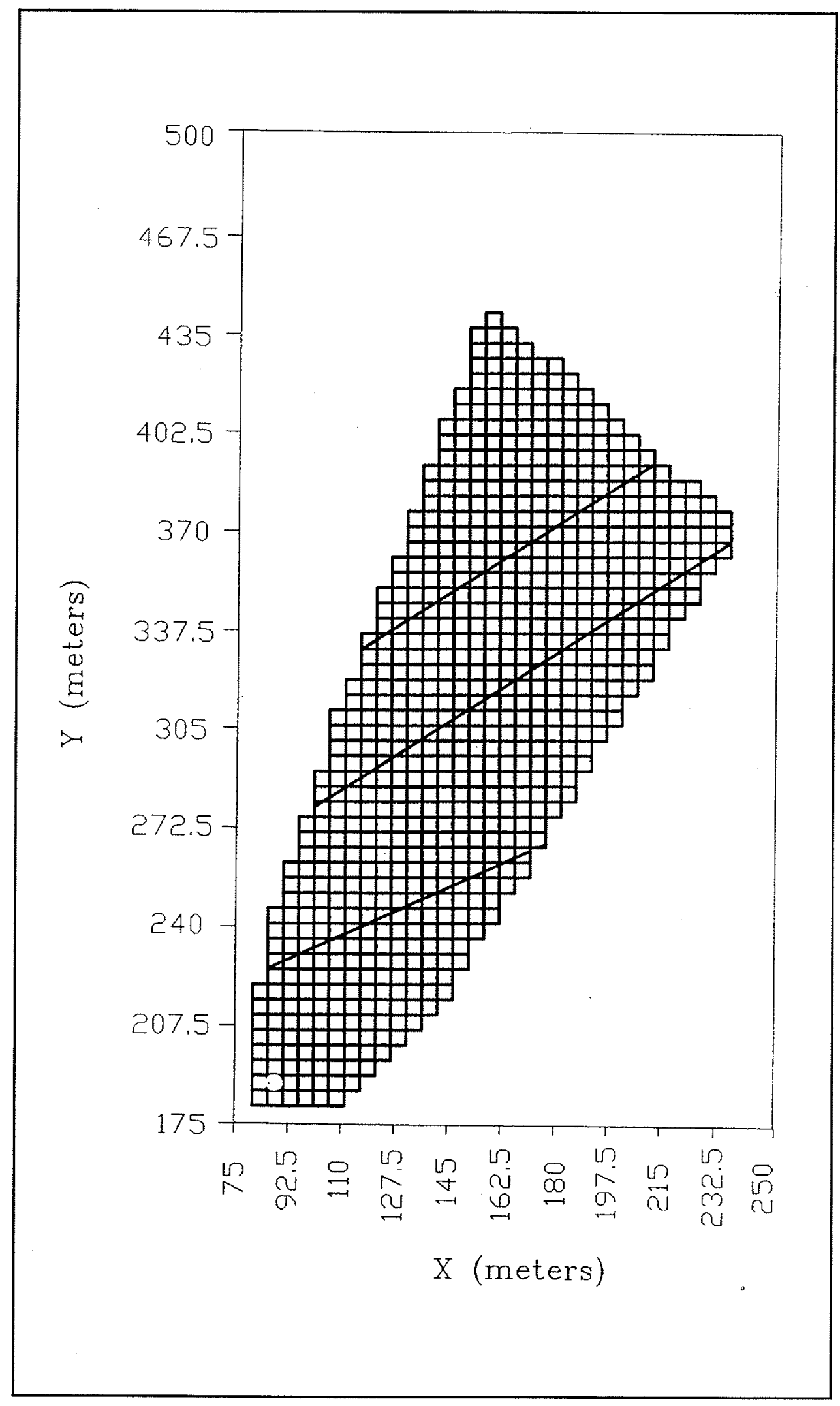

Figure 72. Sensitivity analysis using distributed porosities of $0.31,0.2,0.1$, and 0.31 from top to bottom in plan view 


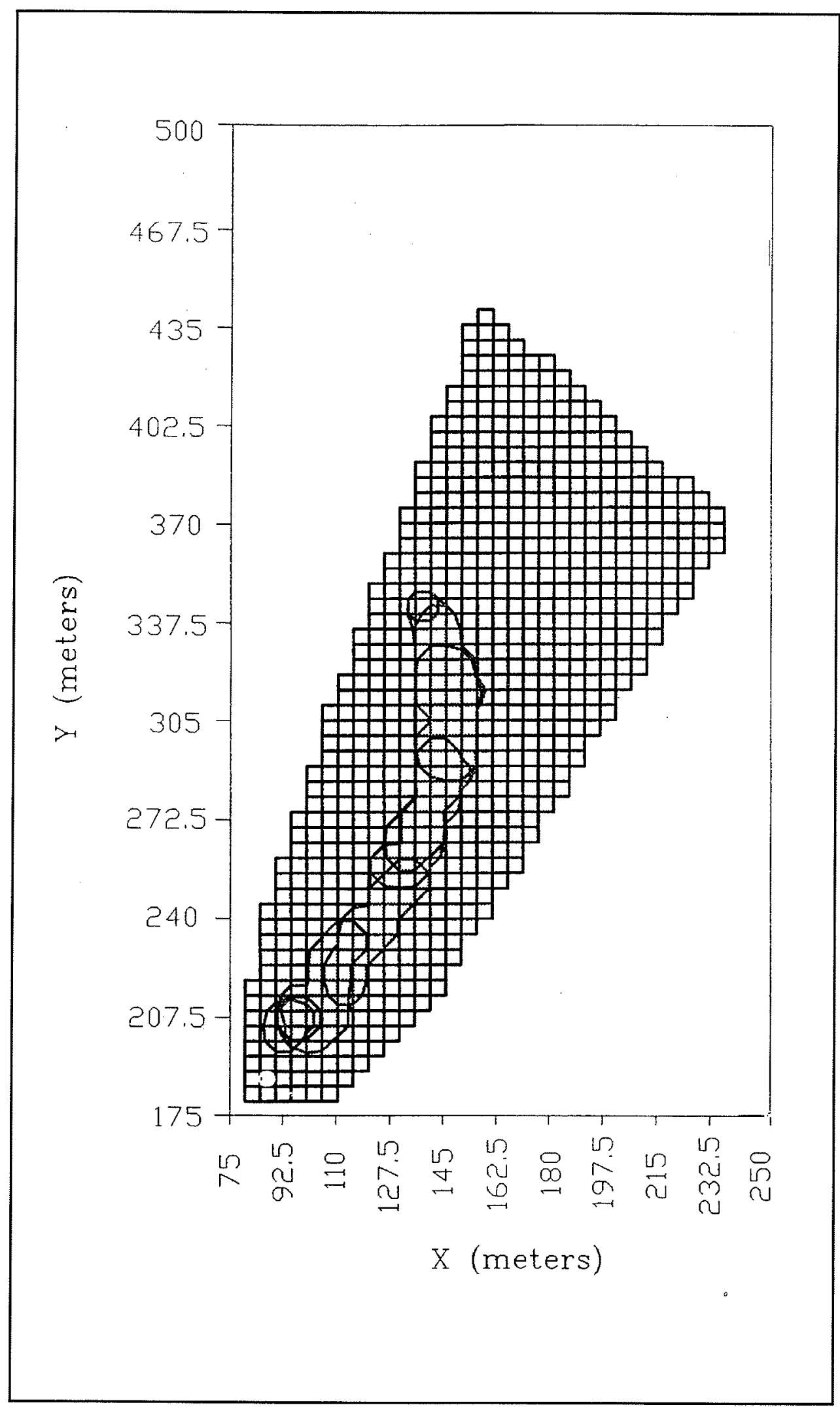

Figure 73. Simulated tritium plume distribution at day 328 using porosity distribution of Figure 72 


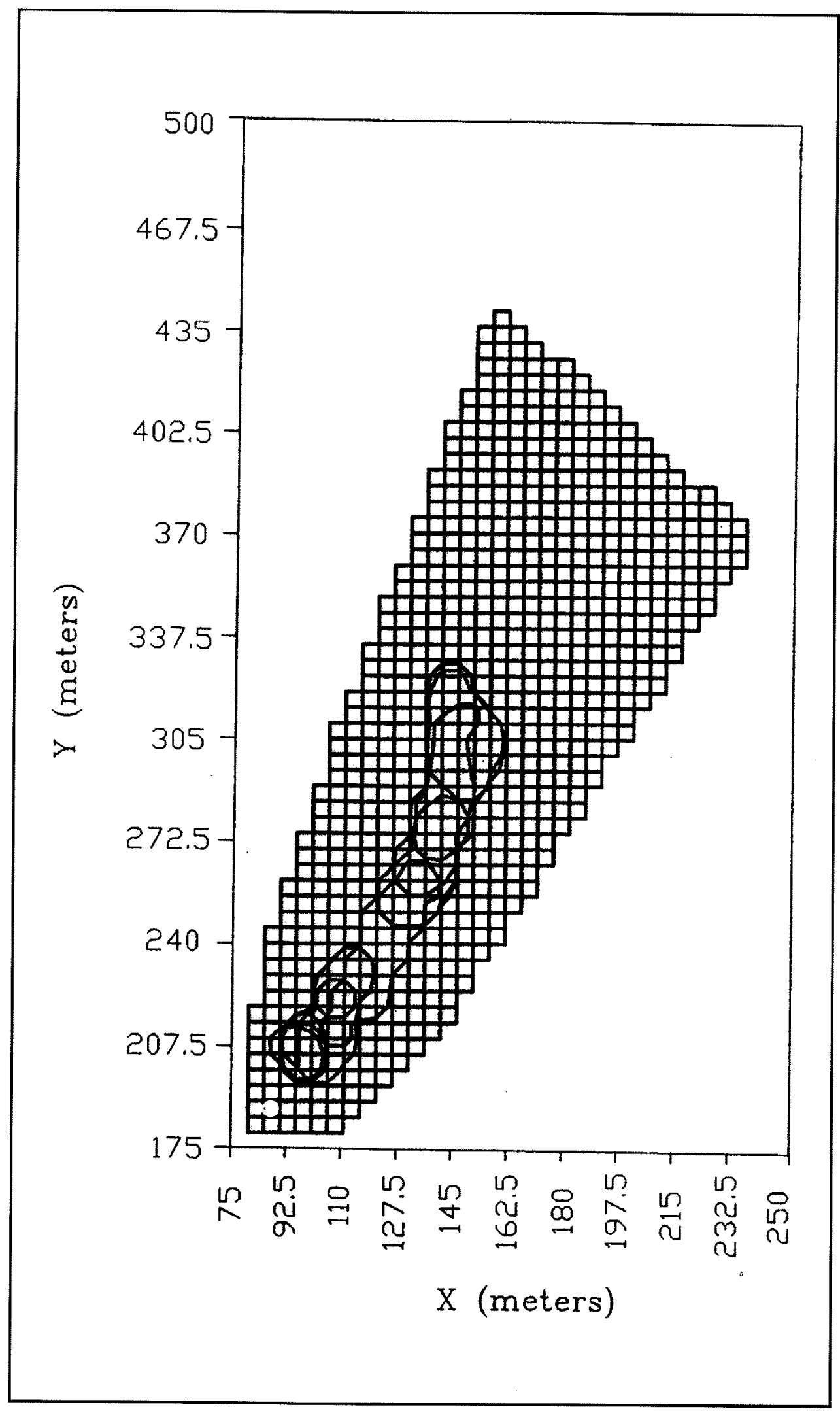

Figure 74. Simulated tritium plume distribution at day 328 with increased infiltration rate 


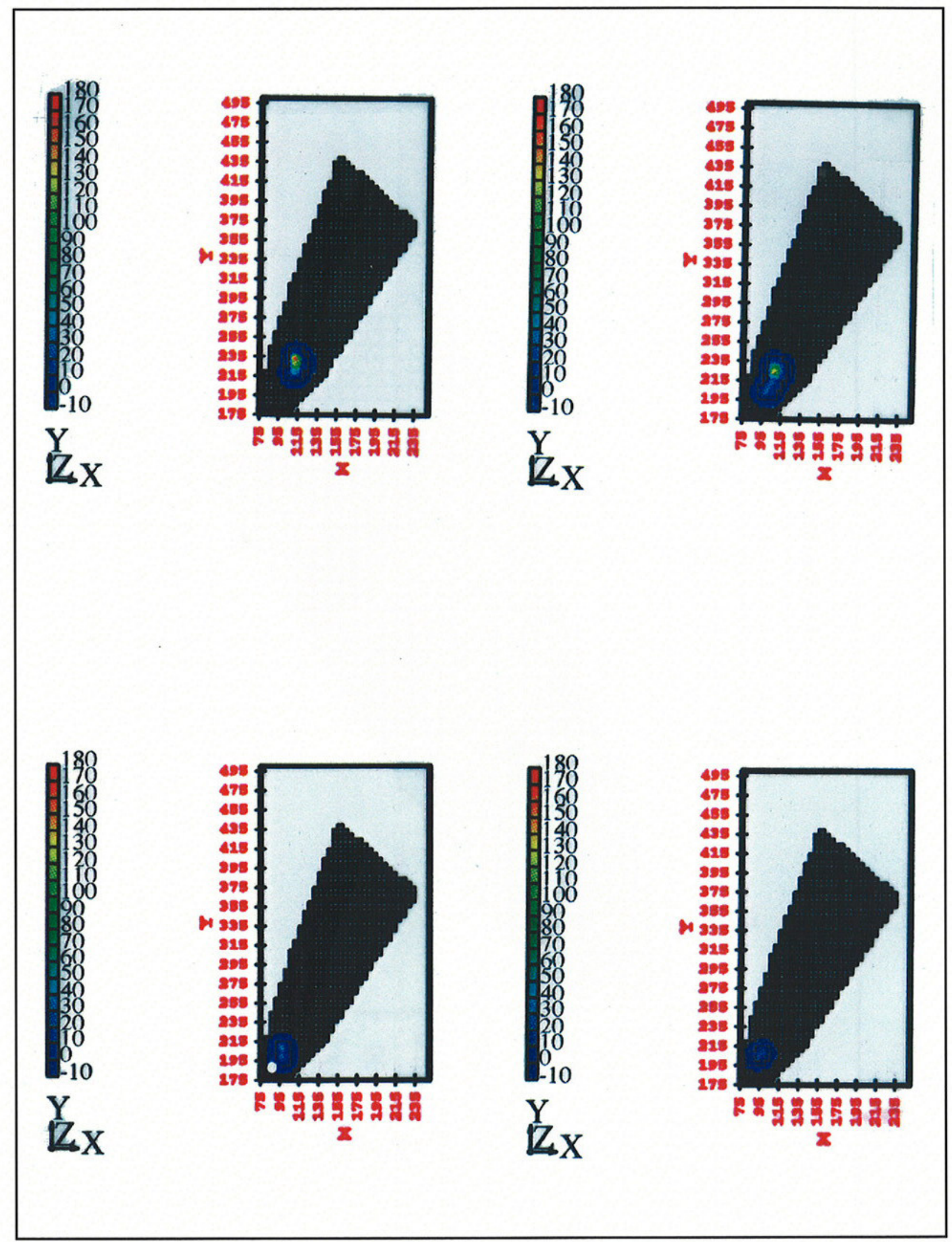

Figure 75. Naphthalene concentration change due to an increase in the biodegradation rate. from 0.007 to $0.010 /$ day for a) layer 3, b) layer 4, c) layer 5 , and d) layer 6 
between a biodegradation rate of $0.007 /$ day and 0.010 /day for naphthalene for layers $3,4,5$, and 6 .

\section{Summary and Discussion of MT3D Results}

Results of this study tend to indicate that one of the most important controlling factors in the simulation of a heterogeneous system is the hydrogeologic conceptualization. Thus, a realization conditioned on both flow and transport would be a highly desirable feature in future versions of the GMS. A better simulation of the observed contaminant plumes could probably be achieved with a grid resolution finer than that used here $(5 \times 5$ x $1 \mathrm{~m})$.

The simulated transport of contaminants through the MADE site was reasonably close to the observed plumes, considering the simplifying assumptions adopted in the flow simulations. The flow model used a quasi-steady-state condition in which the piezometric head for the February 1991 monitoring data set was used for the entire length of the simulation. Most of the simulated conservative tracer (tritium) plumes were close to the observed plumes until approximately 234 days into the simulations.

Around day 203, the average water table elevation is known to increase by approximately $2 \mathrm{~m}$. This poses significant problems when attempting to model a contaminant plume for a lengthy period of time under these conditions. The simulated plume for conservative tracers does not have the required increase in velocity to move the plume nearly the extent of the observed plume. In general, the tracer monitoring layout for the site contained only a few measurements above $62.5 \mathrm{~m}$ which is the upper limit of the simulation grid. The monitoring layout was also noted to increase the horizontal distance between measurement locations for the middle- and far-field regions. It is also noted that approximately over 90 percent of the injected contaminants remained above the injection elevation of $57.5 \mathrm{~m}$. Another observation related to the monitoring layout was that the monitoring that was conducted at 27 days after injection used only a limited number of sampling points near the injection well. The observed data clearly indicate that in most of the observation plots, the observed plumes have reached the furthest extent of the near-field monitoring extent and quite possibly exceeded it. Questions as to how the contaminants are transported in the region above an elevation of $62.5 \mathrm{~m}$ during high-water-table events could not be answered by MODFLOW/MT3D. The limitation of being able to model only the saturated zone (below the $62.5-\mathrm{m}$ elevation) with MODFLOW for flow and MT3D for transport is recognized in this application as being a drawback. In addition, the lack of more detailed contaminant monitoring data in the upper regions of the aquifer above $62.5 \mathrm{~m}$ may inhibit the compilation of an exhaustive data set for the MADE site that can be used as a test data set for the complete analysis of present simulation models. The MADE data set is an impressive one and is the most complete for a heterogeneous site to date. 
Previous reviews of the MADE experiments (Boggs et al. 1993) indicated that there is a strong possibility that organic tracer concentrations could have been significantly reduced by the sampling mechanics due to organic tracer volatility. Most of the organic tracer simulations indicated a plume that traveled further downgradient than the observed plume toward the latter half of the simulations. The exception to this was the o-dichlorobenzene simulation, in which the observed plume traveled further downgradient than the simulated plume and showed extensive spatial discontinuity. The p-xylene simulation demonstrated the transformation of the chemical as compared to the ${ }^{14} \mathrm{C}$ plume which traveled further downgradient than the organic chemical. This is noted because the $\mathrm{p}$-xylene was labeled with the ${ }^{14} \mathrm{C}$ that was tracked in the monitoring.

The simulations were very sensitive to hydraulic conductivity values. A change in the hydraulic conductivity at the injection well caused major effects for the travel of the contaminants, as expected.

The simulation did not appear to be very sensitive to the recharge rates evaluated in the sensitivity analysis. The increase in the recharge rate in the flow model from $0.07 \mathrm{~m} /$ year to $0.26 \mathrm{~m} /$ year induced only a small increase in the tritium plume and the shape of that plume.

The model was sensitive to changes in porosity. A three-tiered porosity profile that followed the meander channel (with a porosity value in the far-field region of 0.31 , the middle-field region of 0.2 , in the meander channel of 0.1 , and in the near-field region of 0.31 ) caused the conservative tracer tritium plume to move approximately $30 \mathrm{~m}$ further than the tritium plume simulated with a porosity profile of 0.10 in the meander channel and 0.31 elsewhere.

Recommendations for future simulations include better representations of the hydraulic conductivity for the site and a model grid with finer resolution. 


\section{References}

Boggs, J. M., and Young, S.C. (1988). "Evaluation of tracer sampling devices for macrodispersion experiment," EPRI Report EA-5816, Electric Power Research Institute, Palo Alto, CA.

Boggs, J. M., Beard, L. M., and Waldrop, W. R. (1993). "Transport of tritium and four organic compounds during a natural-gradient experiment (MADE-2)," EPRI Report TR-101998, Electric Power Research Institute, Palo Alto, CA.

Boggs, J. M., Beard, L. M., Waldrop, W. R., Stauffer, T. B., MacIntyre, W. G., and Antworth, C. P. (1993). "Transport of tritium and four organic compounds during a natural-gradient experiment (MADE-2)," Technical Report, EPRI TR-101998, Project 2485-05, Palo Alto, CA.

Boggs, J. M., Young, S. C., Benton, D. J., and Chung, Y. C. (1990). "Hydrogeologic characterization of the MADE site," EPRI Report EN-6915, Electric Power Research Institute, Palo Alto, CA.

Boggs, J. M., Young, S. C., Hopkins, R. A., and Chung, Y. C. (1988). "Interim hydrogeologic characterization of the Macrodispersion Experiment Site," Draft Technical Report for EPRI, Research Project 2485-5, Palo Alto, CA.

Brigham Young University. (1995). "The Department of Defense Groundwater Modeling System," Engineering Computer Graphics Laboratory, Brigham Young University, Provo, UT.

Electric Power Research Institute. (1989). "Estimation of macrodispersivity based on analysis of hydraulic conductivity variability at the MADE site," EPRI EN-6405, Project 2485-5, Palo Alto, CA.

. (1990). "Hydrogeologic characterization of the MADE site," EPRI EN-6915, Project 2485-5, Palo Alto, CA.

. (1991). "Database for the first macrodispersion experiment (MADE-1)," EPRI EN-7363, Project 2485-5, Palo Alto, CA. 
Electric Power Research Institute. (1993a). "Database for the second macrodispersion experiment (MADE-2)," EPRI TR-102072, Project 2485-05, Palo Alto, CA.

. (1993b). "Transport of tritium and four organic compounds during a natural-gradient experiment (MADE-2)," EPRI TR-101998, Project 2485-05, Palo Alto, CA.

Gray, D. D., and Dale, F. R. (1995). "Transport modeling of tritium at the MADE-2 site." Proceedings of Groundwater Management. R. J. Charbeneau, ed., American Society of Civil Engineers, New York, 164-168.

Hill, M. C. (1990). "MODFLOWP: A computer program for estimating parameters of a transient, three-dimensional groundwater flow model using nonlinear regression," Open-File Report, U.S. Geological Survey.

Leake, S. A., and Prudic, D. E. (1988). "Documentation of a computer program to simulate aquifer-system compaction using the modular finite-difference ground-water flow model," Open-File Report 88-482, Appendix C, 69-80, U.S. Geological Survey, AZ.

Lin, H-C. J., Richards, D. R., Yeh, G-T., Cheng, J-R., Cheng, H-P., and Jones, N. L. (1997). "FEMWATER: A three-dimensional finite element computer model for simulating density-dependent flow and transport in variably saturated media," Technical Report CHL-97-12, U.S. Army Engineer Waterways Experiment Station, Vicksburg, MS.

McDonald, M. G., and Harbaugh, A. W. (1988). "A modular three-dimensional finite-difference ground-water flow model," U.S. Geological Survey Techniques of Water-Resources Investigations, Book 6, Chapter A1.

Mullins, J. A., Carse1, R. F., Scarbrough, J. E., and Ivery, A. M. (1993). "PRZM-2, a model for predicting pesticide fate in the crop root and unsaturated soil zones: Users manual for release 2.0," Environmental Research Laboratory, U. S. Environmental Protection Agency, Athens, GA.

Rehfeldt, K. R., Boggs, J. M., and Gelhar, L. W. (1992). "Field study of dispersion in a heterogeneous aquifer; 3, Geostatistical analysis of hydraulic conductivity," Water Resources Research.

Rehfeldt, K. R., Gelhar, L. W., Southard, J. B., and Dasinger, A. ${ }_{\text {M. }}$ (1989b). "Estimates of macrodispersivity based on analysis of hydraulic conductivity variability at the MADE site," EPRI Report EN-6405, Electric Power Research Institute, Palo Alto, CA. 
Rehfeldt, K. R., Hufschmied, P., Gelhar, L. W., and Schaefer, M. E. (1989a). "The borehole flowmeter technique for measuring the vertical distribution of hydraulic conductivity," Electric Power Research Institute, Technical Report EN-6511, Palo Alto, CA.

Zheng, C. (1990). "MT3D: A modular three-dimensional transport model for simulation of advection, dispersion and chemical reactions of contaminants in groundwater systems," S.S. Papadopulos and Associates, Rockville, MD. 



\section{Appendix A Interpolated Hydraulic Conductivity}

The interpolated hydraulic conductivity values (units of $\mathrm{m} / \mathrm{day}$ ) for each layer of the model grid are shown in the following Figures A1-A11. 


\section{Layer $1 \mathrm{HC}$ fleld}

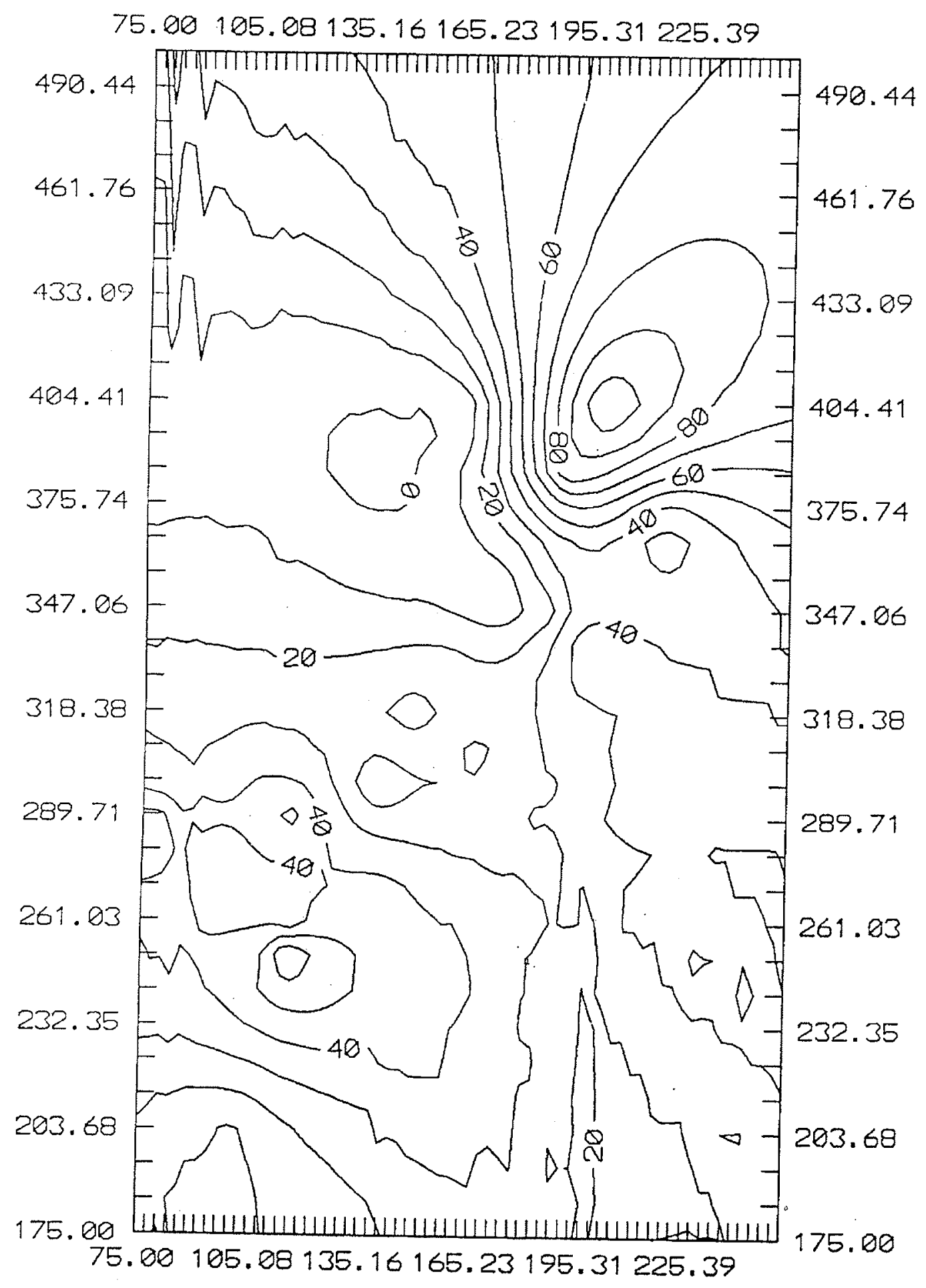

Figure A1. Interpolated Hydraulic Conductivity for Model Layer 1 
Layer $2 H C$ fleld

$75.00 \quad 105.08135 .16165 .23195 .31225 .39$

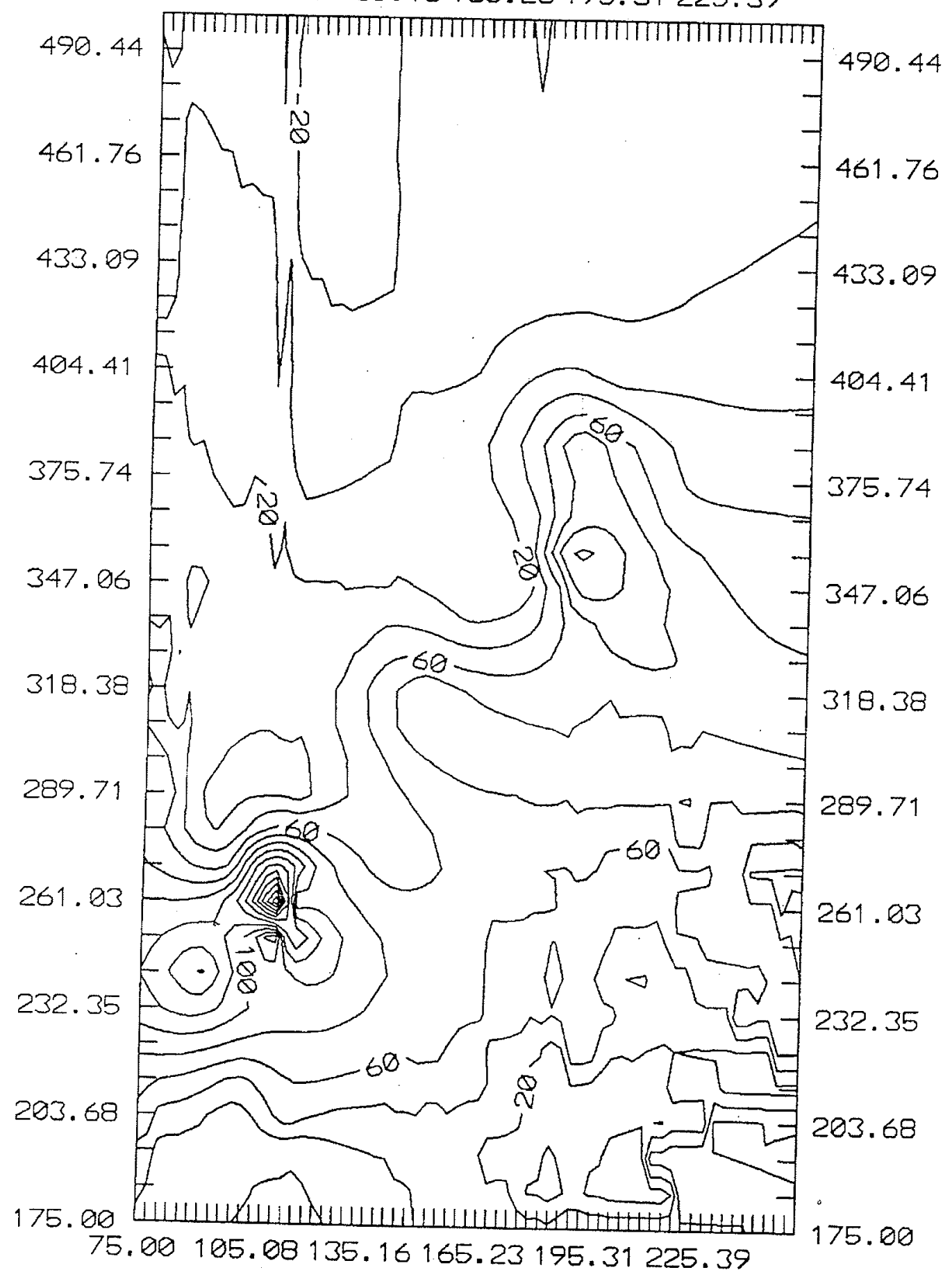

Figure A2. Interpolated Hydraulic Conductivity for Model Layer 2 


\section{Layer $3 \mathrm{HC}$ fleld}

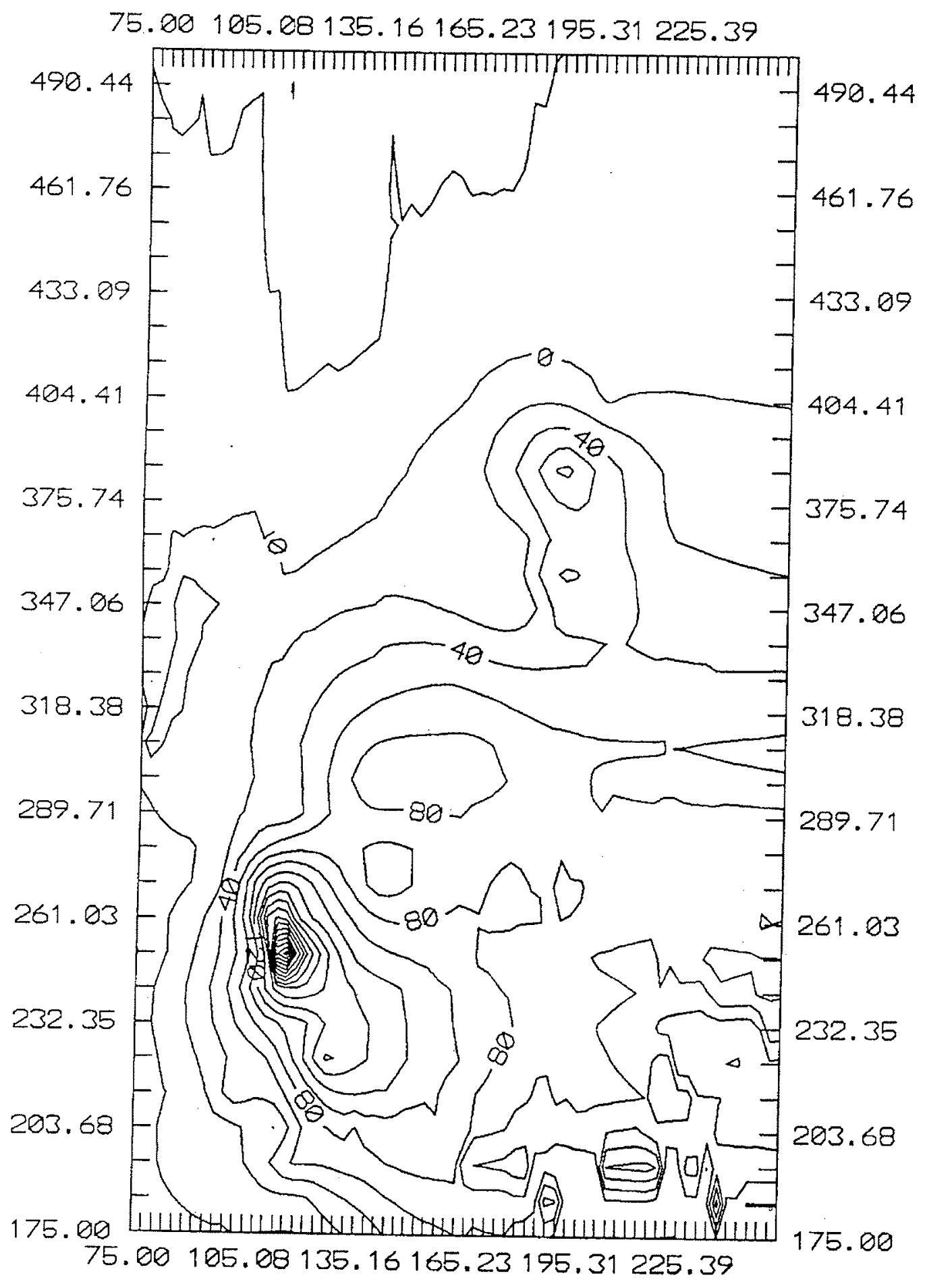

Figure A3. Interpolated Hydraulic Conductivity for Model Layer 3 
Layer. 4 HC fleld

75.00105 .08135 .16165 .23195 .31225 .39

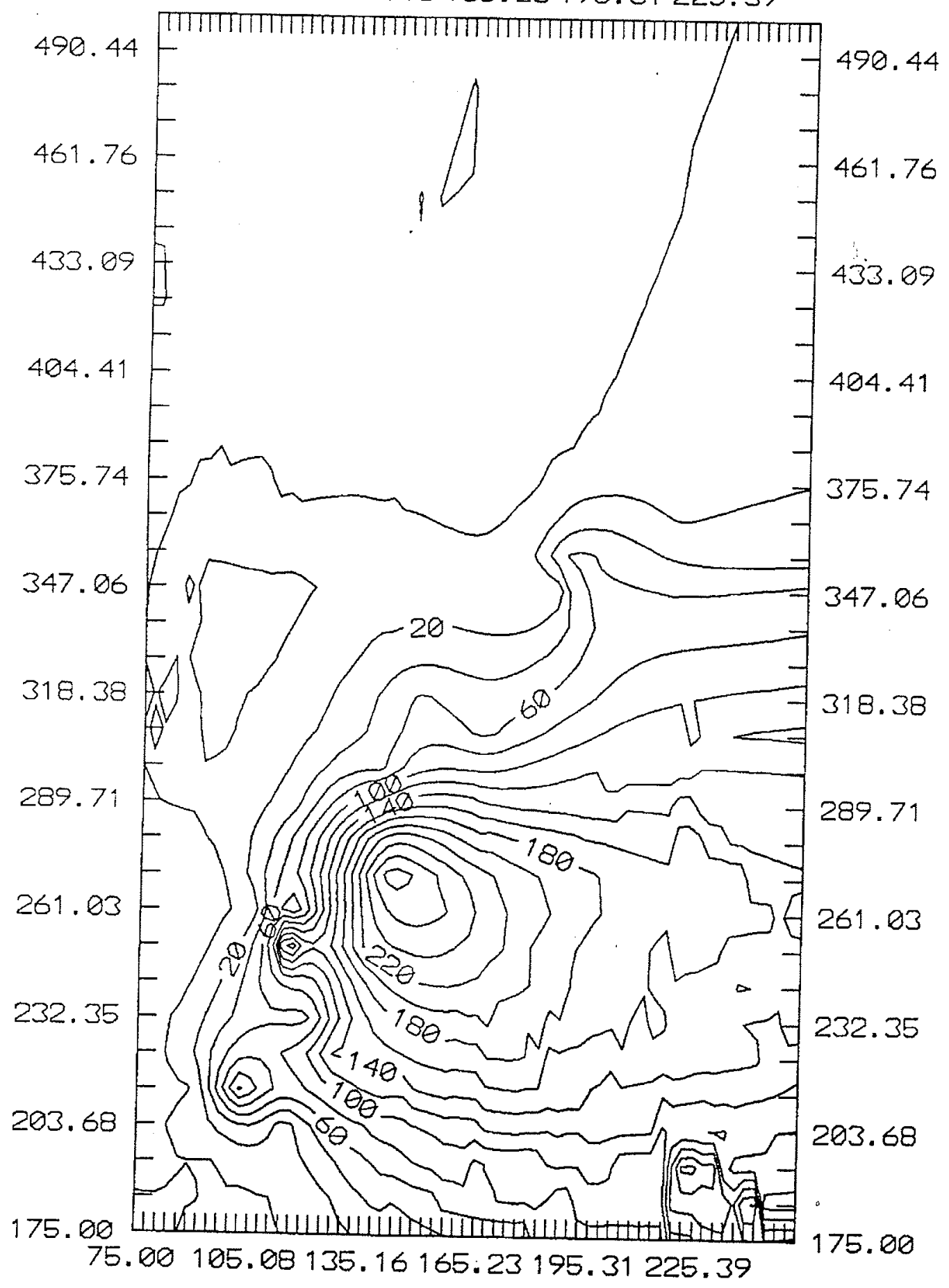

Figure A4. Interpolated Hydraulic Conductivity for Model Layer 4 


\section{Layer $5 \mathrm{HC}$ field}

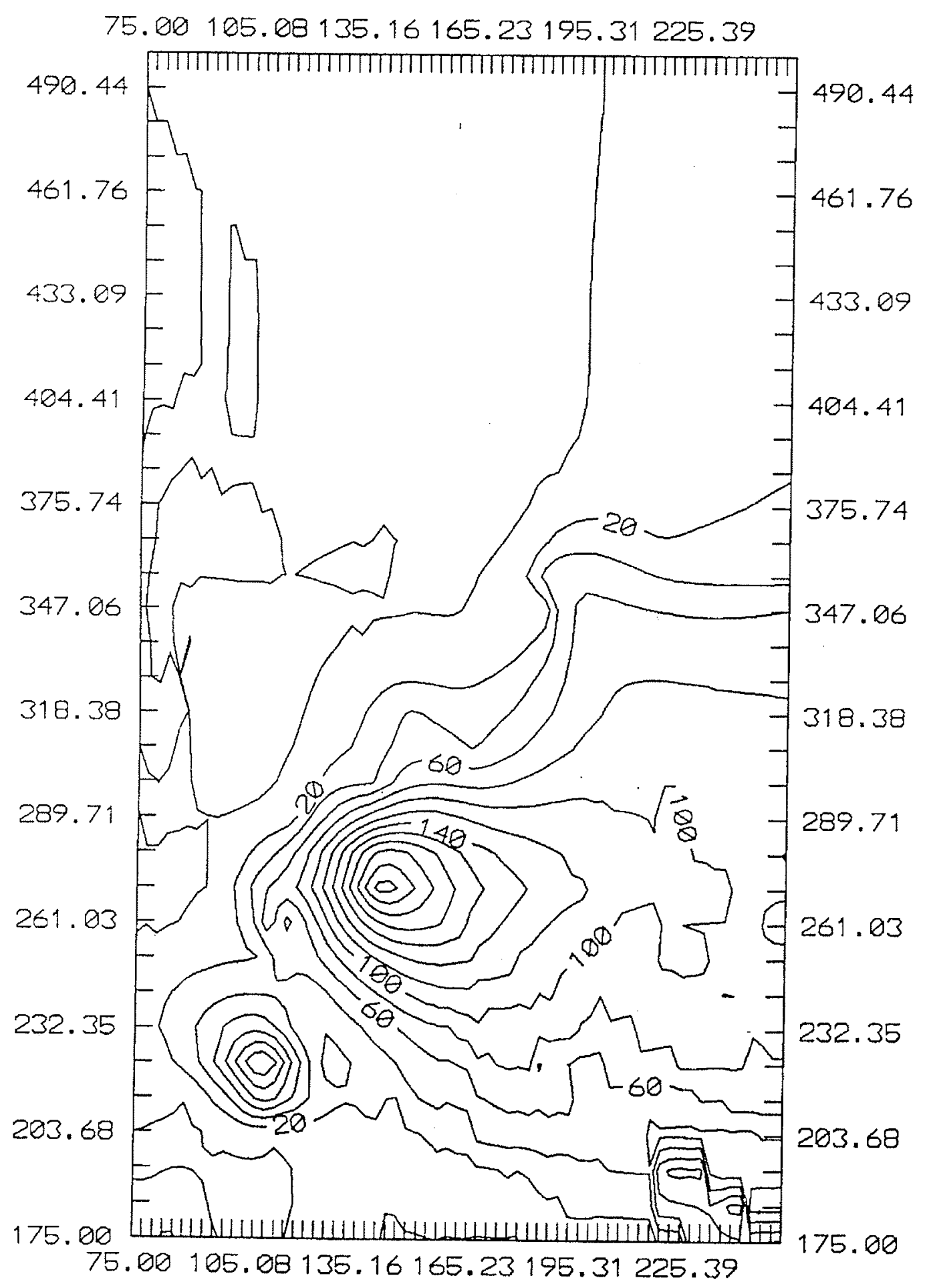

Figure A5. Interpolated Hydraulic Conductivity for Model Layer 5 
Layer 6 HC field

75.00105 .08135 .16165 .23195 .31225 .39

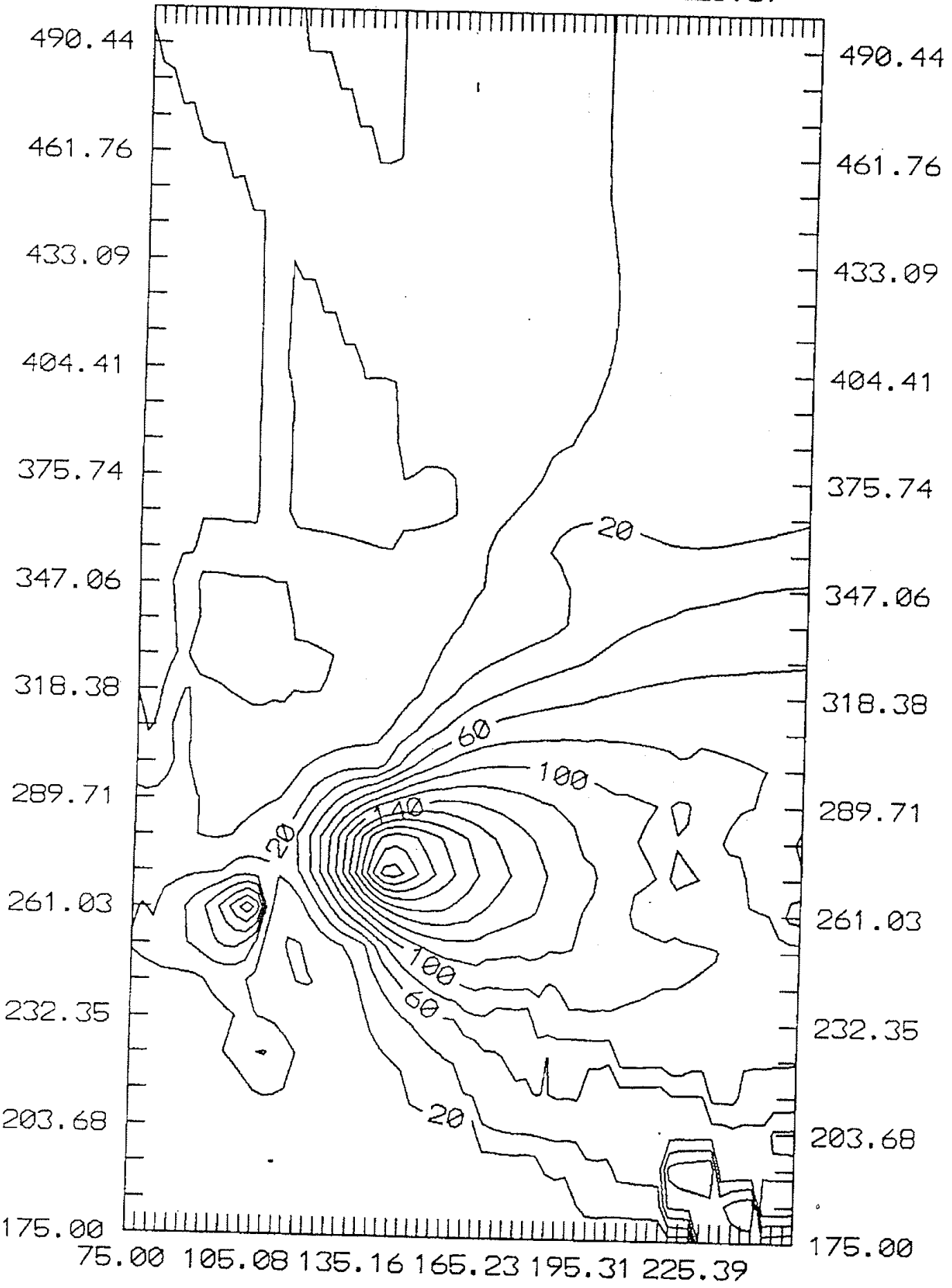

Figure A6. Interpolated Hydraulic Conductivity for Model Layer 6 


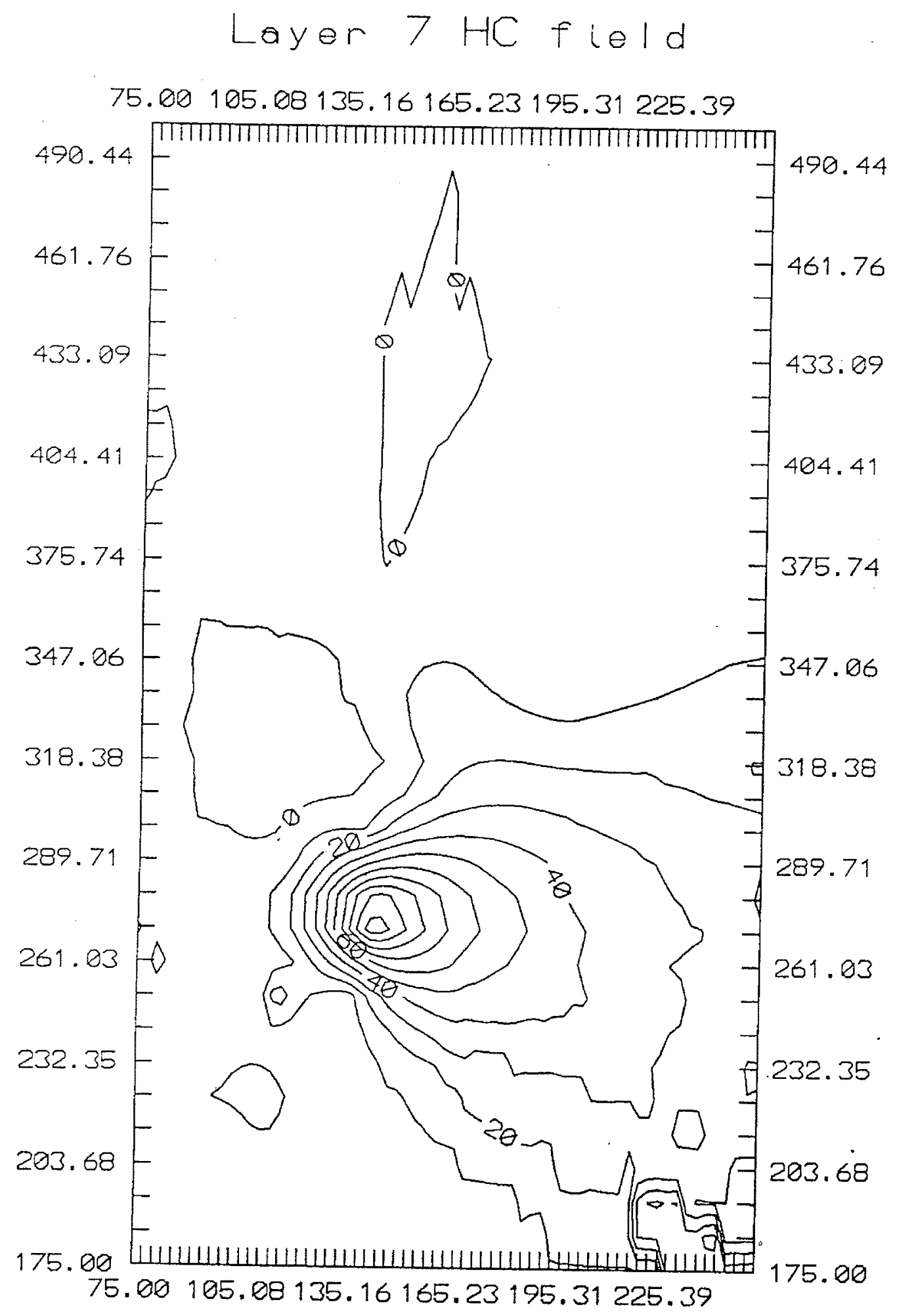

Figure A7. Interpolated Hydraulic Conductivity for Model Layer 7 


\section{Layer $8 H C \cdot f i e \mid d$}

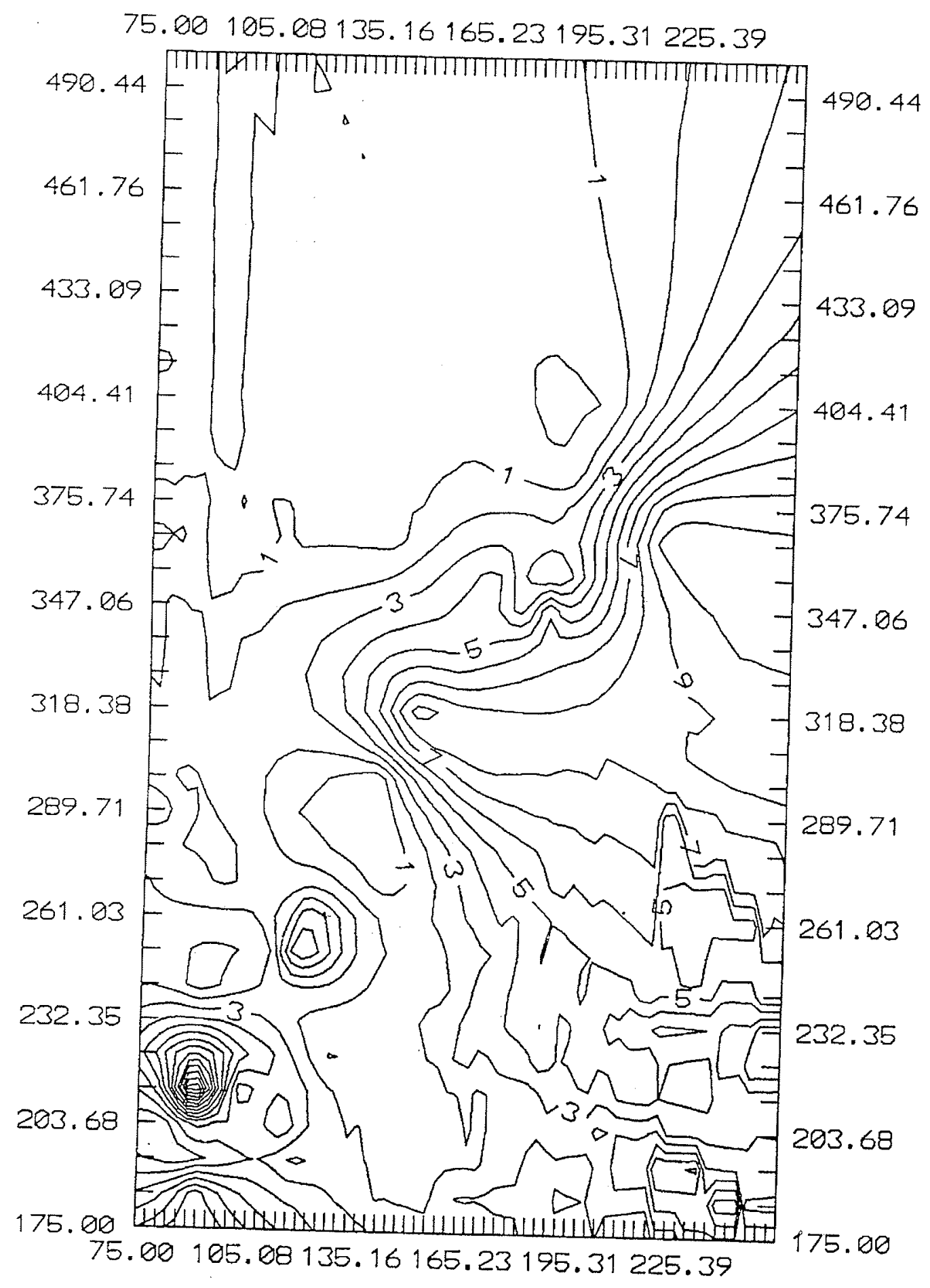

Figure A8. Interpolated Hydraulic Conductivity for Model Layer 8 


\section{Layer $9 H C$ fleld}

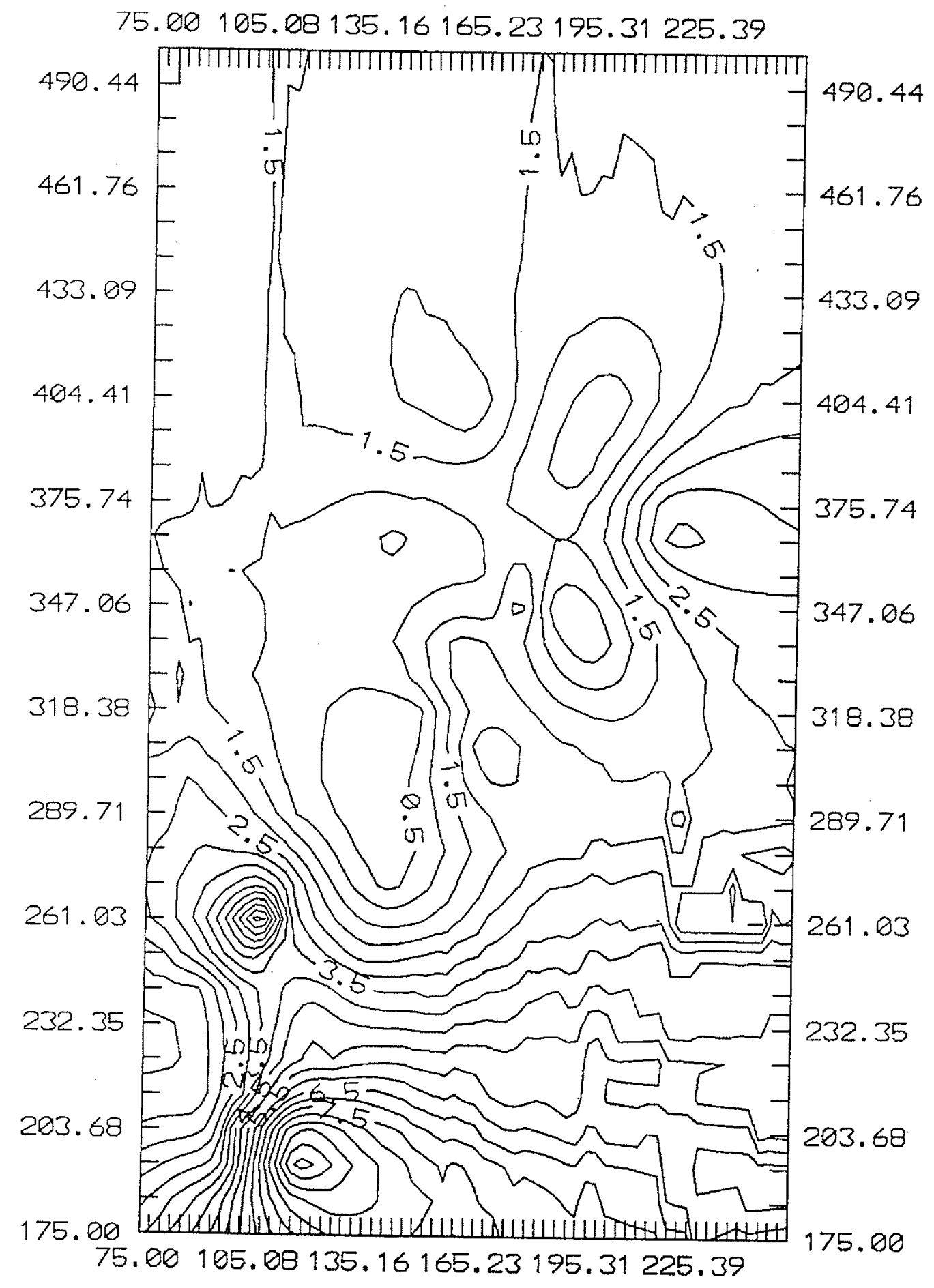

Figure A9. Interpolated Hydraulic Conductivity for Model Layer 9 


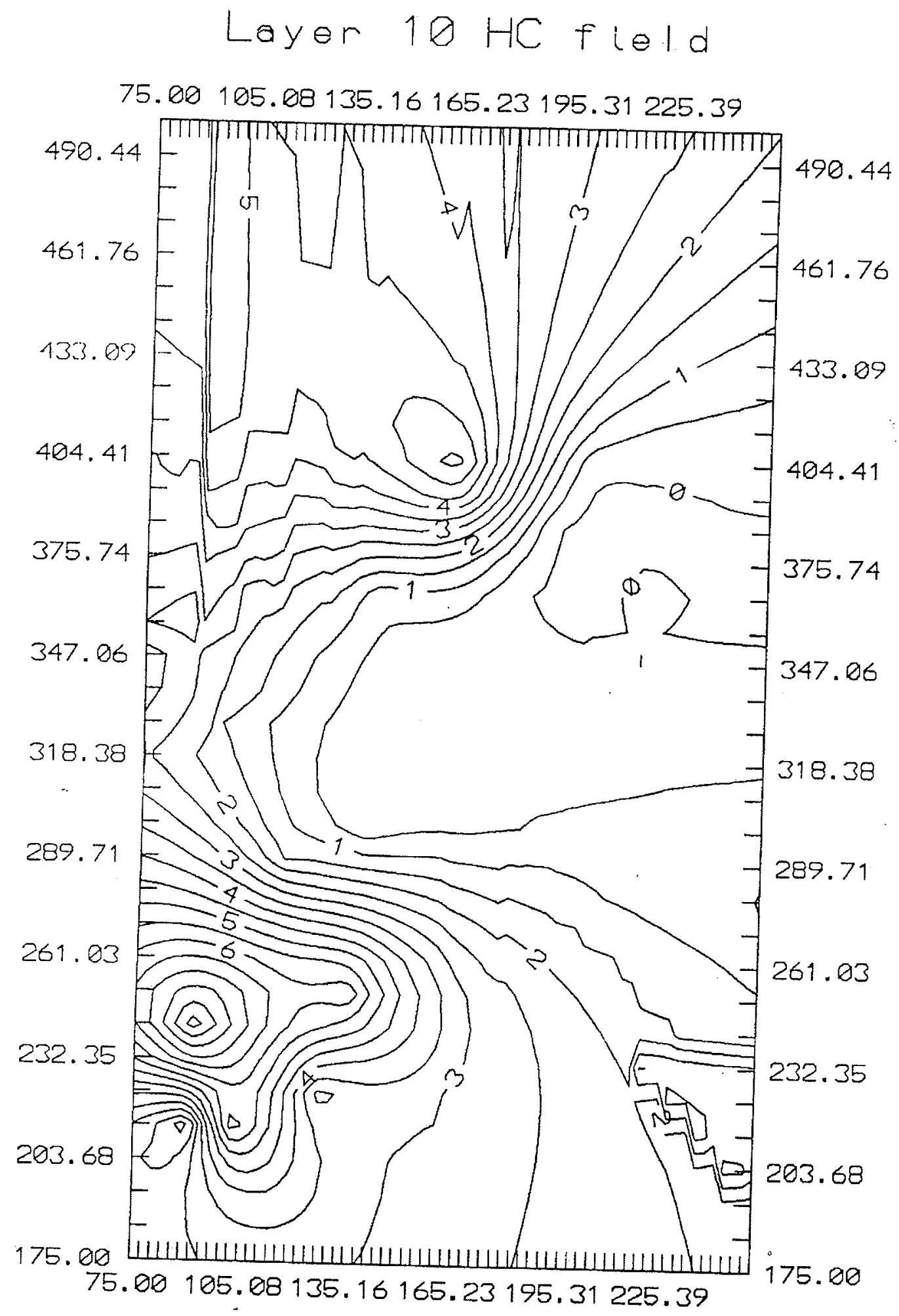

Figure A10. Interpolated Hydraulic Conductivity for Model Layer 10 


\section{Layer 11 HC field}

75.00105 .88135 .16165 .23195 .31225 .39

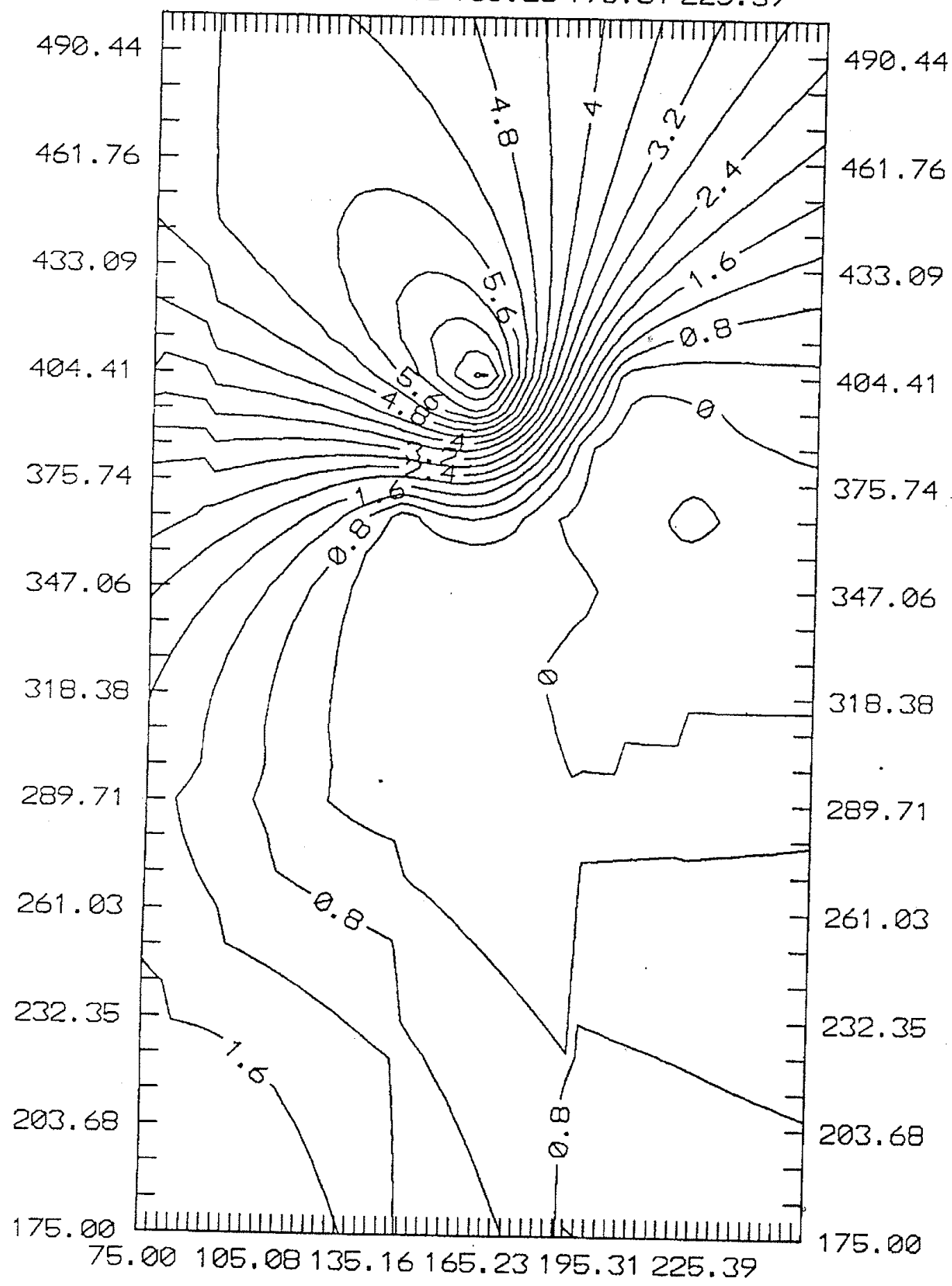

Figure A11. Interpolated Hydraulic Conductivity for Model Layer 11 


\section{Appendix B \\ Piezometric Head Contours}

This appendix shows the average head contours for both the shallow and deep parts of the aquifer for each day of the available data. The plots follow and are not labeled with individual figures since there are several and the headings are believed to be self-explanatory. 


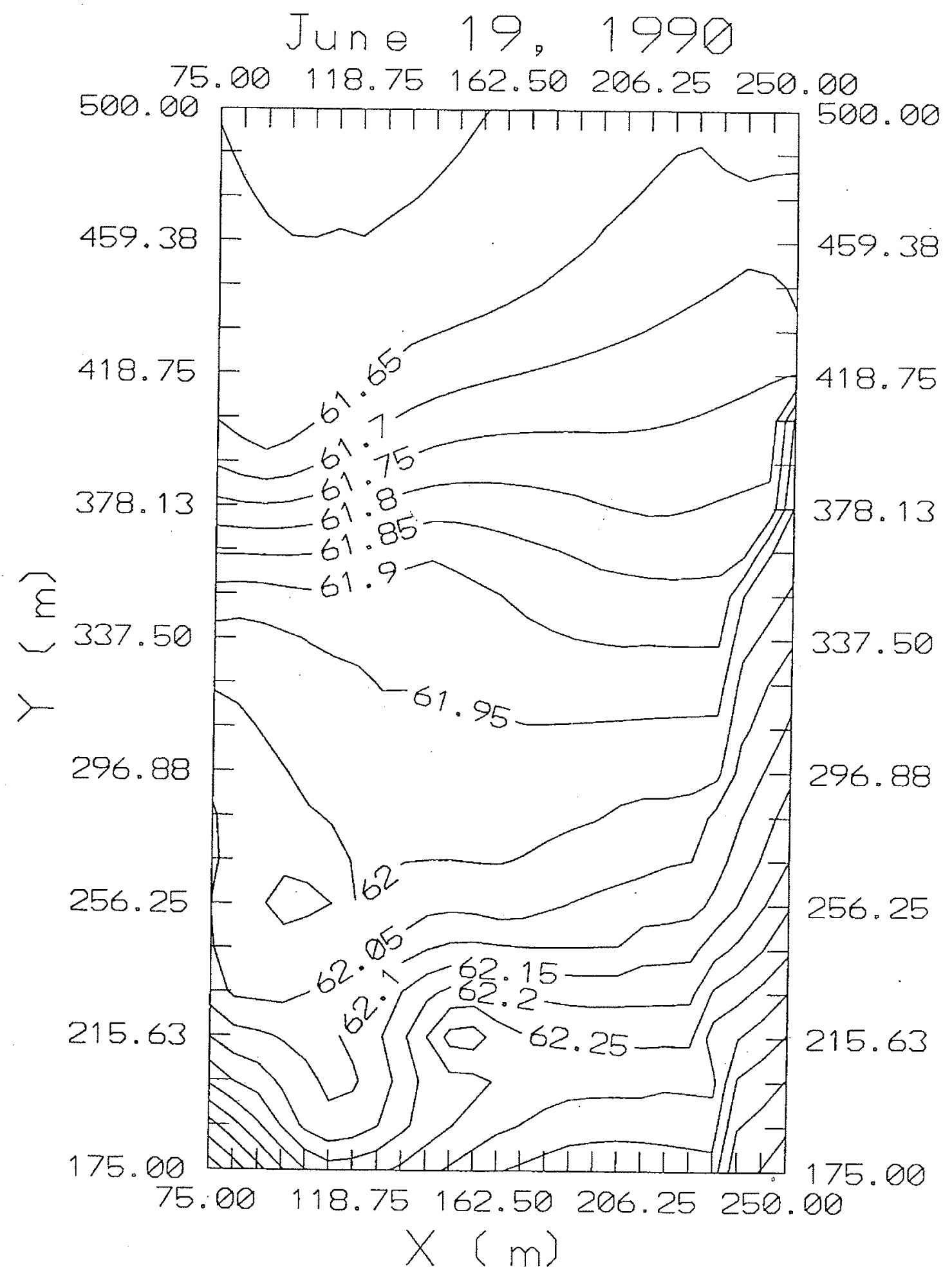




\section{July 23, 1990}

$\begin{array}{llllll}75.00 & 118.75 & 162.50 & 206.25 & 250.00\end{array}$

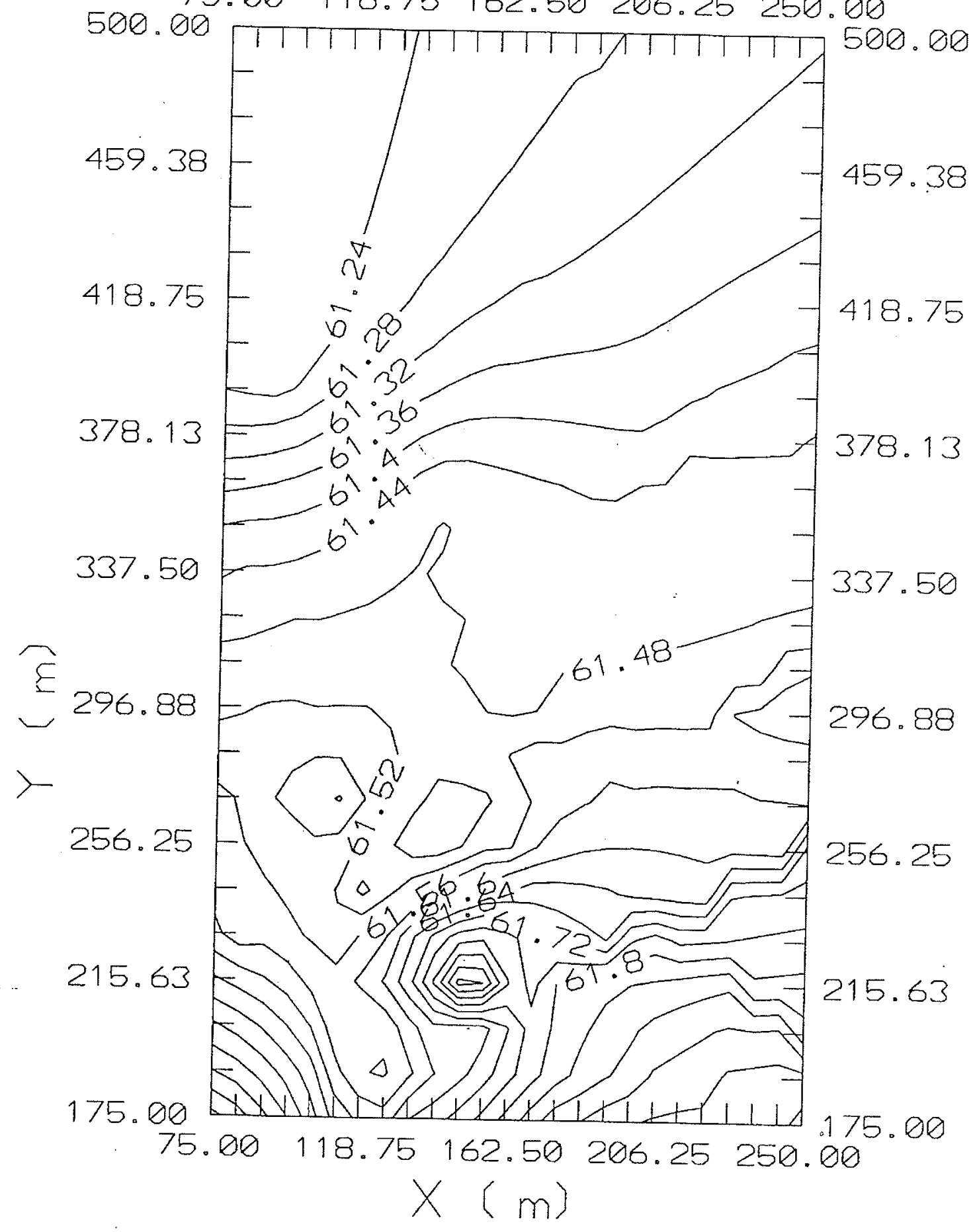




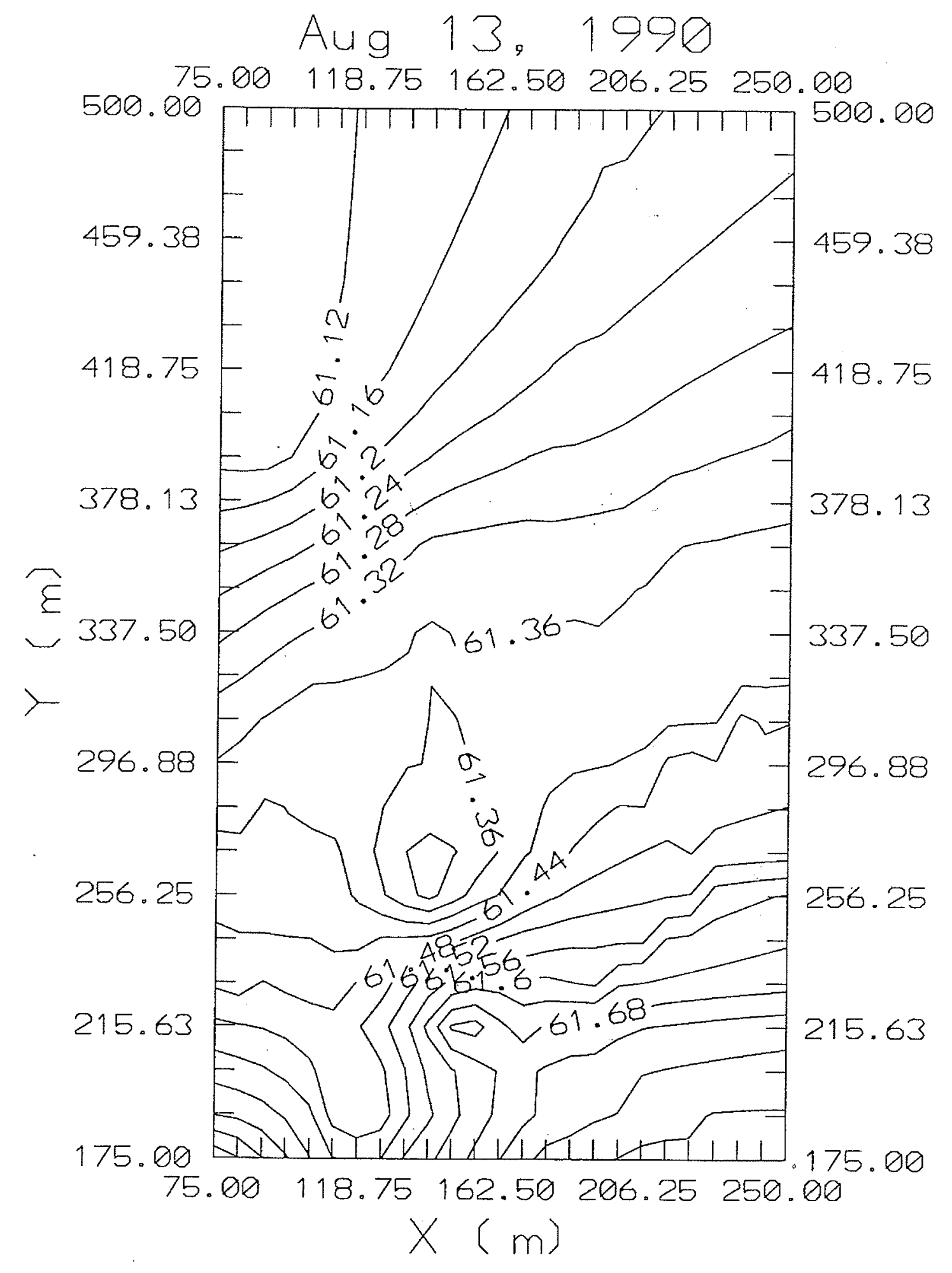




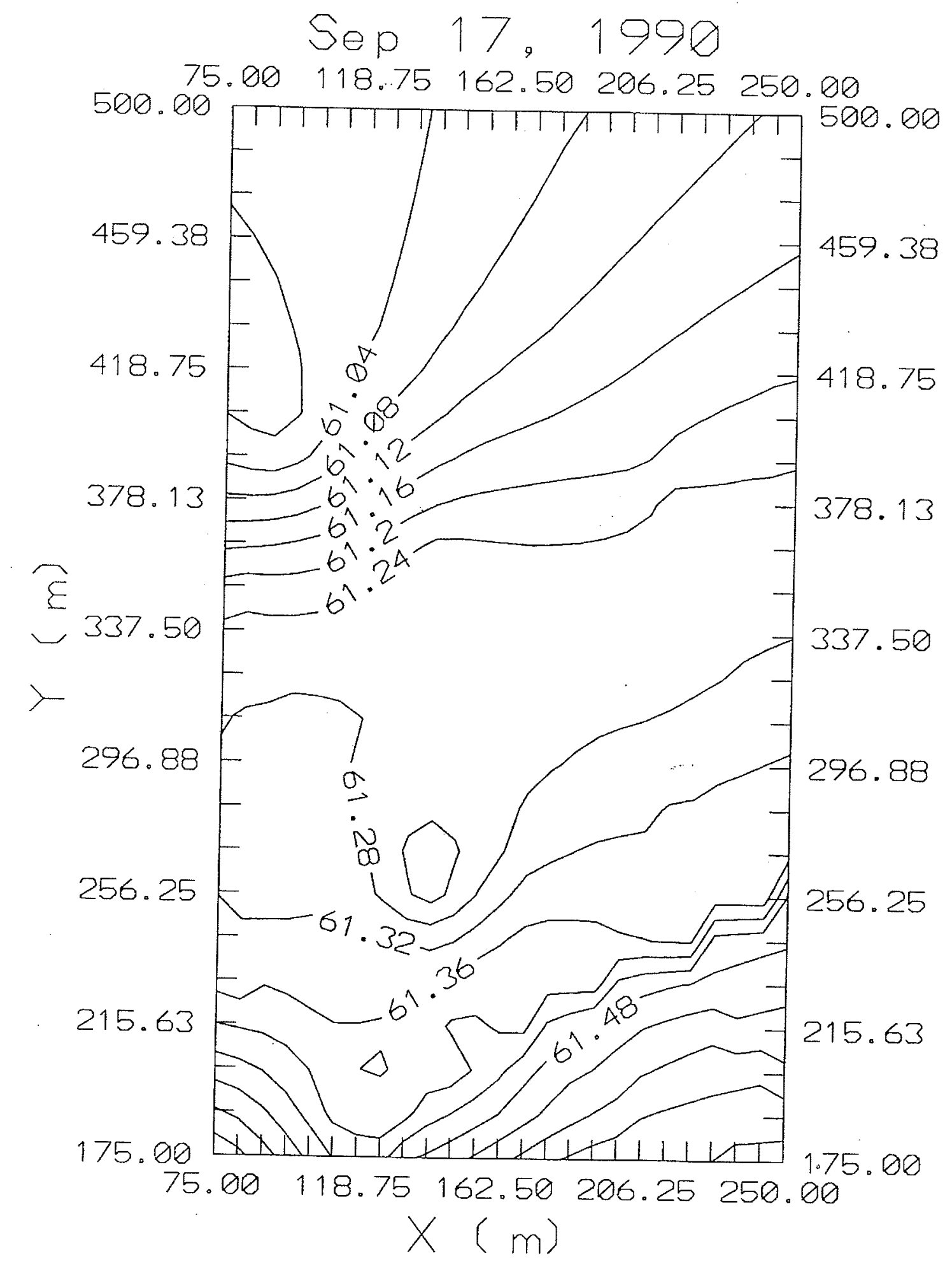




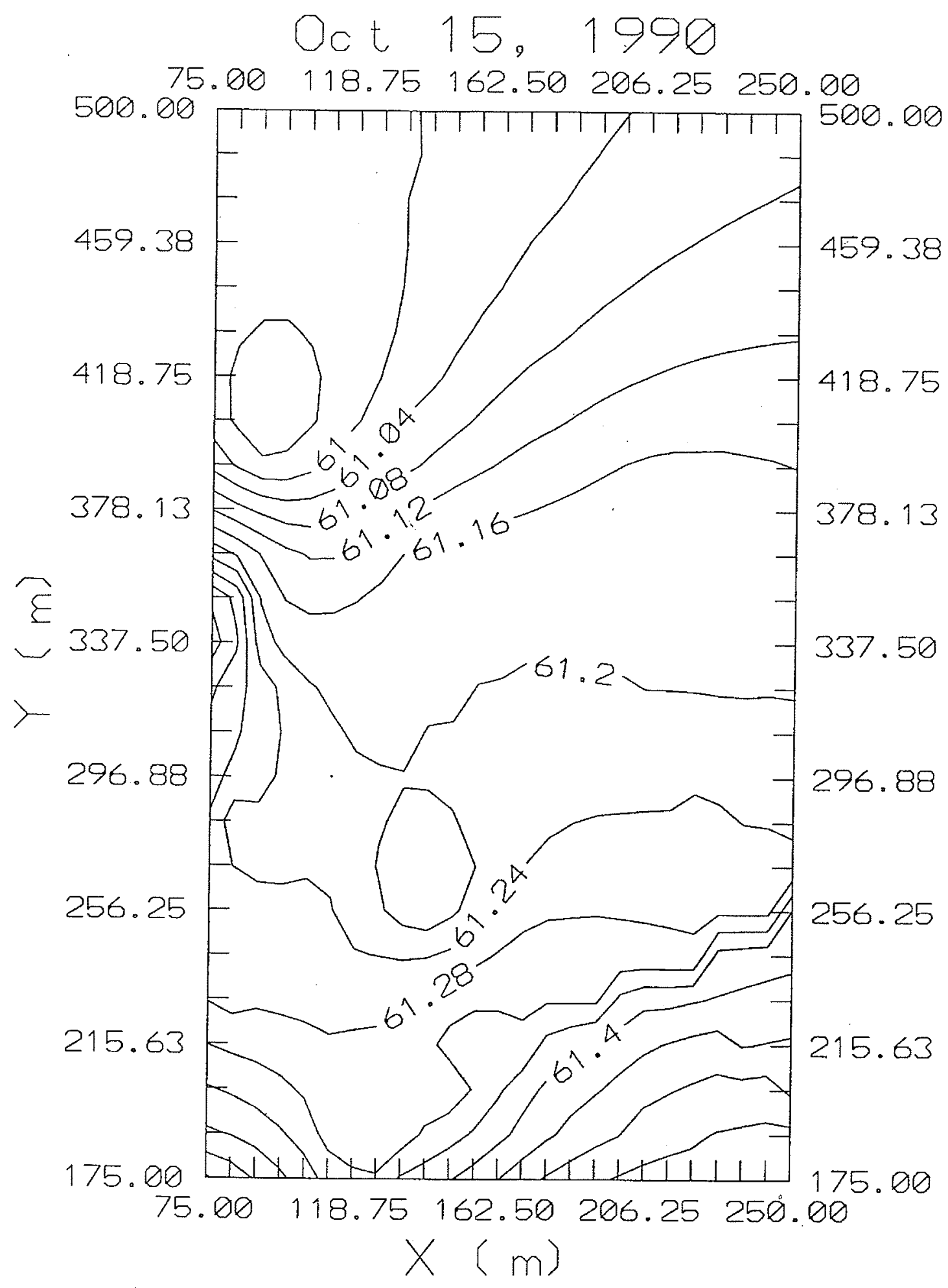


Nov 7, 1990

$\begin{array}{lllllll}75.00 & 118.75 & 162.50 & 206.25 & 250.00\end{array}$

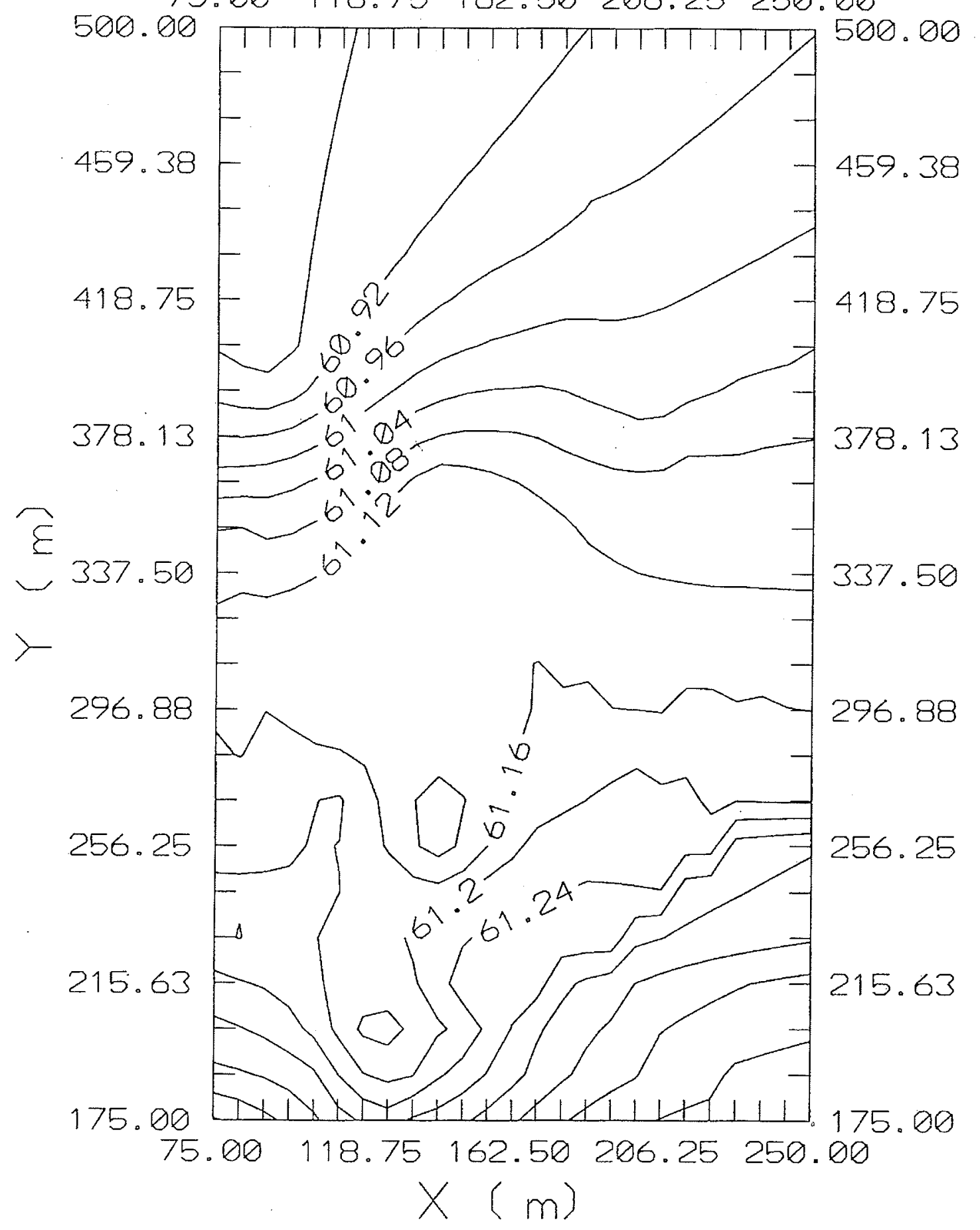




\section{Dec 5, 1990}

$\begin{array}{lllllll}75.00 & 118.75 & 162.50 & 206.25 & 250.00\end{array}$

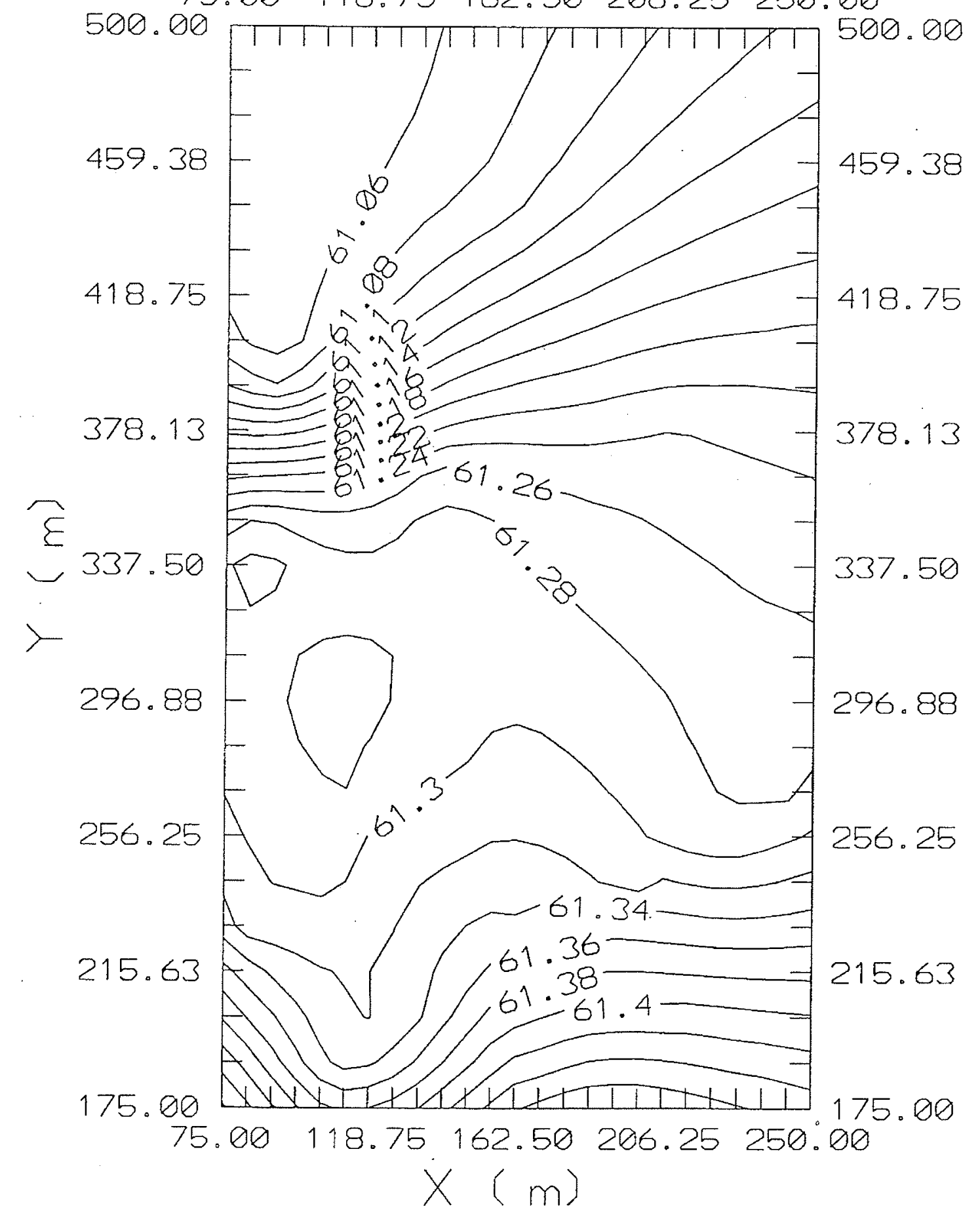




\section{Jan 8, 1991}

$\begin{array}{lllll}75.00 & 118.75 & 162.50 & 206.25 & 250.00\end{array}$

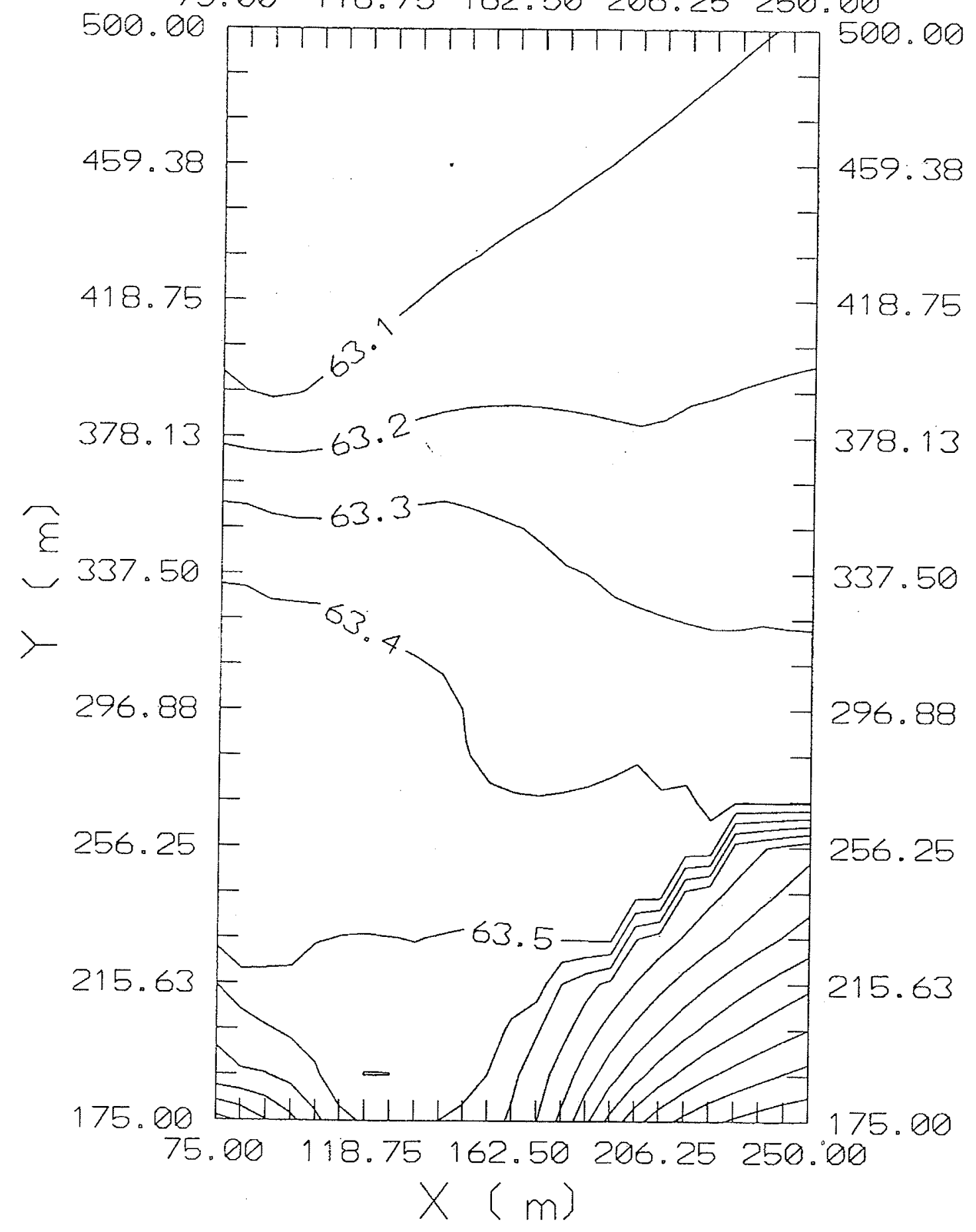




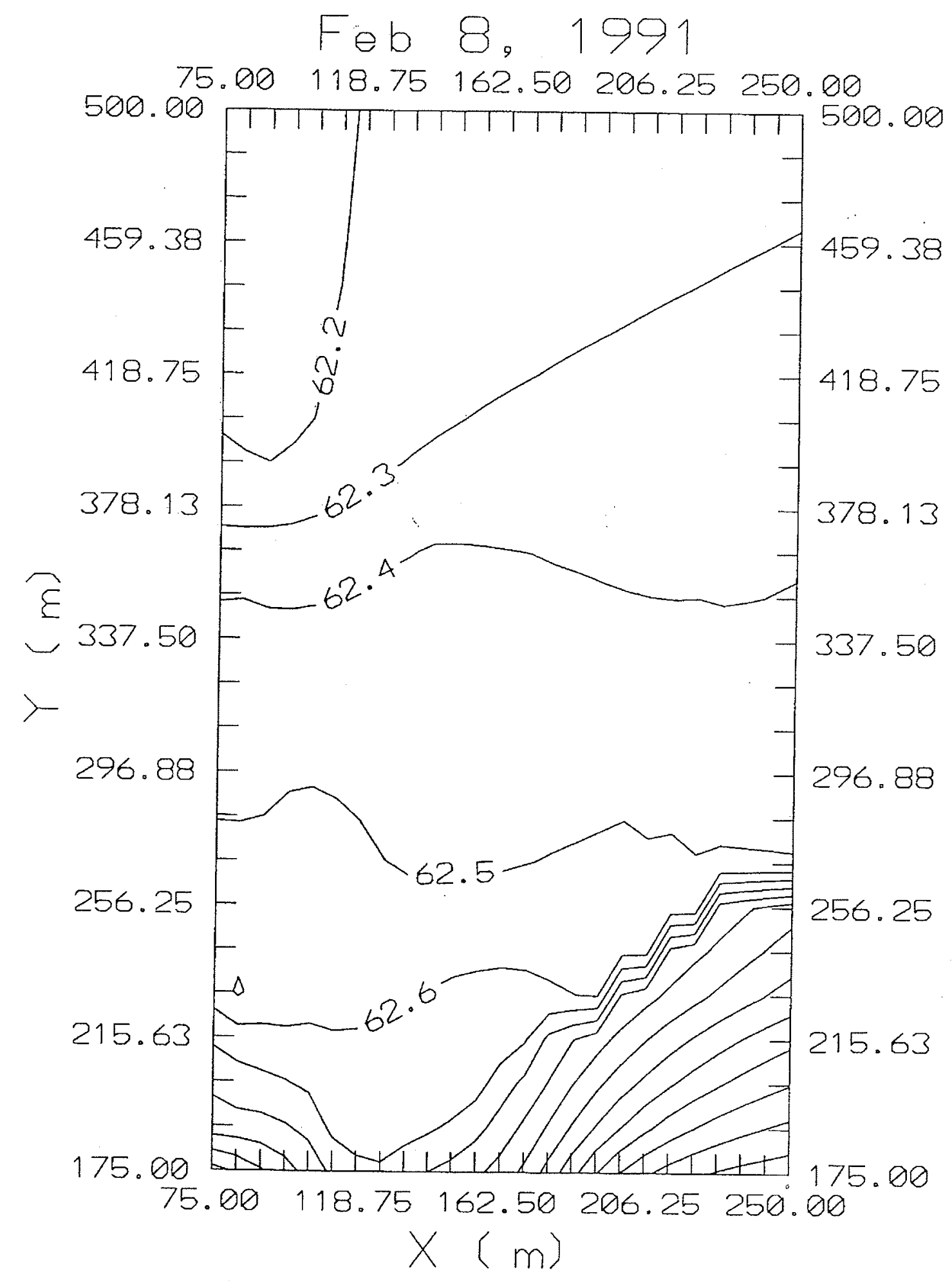




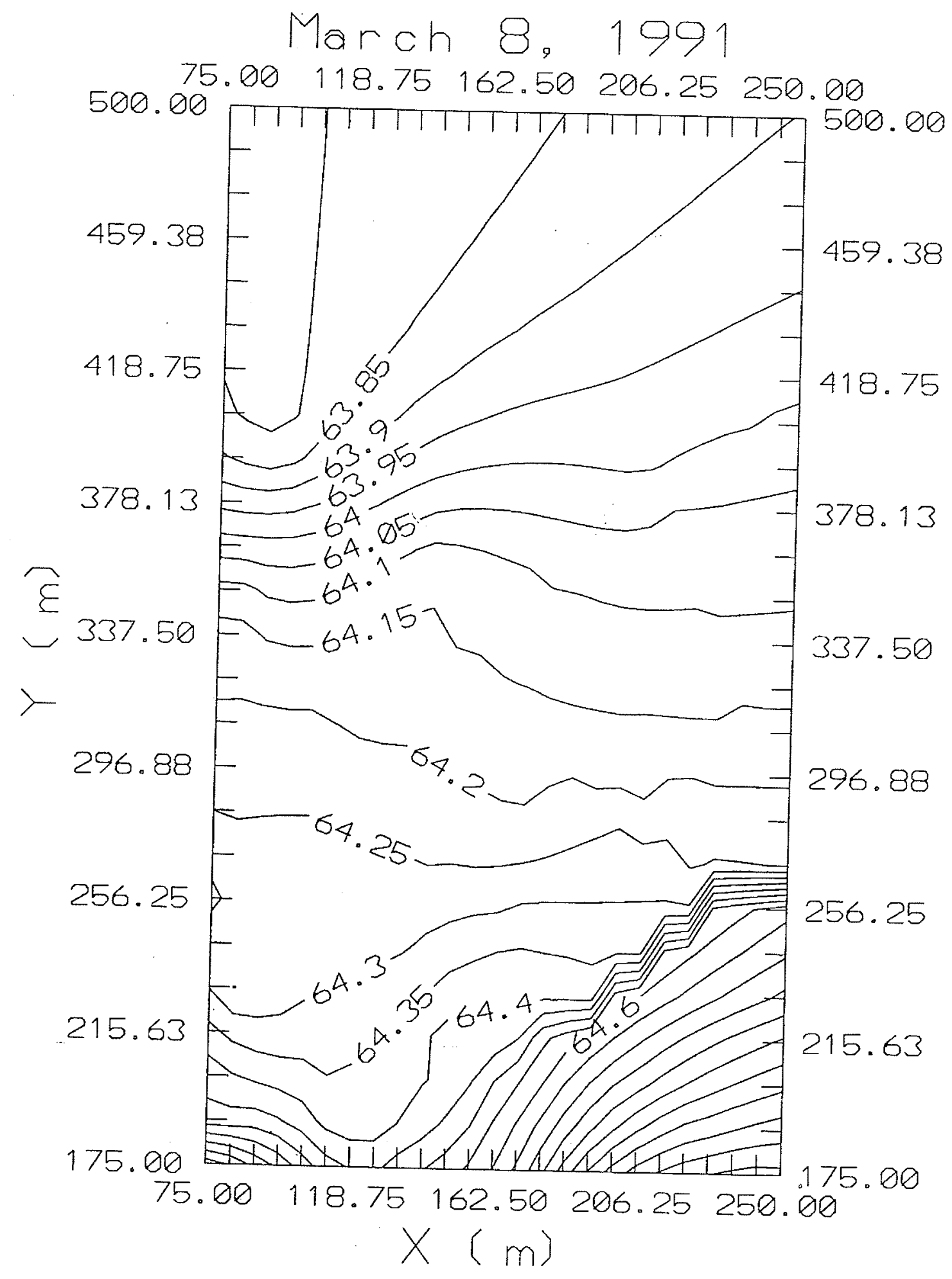




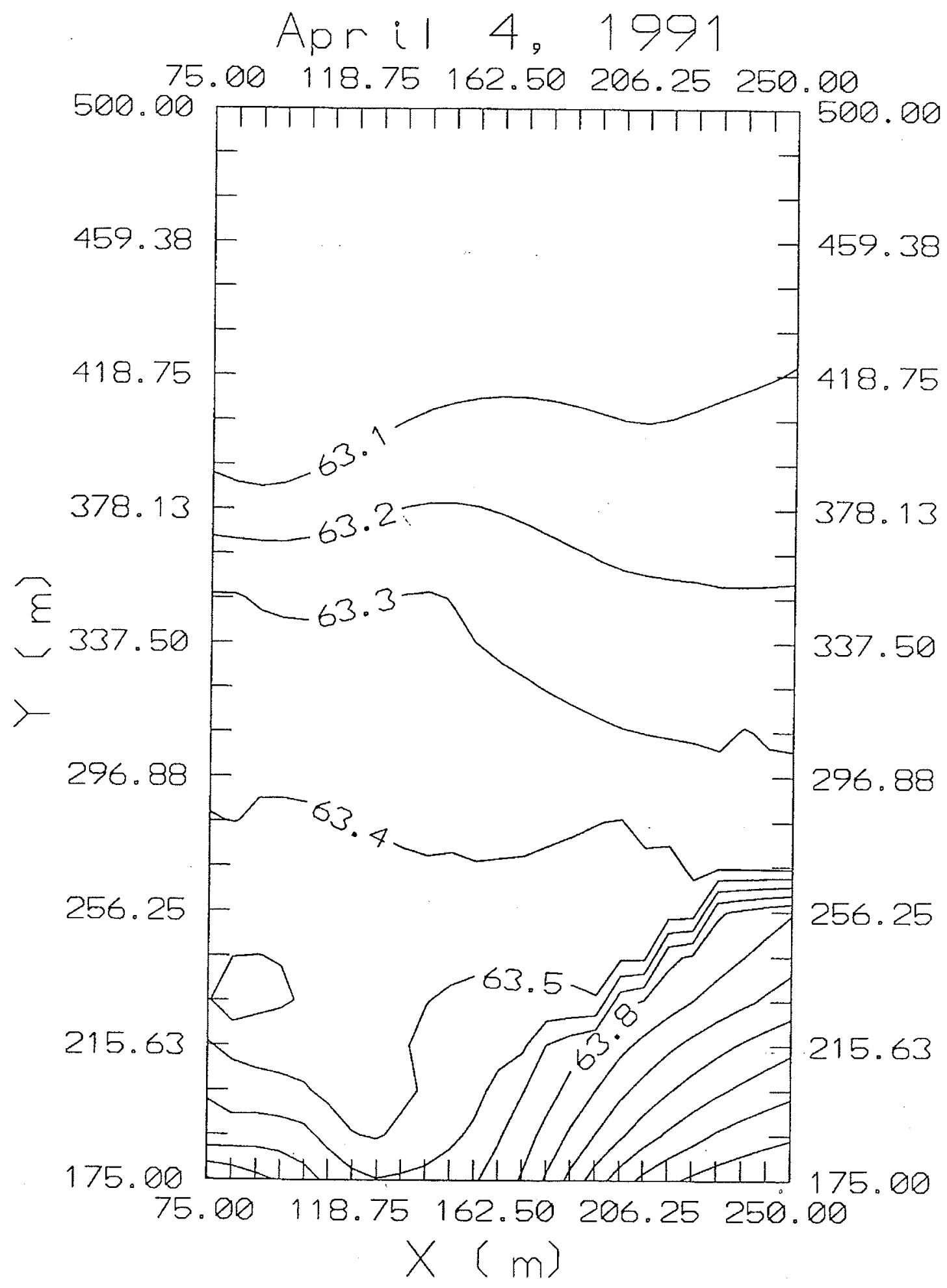




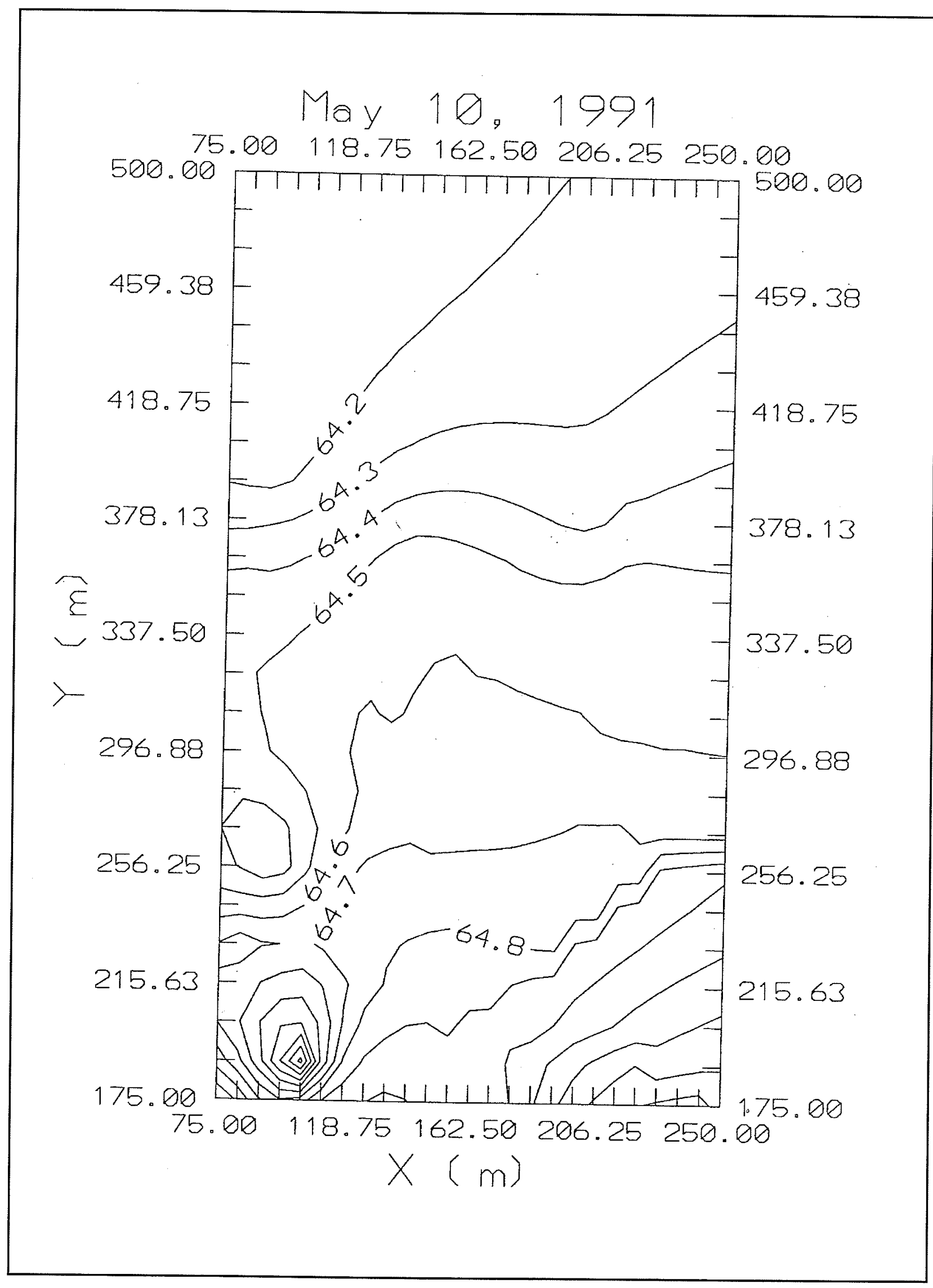




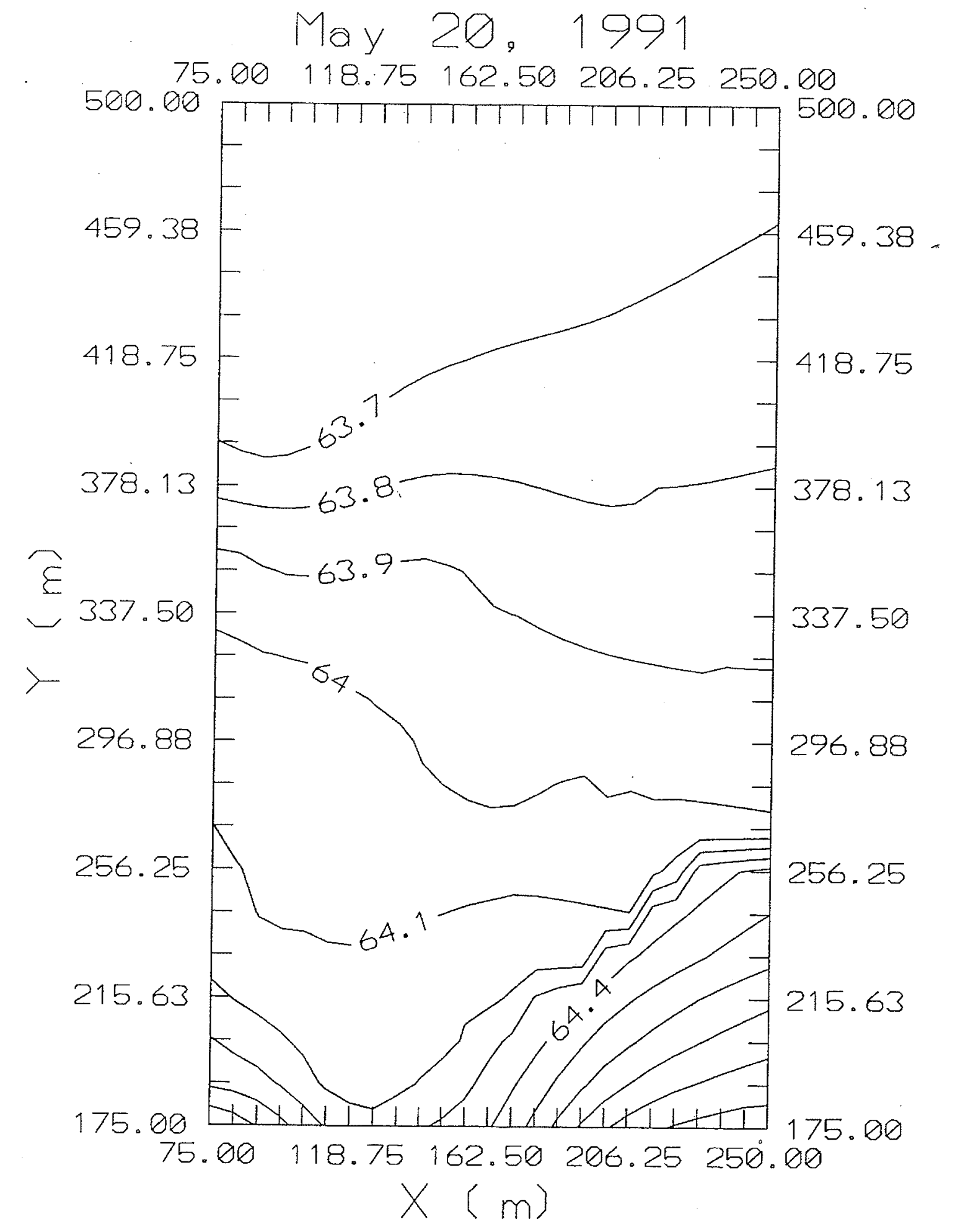




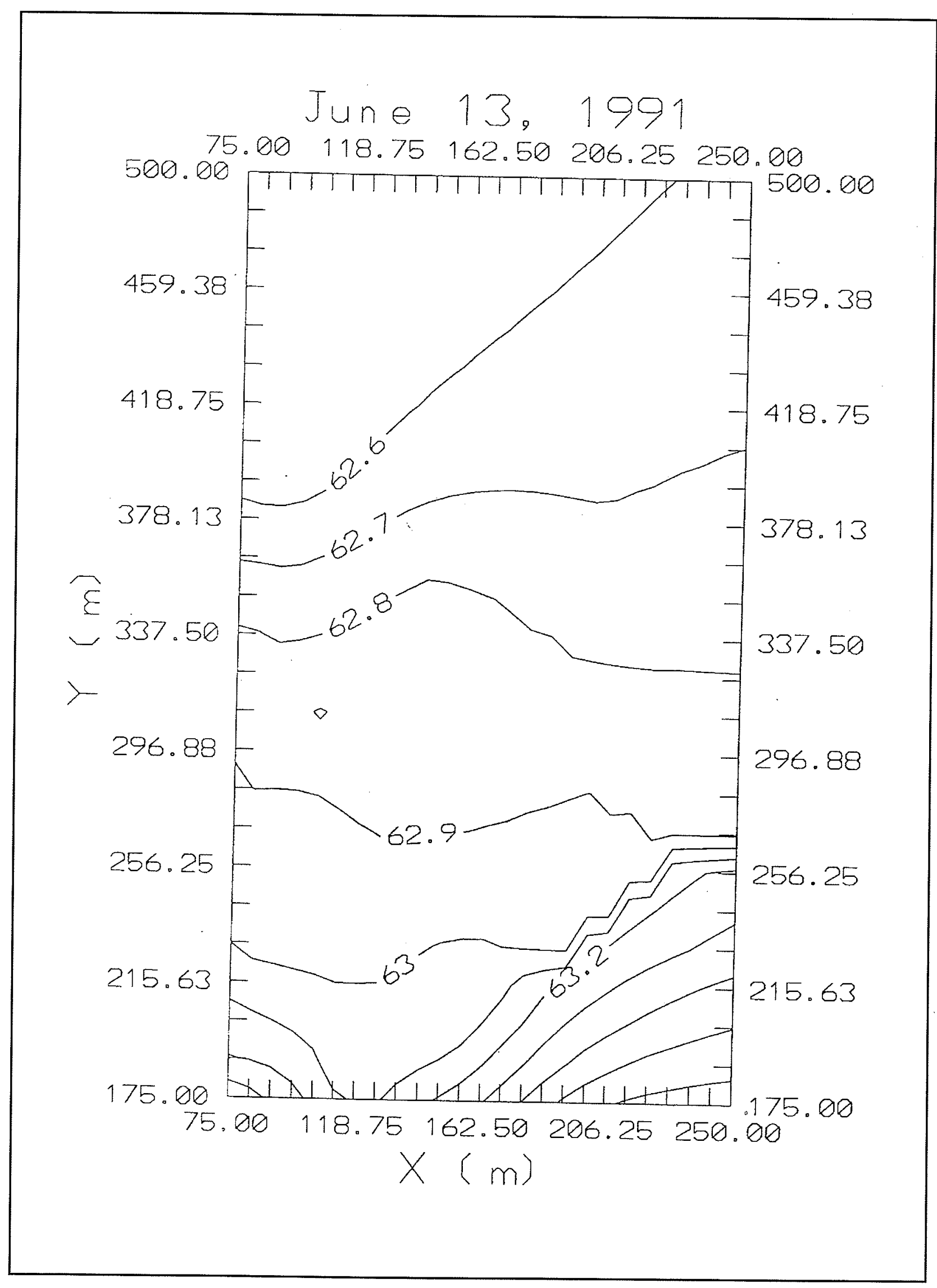




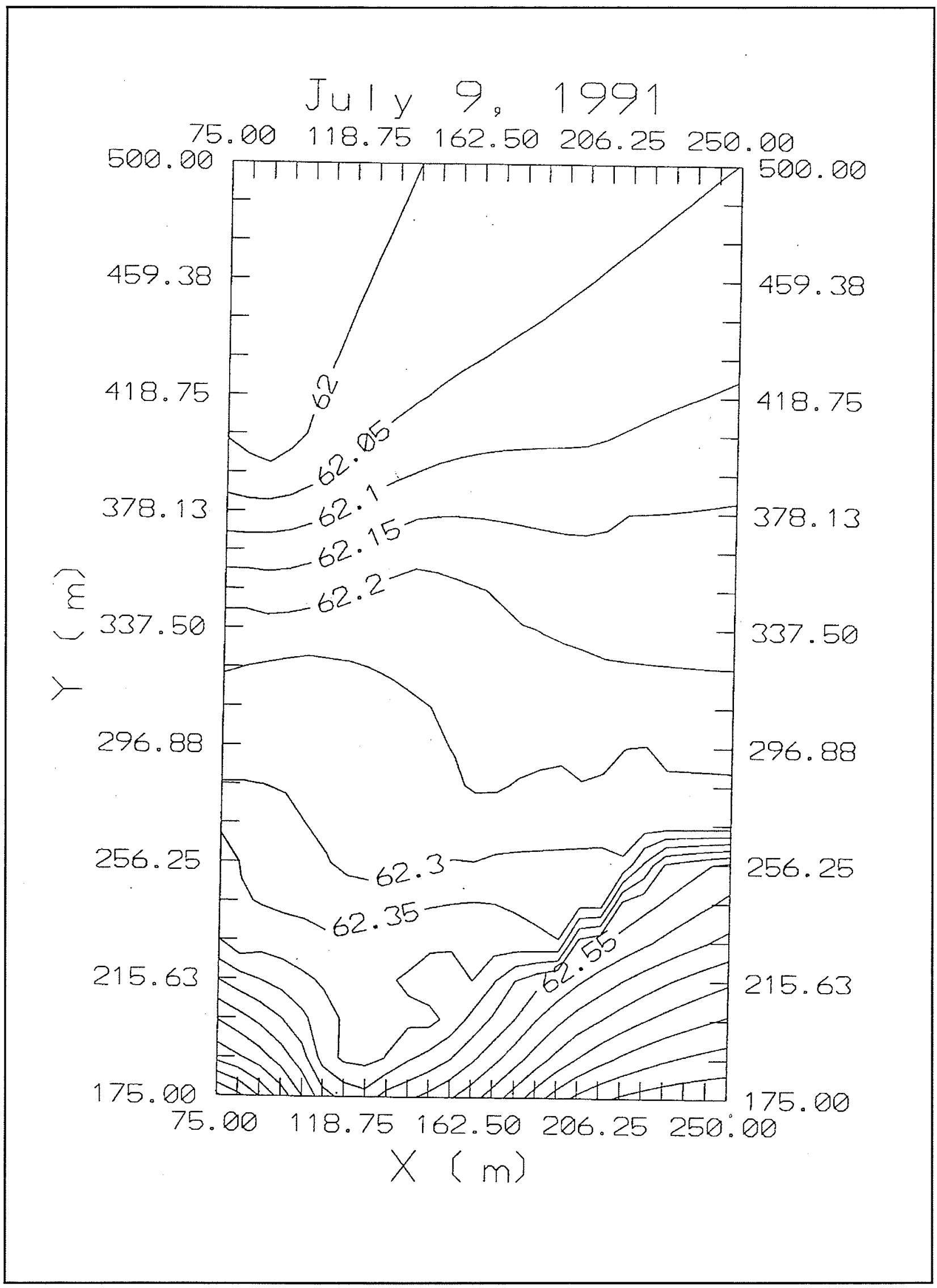




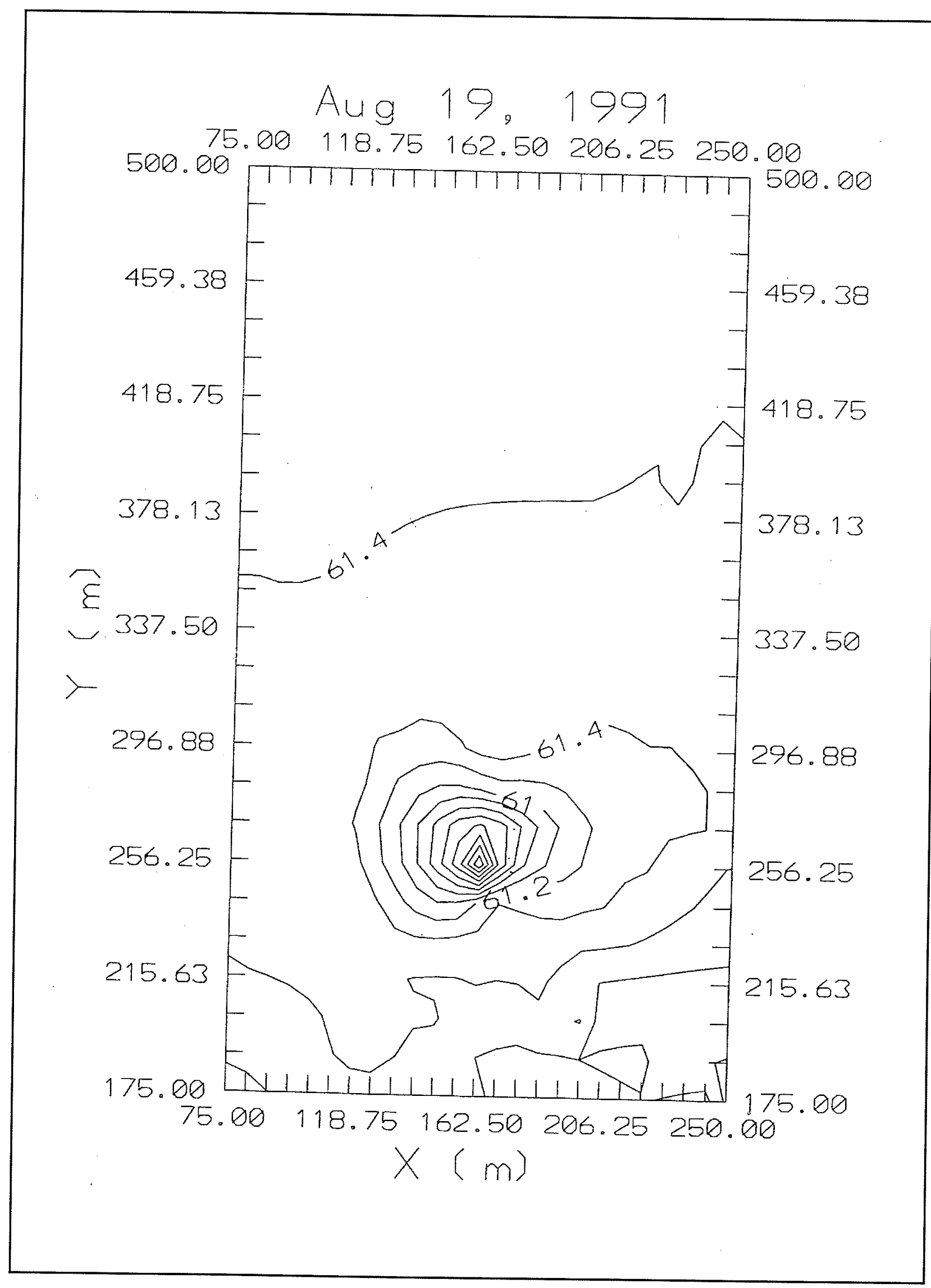




$$
\text { Sep 11, } 91
$$

$75.00 \quad 118.75 \quad 162.50 \quad 206.25 \quad 250.00$

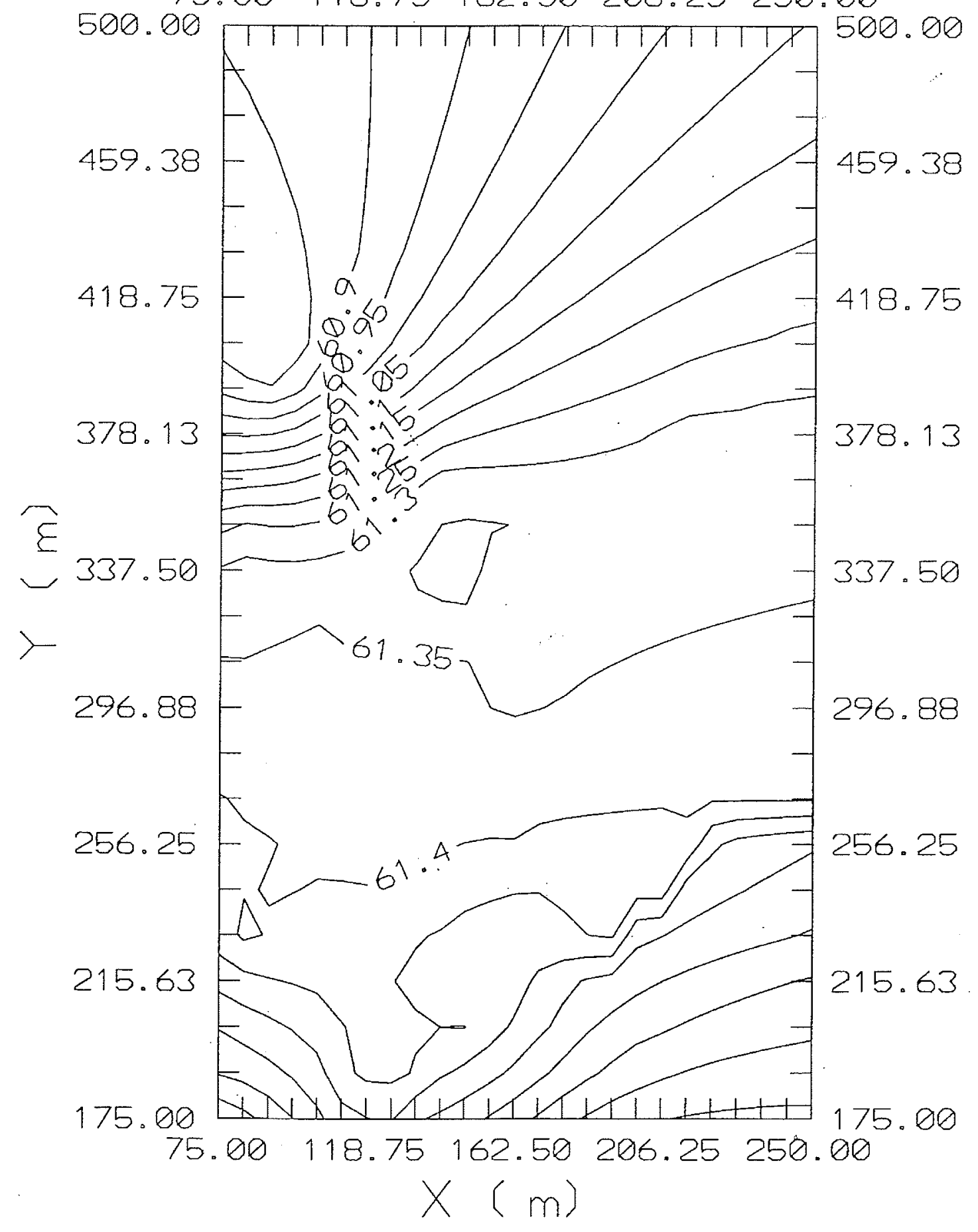




\section{Appendix C Gauge Plots of Transient Flow Simulations}

This appendix shows some of the Groundwater Modeling system (GMS) gauge plot comparisons for an attempt at a transient flow simulation with a grid consisting of over 175,000 cells. The plots show the correlation between the simulated head and the observed head for the simulation. Transient simulations using this enhanced grid required over 1 gigabyte of storage for a single output file. The attempt was aborted due to a combination of problems including memory, space, unsaturated zones in the model, too many boundary conditions driving the simulation, etc. 

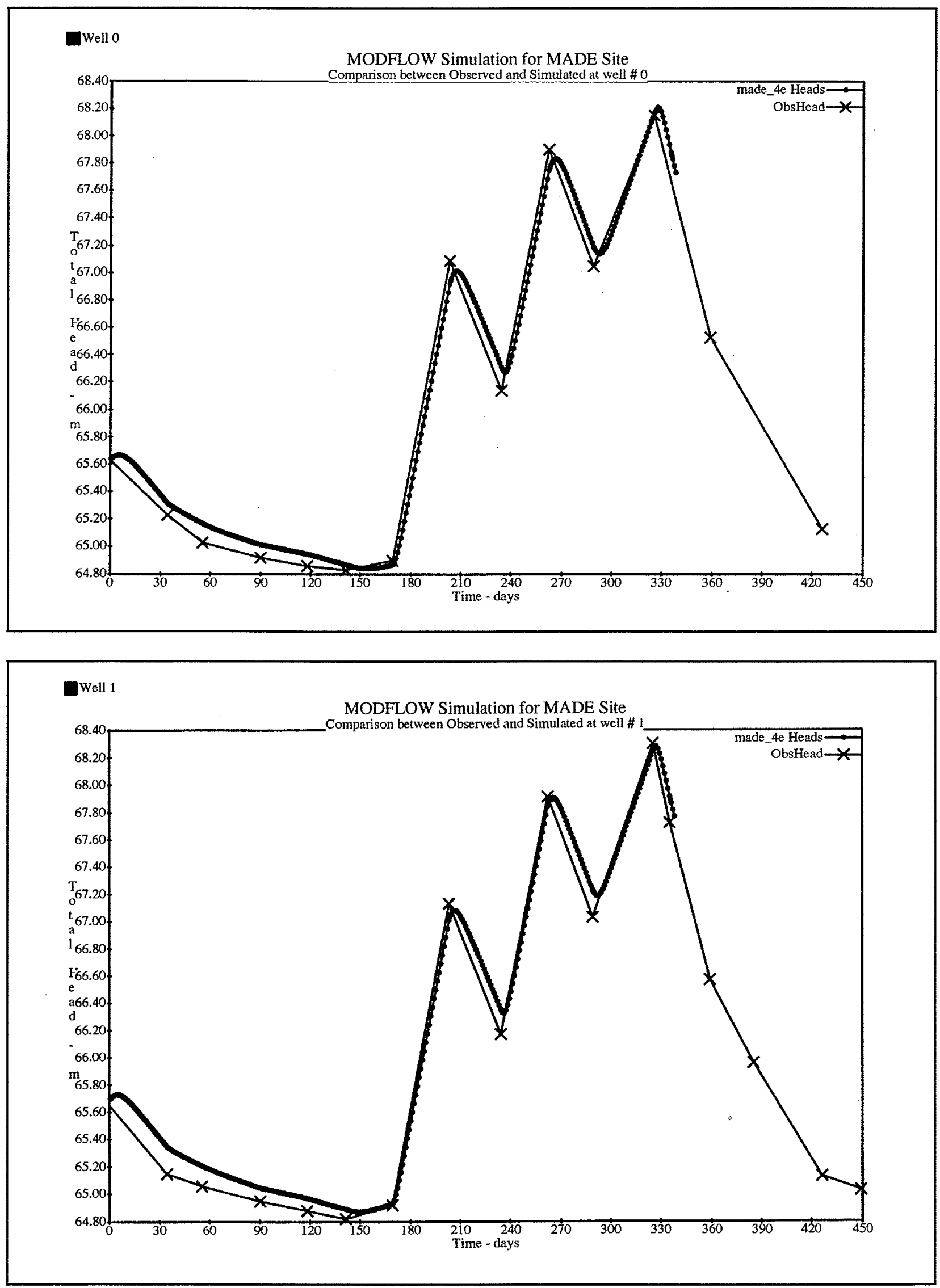


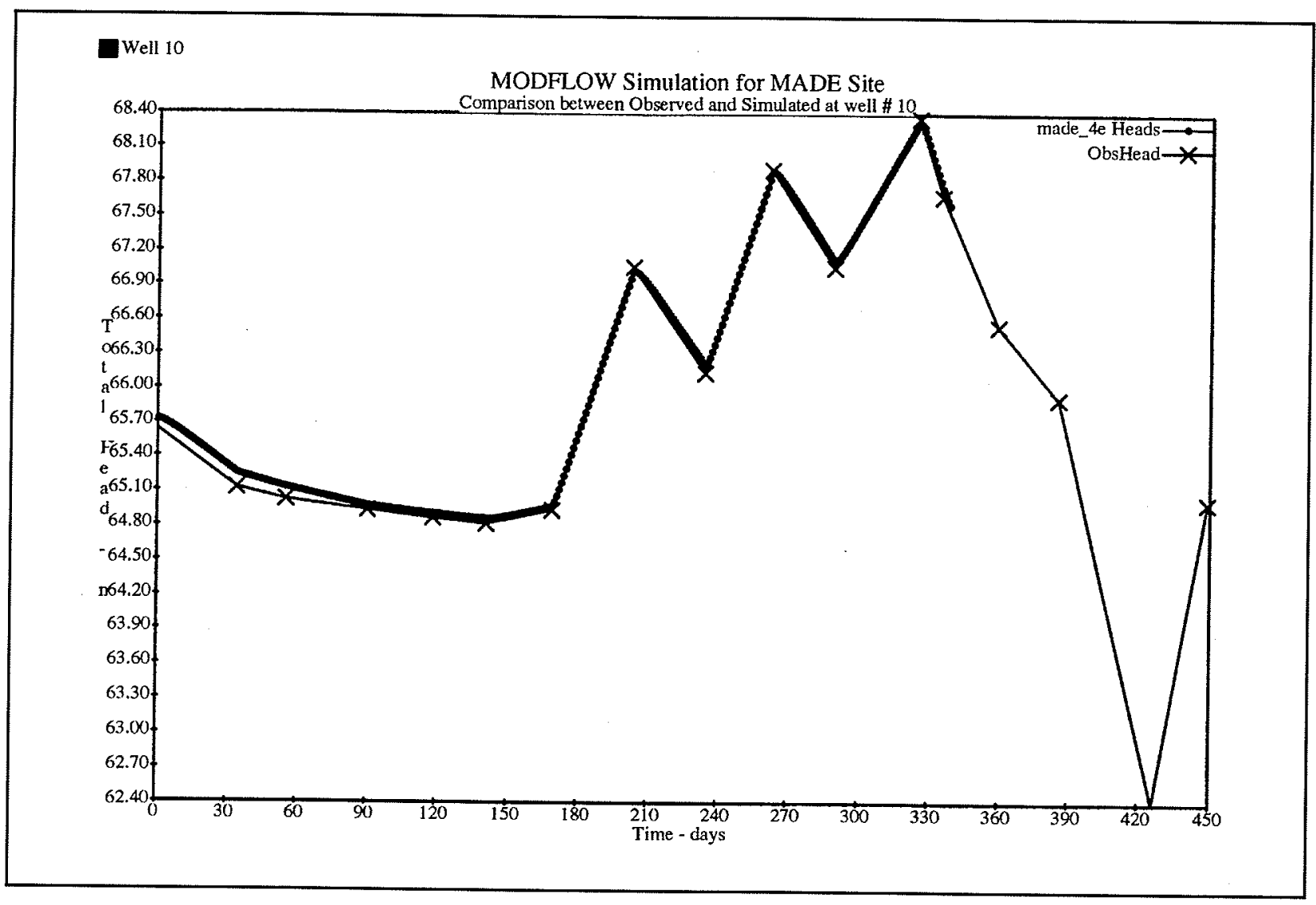

Well 11

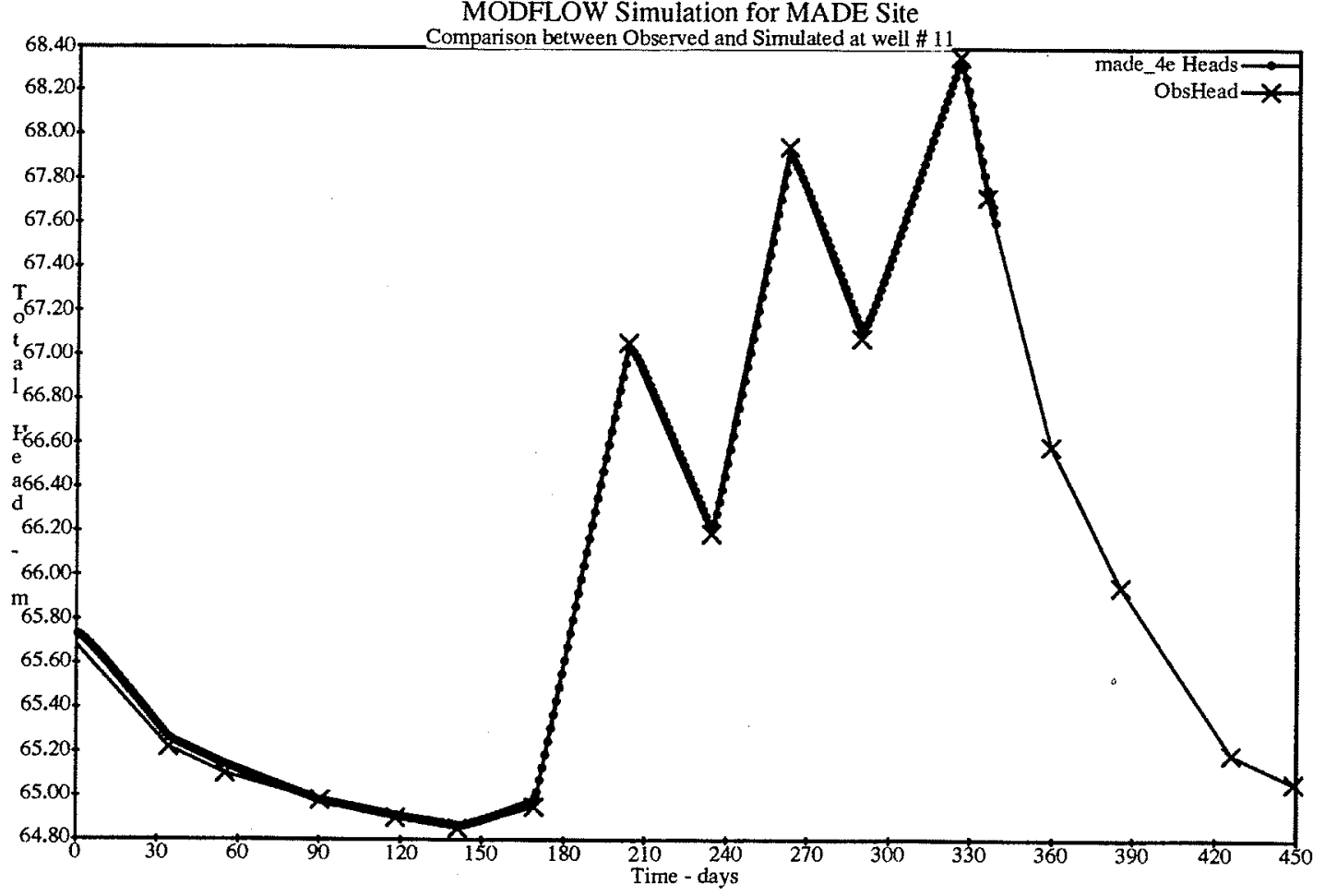

Appendix C Gauge Plots of Transient Flow Simulations 


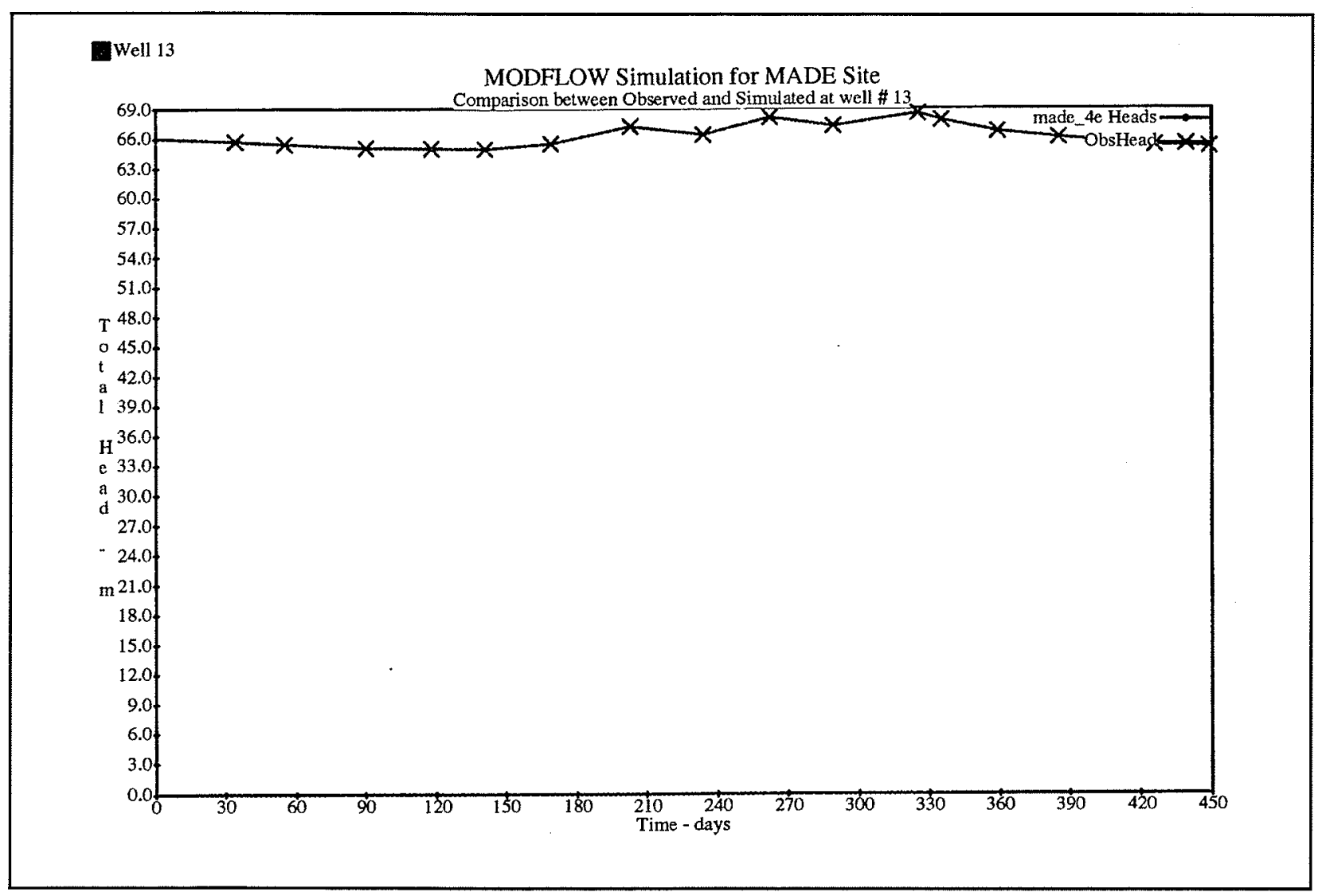

Well 14

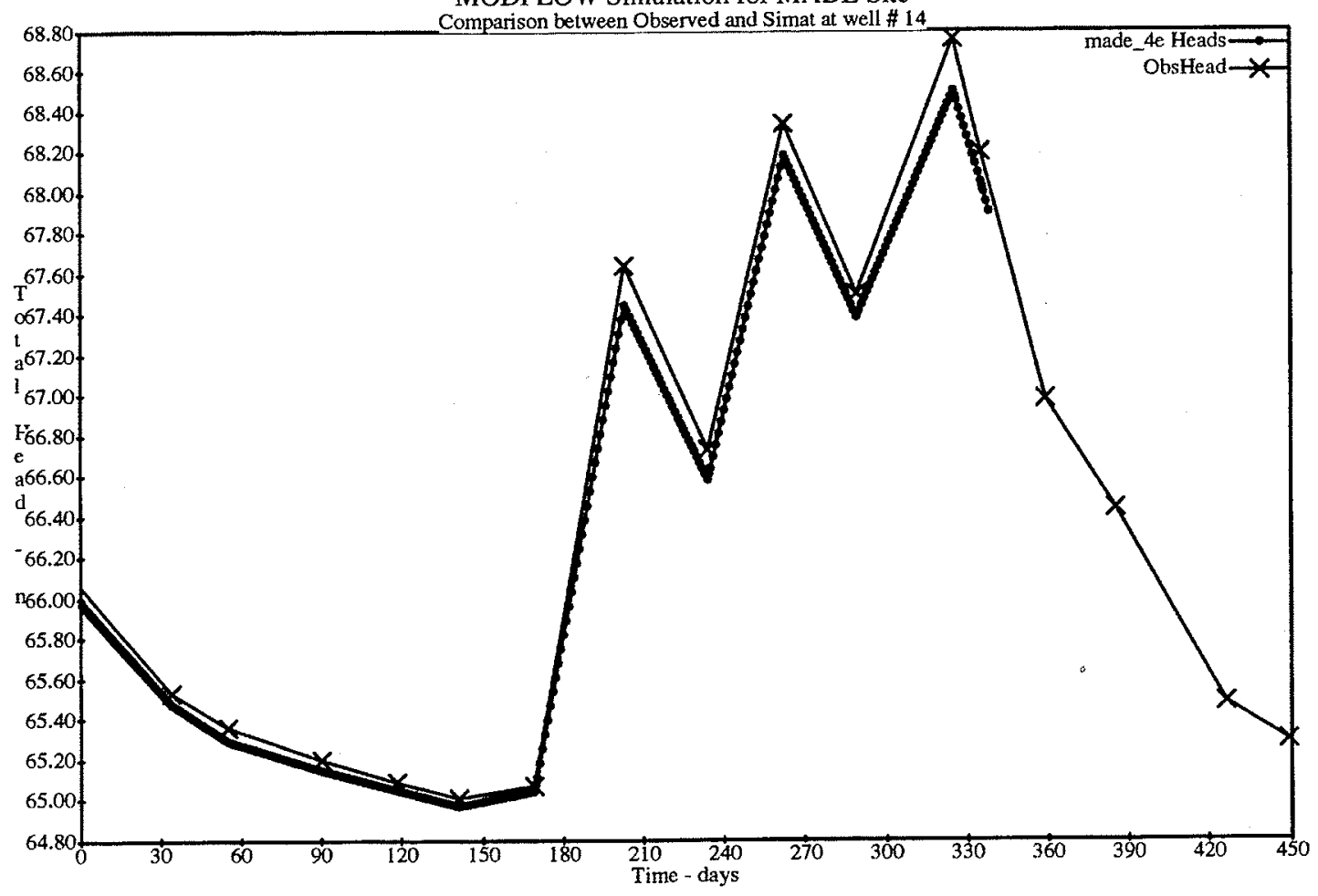



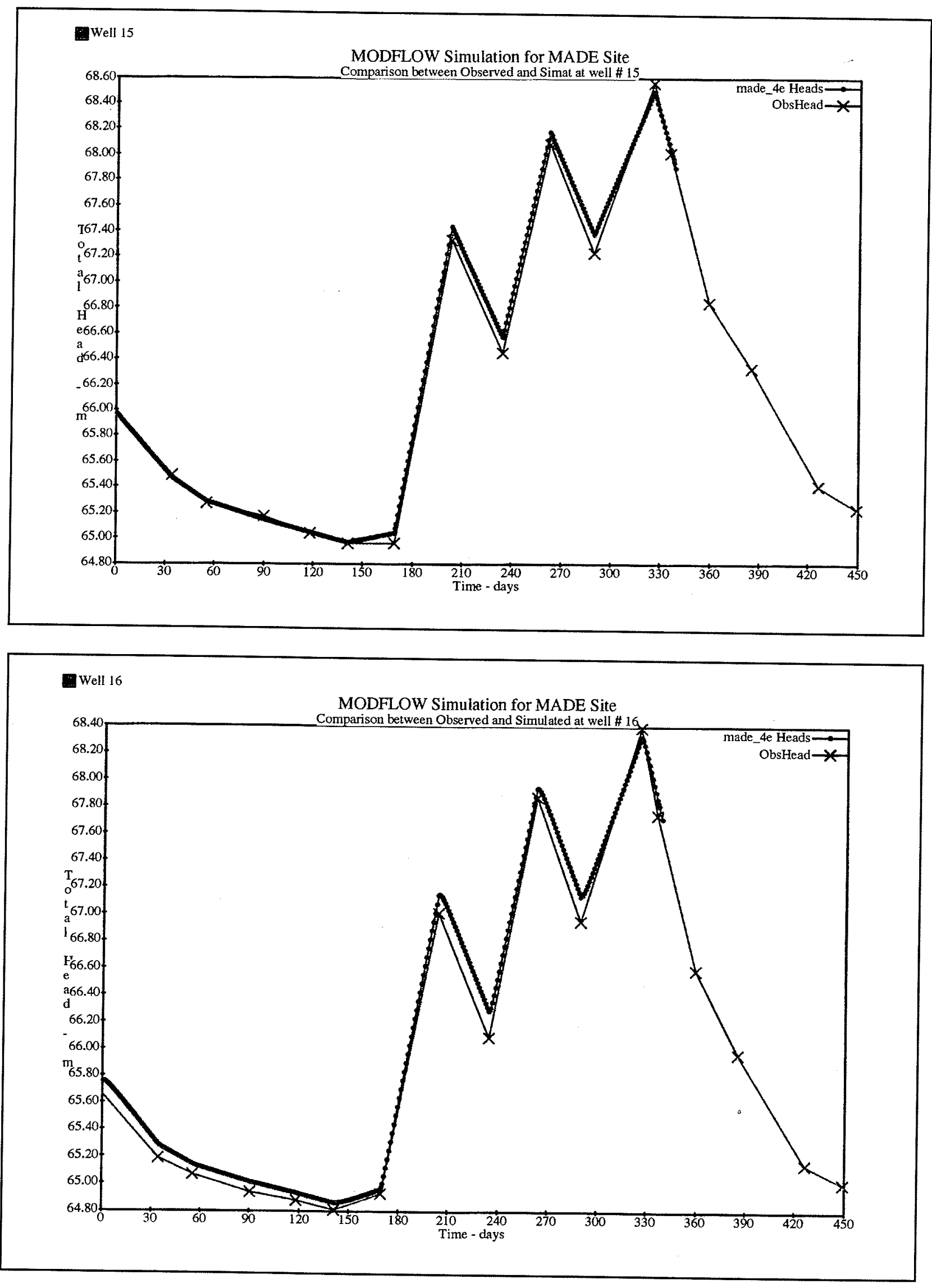

Appendix C Gauge Plots of Transient Flow Simulations 


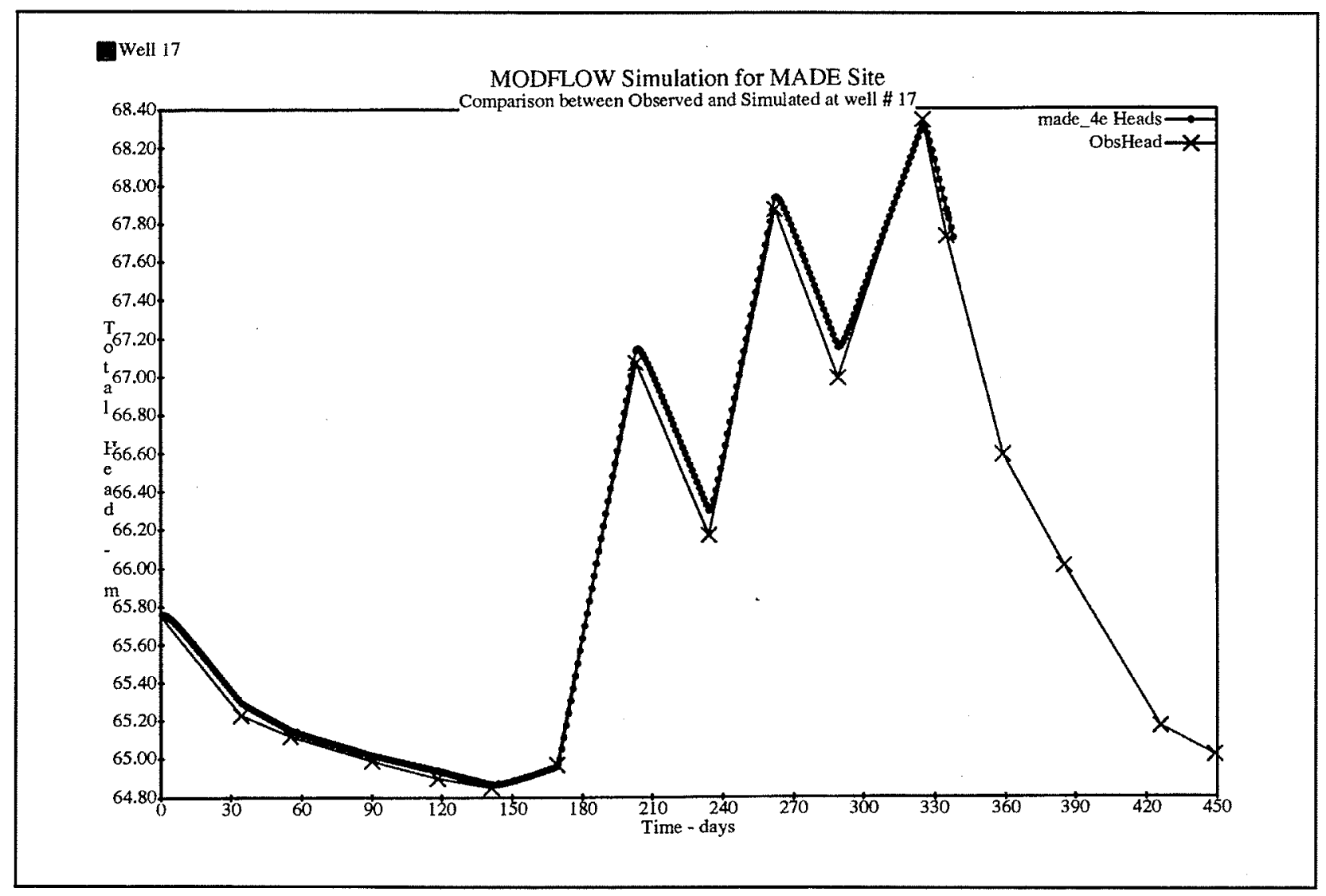

Well 18

MODFLOW Simulation for MADE Site

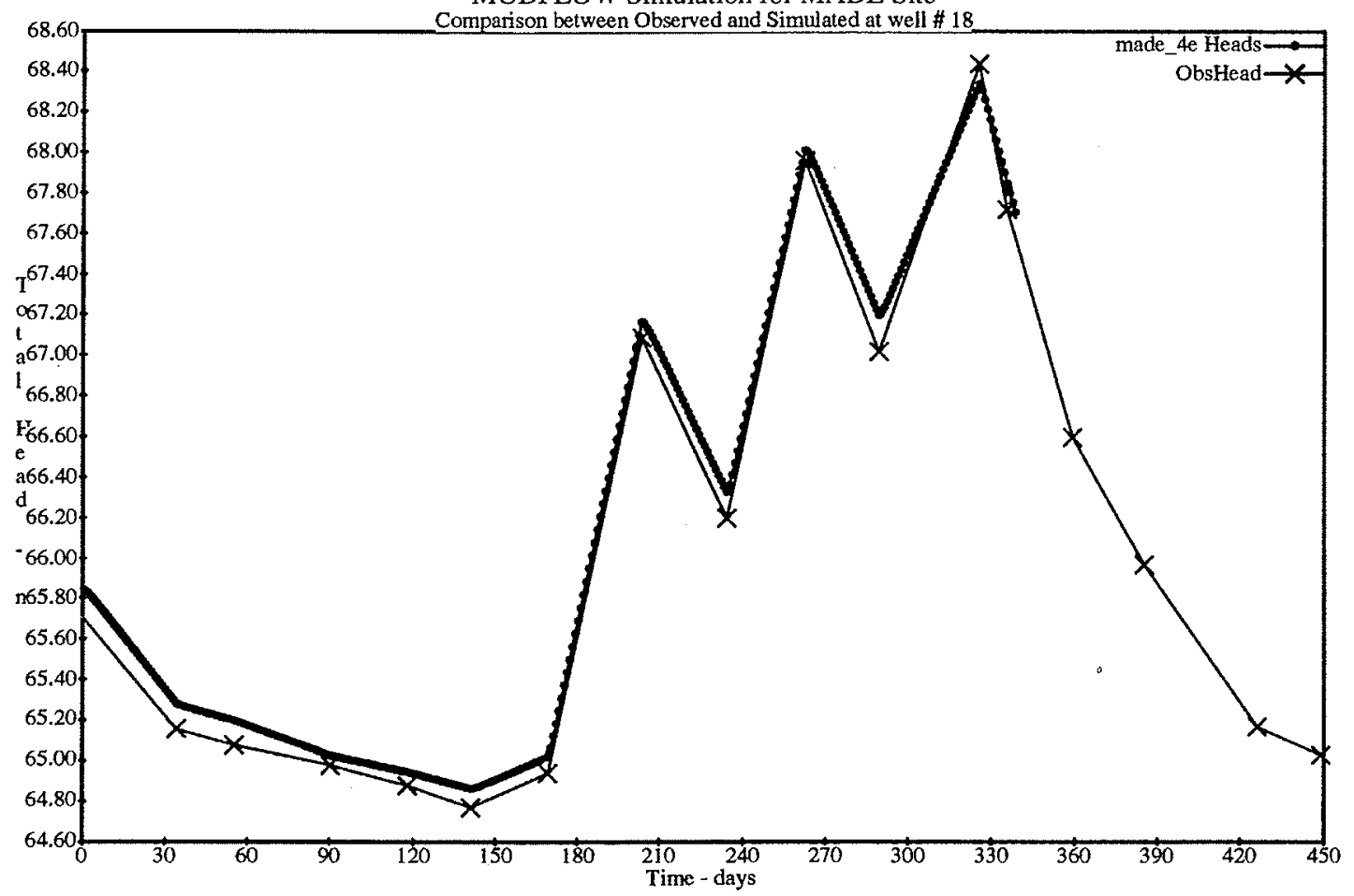



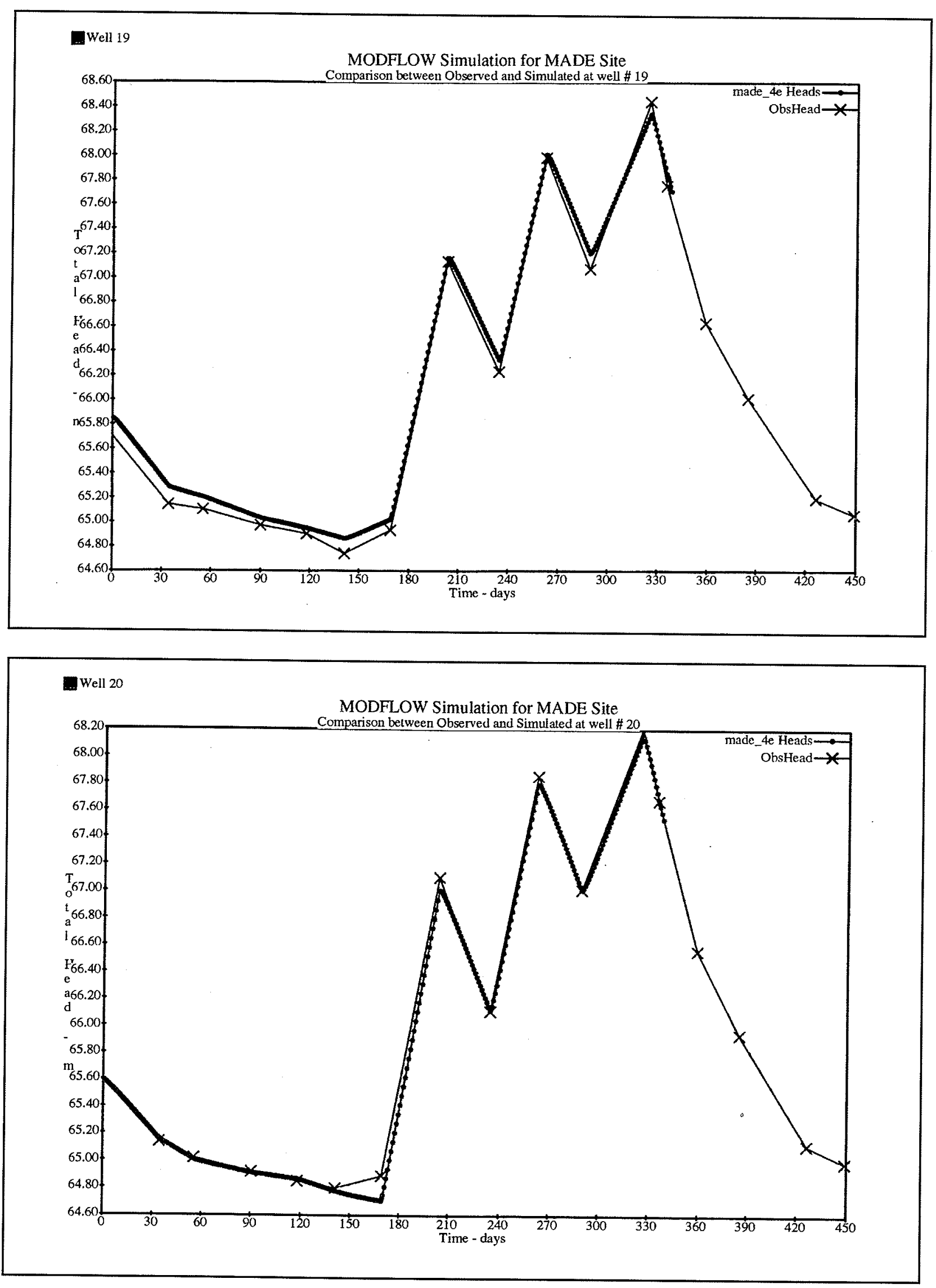

Appendix C Gauge Plots of Transient Flow Simulations 


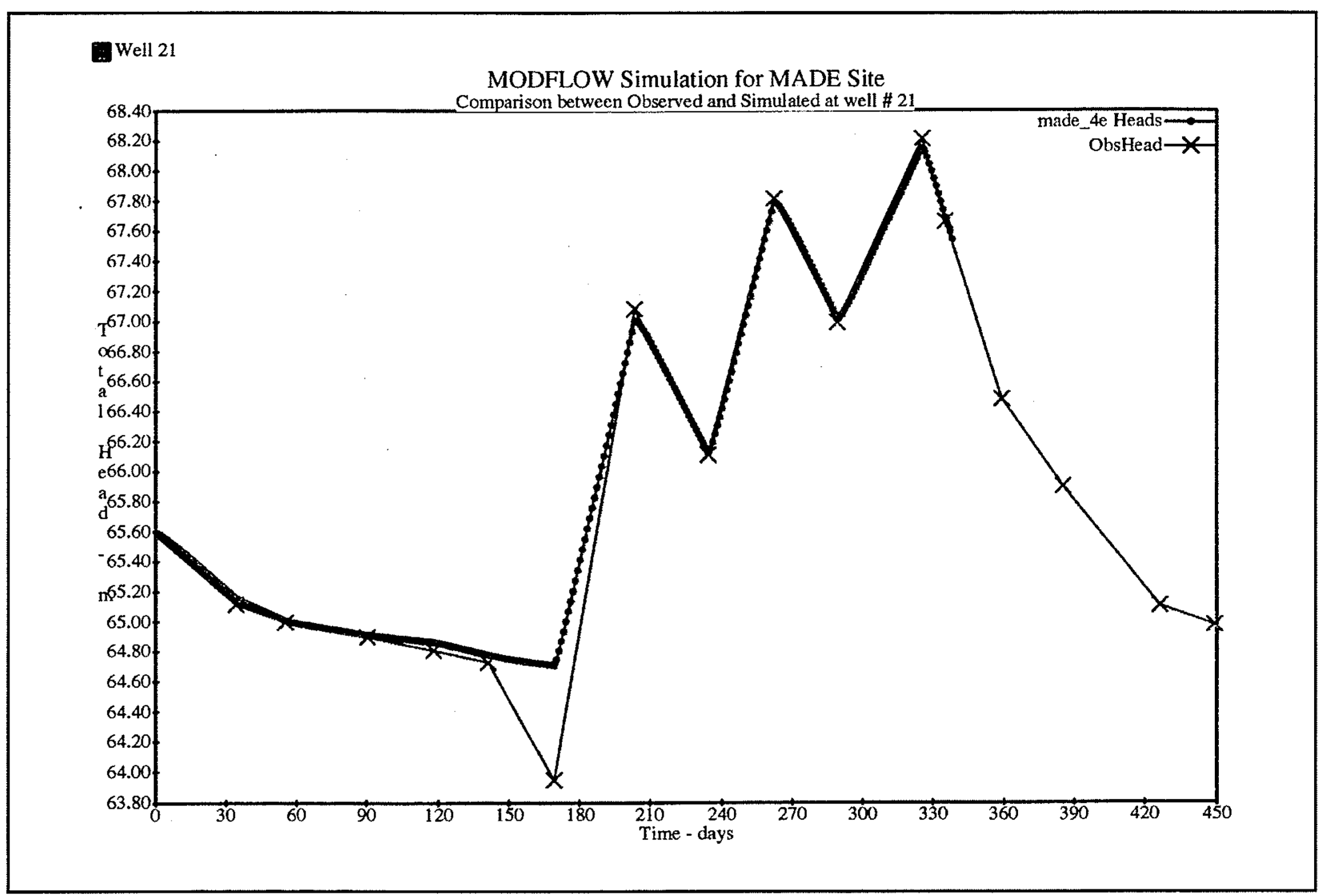

閣Well 22

MODFLOW Simulation for MADE Site

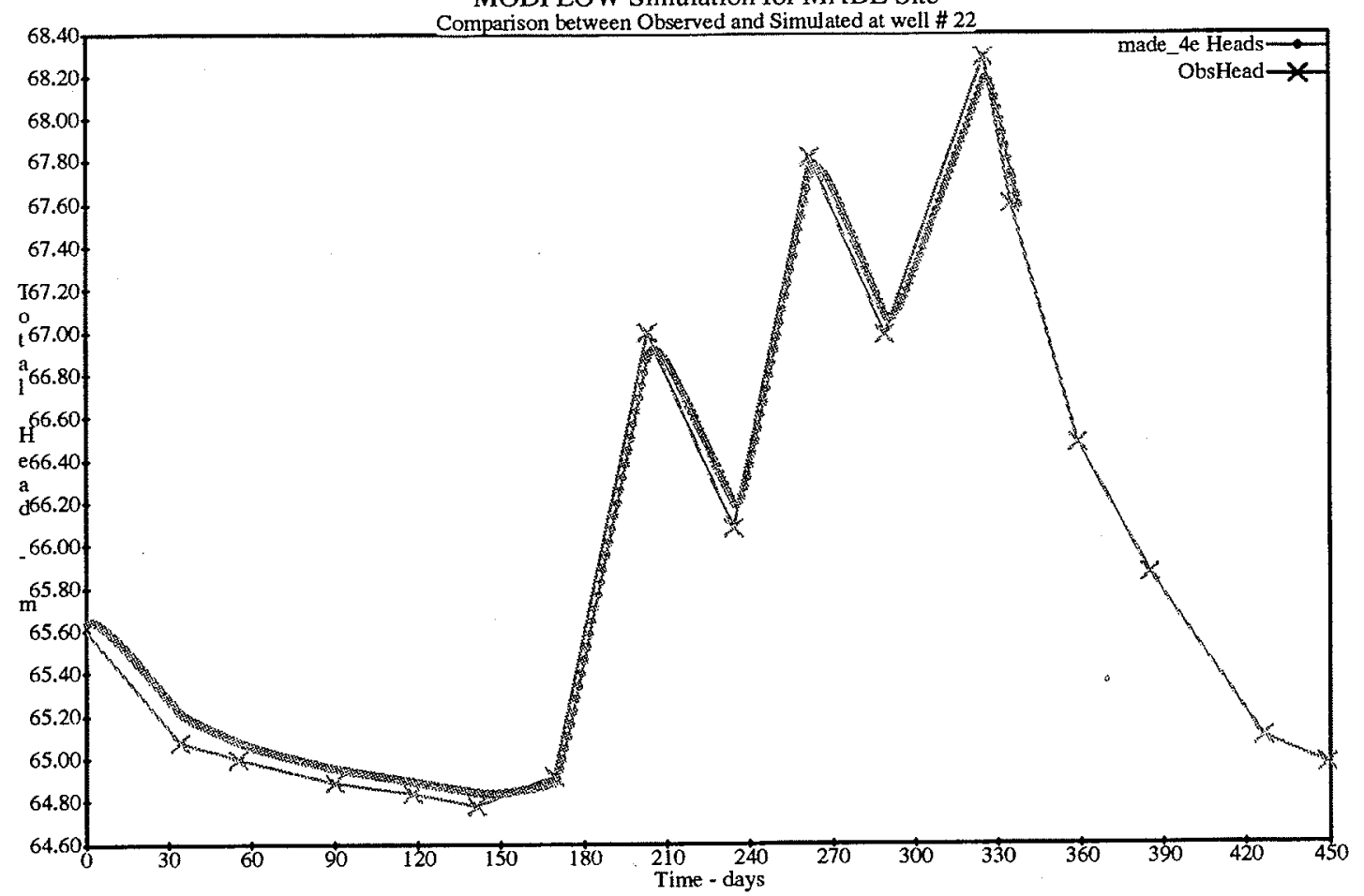




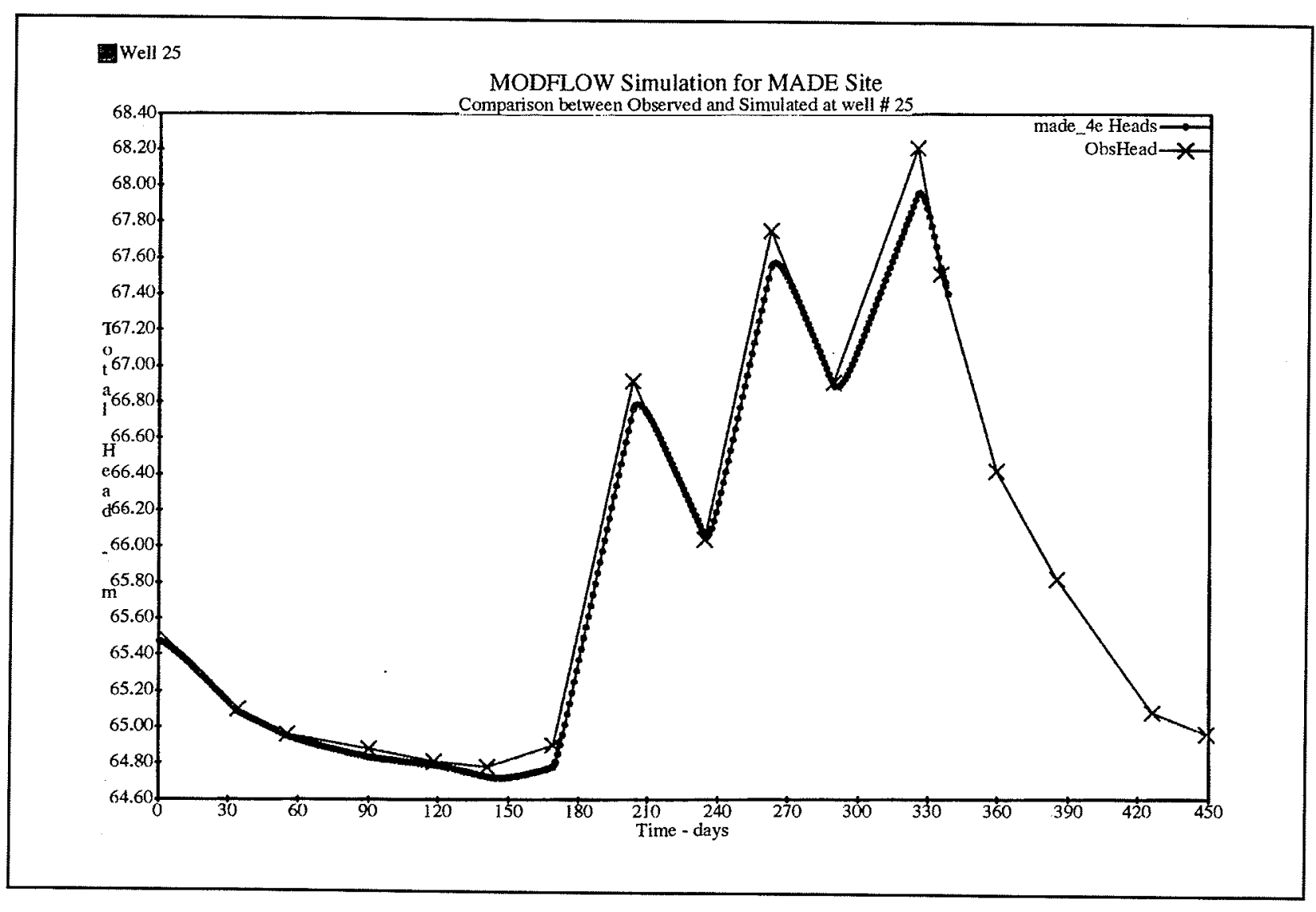

... Well 26

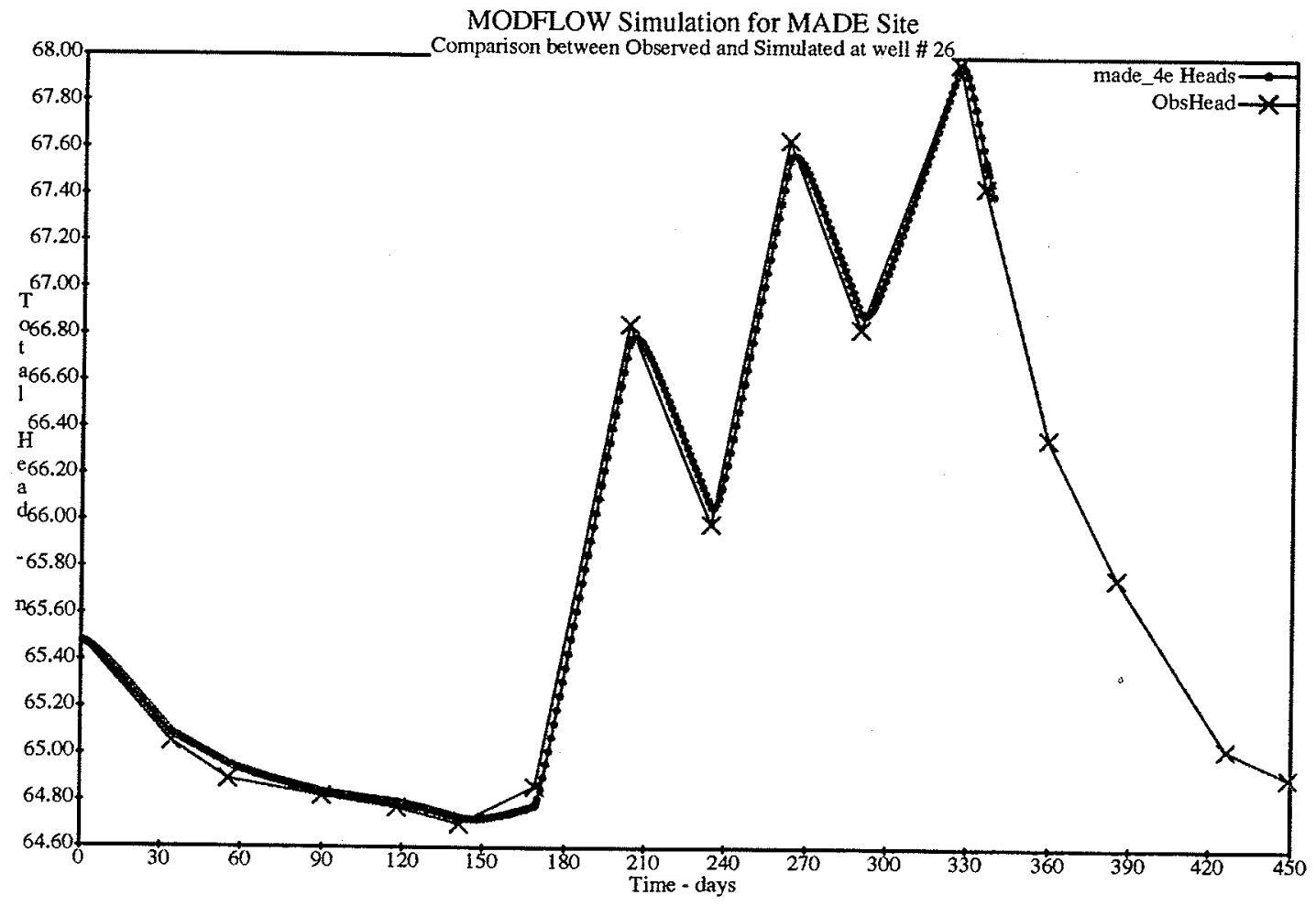

Appendix C Gauge Plots of Transient Flow Simulations 

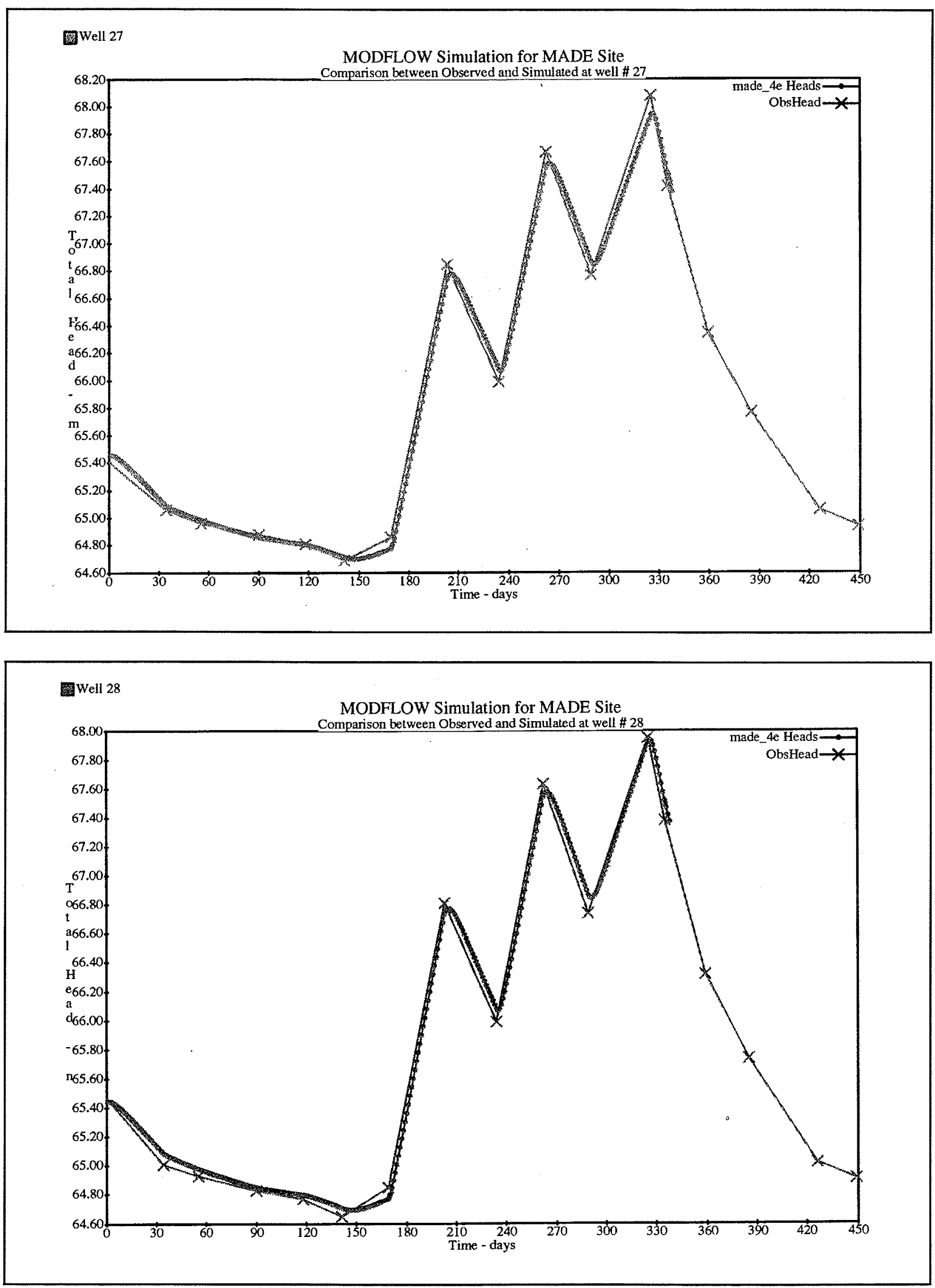
Well 29

MODFLOW Simulation for MADE Site

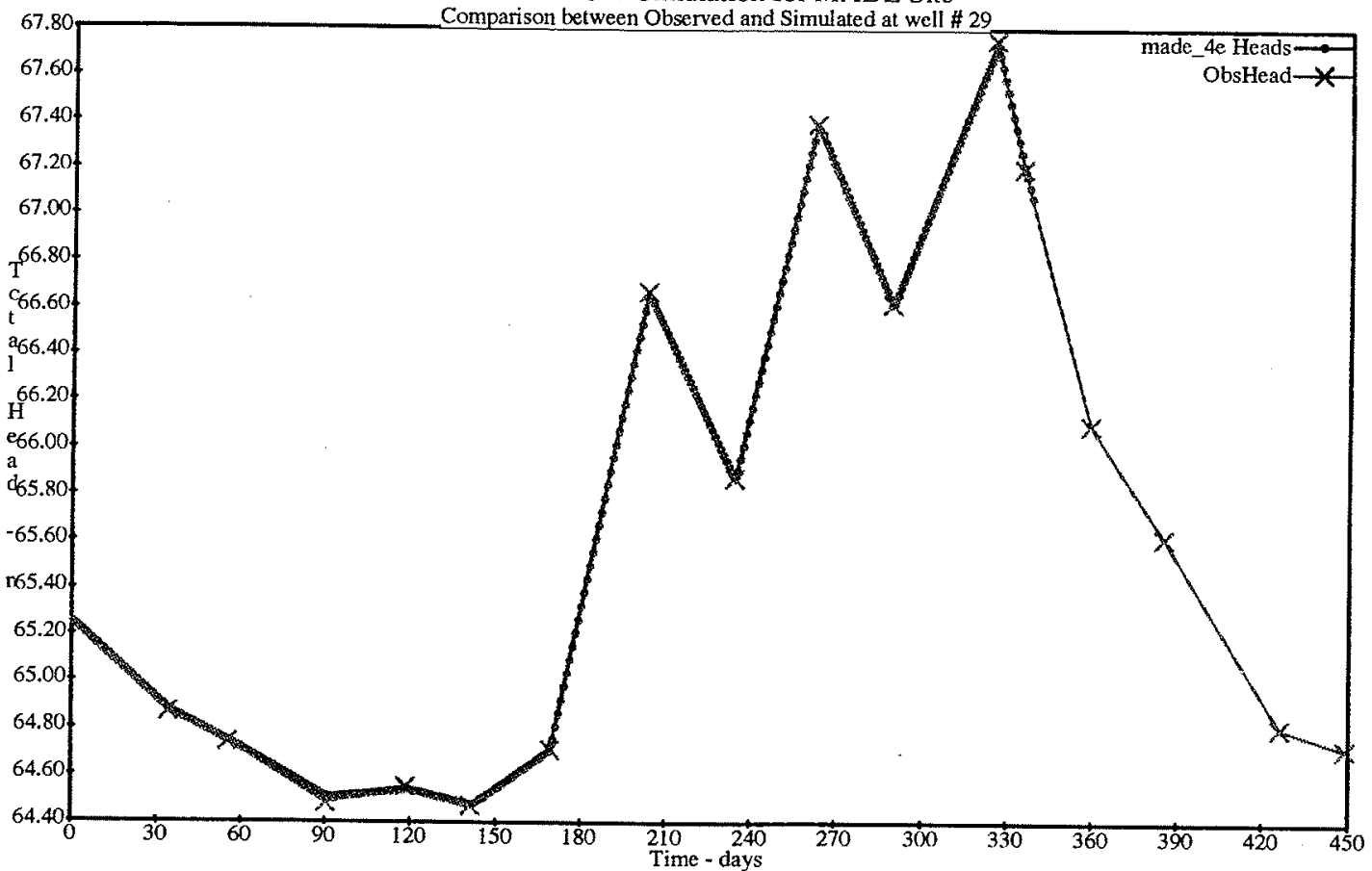

Well 30

MODFLOW Simulation for MADE Site

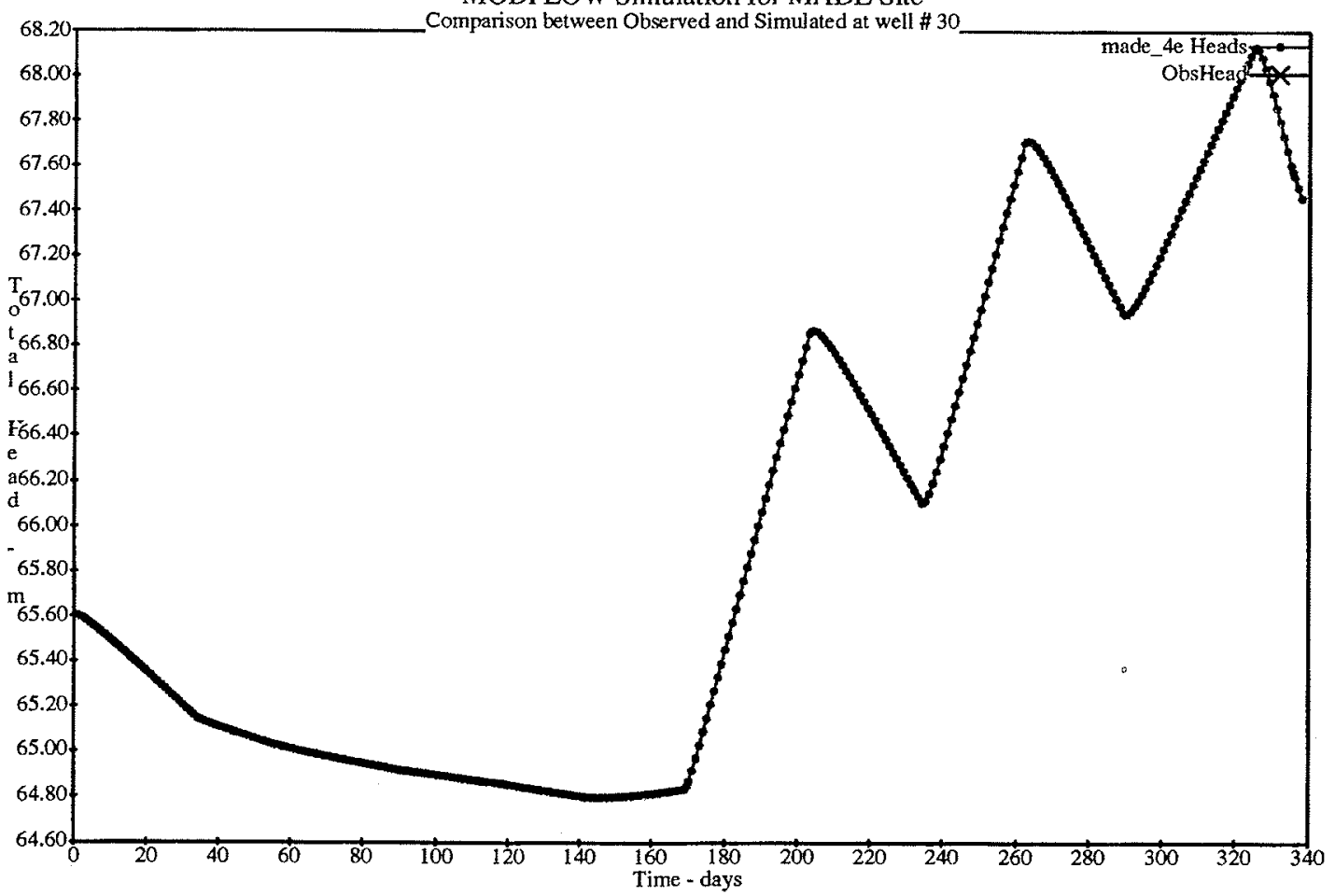



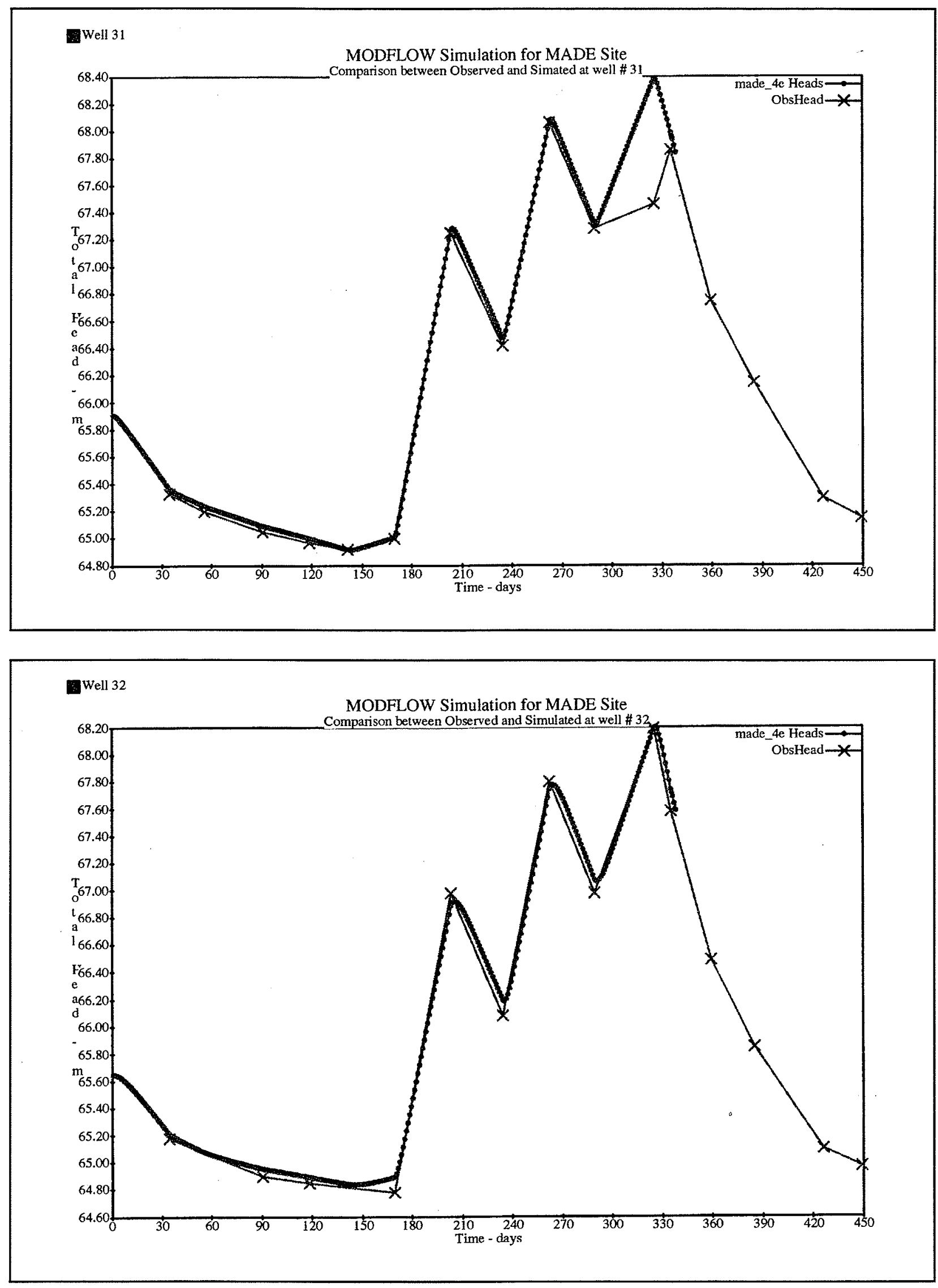


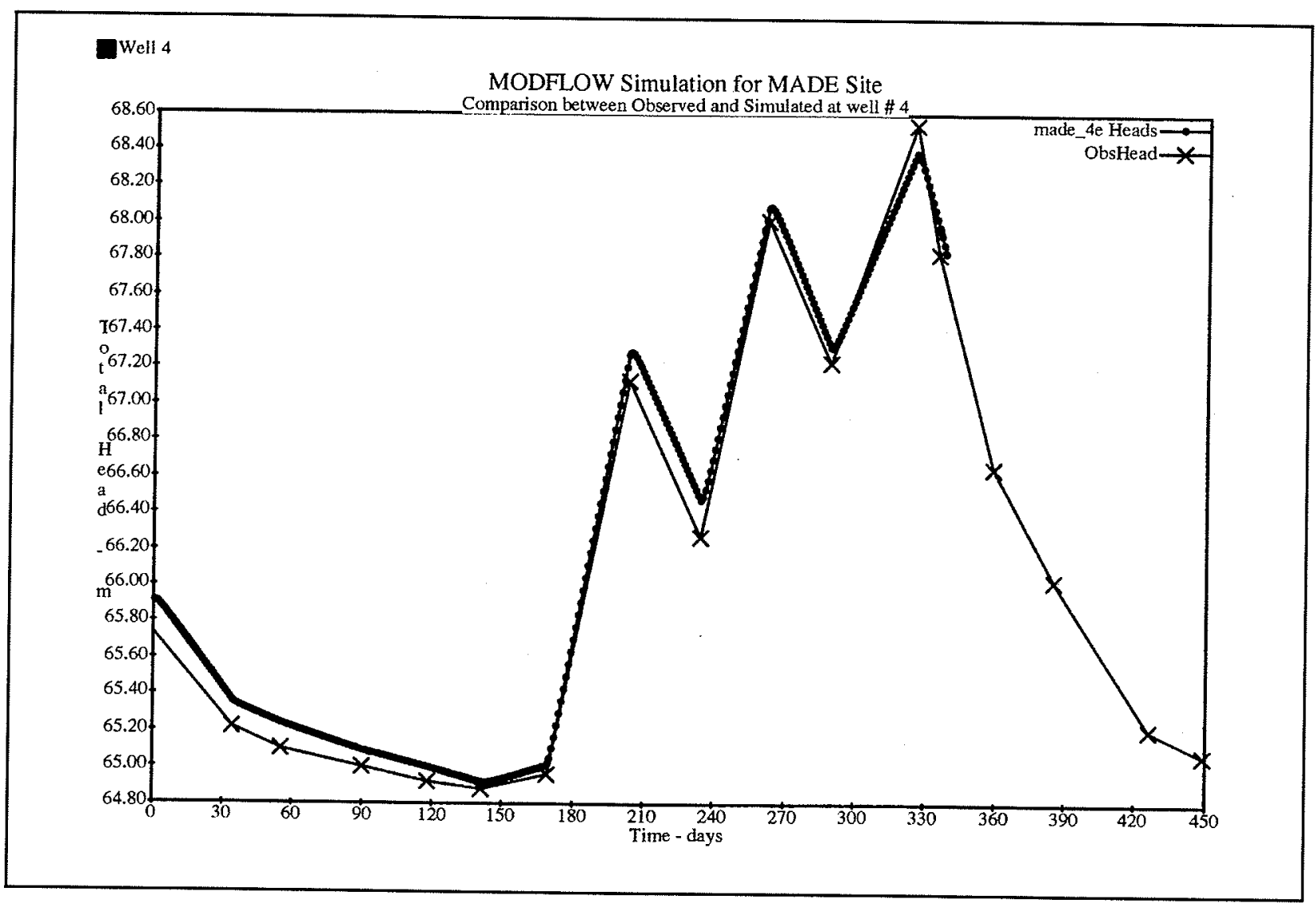

Well 5

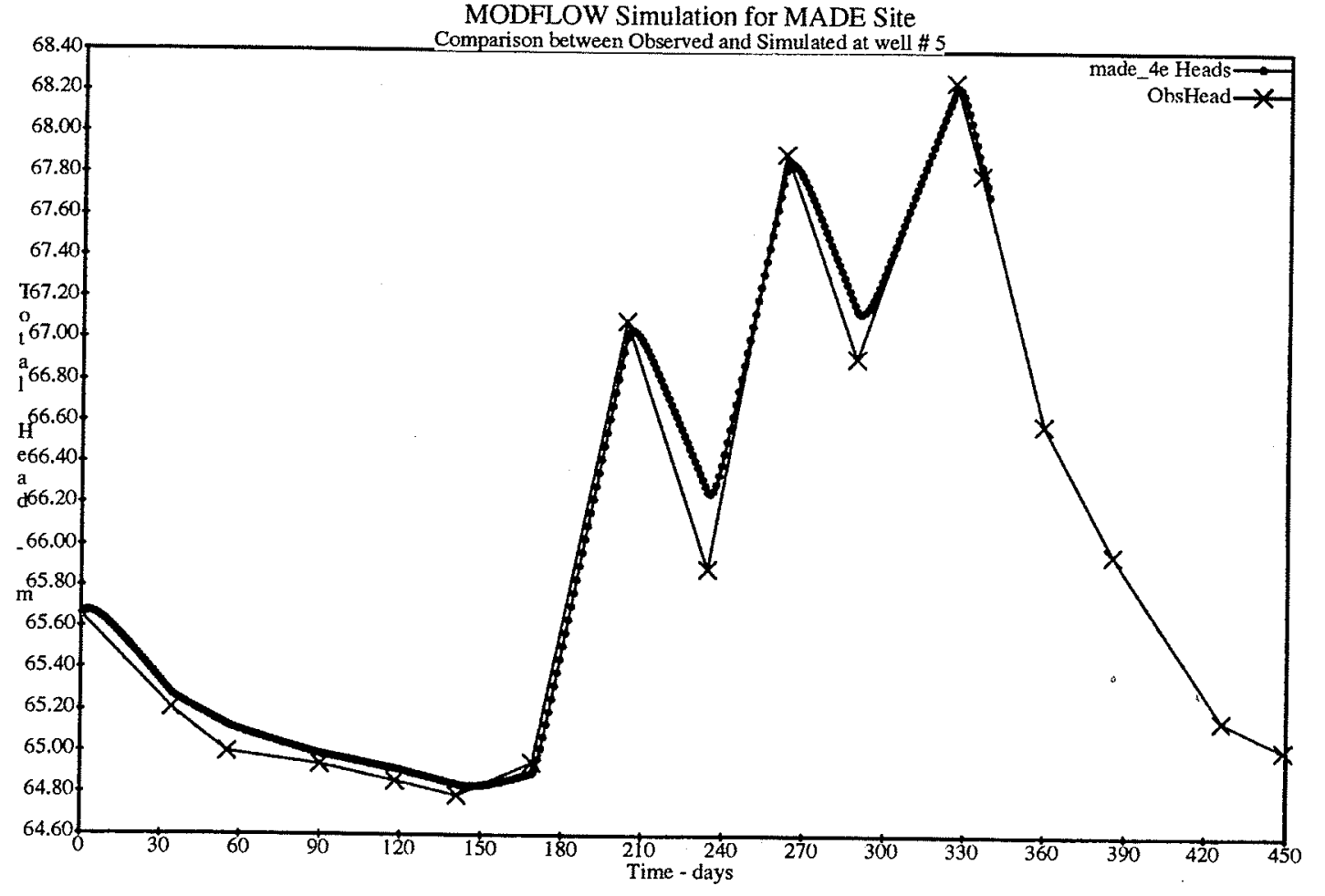

Appendix C Gauge Plots of Transient Flow Simulations 

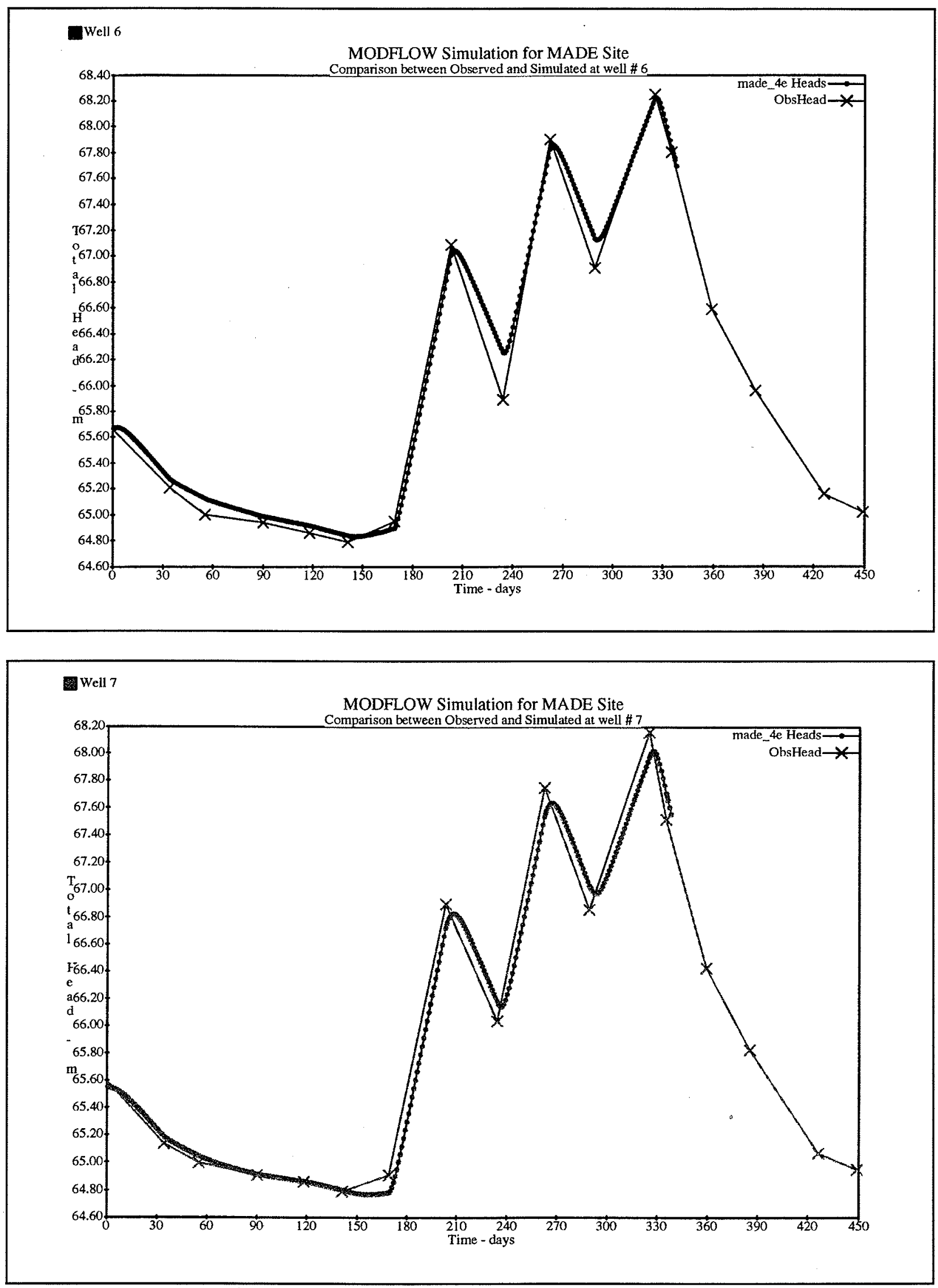

C14 


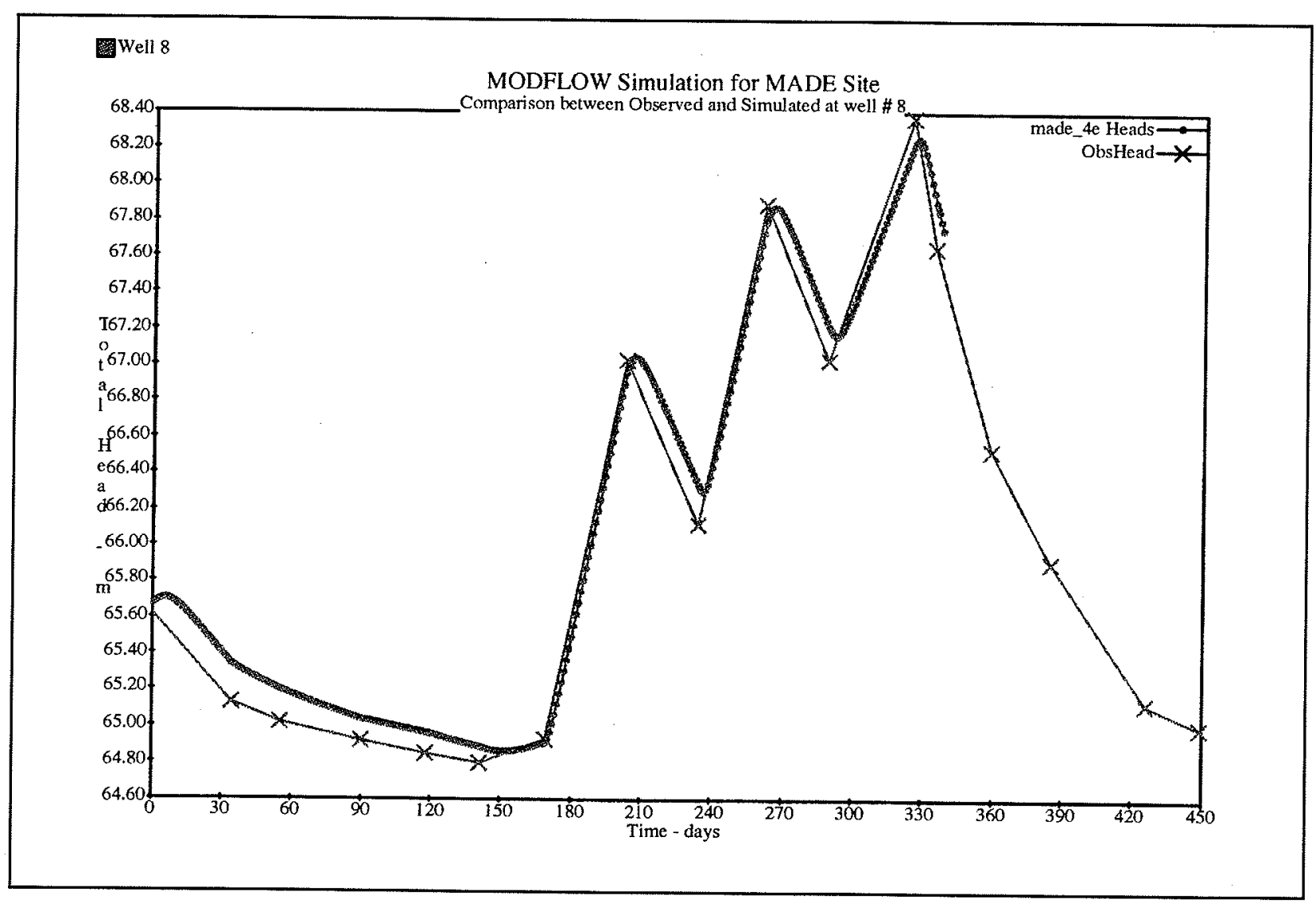

Well 9

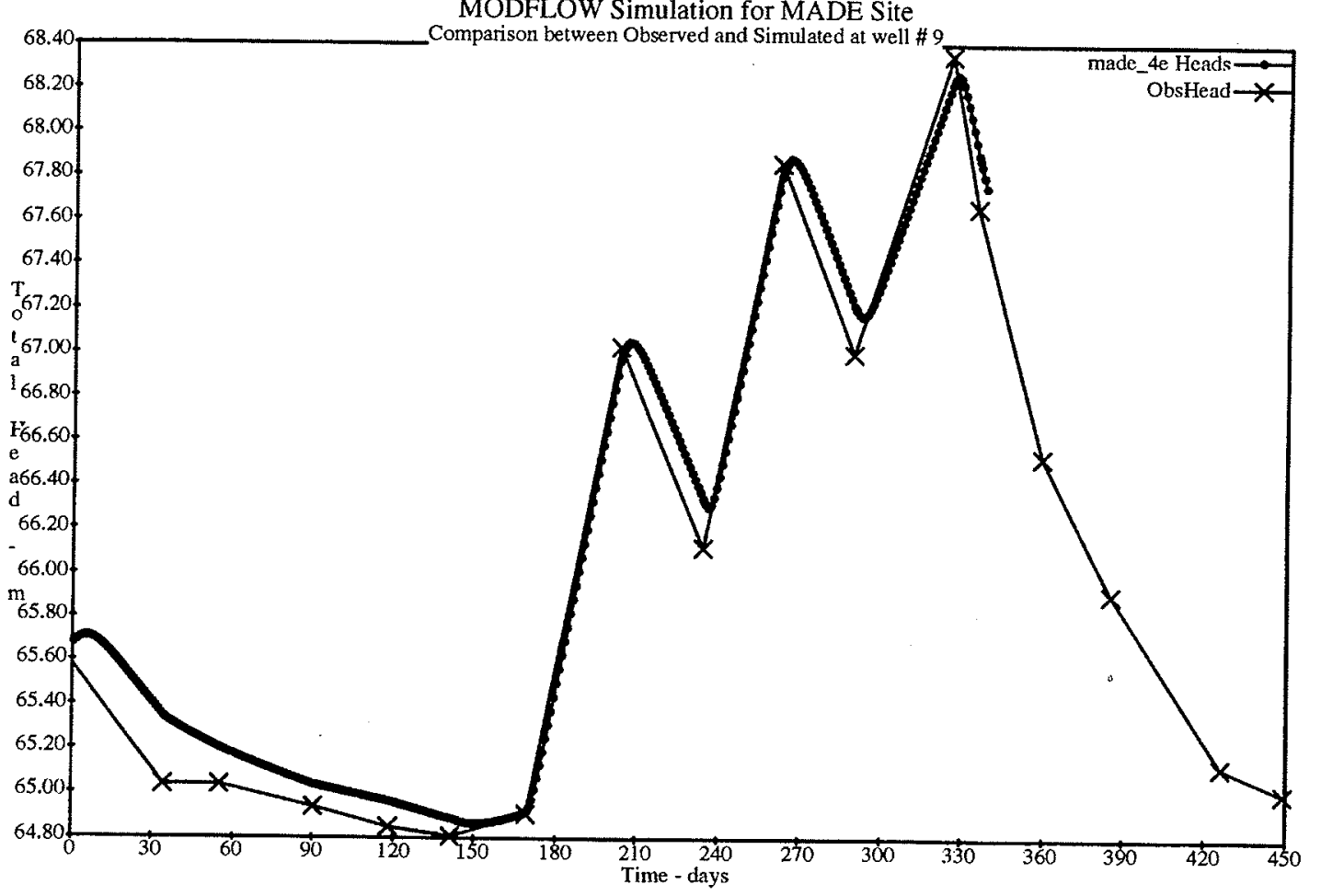





\section{REPORT DOCUMENTATION PAGE}

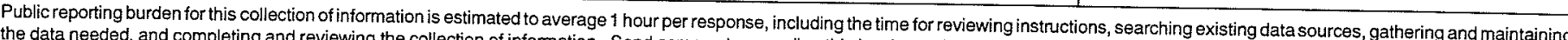

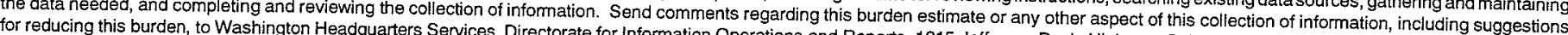

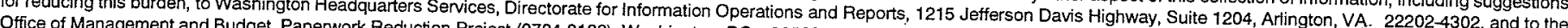
Office of Management and Budget, Paperwork Reduction Project (0704-0188), Washington, DC 20503.
1. AGENCY USE ONLY (Leave blank)
2. REPORT DATE
3.
August 1997
. REPORT TYPE AND DATES COVERED
Final report

\section{TITLE AND SUBTITLE}

Demonstration of the Department of Defense Groundwater Modeling System

(GMS) at Columbus Air Force Base, Columbus, MS

6. AUTHOR(S)

Mansour Zakikhani, Kenneth C. Black, and Jeffrey A. Gerald

\section{PERFORMING ORGANIZATION NAME(S) AND ADDRESS(ES)}

U.S. Army Engineer Waterways Experiment Station, 3909 Halls Ferry Road, Vicksburg, MS 39180-6199; Environmental Consulting Engineers, P.O. Box 22668, Knoxville, TN 37933; AScI Corporation, 1365 Beverly Road, McLean, VA 22101

\section{SPONSORING/MONITORING AGENCY NAME(S) AND ADDRESS(ES)}

U.S. Army Environmental Center

Aberdeen Proving Ground, MD 21010-5401

\section{FUNDING NUMBERS}

\section{PERFORMING ORGANIZATION REPORT NUMBER}

Technical Report EL-97-17

\section{SPONSORING/MONITORING} AGENCY REPORT NUMBER

\section{SUPPLEMENTARY NOTES}

Available from National Technical Information Service, 5285 Port Royal Road, Springfield, VA 22161.

\section{2a. DISTRIBUTION/AVAILABILITY STATEMENT}

Approved for public release; distribution is unlimited.

12b. DISTRIBUTION CODE

\section{ABSTRACT (Maximum 200 words)}

The Department of Defense Groundwater Modeling System (GMS) was applied to a site at Columbus Air Force Base (CAFB), Mississippi. The CAFB site is the location of two macrodispersion experiments (MADE-1 and MADE-2) and the ongoing natural attenuation study (NATS). The hydraulic conductivity profile of the site illustrated the extreme heterogeneity of the aquifer. Two different numerical approaches of finite element (FEMWATER) and finite difference (MODFLOW/ MT3D) were applied to the site using MADE-2 data sets. The results of the study are described in this report. A careful examination of the MADE-2 hydrogeologic databases indicated that the numerical simulating of this experiment could be difficult. The movement of the tracers was strongly influenced by the heterogeneous porous media and by the transient flow system during the latter half of the experiment. Simulated results of the first 180 days of the experiment showed that tracer concentrations can be reproduced quite well with FEMWATER. The concentration distributions of the latter half of the experiment were difficult to reproduce. The transient rainfall recharge that occurred during this time had two net effects which must be accounted for to obtain accurate numerical results. First, the hydraulic gradients increased, at times by as much as a factor of 4 . Secondly, the additional infiltrated water diluted the plume, causing reduced and dispersed concentrations at the leading edge of the plume. Two steady-state flow fields with FEMWATER were used to reproduce flow conditions during the

14. SUBJECT TERMS

Columbus Air Force Base GMS
Groundwater

Modeling

(Continued)

15. NUMBER OF PAGES 177

\section{PRICE CODE}

\section{SECURITY CLASSIFICATION OF REPORT \\ 18. SECURITY CLASSIFICATION OF THIS PAGE \\ UNCLASSIFIED \\ UNCLASSIFIED}

NSN 7540-01-280-5500
Standard Form 298 (Rev. 2-89) Prescribed by ANSI Std. Z39-18 298-102 


\section{3. (Concluded).}

experiment. The flow results then were used to reproduce the tritium transport. After extensive model testing and analysis of the concentration data, the dilution effects caused by transient recharge during the last half of the experiment make it virtually impossible to match the low-concentration, leading edge of the tracer plumes. For example, the tritium plume has a peculiar characteristic in that much of the high concentration portions of the plume stay in the injection area during most of the experiment. The MODFLOW simulation appeared to match the observed flow data relatively well. The simulated piezometric heads in most cases were within $0.2 \mathrm{~m}$ of the observed data. The simulation assumed steady-state conditions taken as the average of the piezometric head monitoring data from June 1990 through September 1991. It is very likely that the transport simulation (MT3D) could have been improved overall by simulating a low- and high-water table for the simulation period of 328 days as described in the FEMWATER application chapters. The simulation without the high-water-table event showed that the travel extent of simulated contaminant plumes is limited compared to observed plumes. Most of the MT3D simulated conservative tracer (tritium) plumes were close to the observed plumes until approximately 234 days into the simulations. Previous reviews of the MADE experiments indicated that there is a strong possibility that the organic tracer concentrations could have been significantly reduced by volatility losses. Most of the organic tracer simulations indicated a plume that traveled further downgradient than the observed plume toward the latter half of the simulations. The exception to this was the o-dichlorobenzene simulation in which the observed plume traveled further downgradient than the simulated plume and showed extensive spatial discontinuity. 